NIST Technical Note 2003

Revision 1

\title{
Building Industry Reporting and Design for Sustainability (BIRDS) Low-Energy Residential Incremental Energy Efficiency Improvements Database Technical Manual: Update
}

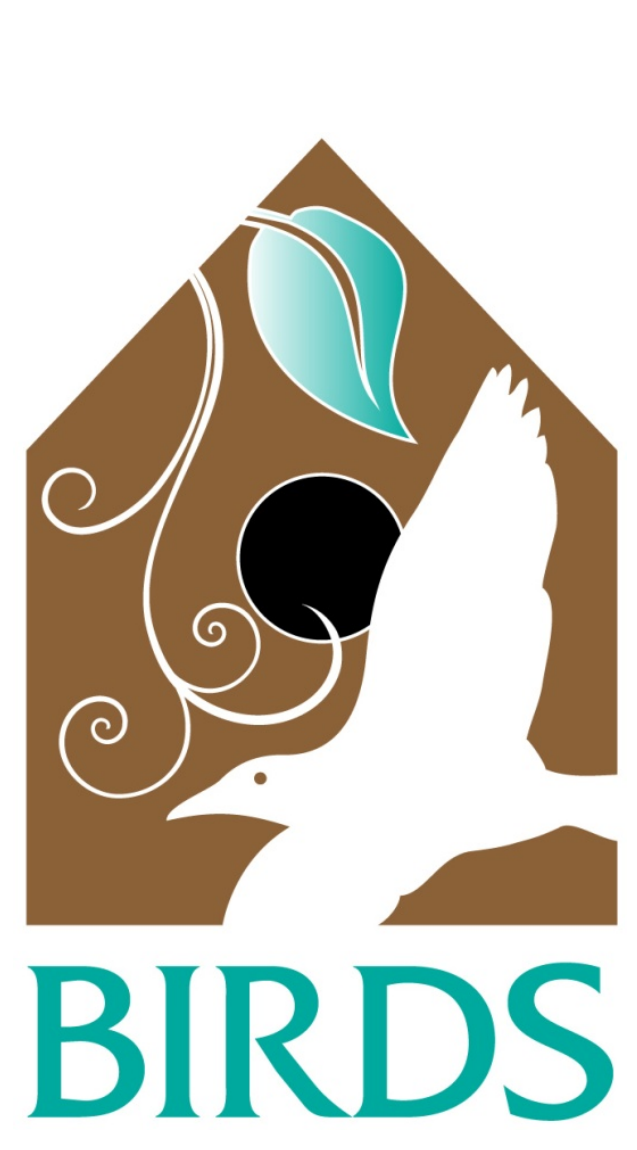

Joshua Kneifel Eric O'Rear

Priya Lavappa Anne Landfield Greig Sangwon Suh

This publication is available free of charge from: https://doi.org/10.6028/NIST.TN.2003r1

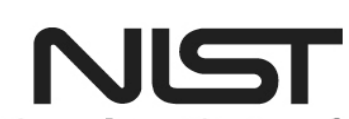

National Institute of Standards and Technology U.S. Department of Commerce 


\section{Building Industry Reporting and Design for Sustainability (BIRDS) Low-Energy Residential Incremental Energy Efficiency Improvements Database Technical Manual: Update} Joshua Kneifel Eric O'Rear Priya Lavappa Applied Economics Office Engineering Laboratory

Anne Landfield Greig Four Elements Consulting, LLC

Sangwon Suh Industrial Ecology Research Services, LLC

This publication is available free of charge from: https://doi.org/10.6028/NIST.TN.2003r1

September 2020

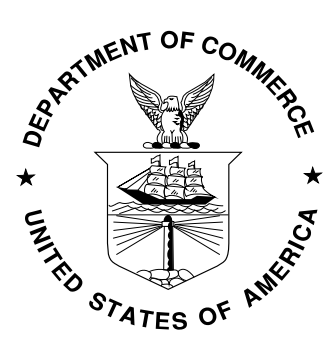

U.S. Department of Commerce Wilbur L. Ross, Jr., Secretary 
Certain commercial entities, equipment, or materials may be identified in this document in order to describe an experimental procedure or concept adequately. Such identification is not intended to imply recommendation or endorsement by the National Institute of Standards and Technology, nor is it intended to imply that the entities, materials, or equipment are necessarily the best available for the purpose.

National Institute of Standards and Technology Technical Note 2003 Revision 1 Natl. Inst. Stand. Technol. Tech. Note 2003 Rev. 1, 171 pages (September 2020) CODEN: NTNOEF

This publication is available free of charge from: https://doi.org/10.6028/NIST.TN.2003r1 


\begin{abstract}
Building stakeholders need practical metrics, data, and tools to support decisions related to sustainable building designs, technologies, standards, and codes. The Engineering Laboratory of the National Institute of Standards and Technology (NIST) has addressed this high priority national need by extending its metrics and tools for sustainable building products, known as Building for Environmental and Economic Sustainability (BEES), to whole-buildings. A sustainability measurement system has been developed consisting of whole-building sustainability metrics that are based on innovative extensions to life-cycle assessment (LCA) and life-cycle costing (LCC) approaches involving whole-building energy simulations. The measurement system evaluates the sustainability of both the materials and the energy used by a building over time. It assesses the "carbon footprint" of buildings as well as 11 other environmental performance metrics, and integrates economic performance metrics to yield science-based measures of the business case for investment choices in high-performance green buildings.

Building Industry Reporting and Design for Sustainability (BIRDS) applies the sustainability measurement system to an extensive whole-building performance database NIST has compiled for this purpose. Based on the NIST Net-Zero Energy Residential Test Facility (NZERTF), the BIRDS Low-Energy Residential Incremental Energy Efficiency Improvements Database includes energy, environmental, and cost measurements for 960000 design variations of the NZERTF for Gaithersburg, MD for study periods up to 30 years. Focusing on a single location allows for the consideration of incremental building energy efficiency measures, both those specified in the most recent International Energy Conservation Code (IECC) and those implemented in the NZERTF. Buildings designed to meet current energy codes can be compared to alternative building designs to determine the impacts of improving building energy efficiency on overall sustainability performance. This report describes the latest version of BIRDS (v4.1) including new options, namely natural gas-fired space and water heater equipment.
\end{abstract}

\title{
Keywords
}

Building economics; economic analysis; life-cycle costing; life-cycle assessment; energy efficiency; residential buildings; low-energy buildings; net-zero energy performance 


\section{Preface}

This documentation was developed by the Applied Economics Office (AEO) in the Engineering Laboratory (EL) at the National Institute of Standards and Technology (NIST). The document explains how the BIRDS Low-Energy Residential Incremental Energy Efficiency Improvements Database was developed, including the assumptions and data sources for the energy, environmental, and cost estimate calculations. The intended audience are BIRDS users, researchers and decision makers in the residential building sector, and others interested in building sustainability.

\section{Disclaimers}

The policy of the National Institute of Standards and Technology is to use metric units in all of its published materials. Because this report is intended for the U.S. construction industry that uses U.S. customary units, it is more practical and less confusing to include U.S. customary units as well as metric units. Measurement values in this report are therefore stated in metric units first, followed by the corresponding values in U.S. customary units within parentheses. 


\section{Acknowledgements}

The authors wish to thank all those who contributed ideas and suggestions for this report. They include Dr. Cheyney O'Fallon and Dr. David Butry of EL's Applied Economics Office, Stuart Dols of EL's Energy and Environment Division, and Dr. Nicos S. Martys of EL's Materials and Structural Systems Division. A special thanks to the Industrial Ecology Research Services team of Shivira Tomar, Christine Chen, and Matthew Leighton for their superb technical support in developing whole-building environmental life-cycle assessments for BIRDS. Thanks go to researchers at the Institute for Software Integrated Systems of the School of Engineering at Vanderbilt University for assisting in generating and compiling the energy simulation results. Thanks goes to our industry contacts that were instrumental in advising on the assumptions used to develop the product-level life-cycle impact assessments: Daniel Lea of the Cellulose Insulation Manufacturers Association, Dr. Richard S. Duncan of the Spray Polyurethane Foam Alliance (SPFA), Anders Schmidt of dk-Teknik Energy \& Environment, and members of the Extruded Polystyrene Foam Association (XPSA). Thanks to Ms. Shannon Grubb for assisting in developing the low-energy residential incremental improvements sustainability database. Finally, the many Beta testers of BIRDS deserve special thanks for contributing suggestions leading to substantial improvements in the tool. 


\section{Author Information}

Joshua Kneifel

Economist

National Institute of Standards and Technology

Engineering Laboratory

100 Bureau Drive, Mailstop 8603

Gaithersburg, MD 208998603

Tel.: 301-975-6857

Email: joshua.kneifel@nist.gov

Eric O'Rear

Economist

National Institute of Standards and Technology

Engineering Laboratory

100 Bureau Drive, Mailstop 8603

Gaithersburg, MD 208998603

Tel.: 301-975-4570

Email: eric.orear@nist.gov

Priya Lavappa

Computer Specialist

National Institute of Standards and Technology

Engineering Laboratory

100 Bureau Drive, Mailstop 8603

Gaithersburg, MD 208998603

Tel.: 301-975-4522

Email: priya.lavappa@nist.gov

Anne Landfield Greig

Principal

Four Elements Consulting, LLC

Seattle, WA

Tel: 206-935-4600

Email: anne@fourelementsllc.com

Sangwon Suh

Director and Founder

Industrial Ecology Research Services (IERS), LLC

5951 Encina Rd, Suite 206

Goleta, CA 93117

Tel: 805-324-4674

Email: suh@iersweb.com 


\section{Contents}

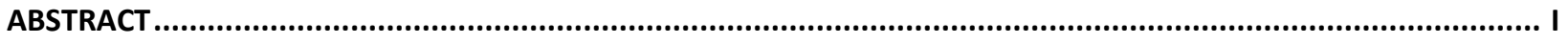

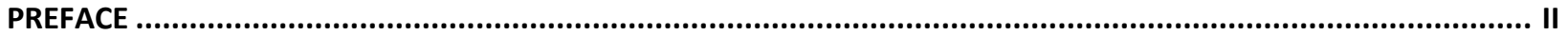

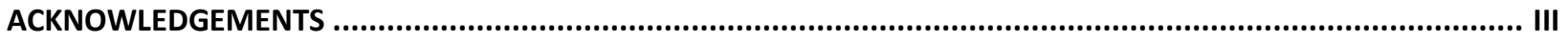

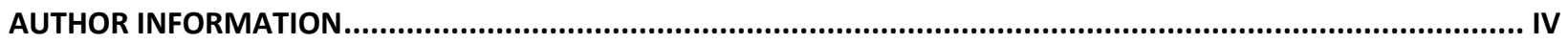

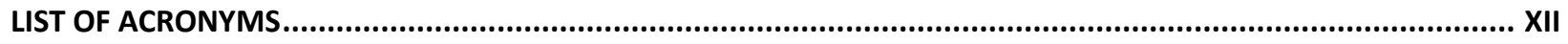

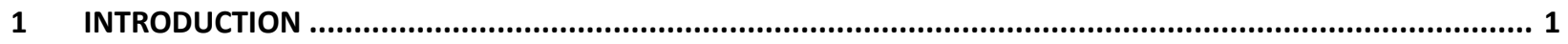

1.1 PURPOSE

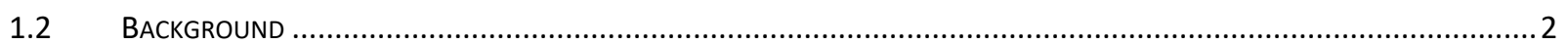

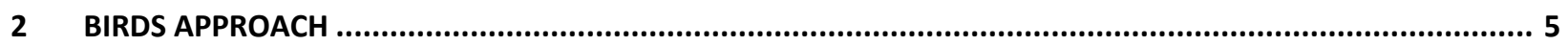

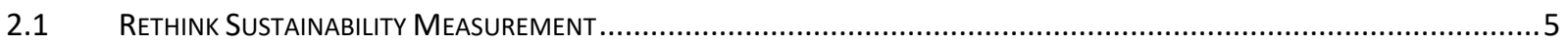

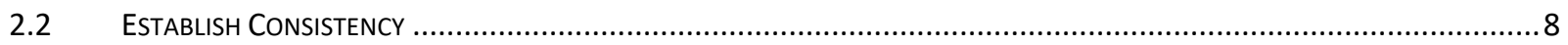

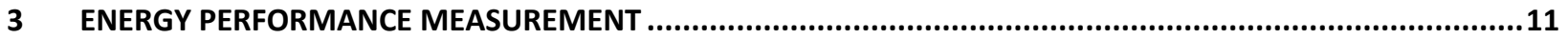

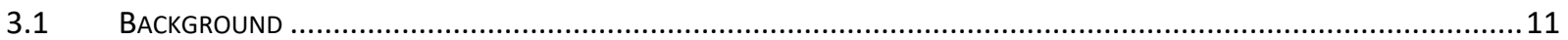

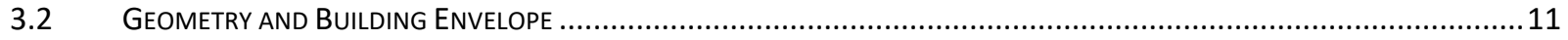

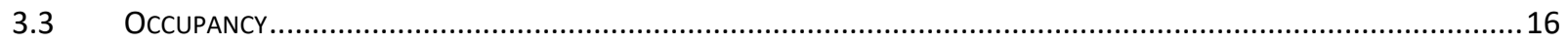

LIGHTING

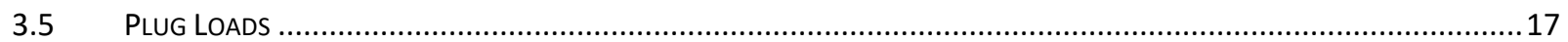

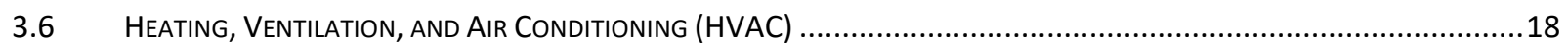

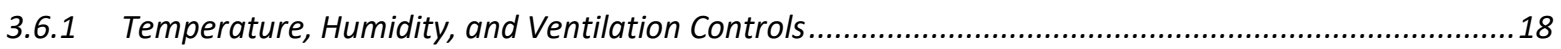

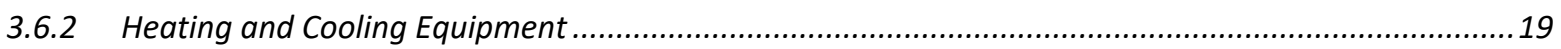

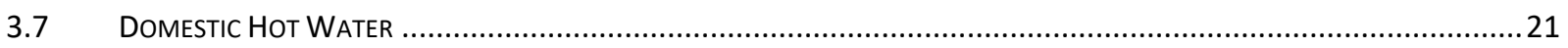

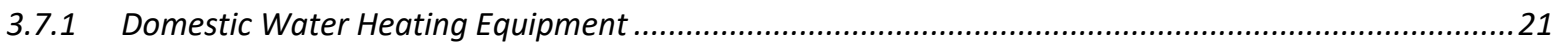

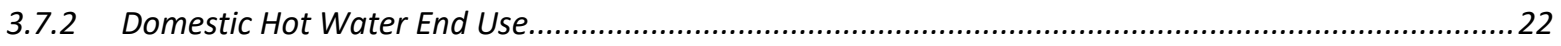

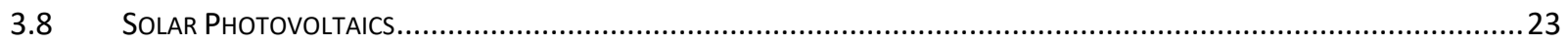

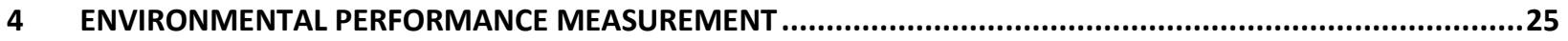

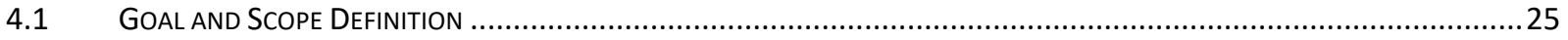

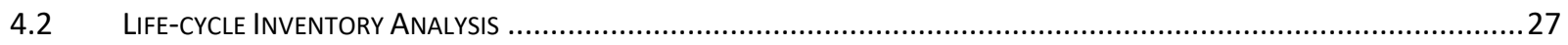

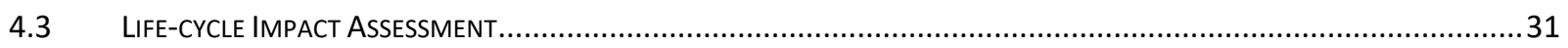

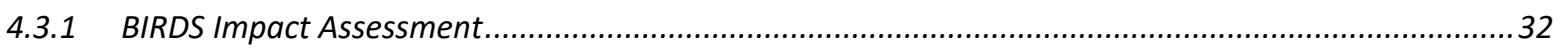

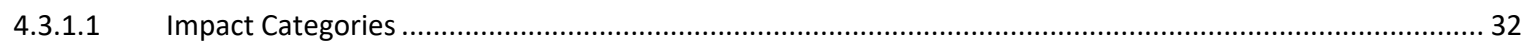

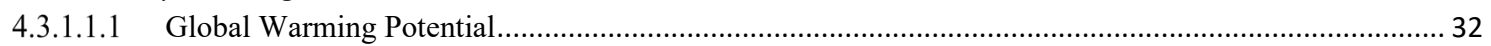

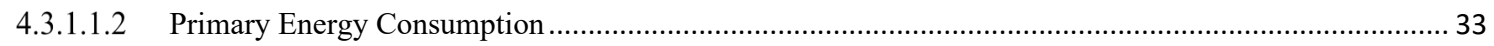

4.3.1.1.3 Human Health - Criteria Air Pollutants ………….......................................................................... 33

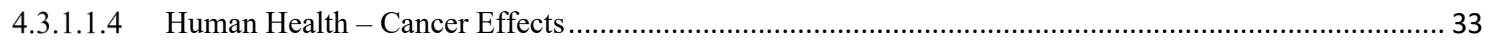

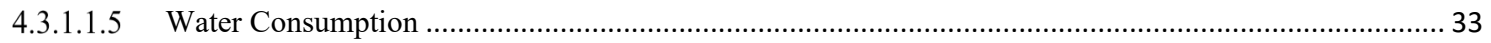

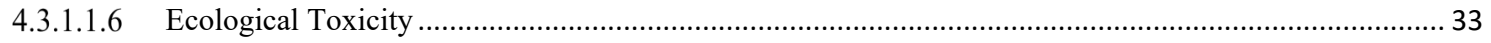

4.3.1.1.7 Eutrophication Potential............................................................................................................ 33

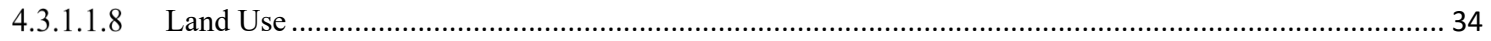

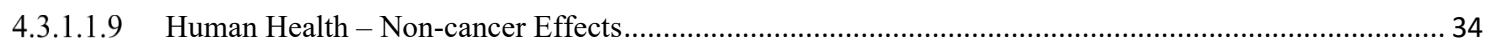

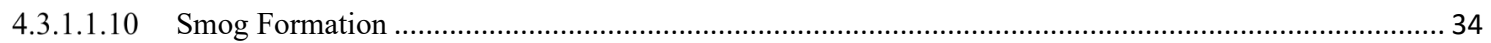

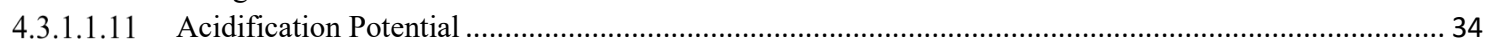

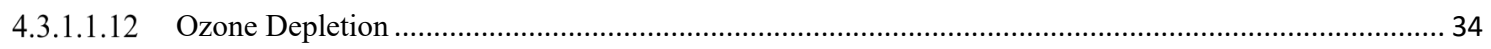

4.3.1.2 Computational Algorithms ......................................................................................................... 34 


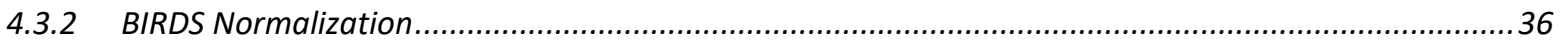

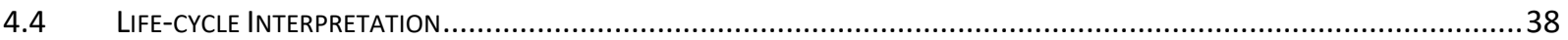

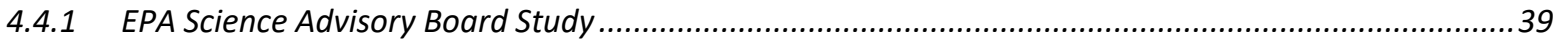

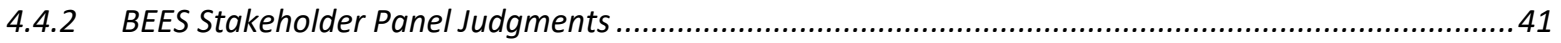

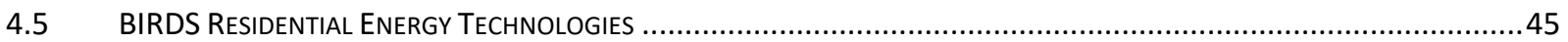

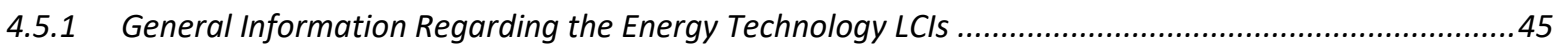

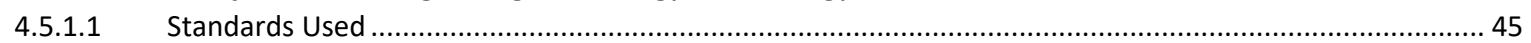

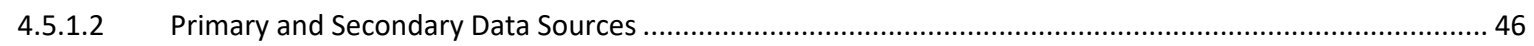

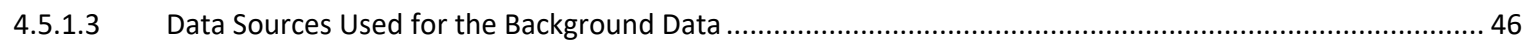

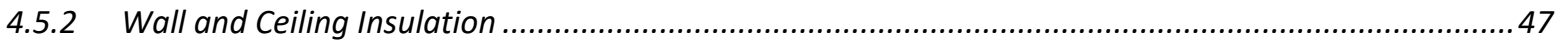

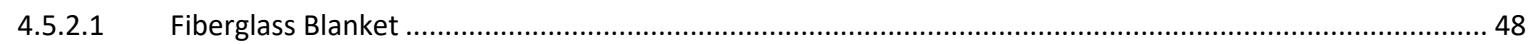

4.5.2.1.1 Upstream Materials Production through Manufacturing …………………………………................. 49

4.5.2.1.2 Transportation to the Building through End-of-Life …….............................................................. 50

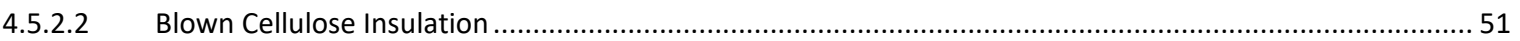

4.5.2.2.1 Upstream Materials Production through Manufacturing ……………………………………............. 51

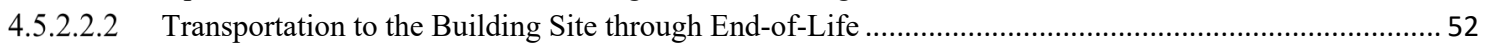

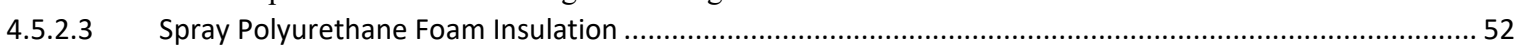

4.5.2.3.1 Upstream Materials Production through Manufacturing ........................................................................ 53

4.5.2.3.2 Transportation to the Building Site through End-of-Life .................................................................. 57

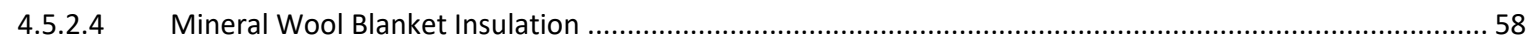

4.5.2.4.1 Upstream Materials Production through Manufacturing ………………............................................ 58

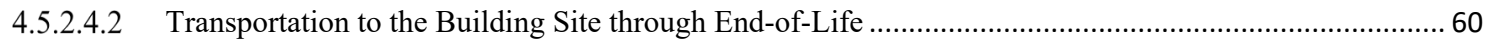

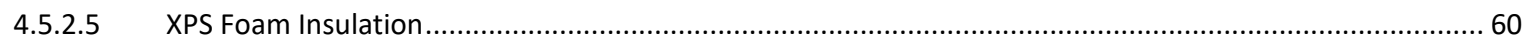

4.5.2.5.1 Upstream Materials Production through Manufacturing ……………………………………............... 60

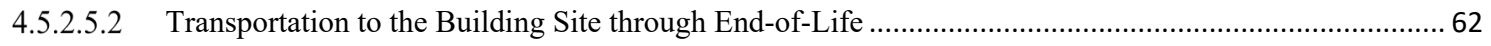

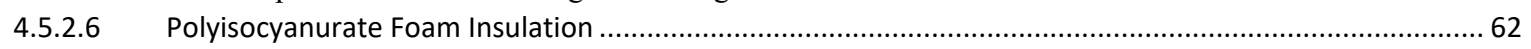

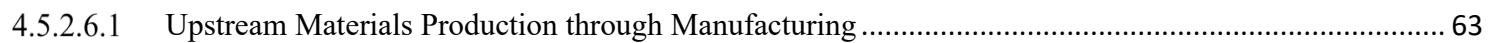

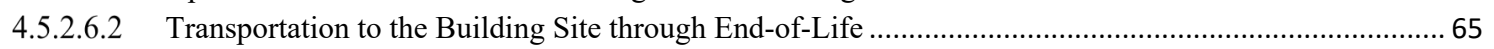

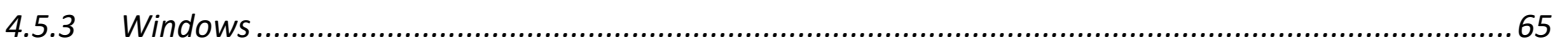

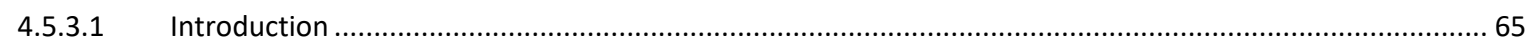

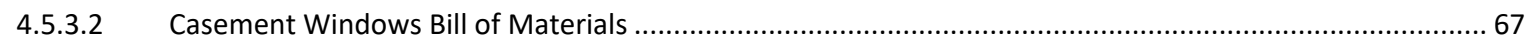

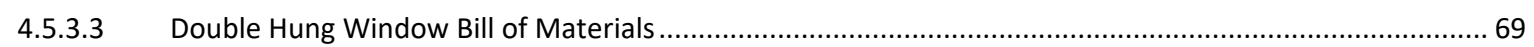

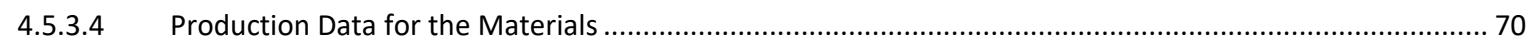

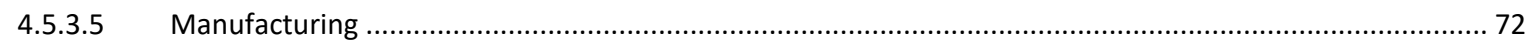

4.5.3.6 Transportation to the Building Site, Use and Maintenance ........................................................... 73

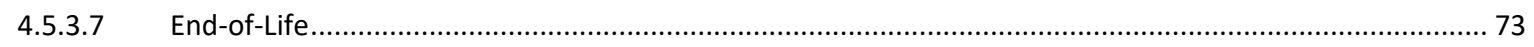

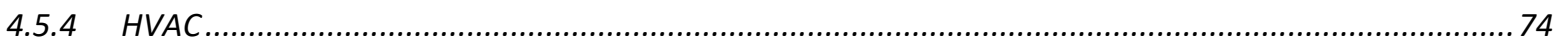

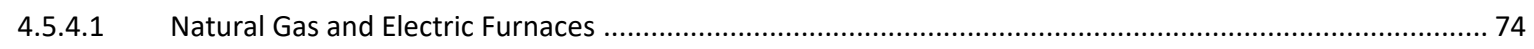

4.5.4.1.1 Upstream Materials Production through Manufacturing …........................................................... 74

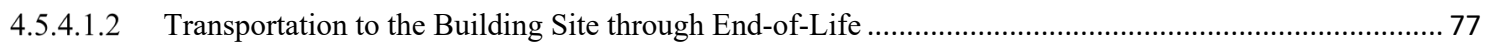

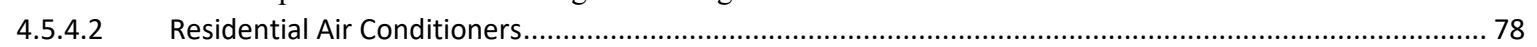

4.5.4.2.1 Upstream Materials Production through Manufacturing .................................................................... 78

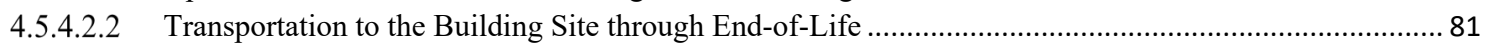

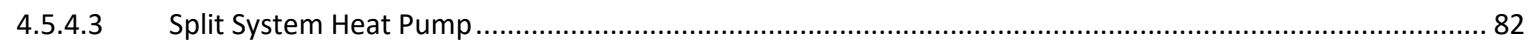

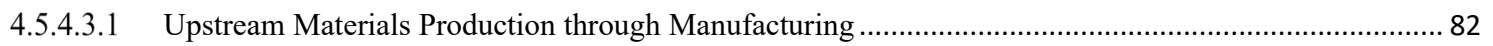

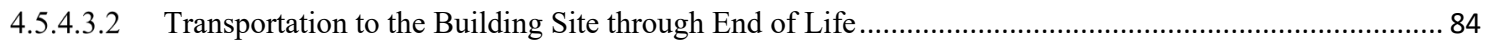

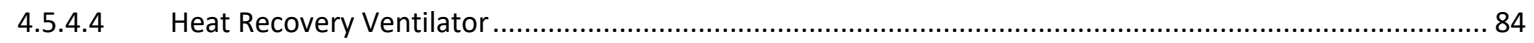

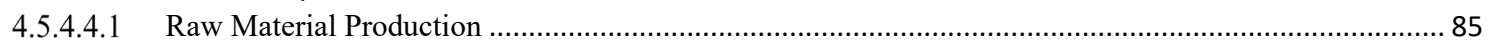

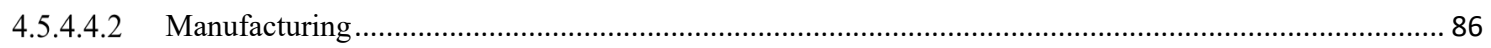

4.5.4.4.3 Transportation to the Building Site through End of Life ............................................................. 87

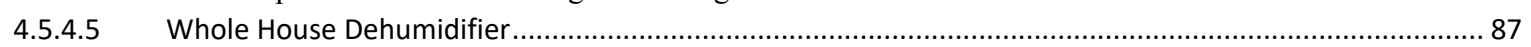

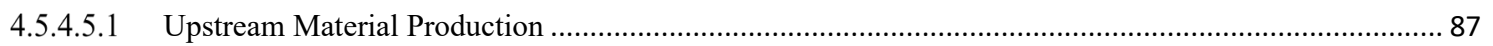

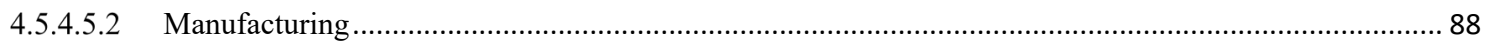


4.5.4.5.3 Transportation to the Building Site through End of Life ................................................................. 89

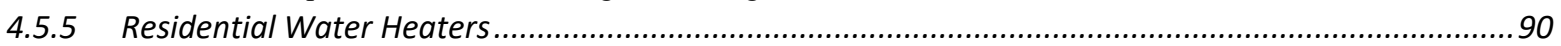

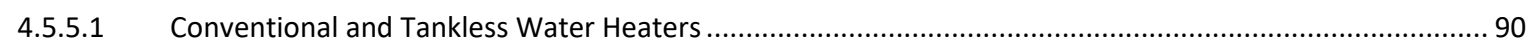

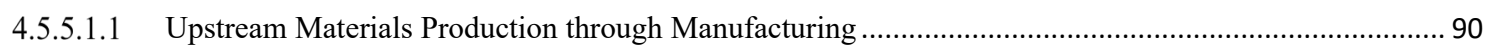

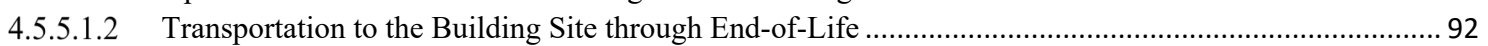

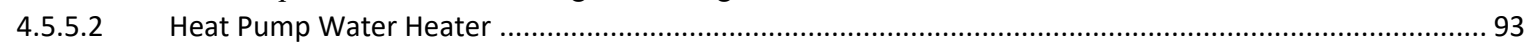

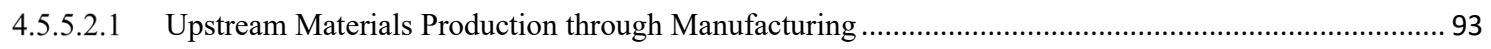

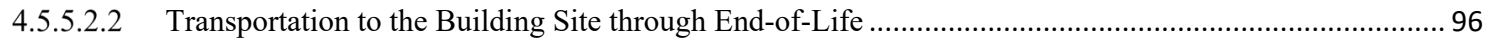

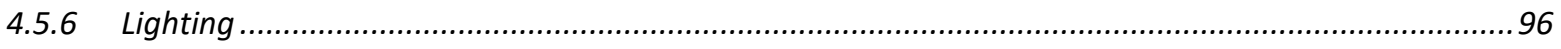

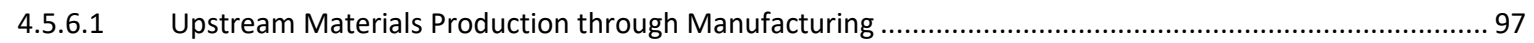

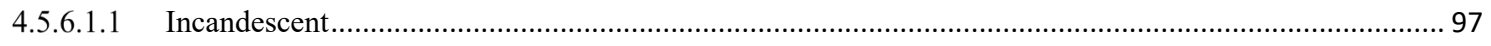

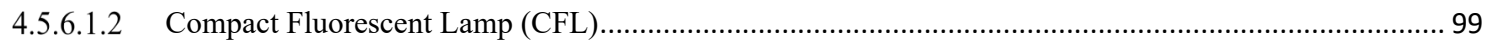

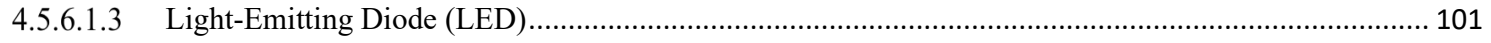

4.5.6.2 Transportation to the Building Site through End-of-Life ............................................................... 103

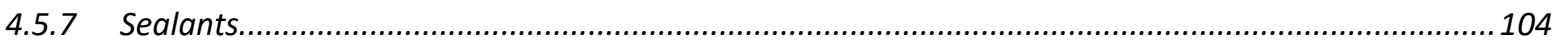

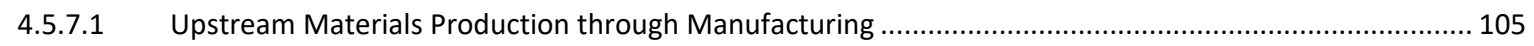

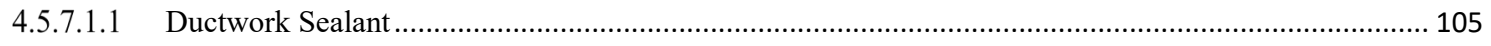

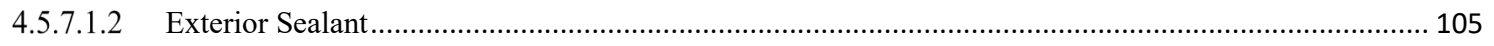

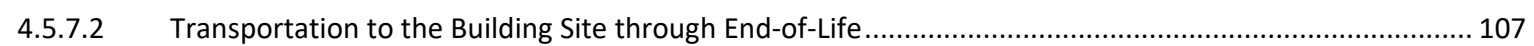

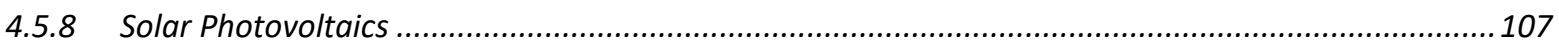

4.5.8.1 Upstream Materials Production through Manufacturing ....................................................................... 108

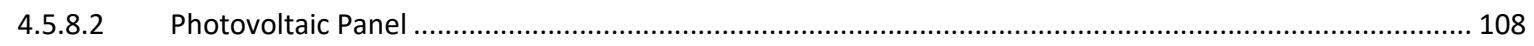

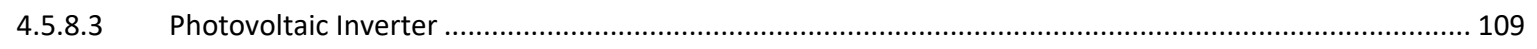

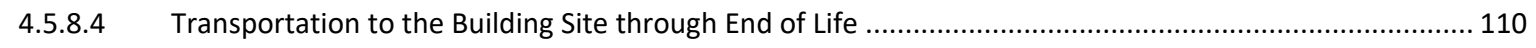

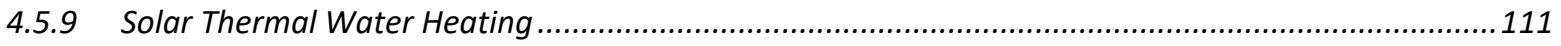

4.5.9.1 Upstream Materials Production through Manufacturing …................................................................ 112

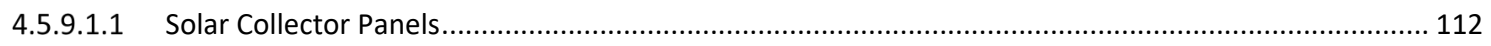

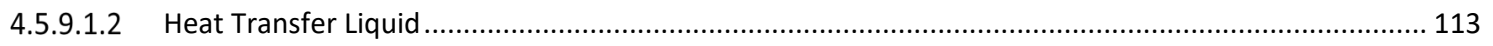

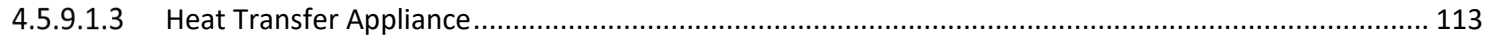

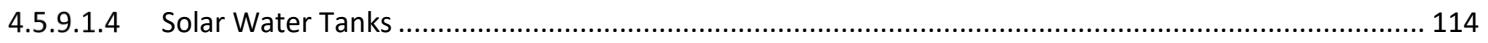

4.5.9.2 Transportation to the Building Site through End of Life ............................................................. 115

5 ECONOMIC PERFORMANCE MEASUREMENT ........................................................................... 117

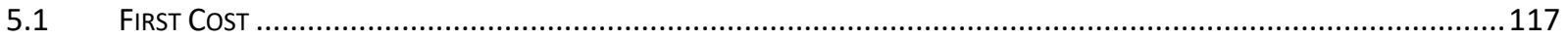

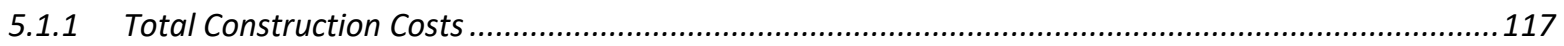

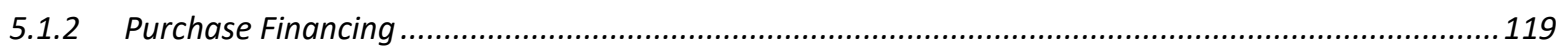

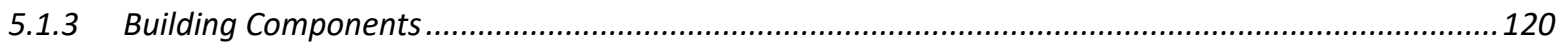

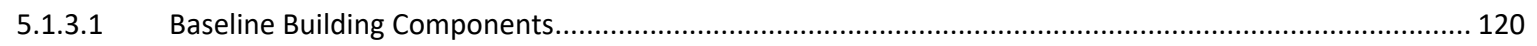

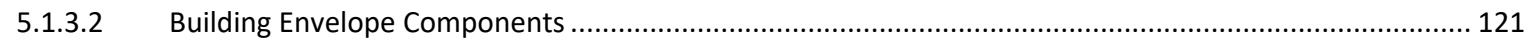

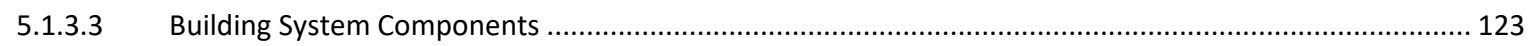

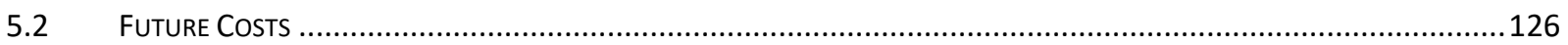

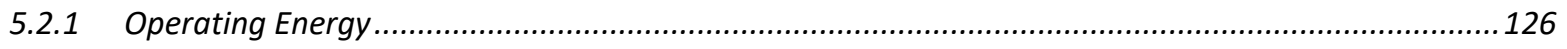

5.2.2 Maintenance, Repair, and Replacement (MRR) Costs ............................................................... 127

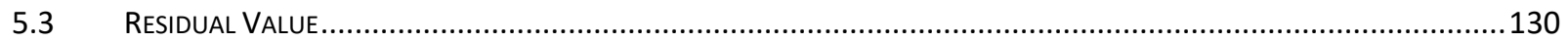

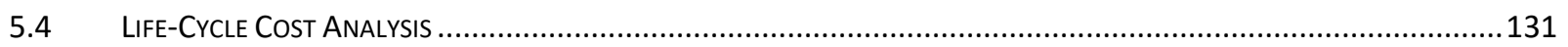

6 INDOOR ENVIRONMENTAL QUALITY PERFORMANCE ...............................................................133

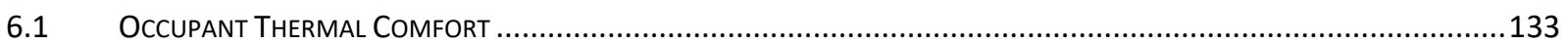

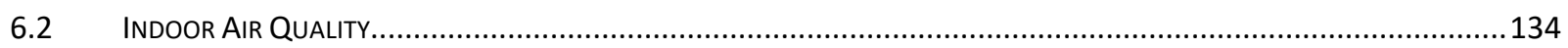

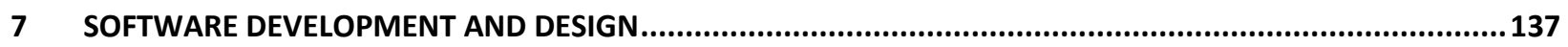

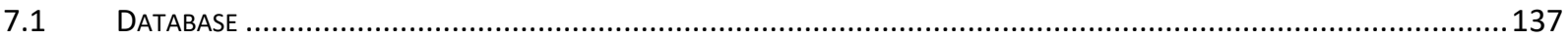




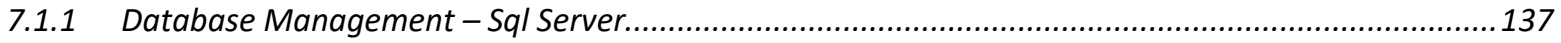

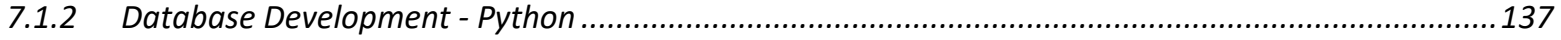

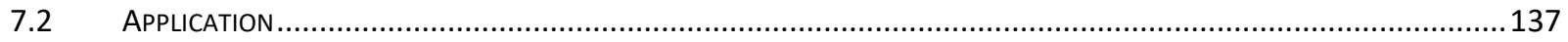

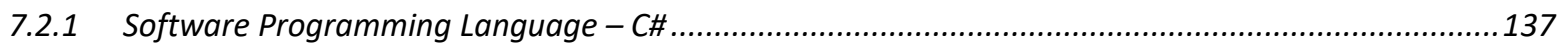

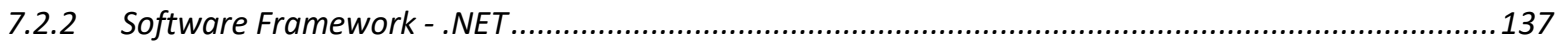

7.2.3 Web Development Technologies - HTML, CSS, JavaScript, JQuery, jqChart ...................................138

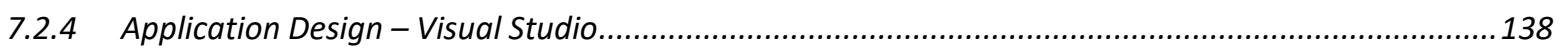

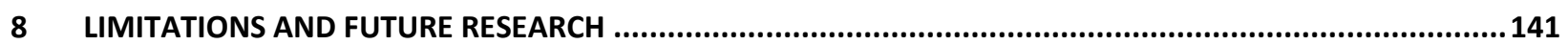

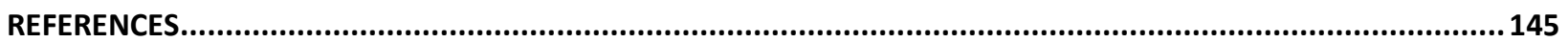




\section{List of Figures}

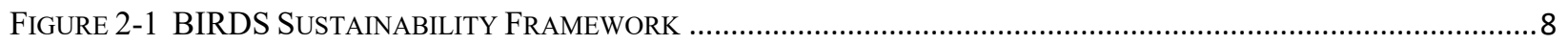

FIgURE 3-1 BSC ARChITECTURAL MASSING MODEL AND NZERTF AS BUILT ……...................................................12

Figure 3-2 GoOgle SKetchUP 3-D Representation Of THE E+ Model ……........................................................12

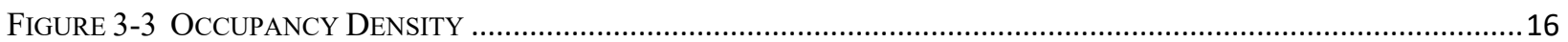

Figure 3-4 Electrical Equipment Load Profiles as a Proportion of Peak Wattage, By Hour ..................18

FIGURE 3-5 HVAC SYSTEM LAYOUT FOR (A) STANDARD EFFICIENCY (B) NZERTF ..............................................20

Figure 3-6 Domestic Hot Water Heating Systems (a) Heat Pump Water Heater with Solar Thermal (B)

Electric/Natural Gas Water Heater With Solar Thermal (C) Heat Pump Water Heater (D)

ELECTRIC/NATURAL GAS WATER HEATER …………..............................................................................22

Figure 3-7 Domestic Hot Water Load Profiles as a Proportion of Peak Flow Rate, By Hour .................23

FIGURE 4-1 COMPILING LCA INVENTORIES OF ENVIRONMENTAL INPUTS AND OUTPUTS .........................................28

FigURE 4-2 ILlUSTRATION OF SUPPLY CHAIN CONTRIBUTIONS TO U.S. CONSTRUCTION INDUSTRY ..........................30

Figure 4-3 BEES Stakeholder Panel Importance Weights Synthesized ACross Voting Interest and Time

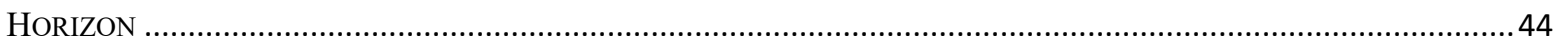

FigURE 4-4 BEES STAKeHOLDER PANEL IMPORTANCE WEIGHTS BY STAKEHOLDER VOTING INTEREST ...................44

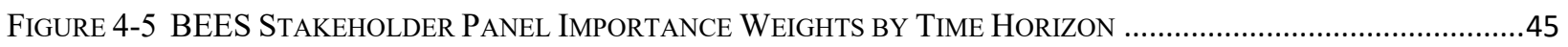

FIGURE 4-6 INSULATION SYSTEM BOUNDARIES - FIBERGLASS BLANKET EXAMPLE …………….............................48

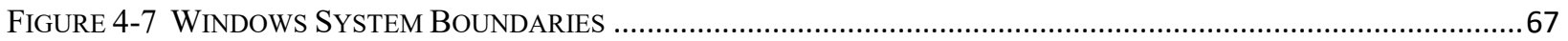

FIGURE 4-8 HVAC SYSTEM BOUNDARIES - ELECTRIC FURNACE EXAMPLE ………….......................................74

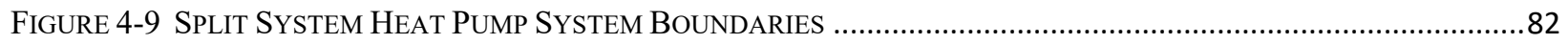

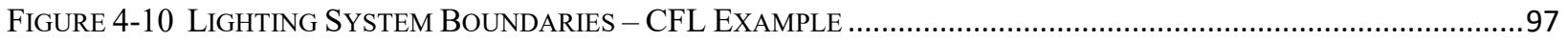

Figure 4-11 SEALANTS SySTEM BoundariES - EXTERIOR SEALANT EXAMPLE …….........................................104

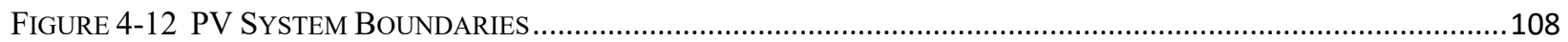

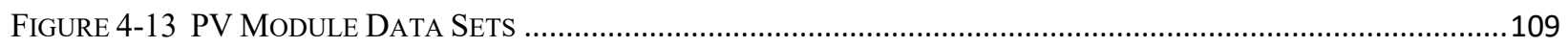

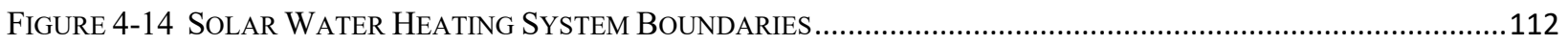

FIGURE 5-1 RS MEANS ONLINE SQUARE FoOt COST ESTIMATOR (SFCE) ……......................................................118

FiguRE 5-3 BASELINE MAINTENANCE AND REPAIR COSTS BY YEAR …….........................................................129

Figure 6-1 ASHRAE STANDARD 55-2004 THERMAL COMFORT RANGE - Winter (LEFT) AND SUMMER (RIGHT)...134

FIGURE 7-1 APPLICATION INFORMATION FLOW ………...................................................................................138 


\section{List of Tables}

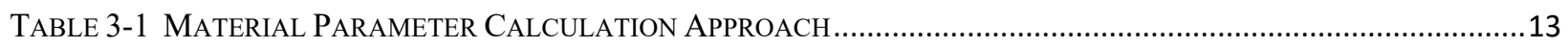

TABLE 3-2 CONSTRUCTIONS - RoOF, CEILING, WALl AND FoundATION ...............................................................14

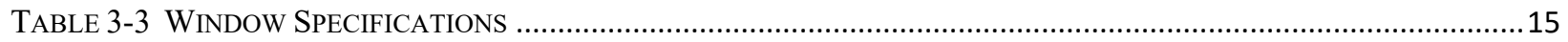

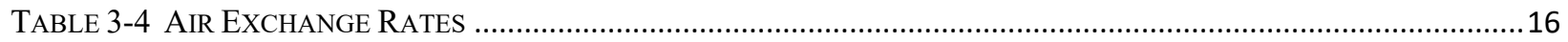

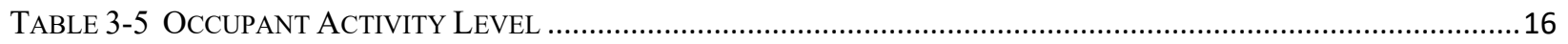

TABLE 3-6 Lighting Total Wattage By Floor By Design Options .....................................................................17

TABLE 3-7 DAILY DOMESTIC Hot WATER USE AND TARget TEMPERATURES ...........................................................23

TABLE 4-1 CONSTRUCTION INDUSTRY OUTPUTS MAPPED TO BIRDS BUILDING TYPES ..............................................31

TABLE 4-2 BIRDS LIFE-CYClE IMPACt ASSESSMENT CALCULATIONS BY BUILDING COMPONENT .............................36

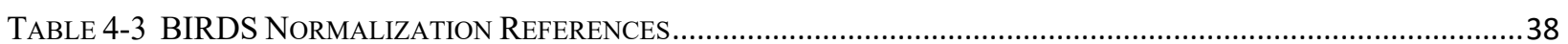

TABLE 4-4 PAIRWISE COMPARISON VALUES FOR DERIVING IMPACT CATEGORY IMPORTANCE WEIGHTS ...................40

TABLE 4-5 RELATIVE IMPORTANCE WEIGHTS BASED ON SCIENCE ADVISORY BOARD STUDY ...................................41

TABLE 4-6 RELATIVE IMPORTANCE WeIGHTS BASED ON BEES STAKEHOLDER PANEL JUdGMENTS ..........................43

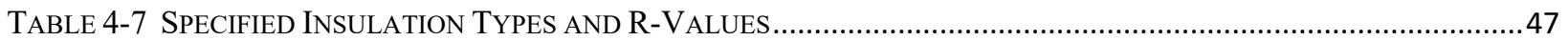

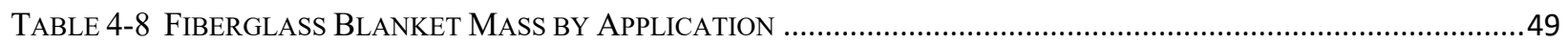

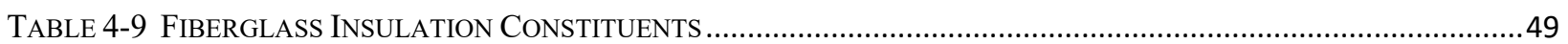

TABLE 4-10 ENERGY REQUIREMENTS FOR FIBERGLASS INSULATION MANUFACTURING ..........................................50

TABLE 4-11 BLOWN CELLULOSE INSULATION BY APPLICATION ...................................................................................51

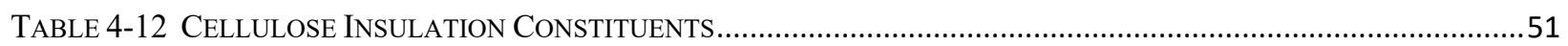

TABle 4-13 B-Side Formulation - Material Constituent PercentageS ……………..................................54

TABLE 4-14 SPF INSULATION REFERENCE UNIT PARAMETERS FOR ORIGINAL AND BIRDS LCAS............................55

TABLE 4-15 MATERIAl CONSTITUENTS FOR OPEN-CELl AND ClOSED-CELl SPF InSUlaTiOn ................................56

TABLE 4-16 Mineral WoOl Blanket MASS By APPLICATION ........................................................................58

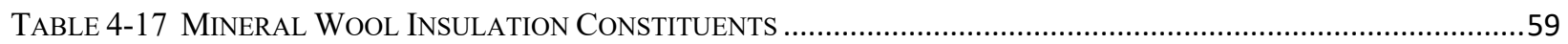

TABLE 4-18 ENERGY REQUIREMENTS FOR MINERAL WOOL INSULATION MANUFACTURING......................................59

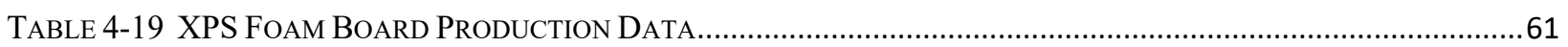

TABLE 4-20 RAW MATERIAL InPUTS To ProduCE Polyiso FoAM ……........................................................................63

TABLE 4-21 ENERGY INPUTS AND PROCESS OUTPUTS FOR 1 BOARD-FOOT POLYISO FOAM ......................................64

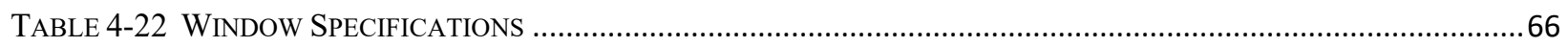

TABLE 4-23 Dimensions AND MaIN PARTS OF THE WoOd Clad CASEMENT Window ...........................................68

TABLE 4-24 Dimensions AND MaIN PARTS OF THE ALUMINUM CASEMENT Window ……….................................68

TABLE 4-25 DimenSIONS AND MAIN PARTS OF THE VINYL CASEMENT WINDOW …….............................................68

TABLE 4-26 Dimensions AND MaIN PARTS OF THE WoOd Clad DOUBle Hung Window ......................................69

TABLE 4-27 Dimensions AND MAIN PARTS OF THE AluminUm DOUBLE HUNG Window ..........................................70

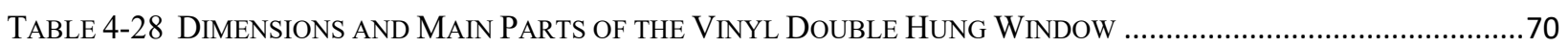

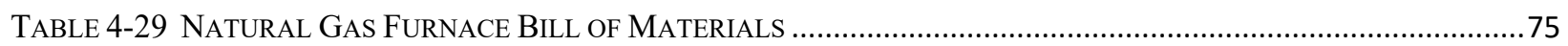

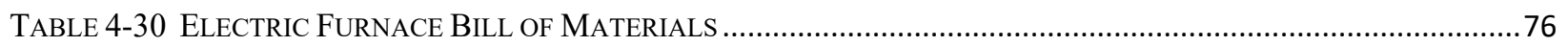

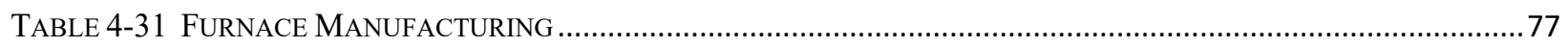

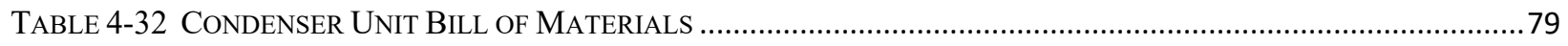

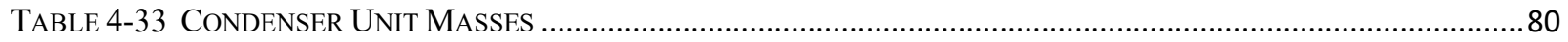

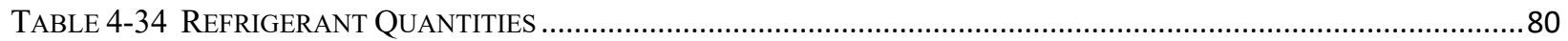

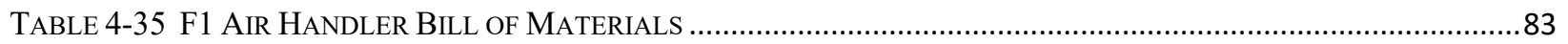

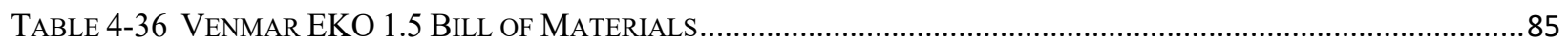

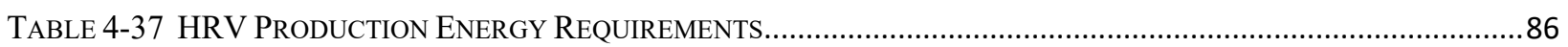

TAble 4-38 Ultra-Aire 70H Whole-House Ventilating Dehumidifier BiLl OF Materials ............................88

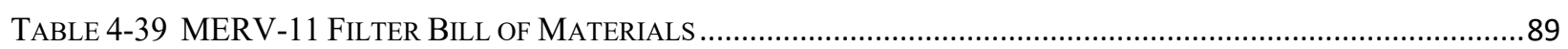

TABLE 4-40 ELECTRIC WATER HEATER BILl OF MATERIALS ................................................................................90 


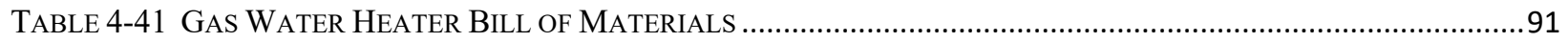

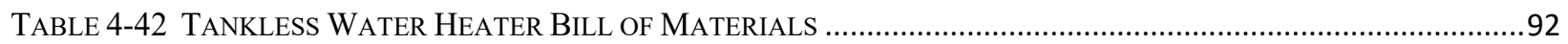

TABLE 4-43 Heat Pump Water Heater Weight Estimation .........................................................................9

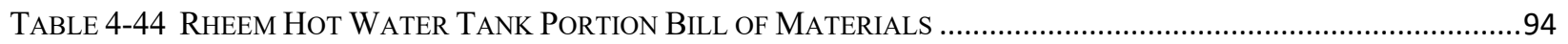

TABLE 4-45 RHEEM HEAT PUMP PORTION BILL OF MATERIALS ..........................................................................95

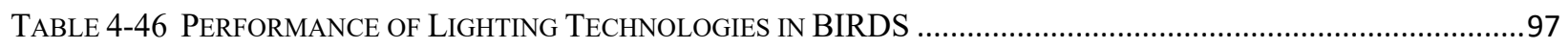

TABLE 4-47 INCANDESCENT LIGHT BULB BILL OF MATERIALS ............................................................................98

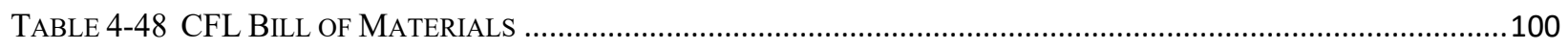

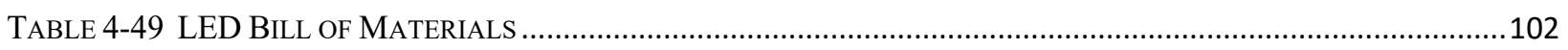

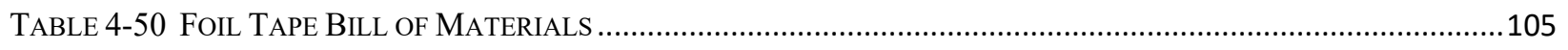

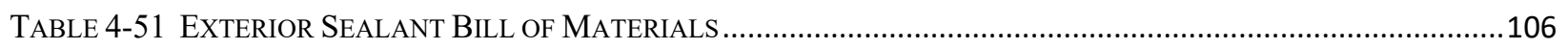

TABLE 4-52 SUNPOWER 5000M LUT PV INVERTER BILL OF MATERIALS ............................................................110

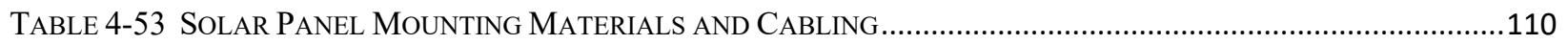

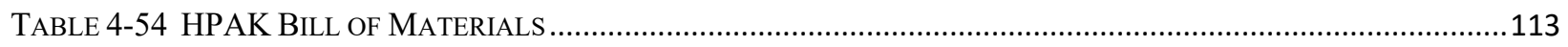

TABLE 4-55 Heliodyne Solar WATER StORAge TANKS BiLl OF MATERIALS ……….......................................114

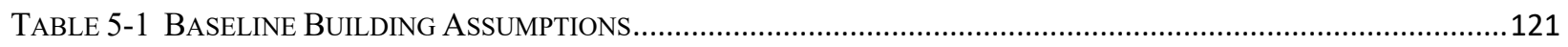

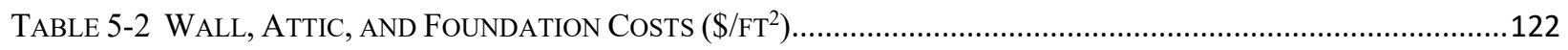

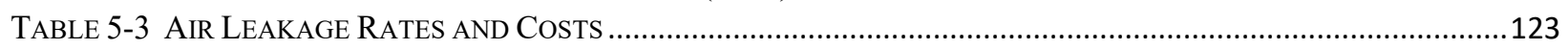

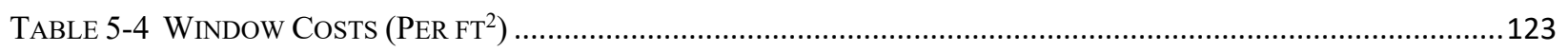

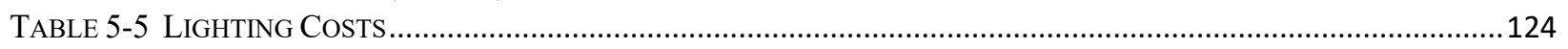

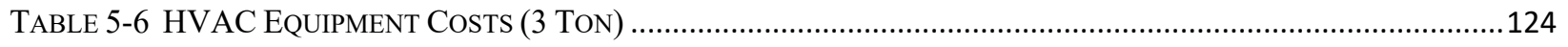

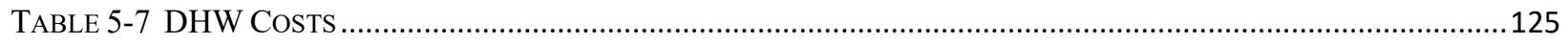

TABLE 5-8 2017 SPV Discount Factors For Future Non-Fuel Costs, 8 \% AND 3 \% REAL DisCount Rate...127

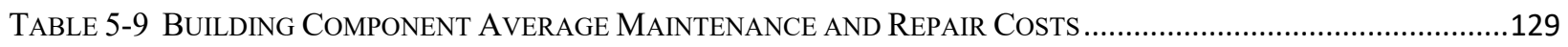




\section{List of Acronyms}

\section{Acronym Definition}

\begin{tabular}{|c|c|}
\hline $\mathrm{ABS}$ & acrylontrile-butadiene-styrene \\
\hline $\mathrm{ACH}$ & air changes per hour \\
\hline $\mathrm{AEO}$ & Applied Economics Office \\
\hline AHP & Analytical Hierarchy Process \\
\hline AHRI & Air Conditioning, Heating, and Refrigeration Institute \\
\hline AHS & American Housing Survey \\
\hline ASHRAE & American Society of Heating, Refrigerating and Air-Conditioning Engineers \\
\hline BA & Building America \\
\hline BEA & Bureau of Economic Analysis \\
\hline BEES & Building for Environmental and Economic Sustainability \\
\hline BIRDS & Building Industry Reporting and Design for Sustainability \\
\hline BSC & Building Science Corporation \\
\hline C\&D & construction and demolition \\
\hline CEN & European Committee for Standardization \\
\hline CFA & conditioned floor area \\
\hline CFC-11 & trichlorofluoromethane \\
\hline CFL & compact fluorescent lamp \\
\hline CFM & cubic feet per minute \\
\hline clo & clothing insulation \\
\hline $\mathrm{CO} 2$ & carbon dioxide \\
\hline $\mathrm{CO} 2 \mathrm{e}$ & carbon dioxide equivalent \\
\hline $\mathrm{COP}$ & coefficient of performance \\
\hline $\mathrm{E}+$ & EnergyPlus \\
\hline EERE & Office of Energy Efficiency \& Renewable Energy \\
\hline eGDP & environmental gross domestic product \\
\hline EIA & Energy Information Administration \\
\hline EL & Engineering Laboratory \\
\hline ELA & effective leakage area \\
\hline EPA & Environmental Protection Agency \\
\hline EPD & environmental product declaration \\
\hline EPDM & ethylene propylene diene monomer \\
\hline
\end{tabular}




$\begin{array}{ll}\text { Acronym } & \text { Definition } \\ \text { EPS } & \text { expanded polystyrene } \\ \text { GDP } & \text { gross domestic product } \\ \text { HBCD } & \text { hexabromocyclododecane } \\ \text { HCFC } & \text { hydrochlorofluorocarbon } \\ \text { HDPE } & \text { high density polyethylene } \\ \text { HFC } & \text { hydrochlorofluorocarbon } \\ \text { HSPF } & \text { heating seasonal performance factor } \\ \text { HVAC } & \text { heating, ventilation, and air-conditioning } \\ \text { IAQ } & \text { indoor air quality } \\ \text { IECC } & \text { International Energy Conservation Code } \\ \text { IGU } & \text { insulated glass unit } \\ \text { I-O } & \text { input-output } \\ \text { IPCC } & \text { Intergovernmental Panel on Climate Change } \\ \text { ISO } & \text { International Organization for Standardization } \\ \text { LBNL } & \text { Lawrence Berkeley National Laboratory } \\ \text { LCA } & \text { life-cycle assessment } \\ \text { LCC } & \text { life-cycle cost } \\ \text { LCI } & \text { life-cycle inventory } \\ \text { LCIA } & \text { life-cycle impact assessment } \\ \text { LED } & \text { light-emitting diode } \\ \text { Low-E } & \text { low-emissivity } \\ \text { M\&R } & \text { maintenance and repair } \\ \text { MBH } & \text { million Btu per hour } \\ \text { MDI } & \text { methylene diphenyl diisocyanate } \\ \text { MRR } & \text { maintenance, repair, and replacement } \\ \text { MSDS } & \text { material safety data sheet } \\ \text { NAHB } & \text { National Association of Home Builders } \\ \text { NIST } & \text { National Institute of Standards and Technology } \\ \text { NS } & \text { net savings } \\ \text { NEt-Zero Energy Residential Test Facility } \\ \text { polybrominated diphenyl ethers } \\ \text { PBoduct category rules }\end{array}$




$\begin{array}{ll}\text { Acronym } & \text { Definition } \\ \text { PIB } & \text { polyisobutylene } \\ \text { PIMA } & \text { Polyisocyanurate Insulation Manufacturers Association } \\ \text { PM10 } & \text { particulate matter less than } 10 \text { micrometers in diameter } \\ \text { pMDI } & \text { polymeric methylene diphenyl diisocyanate } \\ \text { PNS } & \text { Net LCC savings as a percentage of base case LCC } \\ \text { PP } & \text { propylene } \\ \text { ppm } & \text { parts per million } \\ \text { PUR } & \text { polyurethane } \\ \text { PV } & \text { present value } \\ \text { PVC } & \text { polyvinyl chloride } \\ \text { SAB } & \text { Science Advisory Board } \\ \text { SEER } & \text { seasonal energy efficiency ratio } \\ \text { SHGC } & \text { solar heat gain coefficient } \\ \text { SPF } & \text { spray polyurethane foam } \\ \text { SPFA } & \text { Spray Poluurethane Foam Association } \\ \text { SPV } & \text { single present value } \\ \text { TCPP } & \text { tris(2-chloroisopropyl)phosphate } \\ \text { TRACI } & \text { Tool for the Reduction and Assessment of Chemical and other environmental Impact } \\ \text { UPV* } & \text { modified uniform present value discount factor } \\ \text { VOC } & \text { volatile organic compound } \\ \text { VT } & \text { visible transmittance } \\ \text { XPS } & \text { extruded polystyrene } \\ \text { XPSA } & \text { extruded polystyrene foam association } \\ & \end{array}$




\section{Introduction}

\subsection{Purpose}

Building stakeholders need practical metrics, data, and tools to support decisions related to sustainable building designs, technologies, standards, and codes. The Engineering Laboratory (EL) of the National Institute of Standards and Technology (NIST) has addressed this high priority national need by extending its metrics and tools for sustainable building products, known as Building for Environmental and Economic Sustainability (BEES), to whole-buildings. Whole-building sustainability metrics have been developed based on innovative extensions to environmental life-cycle assessment (LCA) and life-cycle costing (LCC) approaches involving whole-building energy simulations. The measurement system evaluates the sustainability of both the materials and energy used by a building over time. It assesses the "carbon footprint" of buildings as well as 11 other environmental performance metrics and integrates economic performance metrics to yield science-based measures of the business case for investment choices in high-performance green buildings.

The approach previously developed for BEES has now been applied at the wholebuilding level to address building sustainability measurement in a holistic, integrated manner that considers complex interactions among building materials, energy technologies, and systems across dimensions of performance, scale, and time. Building Industry Reporting and Design for Sustainability (BIRDS) applies the sustainability measurement system to an extensive whole-building performance database NIST has compiled for this purpose. The energy, environment, and cost data in BIRDS provide measures of building operating energy use based on detailed energy simulations, building materials use through innovative life-cycle material inventories, and building costs over time. BIRDS v1.0 included energy, environmental, and cost measurements for 12540 commercial and non-low rise residential buildings, covering 11 building prototypes in 228 cities across all U.S. states for 9 study periods. (see Lippiatt et al. (2013) for details). BIRDS v2.0 included both a commercial and residential database which incorporated the energy, environmental, and cost measurements for 9120 residential buildings, covering 10 single family dwellings ( 5 one-story and 5 two-story of various conditioned floor area) in 228 cities for study periods ranging from 1 year to 40 years.

Similar to the previous databases, the low-energy residential database incorporated into BIRDS v3.0 included the energy, environmental, and cost measurements. However, instead of considering locations across the country with minimal building design options, BIRDS v3.0 allowed for detailed incremental energy efficiency measure analysis for a single location, 240000 variations in residential building designs based on the NIST NetZero Energy Residential Test Facility (NZERTF) specifications and varying requirements across International Energy Conservation Code (IECC) editions. Again, study periods from 1 year to 40 years are included in the low-energy residential database. The sustainability performance of buildings designed to meet current energy codes can be 
compared to a number of alternative building designs to determine the impacts of improving building energy efficiency as well as varying the investor time horizon and other assumptions affecting overall sustainability performance. ${ }^{1}$ BIRDS v3.1 expanded the low-energy residential database to include indoor environmental quality metrics based on occupant thermal comfort and indoor air quality (IAQ) as well as incorporating an alternative exterior wall finish that increases the number of residential building component combinations to 480000 . Along with the expansion of the database, the BIRDS interface was updated to include additional graphing features to improve the user experience.

BIRDS v4.0 includes an update to all three databases (standards-based commercial database, code-based residential database, and incremental residential database). The updated database includes measurements for 13680 building designs, covering 15 building prototypes ( 13 commercial and 2 non-low rise residential) in 228 cities, for time horizons ranging from 1 year to 40 years. The commercial prototype buildings are based on models developed by the Pacific Northwest National Laboratory (PNNL), referred to as Commercial Prototype Building Models, and are representative of roughly $80 \%$ of newly constructed floor area in the United States. The previous residential database included costs for building construction, operation, maintenance, repair, and replacement in year 2014 dollars $(\$ 2014)$. The updated database includes costs for similar buildingsrelated cost components, but in year 2017 dollars (\$2017). The updated low-energy residential database, now renamed the BIRDS Low-Energy Residential Incremental Energy Efficiency Improvements Database, has expanded the building component combinations to 960000 by adding options for natural gas-fired space and water heating equipment.

The latest version of BIRDS, v4.1, updated the Low-Energy Residential Incremental Energy Efficiency Improvements Database by updating construction costs to 2018 dollars (\$2018), updating current and projected energy costs, updating residential solar photovoltaic installation cost data with a cost function based on installer quotes in 2018, and updated the operational energy environmental impact data based on newly published electricity and natural gas baseline environmental flow databases.

\subsection{Background}

A wave of interest in sustainability gathered momentum in 1992 with the Rio Earth Summit, during which the international community agreed upon a definition of sustainability in the Bruntland report: "meeting the needs of the present generation without compromising the ability of future generations to meet their own needs" (Brundtland Commission 1987). In the context of sustainable development, needs can be thought to include the often-conflicting goals of environmental quality, economic wellbeing, and social justice. While the intent of the 1992 summit was to initiate

\footnotetext{
${ }^{1}$ A forthcoming user guide will include a detailed tutorial of how to use the BIRDS low-energy residential incremental improvements database web interface to make these different types of comparisons.
} 
environmental and social progress, it seemed to have instead brought about greater debate over the inherent conflict between sustainability and economic development (Meakin 1992).

This conflict is particularly apparent within the construction industry. Well-intentioned green development plans may not be executed for economic reasons, and economic development plans may fail to materialize over concerns for the environment and public health. Thus, an integrated approach to sustainable construction - one that simultaneously considers both environmental and economic performance - lies at the heart of reconciling this conflict. For this reason, the BIRDS approach considers both the environmental and economic dimensions of sustainability. BIRDS, however, does not consider the social dimension of sustainability at this time due to the current lack of applicable rigorous measurement methods. 


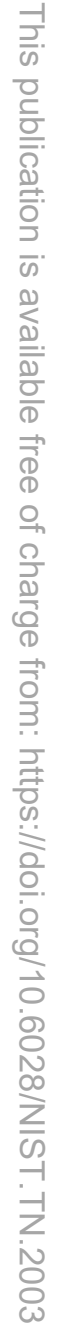




\section{BIRDS Approach}

\subsection{Rethink Sustainability Measurement}

One standardized and preferred approach for scientifically measuring the environmental performance of industrial products and systems is life-cycle assessment (LCA). LCA is a "cradle-to-grave" systems approach for measuring environmental performance. The approach is based on two principles. First, the belief that all stages in the life of a product generate environmental impacts and must be analyzed, including raw materials acquisition, product manufacture, transportation, installation, operation and maintenance, and ultimately recycling and waste management. An analysis that excludes any of these stages is limited because it ignores the full range of upstream and downstream impacts of stage-specific processes. LCA broadens the environmental discussion by accounting for shifts of environmental problems from one life-cycle stage to another. The second principle is that multiple environmental impacts must be considered over these life-cycle stages in order to implement a trade-off analysis that achieves a genuine reduction in overall environmental impact, rather than a simple shift of impact. By considering a range of environmental impacts, LCA accounts for impact-shifting from one environmental medium (land, air, water) to another.

The LCA method is typically applied to products, or simple product assemblies, in a "bottom up" manner. The environmental inputs and outputs to all the production processes throughout a product's life-cycle are compiled. These product life-cycle "inventories" quantify hundreds, even thousands, of environmental inputs and outputs. This is a data-intensive, time-consuming, and expensive process that must be repeated for every product.

The bottom-up approach becomes unwieldy and cost prohibitive for complex systems, such as buildings, that involve potentially hundreds of products. Furthermore, a building's sustainability is not limited to the collective sustainability of its products. The manner in which designers integrate these products and systems at the whole-building level has a large influence on another major dimension of its sustainability performance, operating energy use.

The many dimensions of a building's environmental performance are ultimately balanced against its economic performance. Even the most environmentally conscious policymaker, building designer, or potential homeowner will ultimately weigh environmental benefits against economic costs. A 2006 poll by the American Institute of Architects showed that $90 \%$ of U.S. consumers would be willing to pay more to reduce their home's environmental impact, but only an additional $\$ 4000$ to $\$ 5000$, or about $2 \%$, more. ${ }^{2}$ More recent studies have shown that U.S. home buyers are willing to pay more for sustainable building designs or homes with green attributes like solar photovoltaic (PV). Dastrup, Zivin et al. (2012) used a hedonic pricing approach to find that solar panels are

\footnotetext{
${ }^{2}$ January 2006 survey cited in Green Buildings in the Washington Post (Cohen 2006).
} 
capitalized, on average, at a premium of roughly $3.5 \%$ based on a sample of homes located in San Diego, California and Sacramento, California. Hoen (2011) investigated the effects of solar photovoltaic on the sales prices of homes based on a much larger share of the California housing market. He found that average premiums for residential solar photovoltaic systems range from roughly $\$ 3.90$ to $\$ 5.80$ per watt.

A study conducted by Pfleger, Perry et al. (2011) discovered that ENERGY STAR certified homes in North Carolina, on average, sold for \$5,566 more than similar codecompliant homes when differences between the homes were minimized. They also sold for \$2.99 more per square foot on average. Griffin, Kaufman et al. (2009) found that third-party certified homes in the Portland, Oregon area sold for 4.2\% more on average than non-certified homes. Kok and Kahn (2012) showed that green labeled homes in California realize a sales price that is $\$ 34800$ or $9 \%(+/-4 \%)$ higher than a non-labeled home. In a later study, the same authors found that green labeled homes in California that have been certified by the U.S. Green Building Council (USGBC), U.S. Environmental Protection Agency's (EPA), or Build It Green rating agency, realize an average premium between $2.0 \%$ to $4.0 \%$ (Kahn and Kok 2014). Moreover, they discover that premium values tend to vary based on local climatic conditions and environmental ideologies. Aroul and Hansz (2012) estimated a more modest increase of $2.1 \%$ to $2.4 \%$ in home transaction prices for green-rated homes for two Texas cities, Frisco and McKinney. More recently, Adomatis (2015) discovered that the average and median premium captured by high-performance homes in Washington, D.C. were approximately $3.46 \%$ and $2.91 \%$, respectively. There appears to be significant variation across locations in the value placed on green-rated homes, which may be driven by consumer preferences or knowledge. To satisfy stakeholders, the green building community needs to promote and design buildings with an attractive balance of environmental and economic performance. These considerations require innovative means to address sustainability performance for buildings.

The BIRDS model applies a unifying LCA framework developed for the U.S. economy to the U.S. construction sector and its constituent building types. Through this "topdown" LCA approach, a series of baseline sustainability measurements are made for prototypical buildings, yielding a common yardstick for measuring sustainability with roots in well-established national environmental and economic statistics. Using detailed "bottom-up" data compiled through traditional LCA approaches, the baseline measurements for prototypical buildings are then "hybridized" to reflect a range of improvements in building energy efficiency, enabling assessment of their energy, environmental, and economic benefits and costs. The idea is to provide a cohesive database and measurement system based on sound science that can be used to prioritize green building issues and to track progress over time as design and policy solutions are implemented. "Bottom-up" and "top-down" data sources and approaches will be discussed in further detail in Chapter 4. 
The BIRDS hybrid LCA approach combines the advantages of both the bottom-up and top-down approaches - namely the use of higher-resolution, bottom-up data and the use of regularly-updated, top-down statistical data without truncation (Suh, Lenzen et al. 2004, Suh and Huppes 2005). The hybrid approach generally reduces the uncertainty of existing pure bottom-up or pure top-down systems by reducing truncation error in the former and increasing the resolution of the latter (Suh, Lenzen et al. 2004). The hybrid approach will be discussed in further detail in Chapter 4 .

Operating energy use - a key input to whole-building LCAs - is assessed in BIRDS using the bottom-up approach. Energy use is highly dependent upon a building's function, size, location, and the efficiency of its energy technologies. Energy efficiency requirements in current energy codes for residential buildings vary across states, and many states have not yet adopted a code based on the newest energy code editions. As of November 2015, state energy code adoptions range across all editions of the International Energy Conservation Code (IECC) for Residential Buildings (International Code Council (ICC) 2006, International Code Council (ICC) 2009, International Code Council (ICC) 2012, International Code Council (ICC) 2015). Some states do not have a code requirement for energy efficiency, leaving it up to the locality or jurisdiction to set its own requirement. To address these issues, operating energy use in BIRDS is tailored to building types, locations, and energy codes. The current low-energy residential incremental improvements BIRDS database is constructed based on the NZERTF's current location, Gaithersburg, MD, and includes all combinations of building component specifications defined for each climate zone in each of the IECC editions as well as additional incremental energy efficiency measures (EEMs) based on the NZERTF's building specifications.

Like operating energy use, a building's economic performance is dependent upon a building's design and location. Construction material and labor costs vary by location, as do maintenance, repair, and replacement costs over time. Energy technologies for compliance with a given IECC edition vary across U.S. climate zones, as do their costs. Finally, a building's operating energy costs vary according to the quantity and price of energy use, which depend upon the building's location and fluctuate over time. All these variables are accounted for in the BIRDS databases, as shown in Figure 2-1. The lowenergy residential incremental improvements BIRDS database currently includes a single location and including the variations across climate zones will simplify future expansion of the database to include other locations starting with those within the same climate zone as the NZERTF (Kneifel and O'Rear 2015). 


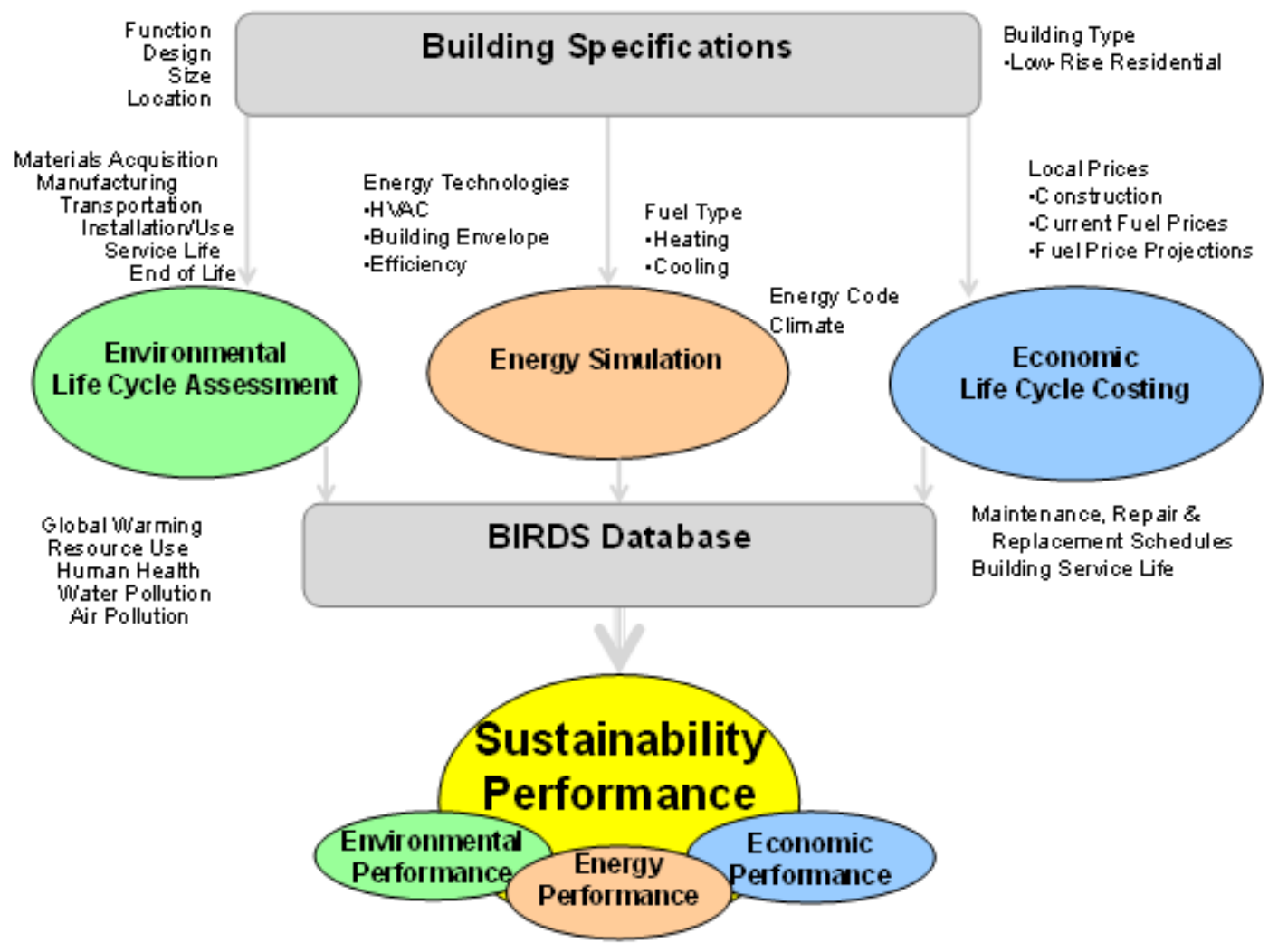

Figure 2-1 BIRDS Sustainability Framework

\subsection{Establish Consistency}

The new way of measuring building sustainability performance in BIRDS requires that special attention be paid to establishing consistency among its many dimensions. While BIRDS develops separate performance metrics for building energy, environmental, and economic performance, they are all developed using the same parameters and assumptions. For each of the 480000 building designs included in the BIRDS low-energy residential incremental improvements database, consistent design specifications are used to estimate its operating energy use, environmental life-cycle impacts, and life-cycle costs. The building energy simulation, for example, specifies the same building envelope and HVAC technologies as do the bottom-up energy technology LCAs and cost estimates.

One of the most important dimensions requiring BIRDS modeling consistency is the study period. The study period is the number of years of building operation over which energy, environmental, and economic performance are assessed. In economic terms, the study period represents the investor's time horizon. Over what time period are investors or policymakers interested in the environmental and economic costs and benefits related to the capital investment decision? Since different stakeholders have different time perspectives, there is no one correct study period for developing a business case for 
sustainability. For this reason, 30 different study period lengths are offered in the BIRDS low-energy residential incremental improvements database, ranging from 1 year to 30 years. ${ }^{3}$

Study period length represents the appropriate investment time horizon. A 1-year study period is representative of a developer that intends to sell a property soon after it is constructed. A 5-year to 15-year study period best represents the typical length of time a homeowner is in a given house. Study periods greater than 20 years better represent homeowners that intend to be a permanent resident of a particular house. BIRDS sets the maximum study period at 40 years for consistency with requirements for federal building life-cycle cost analysis (U.S. Congress 2007). Beyond 40 years, technological obsolescence becomes an issue, data become too uncertain, and the present value cost implications become less important. Note that prior analysis has shown that result interpretations are the same for all study periods of 30 years or greater. To improve software performance study periods greater than 30 years have been dropped from the low-energy residential incremental improvements database.

Once the BIRDS user sets the length of the study period, the energy, environmental, and economic data are all normalized to that time period. This involves adjustments to a building's operating, maintenance, repair, and replacement data as well as to its residual value at the end of the study period. This assures consistency and comparability among the three metrics, and is one of the strengths of the BIRDS approach.

The next 3 chapters present more detail regarding the modeling of the energy, environmental, and economic performance measures within the BIRDS low-energy residential incremental improvements building database.

\footnotetext{
${ }^{3}$ Study periods of greater than 30 years was dropped from the database because the interpretations of the results were identical for both a 30- and 40-year study period (e.g. same building component combinations would be selected).
} 


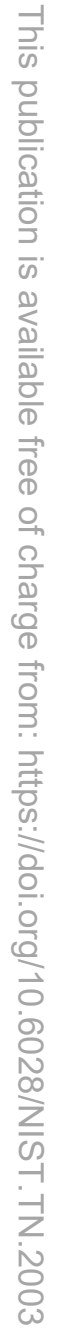




\section{Energy Performance Measurement}

The operating energy component (i.e. energy consumed during use of the building by occupants) of the BIRDS low-energy residential incremental improvements database was built following the framework developed in Kneifel (2010), further expanded in Kneifel (2011a) and Kneifel (2011b) and implemented in previous versions of BIRDS (Lippiatt, Kneifel et al. 2013, Kneifel and Lavappa 2015). The BIRDS low-energy residential incremental improvements database includes the results of 960000 whole-building energy simulations covering all combinations of building component requirements defined in the most recent editions of IECC and the energy efficiency measures implemented in the NZERTF during a one-year demonstration phase during which net-zero energy performance was achieved (Kneifel, Payne et al. 2015).

\subsection{Background}

The National Institute of Standards and Technology (NIST) received funding through the American Recovery and Reinvestment Act (ARRA) to construct a NZERTF. The initial goal of the NZERTF was to demonstrate that a net-zero energy residential design could "look and feel" like a typical home in the Gaithersburg area. The demonstration phase of the project was from July 2013 through June 2014, during which it successfully demonstrated the house performed at "net zero," or produced as much electricity as it consumed over the entire year.

The EnergyPlus $(E+)$ software was chosen to simulate the whole-building energy performance (U.S. Department of Energy (DOE) 2015). The general assumptions required by $E+$ are described in detail in Kneifel (2012). Kneifel et al. (2015) documents the validated model for the NZERTF based on the measured performance of the facility over the initial year of demonstration (July 2013 through June 2014), which is the basis for the 960000 simulations in the BIRDS low-energy residential incremental improvements database. In order to obtain a prediction of a more representative years' worth of energy performance, a Typical Meteorological Year 3 (TMY3) weather file was used for the simulations instead of the Actual Meteorological Year (AMY) weather file used during the model validation process. As in Kneifel et al (2015), the selected weather data is for the KGAI weather station (Weather Analytics 2014) located less than $6 \mathrm{~km}$ (4 miles) from the NIST campus. The validated model was simplified to allow for a 15minute timestep instead of the one-minute timestep used in Kneifel et al. (2015) due to the time constraints of simulating 960000 designs.

\subsection{Geometry and Building Envelope}

The building dimensions specified by BSC (2009) along with the architectural massing model and image of the constructed NZERTF shown in Figure 3-1, were used along with Google SketchUp and National Renewable Energy Laboratory's (NREL) Legacy Open Studio plug-in to construct the building geometry of the NZERTF. Total conditioned floor area (CFA) of the $E+$ model is $284.6 \mathrm{~m}^{2}\left(3063 \mathrm{ft}^{2}\right)$. Actual CFA of the NZERTF is 
$251.7 \mathrm{~m}^{2}\left(2709 \mathrm{ft}^{2}\right)$. There are two reasons the CFA of the simulation model is $32.9 \mathrm{~m}^{2}$ $\left(354 \mathrm{ft}^{2}\right)$ greater than the actual house design. First, the $E+$ model does not account for the open foyer/stairway, which adds approximately $19.0 \mathrm{~m}^{2}\left(204 \mathrm{ft}^{2}\right)$. Second, the gable walls (west wall and east wall) of the $2^{\text {nd }}$ floor have built in storage under the gable, which decreases the modeled CFA by approximately $14.3 \mathrm{~m}^{2}\left(154 \mathrm{ft}^{2}\right)$. These two aspects of the model account for approximately $33.3 \mathrm{~m}^{2}\left(358 \mathrm{ft}^{2}\right)$, which decreases the CFA to $251.3 \mathrm{~m}^{2}\left(2705 \mathrm{ft}^{2}\right)$ or a difference of only $0.4 \mathrm{~m}^{2}\left(4 \mathrm{ft}^{2}\right)$. Even though these two aspects of the house are not considered finished floor area, their volume of space will be conditioned.

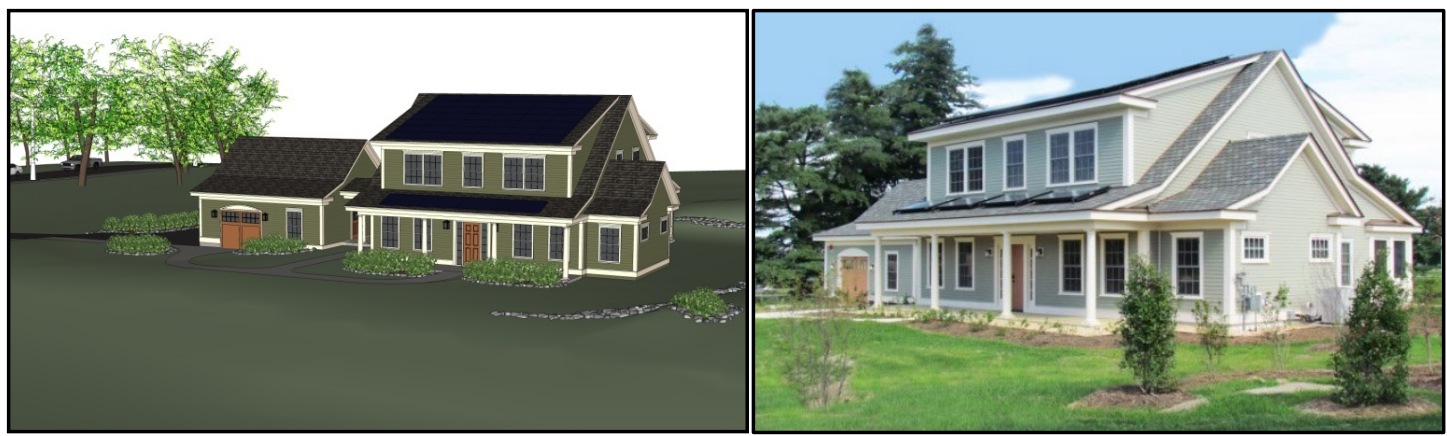

Figure 3-1 BSC Architectural Massing Model and NZERTF as Built

Figure 3-2 shows the Google SketchUp three-dimensional geometry of the $E+$ model for the NZERTF. The model includes seven separate zones with three actively conditioned zones ( $1^{\text {st }}$ floor, $2^{\text {nd }}$ floor, and basement), three inactively conditioned zones - a.k.a. within the conditioned space without ductwork to the space (open web joist space between the $1^{\text {st }}$ and $2^{\text {nd }}$ floors, main attic, and living room attic) -, and one unconditioned zone (patio). The front porch and detached garage with the covered walkway are all treated as shading surfaces, which block sunlight but do not impact the thermal performance of the building envelope.

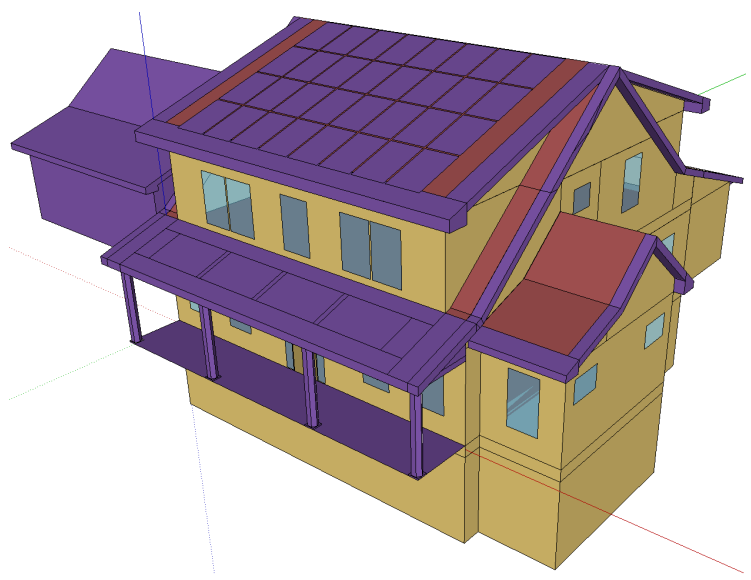

Figure 3-2 Google SketchUp 3-D Representation of the E+ Model 
The E+ parameters for the materials used in the exterior envelope (excluding the roof) are estimated using an average transmittance with the surface-weighted path fractions. In other words, using a simple weighted average of parameter values based on the percentage of framing in the surface. The roof controls for varying materials by splitting the roof into two separate surfaces. The framing percentage for each surface type across different wall and roof constructions is shown in Table 3-1, which varies by construction and framing approach.

Table 3-1 Material Parameter Calculation Approach

\begin{tabular}{cccc}
\hline Construction & Framing & Pct. Frame & Approach \\
\hline Exterior Wall & Advanced & $15 \%$ & surface-weighted path fractions \\
& Typical & $23 \%$ & surface-weighted path fractions \\
\hline Ceiling & Advanced & $11 \%$ & surface-weighted path fractions \\
& Typical & $11 \%$ & surface-weighted path fractions \\
\hline Roof & Advanced & $11 \%$ & split into separate surfaces \\
& Typical & $11 \%$ & split into separate surfaces \\
\hline
\end{tabular}

The NZERTF design adds energy efficiency measures to each aspect of the building envelope listed in Table 3-2, Table 3-3, and Table 3-4: framing, wall, roof, foundation, fenestration, and infiltration. The NZERTF is constructed using "advanced framing," which uses $5.1 \mathrm{~cm} \times 15.2 \mathrm{~cm}$ ( 2 in x 6 in) $61.0 \mathrm{~cm}$ (24 in) on center (OC) framing instead of the common practice or "typical," of $5.1 \mathrm{~cm} \times 10.2 \mathrm{~cm}$ ( 2 in x 4 in) $40.6 \mathrm{~cm}$ (16 in) OC framing (Lstiburek 2010). The thicker framing allows for greater levels of insulation within the wall cavity while decreasing the amount of wood required for framing the house, making it easier to increase the thermal performance of the building envelope.

Five exterior wall design options shown in Table 3-2(a) are included in the low-energy residential incremental improvements database. The first two represent construction requirements defined in different editions of the IECC and assume "typical" framing and include RsI-2.3 (R-13) fiberglass batt insulation in the wall cavity, with Option 2 including R-5 continuous rigid insulation on the exterior. Option 3, Option 4, and the NZERTF design switch to advanced framing with RSI-3.5 (R-20) of blow-in cellulose in the wall cavity. Option 4 and the NZERTF design (Option 5) add Rsi-2.1 (R-12) and RsI4.2 (R-24) of continuous rigid insulation to the exterior of the wall, respectively. 
Table 3-2 Constructions - Roof, Ceiling, Wall and Foundation

(a)

\begin{tabular}{|lc|c|c|c|c|c|}
\hline \multicolumn{2}{|c|}{ Constructions } & Option 1 & Option 2 & Option 3 & Option 4 & Option 5 \\
Exterior & Framing & Typical & Typical & Advanced & Advanced & Advanced \\
Wall & Insulation & $\mathrm{R}_{\mathrm{SI}}-2.3$ & $\mathrm{R}_{\mathrm{SI}}-2.3+0.9$ & $\mathrm{R}_{\mathrm{SI}}-3.5$ & $\mathrm{R}_{\mathrm{SI}}-3.5+3.9$ & $\mathrm{R}_{\mathrm{SI}}-3.5+4.2$ \\
& $(\mathrm{R}-13)$ & $(\mathrm{R}-13+5)$ & $(\mathrm{R}-20)$ & $(\mathrm{R}-20+12)$ & $\mathrm{R}-20+24$ \\
\hline \multicolumn{2}{|l}{ Note 1: Interior + Exterior R-Value } \\
\hline
\end{tabular}

(b)

\begin{tabular}{|cc|c|c|c|c|}
\hline \multicolumn{2}{|c|}{ Constructions } & Option 1 & Option 2 & Option 3 & Option 4 \\
\hline \multirow{2}{*}{ Basement } & Wall & $\mathrm{R}-8$ & $\mathrm{R}-10$ & $\mathrm{R}_{\mathrm{SI}}-3.9(\mathrm{R}-22)$ & $\mathrm{R}_{\mathrm{SI}}-3.9(\mathrm{R}-22)$ \\
& Slab & $\mathrm{R}-0$ & $\mathrm{R}-0$ & $\mathrm{R}-0$ & $\mathrm{R}_{\mathrm{SI}}-1.8(\mathrm{R}-10)$ \\
\hline
\end{tabular}

(c)

\begin{tabular}{|lc|c|c|c|c|c|}
\hline \multicolumn{2}{|c|}{ Constructions } & Option 1 & Option 2 & Option 3 & Option 4 & Option 5 \\
\hline Attic & Roof & R-0 & R-0 & R-45+4 & R-45+15 & $\begin{array}{c}\text { R } \mathrm{SI}^{-}-7.9+5.3 \\
\text { (R-45 + 30) }\end{array}$ \\
& & & & & R-0 & R-0 \\
\hline
\end{tabular}

Single-family residential buildings are primarily wood-framed structures. However, the exterior cladding can vary widely in both material and thermal performance and include different types of siding (e.g., wood, vinyl, cement board) and/or masonry (e.g., brick, stone, concrete). Therefore, two exterior wall finishes are available in this version of BIRDS: wood siding and brick veneer to represent the two aforementioned categories of cladding. The assumed insulation in the five wall designs remain the same for both exterior wall finish options.

Three levels of energy efficiency are included for the basement designs (see Table 3-2(b)). Option 1 includes R-8 continuous rigid insulation on the interior of the basement wall with no insulation under the basement slab. Option 2 increases continuous rigid insulation on the interior of the basement wall to R-10 while still having no insulation under the basement slab. Option 3 increases the thermal performance of the basement by including $\mathrm{R}_{\mathrm{SI}}-3.9$ (R-22) of rigid insulation on the basement wall. The NZERTF design (Option 4) includes the RsI-3.9 (R-22) of rigid insulation on the basement wall from Option 3 and includes R-10 rigid insulation under the basement slab.

Five attic constructions are included in the low-energy residential incremental improvements database (see Table 3-2(c)). Option 1 and Option 2 include naturally vented attics with R-38 and R-49 of blown-in cellulose insulation on the attic floor, respectively. Option 3, Option 4, and the NZERTF attic construction shift the cellulose insulation into the rafter cavity (RsI-7.9 (R-45)). Option 4 and the NZERTF design (Option 5) add continuous rigid insulation to the exterior roof to reach an additional $\mathrm{R}_{\mathrm{SI}^{-}}$ 5.3 (R-30) and RsI-2.7 (R-15), respectively.

The fenestration surface construction materials for windows are defined based on three simple parameters: U-factor, Solar Heat Gain Coefficient (SHGC), and Visible 
Transmittance (VT). This approach allows the rated window performance to be modeled while simplifying window "materials" and "constructions" in the simulation. The window parameters can be seen in Table 3-3 and are based on the Climate Zone 4 requirements for 2006, 2009, 2012, and 2015 IECC and the NZERTF window specifications. ${ }^{4}$ VT is assumed to be the same for all options $(0.4)$ because the IECC does not specify this value.

\section{Table 3-3 Window Specifications}

\begin{tabular}{|l|l|c|c|c|c|c|}
\hline Field & Units & Option 1 & Option 2 & Option 3 & Option 4 & Option 5 \\
\hline U-Factor & $\mathrm{W} / \mathrm{m}^{2}-\mathrm{K}$ & 2.57 & 2.28 & 2.00 & 2.00 & 1.14 \\
& $\left(\mathrm{Btu} / \mathrm{h} \cdot \mathrm{ft}^{2}-\mathrm{F}\right)$ & $(0.45)$ & $(0.40)$ & $(0.35)$ & $(0.35)$ & $(0.20)$ \\
Solar Heat Gain & & 0.60 & 0.60 & 0.60 & 0.40 & 0.25 \\
Visible Transmittance & & 0.40 & 0.40 & 0.40 & 0.40 & 0.40 \\
\hline
\end{tabular}

Blower door tests of the NZERTF measured an air exchange rate of $0.223 \mathrm{~m}^{3} / \mathrm{s}(470 \mathrm{cfm})$ or 0.63 air changes per hour at $50 \mathrm{~Pa}\left(\mathrm{ACH}_{50}\right)$. The infiltration rate is converted to effective leakage area (ELA) using the following formula from Chapter 16 in American Society for Heating, Refrigerating, and Air-Conditioning Engineers (ASHRAE) (2012).

$$
A_{L}=10000 * Q_{r} * \frac{\sqrt{\left(\rho / 2 \Delta p_{r}\right)}}{C_{D}}
$$

Where $A_{L}=$ equivalent or effective air leakage area $\left(\mathrm{cm}^{2}\right)$

$$
\begin{aligned}
& Q_{r}=\text { predicted airflow rate at } \Delta p_{r}\left(\mathrm{~m}^{3} / \mathrm{s}\right) \\
& \rho=\text { air density }\left(\mathrm{kg} / \mathrm{m}^{3}\right) \\
& \Delta p_{r}=\text { reference pressure difference }(\mathrm{Pa}) \\
& C_{D}=\text { discharge coefficient }
\end{aligned}
$$

ASHRAE (2012) states that air exchange rates at $4 \mathrm{~Pa}$, as used in $E+$, typically assumes a discharge coefficient $\left(C_{D}\right)$ of 1.0. The reference pressure difference $\left(\Delta p_{r}\right)$ used in the blower door test is $50 \mathrm{~Pa}$. The air density $(\rho)$ is assumed to be $1.2922 \mathrm{~kg} / \mathrm{m}^{3}$.

Substituting into the equation leads to an estimated ELA of $253.5 \mathrm{~cm}^{2}$. Infiltration was defined using the ZoneInfiltration:EffectiveLeakageArea in the $\mathrm{E}+$ model, and the measured ELA is split between the $1^{\text {st }}$ floor $\left(132.6 \mathrm{~cm}^{2}\right)$ and $2^{\text {nd }}$ floor $\left(120.9 \mathrm{~cm}^{2}\right)$ based on total volume. Stack and wind coefficients of the ZoneInfiltration are set to 0.00029 and 0.000325 , respectively. Other specified ELA values in Table 3-4 are linearly extrapolated based on the ratio of the target $\mathrm{ACH}_{50}$ to the NZERTF $\mathrm{ACH}_{50}$ to meet the maximum air exchange rate values specified in different editions of the IECC.

\footnotetext{
${ }^{4}$ These parameters assume no difference in performance of the windows regardless of the window type (awning or double hung).
} 
Table 3-4 Air Exchange Rates

\begin{tabular}{|l|c|c|c|}
\hline & & \multicolumn{2}{|c|}{ Assumed ELA $\left(\mathrm{cm}^{2}\right)$} \\
\hline Value & $\mathrm{ACH}_{50}$ & $1^{\text {st }}$ Floor & $2^{\text {nd }}$ Floor \\
\hline 2003/2006 IECC & No Max & 1473.3 & 1343.3 \\
\hline 2009 IECC & 7.0 & 1473.3 & 1343.3 \\
\hline 2012/2015 IECC & 3.0 & 403.6 & 368.1 \\
\hline NZERTF & 0.63 & 132.6 & 120.9 \\
\hline
\end{tabular}

\subsection{Occupancy}

A family of four - two parents and two children (14 years old and 8 years old) - is the assumed occupancy for all building designs. The assumed occupant activity levels and the resulting sensible and latent heat gains shown in Table 3-5 are based on Hendron and Engebrecht (2010) and Omar and Bushby (2013). The loads are assumed to be a constant $115 \mathrm{~W}$, which should be representative of the occupancy impacts, on average.

\section{Table 3-5 Occupant Activity Level}

\begin{tabular}{|l|r|r|}
\hline \multirow{2}{*}{ Occupant } & \multicolumn{2}{|c|}{ Watts } \\
\cline { 2 - 3 } Internal Load & \multicolumn{1}{|c|}{$1^{\text {st }}$ Floor } & \multicolumn{1}{|c|}{$2^{\text {nd }}$ Floor } \\
\hline Sensible & 70.15 & 70.15 \\
\hline Latent & 44.85 & 44.85 \\
\hline Total & 115.00 & 115.00 \\
\hline
\end{tabular}

Occupancy schedules for each of the four family members are based on a meticulously detailed seven-day narrative defined in Omar and Bushby (2013). Figure 3-3 condenses the occupancy schedules to create an occupancy density (number of occupants) in the NZERTF by hour of each day of the week. For greater detail, see Omar and Bushby (2013), Kneifel (2012), and Kneifel, Payne et al. (2015).

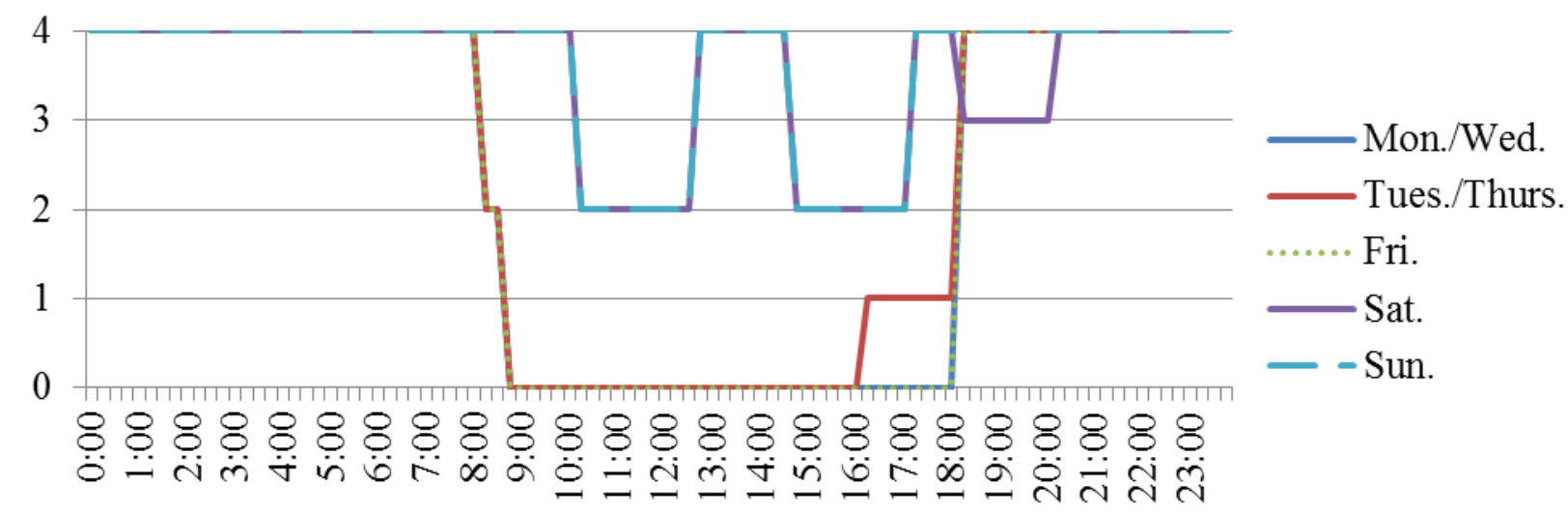

Figure 3-3 Occupancy Density 


\subsection{Lighting}

Electricity use and internal loads from interior lighting are estimated based on Hendron and Engebrecht (2010), which varies from the operation of the NZERTF as defined in Omar and Bushby (2013), in order to simplify and speed up the simulation runs. Rooms on each floor are aggregated and simulated by thermal zone ( $1^{\text {st }}$ and $2^{\text {nd }}$ floors). The sum of lighting wattage by floor is shown in Table 3-6, which varies by the fraction of light fixtures that are high efficiency. Four different levels of efficient lighting are implemented in the 480000 simulations based on the NZERTF design, requirements defined in IECC editions, and a "typical/baseline" lighting mix from Hendron and Engebrecht (2010). The monthly lighting schedules in terms of fraction of peak wattage (FPW) can be found in Hendron and Engebrecht (2010). For comparison purposes, the estimated lighting-based electricity consumption from the formulas in Hendron and Engebrecht (2010) is similar (417 kWh) to both the predicted (428 kWh) and measured performance $(435 \mathrm{kWh})$ from the initial demonstration phase of the NZERTF (Kneifel, Payne et al. 2015).

Table 3-6 Lighting Total Wattage by Floor by Design Options

\begin{tabular}{|l|c|c|c|c|}
\hline & \multicolumn{4}{|c|}{ Fraction of High-efficiency Lighting } \\
\hline & $\mathbf{2 0 0 3 / 2 0 0 6}$ & $\mathbf{2 0 0 9}$ & $\mathbf{2 0 1 2 / 2 0 1 5}$ & NZERTF \\
\hline Floor & $\mathbf{3 4 \%}$ & $\mathbf{5 0 \%}$ & $\mathbf{7 5 \%}$ & $\mathbf{1 0 0 \%}$ \\
\hline $1^{\text {st }}$ & 142 & 113 & 94 & 80 \\
\hline $2^{\text {nd }}$ & 147 & 118 & 98 & 83 \\
\hline
\end{tabular}

Only some of the rooms in the conditioned space are assumed occupied during the narrative. For example, lights in the office, hallways, and unfinished basement are never turned on. Based on the narrative, the use of these areas should be minimal (i.e., a few seconds at a time). Exterior lighting for the patio, garage, and the outdoor lights has been excluded. Garage and exterior lighting are not of a major concern because the lighting does not impact the thermal load of the NZERTF, and would only slightly increase electricity use if included in the model.

\subsection{Plug Loads}

Plug loads are attributed to large appliances and any miscellaneous electrical loads (MELs), such as televisions, computers, hair dryers, etc., i.e., not space conditioning or water heating equipment. The same appliances and MELs operation are assumed for all 480000 building designs. Measured electricity consumption during the demonstration phase combined with the load profiles from Hendron and Engebrecht (2010) in Figure 3-4 are used to reverse engineer the peak wattage for the operation of the refrigerator, clothes washer, clothes dryer, range (combination of oven, cooktop, and range hood), dishwasher, and MELs (split across the $1^{\text {st }}$ and $2^{\text {nd }}$ floor). 


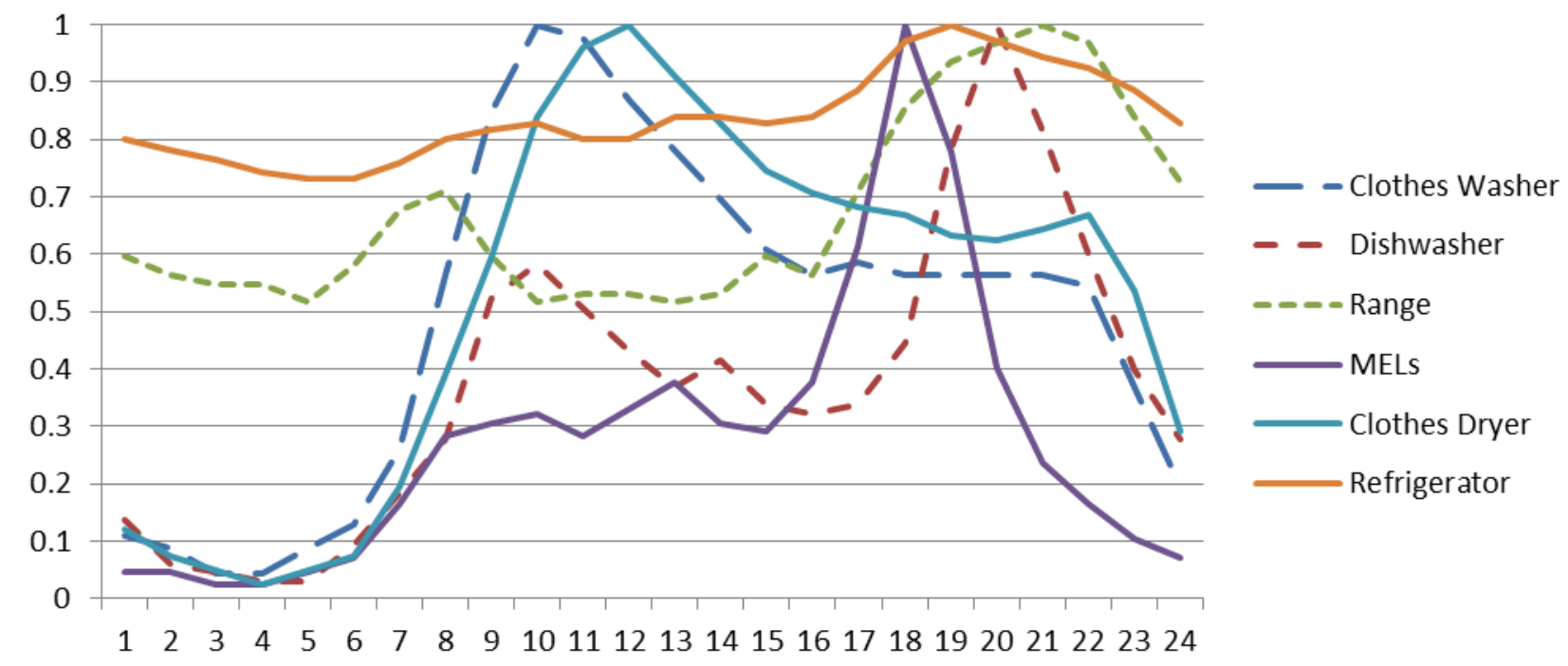

Figure 3-4 Electrical Equipment Load Profiles as a Proportion of Peak Wattage, By Hour

Although this method varies from the detailed narrative defined in Omar and Bushby (2013) and the associated assumptions made in (Kneifel, Payne et al. 2015), the estimated annual electricity consumption due to plug loads is $4214 \mathrm{kWh}$, which is similar to the predicted (4231 kWh) and measured (4307 kWh) consumption in Kneifel, Payne et al. (2015)

\subsection{Heating, Ventilation, and Air Conditioning (HVAC)}

All aspects of an HVAC system and the indoor environmental conditions that the system must maintain must be specified within the E+ representation of the building model, including the thermostat setpoints, ventilation rates, humidity controls, and HVAC equipment specifications. Each of these variables is defined in this section.

\subsubsection{Temperature, Humidity, and Ventilation Controls}

The temperature controls are the same for all 960000 simulations while the humidity controls vary depending on which of the two HVAC system options, referred to as standard efficiency and high efficiency and described in Section 3.6.2, is being implemented in a given simulation. The thermostat setpoints are based on those used during the initial demonstration phase (Phase I) of the NZERTF (Kneifel, Payne et al. 2015), which assume $21.9^{\circ} \mathrm{C}\left(70.0^{\circ} \mathrm{F}\right)$ for heating and $23.9^{\circ} \mathrm{C}\left(75.0^{\circ} \mathrm{F}\right)$ for cooling. Heating and cooling are both made available year-round. Relative humidity is not controlled when the standard efficiency equipment is installed because there is no control technology included in that system. The high efficiency system includes dehumidification control, which operates when the humidity level rises above $50 \%$.

Mechanical ventilation requirements defined in editions of the IECC vary based on the air exchange rate through the building envelope as measured by blower door testing 
(ASTM 2010). Montgomery County (Maryland) residential building energy conservation code (DPS 2016) states that if the measured air exchange rate is greater than $3 \mathrm{ACH}_{50}$, no mechanical ventilation is required. For buildings with an air exchange rate of $3 \mathrm{ACH}_{50}$ or less, mechanical ventilation is required and implements the same air flow values from ASHRAE Standard 62.2-2007. Based on ASHRAE Standard 62.2, the minimum required mechanical outdoor air flow rate for the entire building is $0.0392 \mathrm{~m}^{3} / \mathrm{s}(83 \mathrm{CFM}) . E+$ allows for the provision of a mechanical ventilation rate for each thermal zone. The $1^{\text {st }}$ floor has $52.3 \%$ of the volume while the $2^{\text {nd }}$ floor has $47.7 \%$ of the volume of the occupied space. Based on these values, the required minimum outdoor air flow rates for each zone can be calculated based on a weighted fraction of the whole house mechanical ventilation as $0.02048 \mathrm{~m}^{3} / \mathrm{s}(43.4 \mathrm{CFM})$ for the $1^{\text {st }}$ floor, and $0.0187 \mathrm{~m}^{3} / \mathrm{s}(39.6 \mathrm{CFM})$ for the $2^{\text {nd }}$ floor.

The four types of HVAC systems meet the outdoor air ventilation rate requirements as follows. The standard efficiency system models provide mechanical ventilation via a constant flow of outdoor air through the outdoor air intake of the heat pump. The high efficiency HVAC systems are based on the NZERTF specifications, which includes a heat recovery ventilator (HRV) with its own dedicated ductwork independent of the heating and cooling equipment. The HRV system in the NZERTF is a Venmar AVS HRV EKO 1.5 air-to-air heat exchanger. The HRV transfers heat between the exhaust air and supply air to decrease the heating and cooling load impact of the ventilation air. The $\mathrm{HRV}$ is the sole source of mechanical ventilation and operates year-round, 24 hours a day. The effectiveness of the HRV varies by the air flow rate and temperature differences across the heat exchanger core, but is assumed to be the same for heating and cooling in the $E+$ model. Exhaust air recirculation is used to prevent frost buildup. The outdoor air flow rate for the HRV system was set to the actual operating conditions from Phase I of the NZERTF demonstration, which is $27 \%$ higher than that required by ASHRAE 62.2 at $0.04956 \mathrm{~m}^{3} / \mathrm{s}(49.6 \mathrm{~L} / \mathrm{s}$ or $105 \mathrm{CFM})$. The E+ software does not allow more than one whole-house air loop, which forces the splitting of the HRV system into two zone-level HRV systems. The same volume-based approach as in the standard efficiency HVAC system is used to allocate the air flow rates through each zone level HRV: $0.02592 \mathrm{~m}^{3} / \mathrm{s}$ $(54.9 \mathrm{CFM})$ for the $1^{\text {st }}$ floor and $0.02364 \mathrm{~m}^{3} / \mathrm{s}(23.6 \mathrm{~L} / \mathrm{s}$ or $50.1 \mathrm{CFM})$ for the $2^{\text {nd }}$ floor. For more information on the HRV system, see Kneifel, Payne et al. (2015).

\subsubsection{Heating and Cooling Equipment}

Four heating and cooling system options are included in the low-energy residential incremental improvements database, two that meet minimum federal efficiency and IECC requirements ("standard efficiency") and two based on the system installed in the NZERTF using two different fuel types (electricity and natural gas). Figure 3-5 shows the HVAC system modeled in the $E+$ simulation. The standard efficiency all-electric system includes a single-speed air-to-air heat pump with a rating of SEER 13 for cooling mode and Heating Seasonal Performance Factor (HSPF) 7.7 for heating mode with dedicated outdoor ventilation (as necessary) as shown in Figure 3-5(a). The standard efficiency 
natural gas-heated system includes a single-speed central air conditioner with a rating of Seasonal Energy Efficiency Ratio (SEER) 13 for cooling and a natural gas-fired furnace with an Energy Factor of (EF) of 0.80 for heating with dedicated outdoor ventilation (as necessary). The NZERTF system includes a multispeed air-to-air heat pump with a rating of SEER 16.5 for cooling mode, HSPF 9.1 for heating mode, and a dehumidification-only mode to maintain humidity below the $50 \%$ maximum level. The comparable gas-heated system includes a SEER 16 central air conditioner and a high efficiency $(\mathrm{EF}=0.96)$ furnace. As described previously, the NZERTF system utilizes a separate HRV system (see Figure 3-5(b)).

(a)

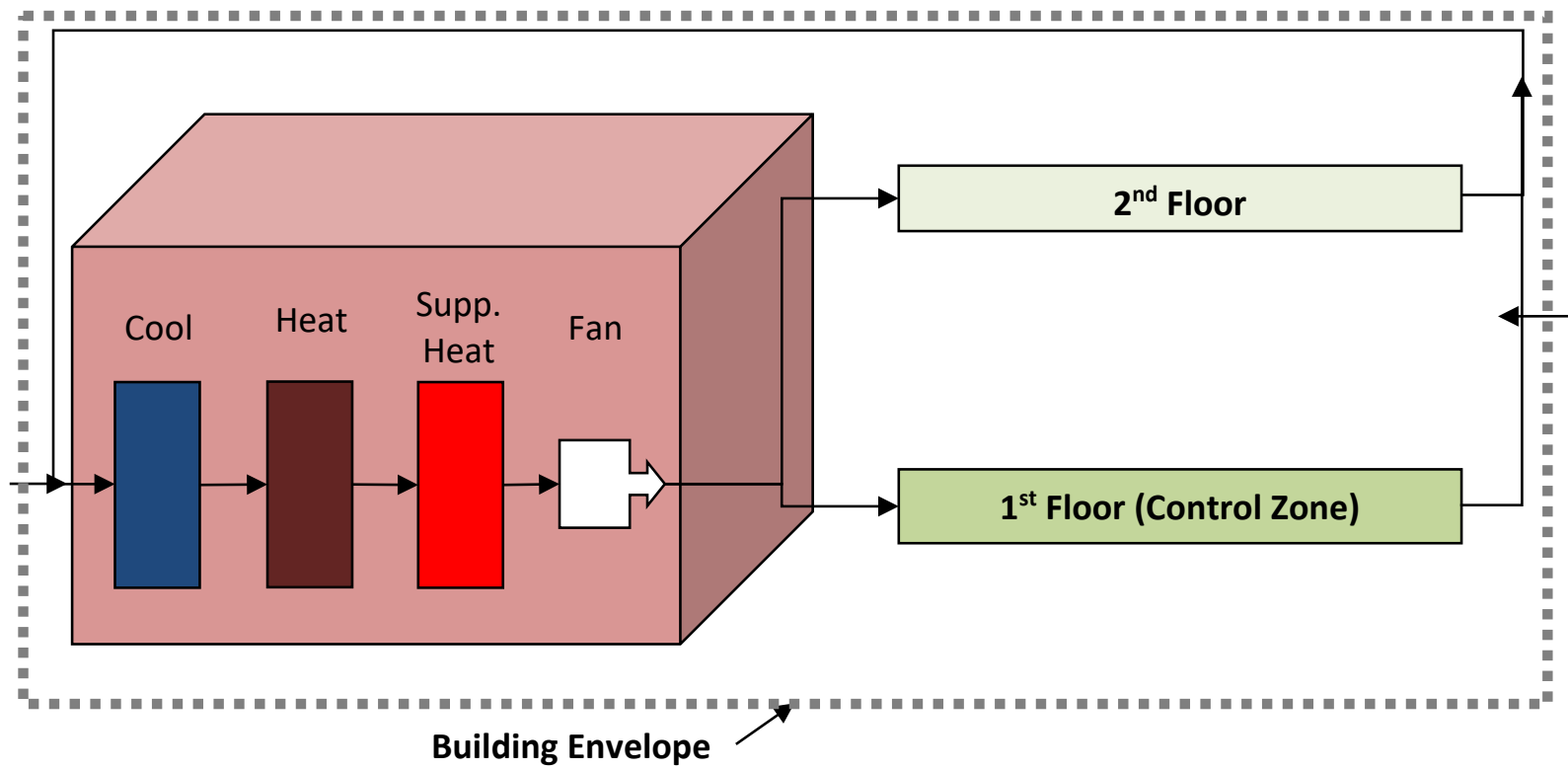

(b)

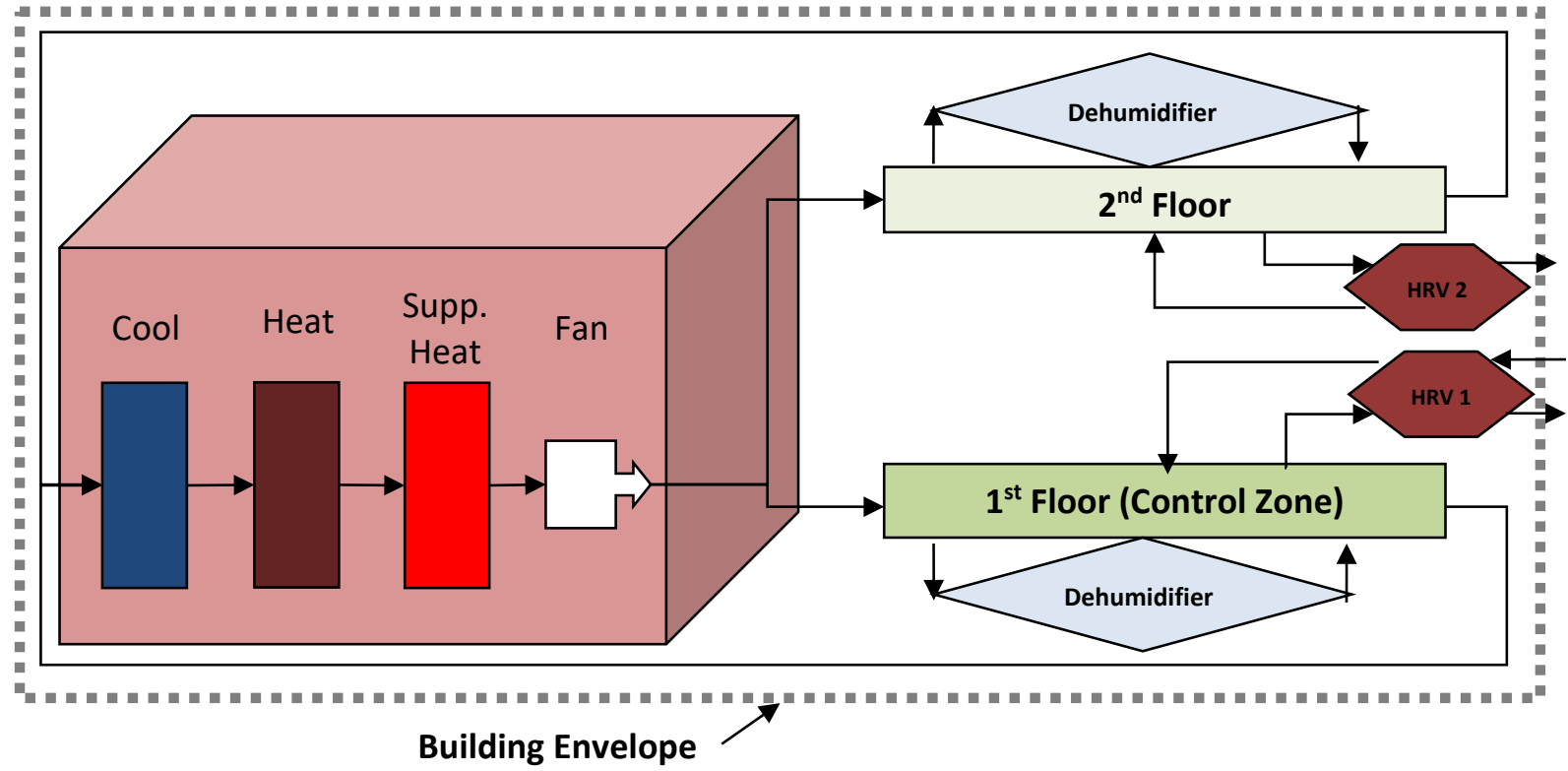

Figure 3-5 HVAC System Layout for (a) Standard Efficiency (b) NZERTF 
The version of $E+$ used for these simulations does not provide a multispeed air-to-air heat pump model that can run in dehumidification-only mode, requiring modeling of separate equipment as shown in Figure 3-5(b) to dehumidify the occupied space. The dehumidifiers remove humidity directly from the zone. Both all-electric system options have an electric resistance heating element with an efficiency of 0.98 to supplement the heat pump when the heat pump cannot meet the heating loads. For more detail on the NZERTF HVAC system including information on zone sizing, coils, dehumidifiers, HRV, and HVAC fans, see Kneifel (2012) and Kneifel, Payne et al. (2015).

\subsection{Domestic Hot Water}

Eight different domestic hot water (DHW) systems were modeled including four using electric and four using natural gas both with and without solar water pre-heating. These systems as well as the DHW loads are described in this section.

\subsubsection{Domestic Water Heating Equipment}

The DHW systems simulated in the model are shown in Figure 3-6. The system shown in Figure 3-6 (a) is based on the NZERTF design. It is a two-tank system located in the basement of the home, with two solar thermal panels located over the front porch providing water for indirect heating an 80-gallon storage tank and an air-to-water heat pump downstream of the storage tank. The closed-loop solar thermal system uses a 50/50 water/glycol mix. The heat pump (rated COP of 2.36) draws water from the storage tank and further heats the water if necessary to meet the target exit temperature. There is an auxiliary heating element in the 50-gallon heat pump water heater tank that assists the heat pump in the event that the heat pump cannot reach the target setpoint.

The system shown in Figure 3-6 (b) is the same system as that in (a) except that the heat pump water heater is replaced with a "standard" water heater, either electric water heater with an efficiency factor $(\mathrm{EF})=0.95$ or natural gas water heater with an $\mathrm{EF}=0.78$. The system shown in Figure 3-6 (c) includes the heat pump from (a), but excludes the solar thermal system. The system shown in Figure 3-6 (d) is the "standard" electric water heater with an $\mathrm{EF}=0.95$ or natural gas water heater with $\mathrm{EF}=0.90$. For additional details on the DHW system components including assumed parameters for tanks, solar collectors, heat exchanger, and coils, see Kneifel (2012) and Kneifel, Payne et al. (2015). 
(a)

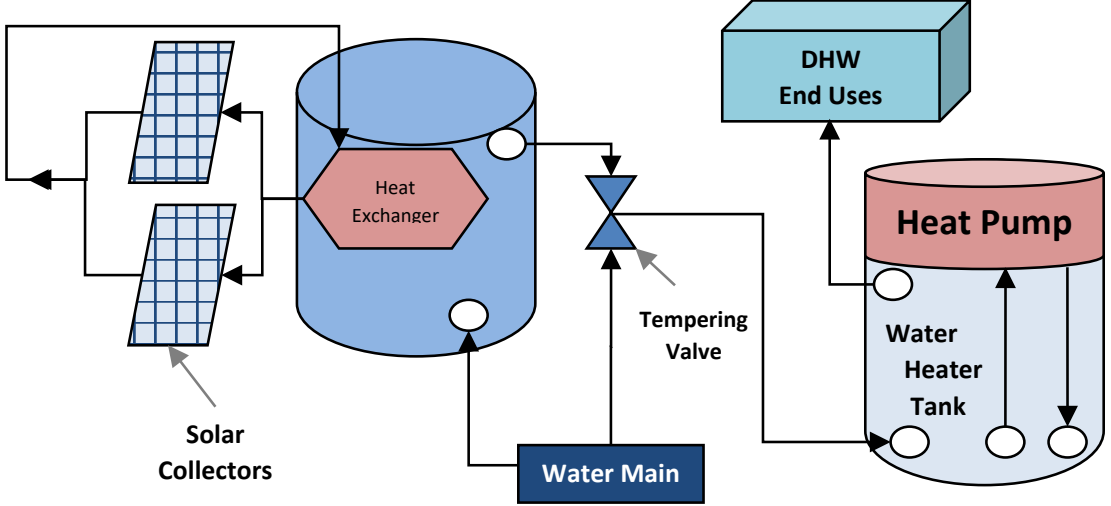

(b)

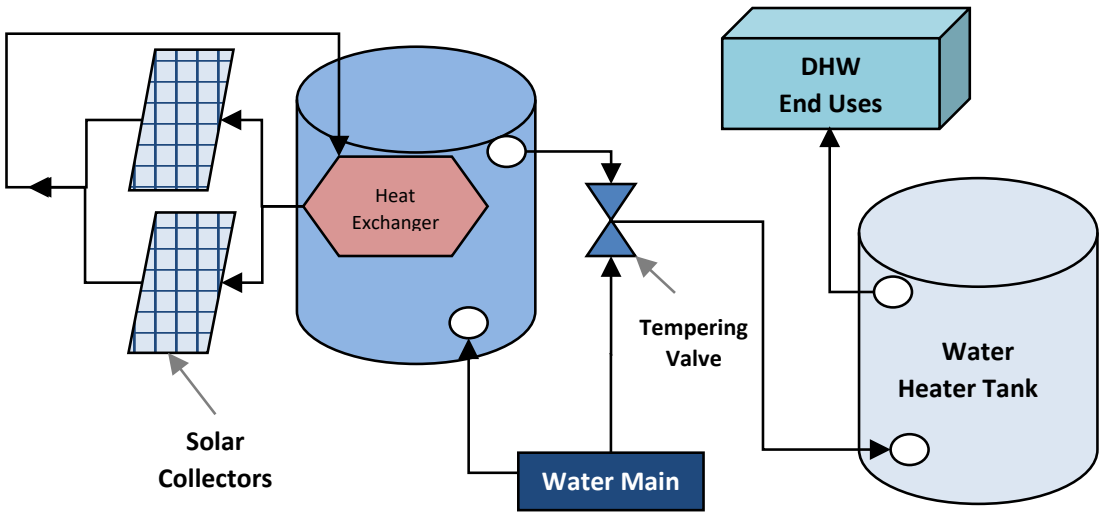

(c)
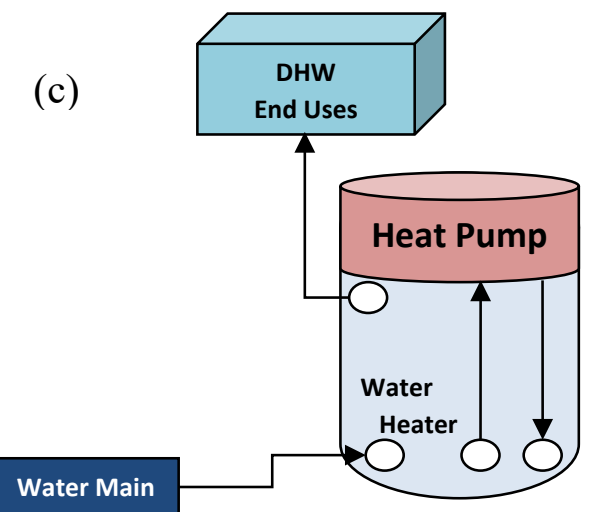

(d)

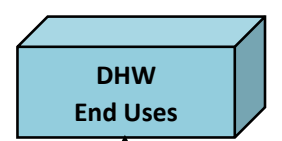

Water Main

Figure 3-6 Domestic Hot Water Heating Systems (a) Heat Pump Water Heater with Solar Thermal (b) Electric/Natural Gas Water Heater with Solar Thermal (c) Heat Pump Water Heater (d) Electric/Natural Gas Water Heater

\subsubsection{Domestic Hot Water End Use}

There are five categories of DHW end use in the NZERTF: bath, shower, sinks, dishwasher, and clothes washer. The peak load fraction use schedules shown in Figure 3-7 are the same for all 480000 simulations and based on those defined in Hendron and 
Engebrecht (2010), which varies from the detailed schedule defined in Omar and Bushby (2013) and implemented in Kneifel, Payne et al. (2015).

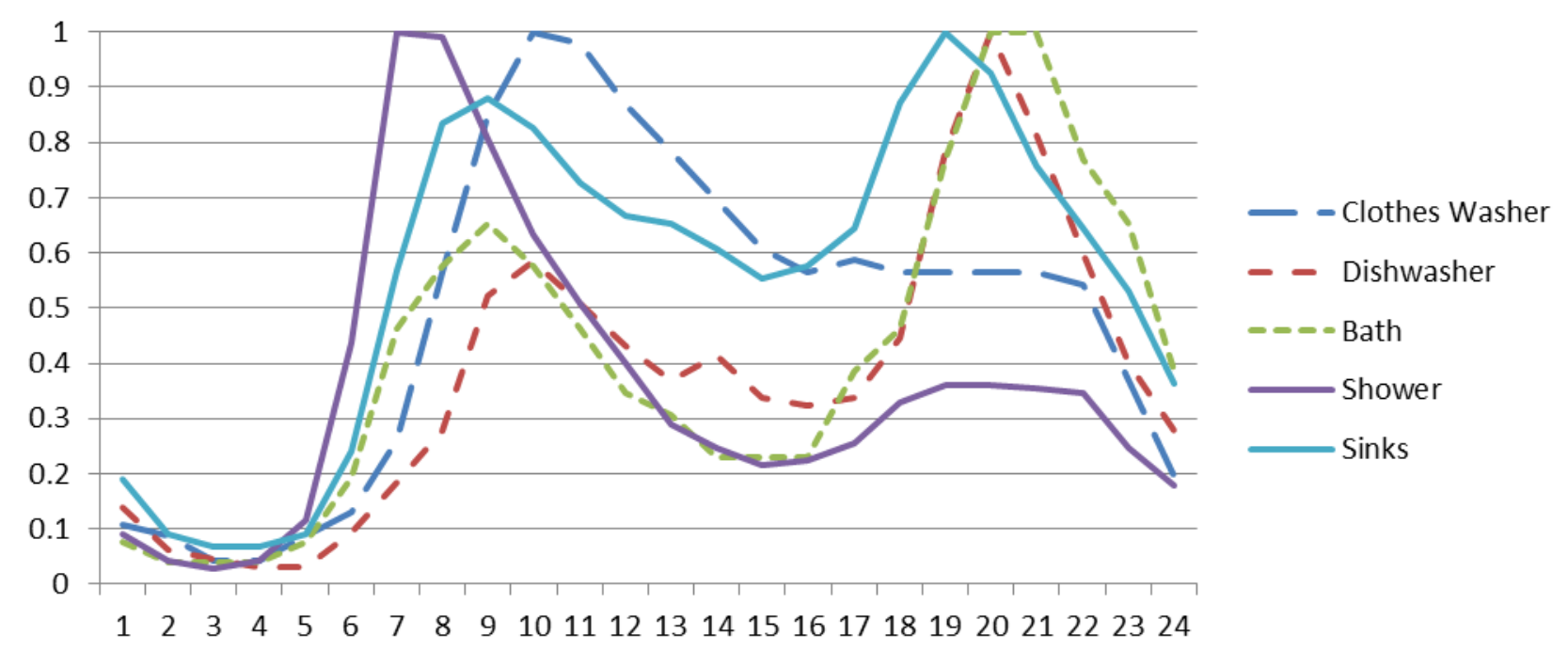

\section{Figure 3-7 Domestic Hot Water Load Profiles as a Proportion of Peak Flow Rate, By Hour}

Table 3-7 defines DHW use in terms of daily water use and water temperature, which are based on measured performance (Kneifel, Payne et al. 2015). Although the load profiles differ, the measured water usage ( $317 \mathrm{~L} /$ day or $83.7 \mathrm{gal} /$ day) is used to reverse engineer the peak flow rate for each category to get similar results in all 480000 simulations (318 L/day or gal/day).

Table 3-7 Daily Domestic Hot Water Use and Target Temperatures

\begin{tabular}{|l|r|r|}
\hline \multicolumn{1}{|c|}{$\begin{array}{c}\text { DHW Use } \\
\text { Category }\end{array}$} & $\begin{array}{c}\text { Water Temp. } \\
{ }^{\circ} \mathbf{C}\left({ }^{\circ} \mathbf{F}\right)\end{array}$ & \multicolumn{1}{c|}{$\begin{array}{c}\text { Daily } \\
\text { L (Gal) }\end{array}$} \\
\hline Clothes Washer & $19.4(67)$ & $48.5(12.8)$ \\
Dishwasher & $40.6(105)$ & $4.9(1.3)$ \\
\hline Shower & $38.9(102)$ & $160.5(42.4)$ \\
Bath & $44.4(112)$ & $33.3(8.8)$ \\
Sinks & $37.7(100)$ & $71.2(18.8)$ \\
\hline
\end{tabular}

\subsection{Solar Photovoltaics}

There are six solar photovoltaic system options included in the low-energy residential incremental improvements database: $0 \mathrm{kWh}, 2.5 \mathrm{kWh}, 5.1 \mathrm{kWh}, 7.6 \mathrm{kWh}, 10.2 \mathrm{kWh}$, and $12.7 \mathrm{kWh}$. When included in a simulation, PV panels are installed on the roof. The solar photovoltaic system is based on the system installed on the NZERTF, which includes 4 horizontal rows of eight $320 \mathrm{~W}$ panels with two inverters. The six options are based on the removal or additional of one string of panels at a time. The inverter(s) specifications 
are adjusted accordingly to appropriately meet the wattage requirements. For additional details on the solar photovoltaic system, see Kneifel (2012) and Kneifel, Payne et al. (2015). 


\section{Environmental Performance Measurement}

BIRDS evaluates the environmental performance of whole-buildings using a life-cycle assessment (LCA) approach, which is based on International Organization for Standardization (ISO) standards. The general LCA methodology involves four steps (International Organization for Standardization (ISO) 2006a, International Organization for Standardization (ISO) 2006b).

1. Goal and scope definition

2. Inventory analysis

3. Impact assessment

4. Interpretation

The goal and scope definition step spells out the purpose of the study and its breadth and depth. The inventory analysis step identifies and quantifies the environmental inputs and outputs associated with a building over its entire life-cycle. Environmental inputs include water, energy, land, and other resources. Outputs include releases to air, land, and water. However, it is not these inputs and outputs, or inventory flows, which are of primary interest. We are more interested in their consequences, or impacts on the environment. Thus, the impact assessment step characterizes these inventory flows in relation to a set of environmental impacts. For example, the impact assessment step might relate carbon dioxide emissions, a flow, to climate change, an impact. Finally, the interpretation step examines the environmental impacts in accordance with the goals of the LCA study.

\subsection{Goal and Scope Definition}

The goal of BIRDS LCAs is to generate environmental performance scores for a range of U.S. building types, each designed to meet four alternative levels of operating energy efficiency. These results will be reported alongside economic performance scores to help designers, investors, and policymakers develop business cases for high-performance green buildings.

The scoping phase of any LCA involves defining the boundaries of the product system or, in the case of BIRDS, the building - under study. In traditional bottom-up LCAs, the setting of the boundary conditions requires expert judgment by the analyst because consideration must be given to the various unit processes related to the construction of the building (e.g. asphalt production for input to the manufacturing of facing for fiberglass batt insulation). Each unit process involves many inventory flows, some of which themselves involve other, subsidiary unit processes. Because including an everexpanding number of unit processes in LCAs is not feasible, the product system's supply chain links are truncated at some point to include only those judged to make nonnegligible contributions to the product system. The analyst typically uses mass, energy, and/or cost contributions as decision criteria. Use of different boundary setting criteria is one of the main reasons LCA results from different studies are often incomparable. 
One important advantage of the BIRDS hybrid approach is that it addresses the bottomup issue of truncation in supply chain links, thereby improving consistency in system boundary selections. Through the hybridization process, truncated supply chain links are connected to the background U.S. economic system represented by the top-down data. These linkages follow the metabolic structure of the U.S. economy, thereby benefitting from a more complete system definition including potentially thousands of supply chain interactions.

Due to their long service lives, buildings are somewhat unique when it comes to the endof-life stage of the life-cycle. For most non-consumable product LCAs, end-of-life waste flows are included in the inventory analysis for full coverage of the life-cycle. If there is an active recycling market that diverts some of the product from the waste stream, that portion of the product's end-of-life flows can be ignored. In BIRDS, however, a residential building lifetime is 65 years, much longer than the 40 -year maximum length for the study period considered in BIRDS. Therefore, $100 \%$ of each building is considered to be "recycled" at the end of the study period and there are no end-of-life waste flows allocated to the building at the end of the BIRDS study period. Rather, endof-life waste flows should be allocated to a different "product," representing use of the building from the end of the study period to the end of the building service life. Similarly, the environmental burdens from building construction are allocated only to its first use (equally distributed across each year of the selected study period); LCAs for all subsequent uses should be treated as free of these initial construction burdens. This effectively credits the use of existing buildings over new construction and ensures there will be no double counting once existing building LCAs are included in future versions of BIRDS as planned.

Defining the unit of comparison is an important task in the goal and scoping phase of LCA. The basis for all units of comparison is the functional unit, defined so that the systems compared are true substitutes for one another. In the BIRDS model, the functional unit is construction and use of one building prototype over a user-defined study period. The functional unit provides the critical reference point to which the LCA results are scaled.

Scoping also involves setting data requirements. With respect to geographic coverage, the BIRDS inventory data are generally U.S. average data. An exception is made for the electricity production inventory data applied to a building's use of electricity. These data are customized to each location mapped to the most representative regionalization. For electricity the appropriate level of aggregation is at the balancing authority level while natural gas is based on the closest natural gas basin. In terms of technology coverage, the top-down inventory data represent the mix of technologies in place as of $2002^{5}$. For the

\footnotetext{
${ }^{5}$ More recent data is not available due to funding limitations of developing environmental inventory data for the most recent U.S. Economic Census.
} 
bottom-up inventory data on building energy technologies, the most representative technology for which data are available is evaluated.

\subsection{Life-cycle Inventory Analysis}

BIRDS applies a hybridized life-cycle assessment approach. The approach is hybridized in the sense that a mixture of top-down and bottom-up data are collected and systematically integrated in the inventory analysis LCA step. Traditional process-based LCAs gather data by modeling all the in-scope industrial processes involved in a product's production (raw materials acquisition, materials processing, manufacture, transportation), use, and waste management. For each industrial process, the analyst collects very detailed, bottom-up data on all its inputs from the environment (e.g., materials, fuel, water, land) and outputs to the environment (e.g., products, water effluents, air emissions, waste). This process is summarized in Figure 4-1.

To address the complexities of a whole building, BIRDS takes a new, multi-layered approach to inventory analysis. Since a building's operating energy efficiency has an important influence on its sustainability performance, and energy efficiency is largely driven by the building's energy technologies, BIRDS pays special attention to the materials used in them. Specifically, BIRDS uses detailed life-cycle inventory (LCI) data for a range of energy technology packages that have been analyzed at the traditional, bottom-up LCA level. These energy technology packages are used to meet the 4 levels of energy efficiency simulated for each building type in 228 different U.S. locations. These bottom-up BIRDS data were developed under contract to NIST by Four Elements Consulting, LLC, of Seattle, Washington, and are documented in Section 4.5.

The bottom-up approach is also used to gather inventory data for a building's use of electricity and natural gas over the study period. The most recent version of the database introduced updated LCI inventories for operational energy from baseline databases.

The Federal LCA Commons created a publicly available Electricity Baseline LCA Model (collaborative effort between EPA, U.S. Department of Agriculture, and DOE national laboratories) that can calculate the LCA data (generation-based or consumption-based) for any region (national average, Federal Energy Regulatory Commission market region, balancing authority) in the country based on 2016 data. The electricity baseline was accessed in the Grid Mix Explorer tool to calculate the LCIA for on-site electricity consumption (Skone 2019).

The electricity baseline was developed using emissions reported to the EPA via three main programs: Air Markets Programs Data, the National Emissions Inventory, and the Toxics Release Inventory. The inventory is divided by the annual generation reported to the Energy Information Administration (EIA) (Form 923) for each power plant in the United States. The remainder of the life cycle is completed using data from NETL coal, natural gas, and petroleum baseline models to represent the supply chain emissions associated with extracting and transporting the fuels. These models primarily rely on the same EPA inventories use for power plant stack emissions. Other non-fossil technologies 
(e.g., wind, solar, nuclear, geothermal, hydro) are largely based on existing models modified in consultation with other DOE experts.

NETL published a Natural Gas Baseline LCA Model that provides both national average as well as basin specific LCA data for the delivery of direct use natural gas (excluding on-site combustion).

NETL has also published LCA data for the unit process for natural gas combustion (NETL 2015). The LCA data is used to generate the LCIA results for each of the EPA Tool for the Reduction and Assessment of Chemical and other environmental Impacts (TRACI) impact categories. By combining the LCIA results for natural gas delivered and its combustion, total LCIA results for the on-site use of natural gas can be calculated.

The LCI data from these "baseline" models are used to develop LCIA results consistent with the BIRDS impact category units for global warming potential, acidification, particulates, eutrophication, ozone depletion, and smog. Due to a lack of available data, the original data for the other impact categories is used.

The two baseline databases published in 2019 (2016 data) were used to generate consumption-based LCIA results for the PJM Interconnection balancing authority (where Maryland is located) and LCIA results for average delivered (direct use) natural gas produced in the Appalachian Shale basin using it's respective extraction technologies (100\% shale), which can be identified as the eastern-most U.S. natural gas basin.

For all other building constituents, industry average LCI data are gathered from the topdown and then systematically combined with bottom-up data into a comprehensive, hybrid LCI for a whole building.

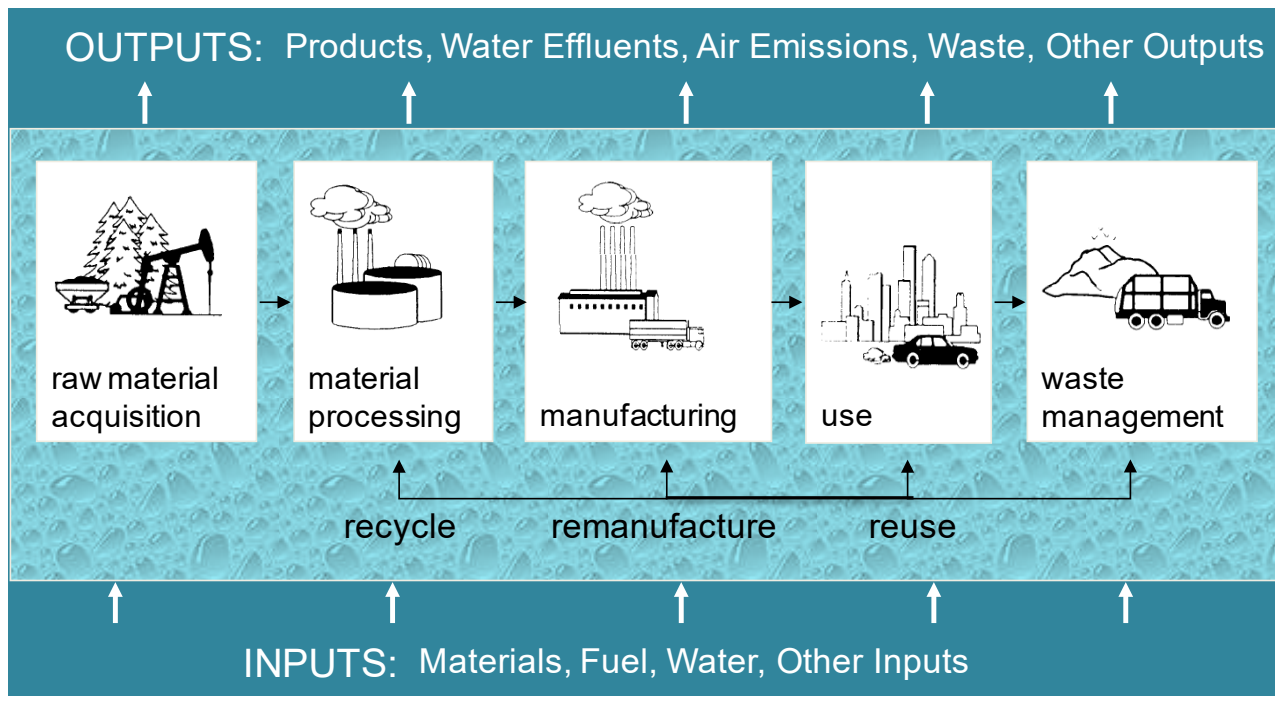

Figure 4-1 Compiling LCA Inventories of Environmental Inputs and Outputs

The inventory data items collected through the bottom-up and top-down approaches are identical - for example, kilogram $(\mathrm{kg})$ carbon dioxide, $\mathrm{kWh}$ primary energy consumption - but some of the data sources are quite different. The systematic hybridization of the data sets bridges these differences to yield coherent and consistent BIRDS life-cycle 
inventories for a wide variety of new commercial and residential buildings. The LCAs for the buildings are then completed by applying conventional methods of life-cycle impact assessment (LCA) and interpretation to the hybrid inventory data.

An economy's accounting structure provides a cost-effective top-down approach to LCA inventory data collection. Many developed economies maintain economic input-output (IO) accounts that trace the flow of goods and services throughout industries. Much the same way that a product's production can be traced upstream through its supply chain, an industry's production can be traced upstream through its supply chain. The U.S. Census Bureau conducts an Economic Census of U.S. industry every five years that establishes industry linkages. Covering $97 \%$ of business receipts, the census reaches nearly all U.S. business establishments. Based on the detailed data collected, the U.S. Bureau of Economic Analysis (BEA) creates what are called Input-Output Accounts, or "I-O tables," for the U.S. economy.

The U.S. I-O tables show how around 500 industries provide input to, and use output from, each other to produce Gross Domestic Product (GDP) - the total value of the consumption of goods and services in a year. These tables, for example, can show how $\$ 100$ million of U.S. economic output in the residential building construction sector traces back through its direct monetary inputs-from the construction process itself- to its indirect inputs from contributing sectors such as the steel, concrete, lumber, and plastics industries. Economic output from the steel, concrete, lumber, and plastics industries, in turn, can be traced back through those supply chains such as mining, forestry, fuel extraction, and so on.

While BEA provides these I-O tables in purely monetary terms, academics have successfully developed "environmentally-extended" I-O tables (Suh 2005, Hendrickson, Lave et al. 2006, Suh 2010). These top-down tables tap into a wide range of national environmental statistics to associate environmental inputs and outputs with economic activity in industry sectors, including use of raw materials, fuel, water, and land and releases of water effluents, air emissions, and waste. BIRDS uses environmentallyextended I-O tables for the U.S. construction industry developed under contract to NIST by Industrial Ecology Research Services of Goleta, California. These tables are based on the 2007 release of the 2002 BEA I-O data, the latest available, and quantify 6204 environmental inputs and outputs occurring throughout production supply chains.

To understand the contribution of building construction to the nation's environmental footprint (impact), it is useful to focus on the concept of "final demand." The BEA's monetary I-O tables use GDP to measure final demand. This value consists of spending and investment by consumers, businesses, and government, as well as net exports. Since final demand is satisfied through annual production - goods and services need to be produced before they can be bought - each industry's value-added, or "direct" contribution to GDP, reflects its share of final demand, and will be referred to as GDP for the remainder of this document. 
The environmentally-extended I-O tables translate economic activity into environmental terms, or monetary GDP into environmental GDP (eGDP). In LCA terms, the construction industry's contribution to eGDP is not limited to the direct impact from value-added construction processes and activities. Its contribution to eGDP also includes the indirect impacts stemming from contributions by upstream construction supply chains up to and including raw materials acquisition. The supply chain relationships built into the environmentally-extended I-O tables enable estimation of construction industry impacts on this cumulative, life-cycle basis. Figure 4-2 illustrates these supply chain relationships for some of the inputs to ready-mix concrete manufacturing, an indirect construction industry input.

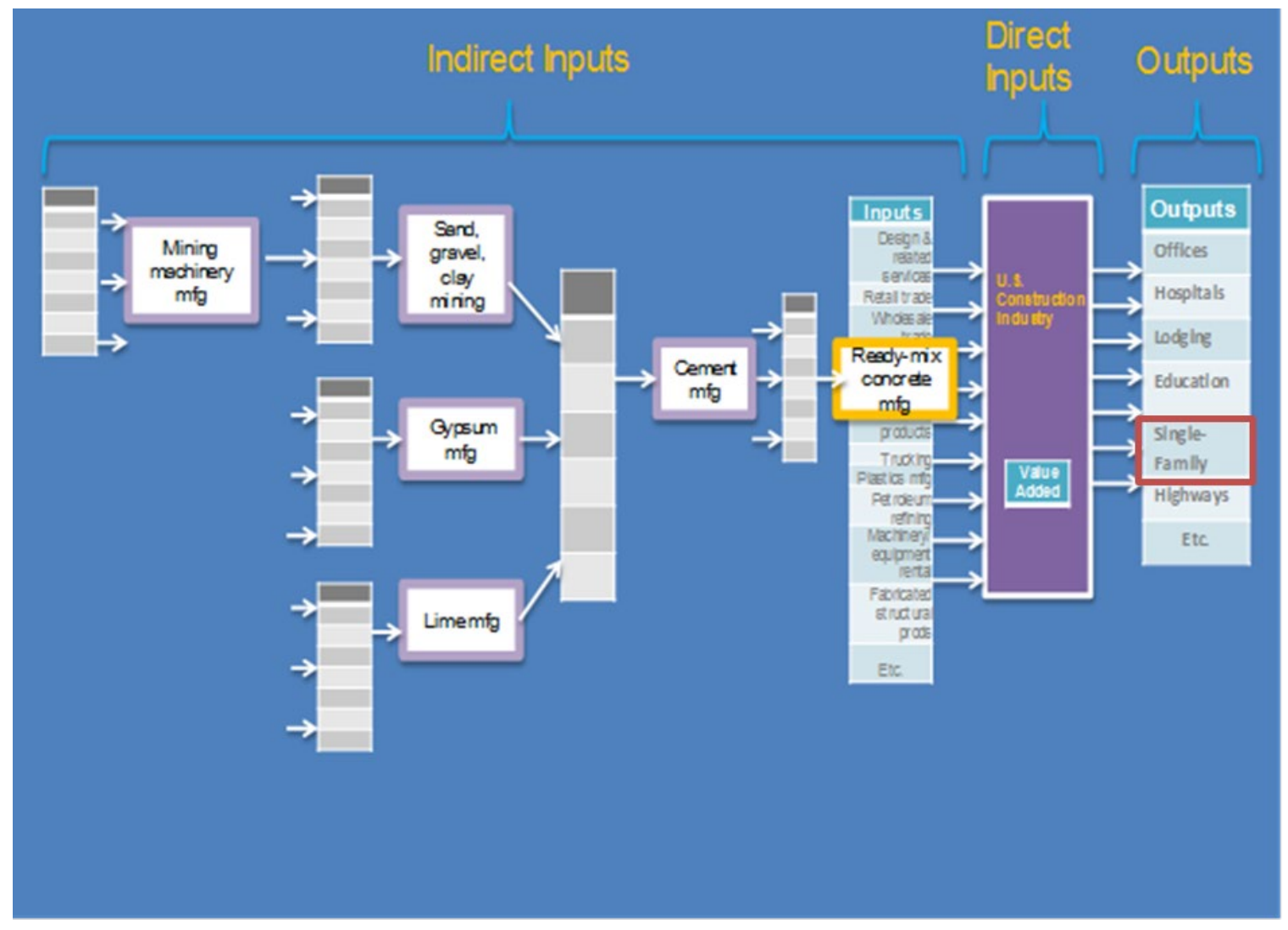

Figure 4-2 Illustration of Supply Chain Contributions to U.S. Construction Industry

The environmentally extended I-O tables classify U.S. construction into 42 distinct industry outputs. In this new residential database of BIRDS, top-down inventory data represent the extended I-O table level of detail for the construction, maintenance, and repair associated with the two residential construction industry outputs shown in Table 4-1. The first output corresponds to new residential construction. The second corresponds to maintenance and repair (M\&R) activities in residential buildings. For both construction industry outputs, the baseline top-down inventory data are expressed in terms of lifecycle environmental flows per dollar of construction. 
Table 4-1 Construction Industry Outputs Mapped to BIRDS Building Types

\begin{tabular}{|l|l|}
\hline Construction Type & \multicolumn{1}{|c|}{ Industry Output } \\
\hline New Construction & New Residential Construction \\
\hline M\&R Construction & Residential maintenance and repair construction \\
\hline
\end{tabular}

One advantage of the BIRDS approach is the economic dimension built into the topdown inventory data. These data are directly associated with U.S. economic data, permitting seamless integration of the economic dimension in the BIRDS sustainability measurement system. The top-down inventory values on a per-dollar basis are multiplied by the corresponding BIRDS construction, maintenance, and repair costs to translate them into the LCA functional unit representing the whole-building over a user-defined study period.

For more information on the mathematics, accounting structure, and step-by-step process under which the BIRDS hybrid environmental database is built, see Suh and Lippiatt (2012).

\subsection{Life-cycle Impact Assessment}

Environmental impacts from building construction and use derive from the 6204 inputs and outputs occurring throughout production supply chains, as quantified in the hybrid BIRDS LCI. The impact assessment step of LCA quantifies the potential contribution of these inventory items to a range of environmental impacts. The approach preferred by most LCA practitioners and scientists today involves a two-step process:

- Classification of inventory flows that contribute to specific environmental impacts. For example, greenhouse gases such as carbon dioxide, methane, and nitrous oxide are classified as contributing to climate change.

- Characterization of the potential contribution of each classified inventory flow to the corresponding environmental impact. This results in a set of indices, one for each impact, which is obtained by weighting each classified inventory flow by its relative contribution to the impact. For instance, the Global Warming Potential (GWP) is derived by expressing each greenhouse gas in terms of its equivalent amount of carbon dioxide heat trapping potential.

There are two general applications of this life-cycle impact assessment (LCIA) approach: midpoint-level and endpoint-level analyses. An endpoint-level analysis attempts to measure the ultimate damage that each environmental input and output in the inventory will have along the cause-effect chain. Methods of this type include just a few impact 
categories, such as damage to human health, ecosystems, and resource availability that are easier to interpret in the final step of life-cycle assessment. This approach is criticized for the numerous assumptions, value judgments, and gaps in coverage of the underlying damage models. A midpoint-level analysis, on the other hand, selects points along the cause-effect chain at which more certain and comprehensive assessments may be carried out. While this approach generates many impact categories and makes life-cycle interpretation more difficult, it is more scientifically defensible. Even so, a midpoint-level analysis does not offer the same degree of relevance for all environmental impacts. For global and regional effects (e.g., climate change and acidification) the method provides an accurate description of the potential impact. For impacts dependent upon local conditions (e.g., smog), it may result in an oversimplification of the actual impacts because the indices are not tailored to localities. Note that some impact assessments apply a mix of midpoint and endpoint approaches.

\subsubsection{BIRDS Impact Assessment}

BIRDS uses a midpoint-level analysis to translate its 6204 environmental inputs and outputs into a manageable set of science-based measurements across 12 environmental impacts. BIRDS primarily uses the TRACI version 2.0 set of state-of-the-art, peerreviewed U.S. life-cycle impact assessment methods (Bare 2011). Since TRACI 2.0 does not include land and water use, these two important resource depletion impacts are assessed using other characterization methods (Guinée 2002, Goedkoop, Heijungs et al. 2008). Together these methods are used to develop BIRDS performance metrics indicating the degree to which construction and use of a building contributes to each environmental impact. Following are brief descriptions of the 12 BIRDS impact categories.

\subsubsection{Impact Categories}

\subsection{Global Warming Potential}

The Earth absorbs radiation from the Sun, mainly at the surface. This energy is then redistributed by the atmosphere and ocean and re-radiated to space at longer wavelengths. Greenhouse gases in the atmosphere, principally water vapor, but also carbon dioxide, methane, chlorofluorocarbons, and ozone, absorb some of the thermal radiation. The absorbed energy is re-radiated in all directions, downwards as well as upwards, such that the radiation that is eventually lost to space is from higher, colder levels in the atmosphere. The result is that the surface loses less heat to space than it would in the absence of the greenhouse gases and consequently stays warmer than it would be otherwise. This phenomenon, which acts like a 'blanket' around the Earth, is known as the greenhouse effect.

The greenhouse effect is a natural phenomenon. The environmental issue is the change in the greenhouse effect due to emissions (an increase in the effect) and absorptions (a decrease in the effect) attributable to humans. A general increase in temperature can alter atmospheric and oceanic temperatures, which can potentially lead to alteration of natural 
circulations and weather patterns. A rise in sea level is also predicted from an increase in temperature due to thermal expansion of the oceans and the melting of polar ice sheets.

\subsection{Primary Energy Consumption}

Primary energy consumption leads to fossil fuel depletion when fossil fuel resources are consumed at rates faster than nature renews them. Some experts believe fossil fuel depletion is fully accounted for in market prices. That is, market price mechanisms are believed to take care of the scarcity issue, with price being a measure of the level of depletion of a resource and the value society places on that depletion. However, price is influenced by many factors other than resource supply, such as resource demand and nonperfect markets (e.g., monopolies and subsidies). The primary energy consumption metric is used to account for the resource depletion aspect of fossil fuel extraction.

\subsection{Human Health - Criteria Air Pollutants}

These pollutants can arise from many activities including combustion, vehicle operation, power generation, materials handling, and crushing and grinding operations. They include coarse particles known to aggravate respiratory conditions such as asthma, and fine particles that can lead to more serious respiratory symptoms and disease.

\subsection{Human Health - Cancer Effects}

These effects can arise from exposure to industrial and natural substances, and can lead to illness, disability, and death. Its assessment is based on the global consensus model known as USEtox, which describes the fate, exposure and effects of thousands of chemicals (Rosenbaum, Huijbregts et al. 2011).

\subsection{Water Consumption}

Water resource depletion has not been routinely assessed in LCAs to date, but researchers are beginning to address this issue to account for areas where water is scarce, such as the Western United States. While some studies use water withdrawals to evaluate this impact, a more refined analysis considers that a portion of water withdrawn may be returned through evapotranspiration (the sum of evaporation from surface water, soil, and plant leaves). BIRDS uses the latter approach to measure water consumption, or water withdrawn net of evapotranspiration. BIRDS evaluates water consumption from cradle to grave, including water consumption during building use.

\subsection{Ecological Toxicity}

Measures of ecological toxicity consider the potential of pollutants from industrial sources to harm land- and water-based ecosystems. Its assessment is based on the global consensus model known as USEtox, which describes the fate, exposure and effects of thousands of chemicals.

\subsection{Eutrophication Potential}

Eutrophication is the addition of mineral nutrients to the soil or water. In both media, the addition of large quantities of mineral nutrients, such as nitrogen and phosphorous, results in generally undesirable shifts in the number of species in ecosystems and a 
reduction in ecological diversity. In water, it tends to increase algae growth, which can lead to a lack of oxygen and subsequent death of species like fish.

\subsection{Land Use}

This impact category measures the use of land resources in hectares by humans which can lead to undesirable changes in habitats. Note that the BIRDS land use approach does not consider the original condition of the land, the extent to which human activity changes the land, or the length of time required to restore the land to its original condition. As impact assessment science continues to evolve, it is hoped that these potentially important factors will become part of BIRDS land use assessment.

\subsection{Human Health - Non-cancer Effects}

The effects can arise from exposure to industrial and natural substances, and range from transient irritation to permanent disability and even death. Its assessment is based on the global consensus model known as USEtox, which describes the fate, exposure and effects of thousands of chemicals.

\subsection{Smog Formation}

Smog forms under certain climatic conditions when air emissions (e.g. NOx, VOCs) from industry and transportation are trapped at ground level where they react with sunlight. Smog leads to harmful impacts on human health and vegetation.

\subsection{Acidification Potential}

Acidifying compounds may, in a gaseous state, either dissolve in water or fix on solid particles. These compounds reach ecosystems through dissolution in rain or wet deposition and can affect trees, soil, buildings, animals, and humans. The two compounds principally involved in acidification are sulfur and nitrogen compounds, with their principal human source being fossil fuel and biomass combustion. Other compounds released by human sources, such as hydrogen chloride and ammonia, also contribute to acidification.

\subsection{Ozone Depletion}

Ozone depletion is the thinning of the stratospheric ozone layer, allows more harmful short wave radiation to reach the Earth's surface, potentially causing undesirable changes in ecosystems, agricultural productivity, skin cancer rates, and eye cataracts, among other issues.

\subsubsection{Computational Algorithms}

There are six building components represented in the BIRDS life-cycle impact assessment (LCIA) calculations for whole-buildings:

- Baseline building: new construction (Base_New)

- Baseline building: maintenance and repair over study period (Base_M\&R)

- Energy technology package: new construction (ETP_New) 
- Energy technology package: annual maintenance and repair (ETP_M\&R)

- Annual operating energy use: electricity (ELEC)

- Annual operating energy use: natural gas (NG)

The hybridized LCI data for each component are expressed in different units. For example, the baseline building inventories are given on a per-dollar basis, the energy technology package inventories on a per-physical unit basis (usually area), and the operating energy use inventories on a per-unit of energy basis. Thus, each requires its own LCIA computational algorithm as shown in Table 4-2. These calculations ensure that after adjusting for study period length, all LCIA results are expressed in the consistent functional unit defined for BIRDS: construction and use of one building prototype over a user-defined study period. In the case of the low-energy residential incremental improvements database, many of the variables have a single value (e.g. building location, state, building type). 
Table 4-2 BIRDS Life-cycle Impact Assessment Calculations by Building Component

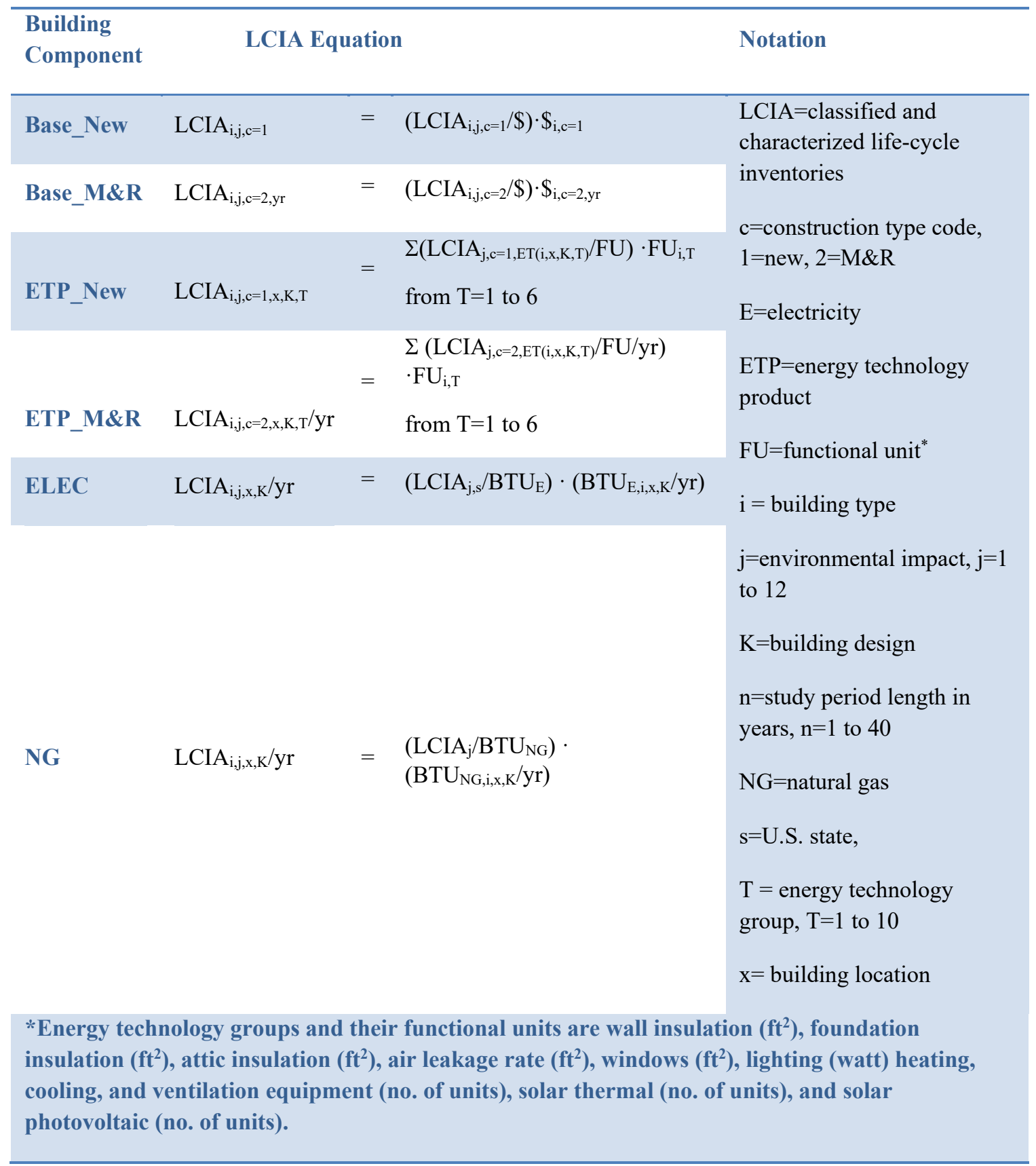

\subsubsection{BIRDS Normalization}

Once impacts have been classified and characterized, the resulting LCIA metrics are expressed in incommensurate units. GWP is expressed in carbon dioxide equivalents $\left(\mathrm{CO}_{2} \mathrm{e}\right)$, acidification in hydrogen ion equivalents, eutrophication in nitrogen equivalents, 
and so on. In order to assist in the next LCA step, interpretation, these metrics are often placed on the same scale through normalization.

The EPA has developed "normalization references" corresponding to its TRACI set of impact assessment methods (Bare, Gloria et al. 2006). These U.S. data are updated and expanded for use in BIRDS. Shown in Figure 4-3, these values quantify the U.S.

economy's annual contributions to each impact category. As such, they represent a "U.S. impact yardstick" against which to evaluate the significance of building-specific impacts. Normalization is accomplished by dividing BEES building-specific impact assessment results by the fixed U.S.-scale normalization references, expressed in the same units, yielding an impact category score for a building that has been placed in the context of annual U.S. contributions to that impact. By placing each building-specific impact result in the context of its associated U.S. impact result, the measures are all reduced to the same scale, allowing comparison across impacts.

The environmental impact of a single building is small relative to the total U.S. emissions in an impact category, leading to normalized values that are small fractions of a percent. To improve the user experience, the low-energy residential incremental improvements database adjusted these normalized values by multiplying by the U.S. population $(\sim 309$ million), creating a normalized value that represents the fraction of emissions per capita for each impact category. 
Table 4-3 BIRDS Normalization References

\begin{tabular}{|c|c|c|}
\hline Impact Category & $\begin{array}{l}\text { Normalization } \\
\text { reference } \\
\text { (U.S. total/yr) }\end{array}$ & Units \\
\hline GWP & $7.16 \mathrm{E}+12$ & $\mathrm{~kg} \mathrm{CO} 2 \mathrm{e}$ \\
\hline $\begin{array}{l}\text { Primary Energy } \\
\text { Consumption }\end{array}$ & $\begin{array}{l}3.52 \mathrm{E}+13 \\
(1.20 \mathrm{E}+14)\end{array}$ & $\begin{array}{l}\mathrm{kWh} \\
(\mathrm{kBTU})\end{array}$ \\
\hline HH Criteria Air & $2.24 \mathrm{E}+10$ & $\begin{array}{l}\text { kg particulate matter } 10 \text { equivalents } \\
(\text { PM10 = particulate matter }<10 \\
\text { microns in diameter) }\end{array}$ \\
\hline HH Cancer & $1.05 \mathrm{E}+04$ & comparative human toxicity units \\
\hline Water Consumption & $1.69 \mathrm{E}+14$ & L \\
\hline Ecological Toxicity & $3.82 \mathrm{E}+13$ & comparative ecotoxicity units \\
\hline Eutrophication & $1.01 \mathrm{E}+10$ & $\mathrm{~kg}$ nitrogen equivalents \\
\hline Land Use & $\begin{array}{l}7.32 \mathrm{E}+08 \\
(1.81 \mathrm{E}+09)\end{array}$ & $\begin{array}{l}\text { hectare } \\
\text { (acre) }\end{array}$ \\
\hline HH Non-cancer & $5.03 \mathrm{E}+05$ & comparative human toxicity units \\
\hline Smog Formation & $4.64 \mathrm{E}+11$ & $\mathrm{~kg}$ ozone equivalents \\
\hline Acidification & $1.66 \mathrm{E}+12$ & moles hydrogen ion equivalents \\
\hline Ozone Depletion & $5.10 \mathrm{E}+07$ & $\begin{array}{l}\mathrm{kg} \mathrm{CFC}-11 \text { equivalents }(\mathrm{CFC}-11= \\
\text { trichlorofluoromethane) }\end{array}$ \\
\hline
\end{tabular}

\subsection{Life-cycle Interpretation}

At the BIRDS LCA interpretation step, a building's normalized impact scores are evaluated. The midpoint-level impact assessment yields scores for twelve impact categories, making interpretation at this level difficult. To enable comparisons across buildings, the scores across impact categories may be synthesized. Note that in BIRDS, the synthesis of impact scores is optional.

Impact scores may be synthesized by weighting each impact category by its relative importance to overall environmental performance, then computing the weighted average impact score. In the BIRDS software, the set of importance weights is selected by the user. Several alternative weight sets are provided as guidance, and may be either used 
directly or as a starting point for developing user-defined weights. The alternative weight sets are based on an EPA Science Advisory Board study, a BEES Stakeholder Panel's structured judgment, a set of equal weights, and a set exclusively focusing on the climate change impact, representing a spectrum of ways in which people value diverse aspects of the environment.

\subsubsection{EPA Science Advisory Board Study}

In 1990 and again in 2000, EPA's Science Advisory Board (SAB) developed lists of the relative importance of various environmental impacts to help EPA best allocate its resources (U.S. EPA Science Advisory Board 1990, U.S. EPA Science Advisory Board 2000). The following criteria were used to develop the lists:

- The spatial scale of the impact

- The severity of the hazard

- The degree of exposure

- The penalty for being wrong

Ten of the twelve BIRDS impact categories were covered by the SAB lists of relative importance:

- Highest-Risk Problems: climate change, land use

- High-Risk Problems: ecological toxicity, human health (cancer and non-cancer effects)

- Medium-Risk Problems: ozone depletion, smog, acidification, eutrophication, and human health - criteria air pollutants

The SAB did not explicitly consider primary energy consumption or water consumption. For BIRDS, these impacts are assumed to be relatively medium-risk and low-risk problems, respectively, based on other relative importance lists (Levin 1996).

Verbal importance rankings, such as "highest risk," may be translated into numerical importance weights by following ASTM International standard guidance for applying a Multi-attribute Decision Analysis method known as the Analytic Hierarchy Process (AHP) (ASTM 2011). The AHP methodology suggests the following numerical comparison scale: 
1 Two impacts contribute equally to the objective (in this case environmental performance)

3 Experience and judgment slightly favor one impact over another

5 Experience and judgment strongly favor one impact over another

7 One impact is favored very strongly over another, its dominance demonstrated in practice

9 The evidence favoring one impact over another is of the highest possible order of affirmation

$* 2,4,6$, and 8 can be selected when compromise between values of $1,3,5,7$, and 9 , is needed.

Through an AHP known as pairwise comparison, numerical comparison values are assigned to each possible pair of environmental impacts. Relative importance weights can then be derived by computing the normalized eigenvector of the largest eigenvalue of the matrix of pairwise comparison values. Table 4-4 and Table 4-5 list the pairwise comparison values assigned to the verbal importance rankings, and the resulting $\mathrm{SAB}$ importance weights computed for the BIRDS impacts, respectively. Note that the pairwise comparison values were assigned through an iterative process based on NIST's background and experience in applying the AHP technique. Furthermore, while the SAB evaluated cancer and non-cancer effects as a group, the resulting $13 \%$ weight was apportioned between the two based on the relative judgments of the BEES Stakeholder Panel discussed in the next section.

Table 4-4 Pairwise Comparison Values for Deriving Impact Category Importance Weights

\begin{tabular}{lc}
\hline $\begin{array}{c}\text { Verbal Importance } \\
\text { Comparison }\end{array}$ & $\begin{array}{c}\text { Pairwise } \\
\text { Comparison Value }\end{array}$ \\
\hline Highest vs. Low & 6 \\
\hline Highest vs. Medium & 3 \\
\hline Highest vs. High & 1.5 \\
\hline High vs. Low & 4 \\
\hline High vs. Medium & 2 \\
\hline Medium vs. Low & 2 \\
\hline
\end{tabular}


Table 4-5 Relative Importance Weights based on Science Advisory Board Study

\begin{tabular}{lc}
\hline Impact Category & $\begin{array}{c}\text { Relative Importance } \\
\text { Weight (\%) }\end{array}$ \\
\hline GWP & 7 \\
\hline $\begin{array}{l}\text { Primary Energy } \\
\text { Consumption }\end{array}$ & 7 \\
\hline HH Criteria Air & 8 \\
\hline HH Cancer & 3 \\
\hline Water Consumption & 12 \\
\hline Ecological Toxicity & 5 \\
\hline Eutrophication & 18 \\
\hline Land Use & 5 \\
\hline HH Non-cancer & 7 \\
\hline Smog Formation & 5 \\
\hline Acidification & 5 \\
\hline Ozone Depletion & \\
\hline
\end{tabular}

\subsubsection{BEES Stakeholder Panel Judgments}

While the derived EPA SAB-based weight set is helpful and offers expert guidance, several interpretations and assumptions were required in order to translate $\mathrm{SAB}$ findings into numerical weights for interpreting LCA-based analyses. A more direct approach to weight development would consider a closer match to the context of the application; that is, environmentally preferable purchasing in the United States based on life-cycle impact assessment results, as reported by BIRDS.

In order to develop such a weight set, NIST assembled a volunteer stakeholder panel that met at its facilities in Gaithersburg, Maryland, for a full day in May 2006. To convene the panel, invitations were sent to individuals representing one of three "voting interests:" producers (e.g., building product manufacturers), users (e.g., green building designers), and LCA experts. Nineteen individuals participated in the panel: seven producers, seven users, and five LCA experts. These "voting interests" were adapted from the groupings ASTM International employs for developing voluntary standards, in order to promote balance and support a consensus process. 
The BEES Stakeholder Panel was led by Dr. Ernest Forman, founder of the AHP firm Expert Choice Inc. Dr. Forman facilitated panelists in weighting the BEES impact categories using the AHP pairwise comparison process. The panel weighted all impacts in the Short Term ( 0 years to 10 years), Medium Term (10 years to 100 years), and Long Term ( $>100$ years). One year's worth of U.S. flows for each pair of impacts was compared, with respect to their contributions to environmental performance. For example, for an impact comparison over the Long Term, the panel evaluated the effect that the current year's U.S. emissions would have more than 100 years hence.

Once the panel pairwise-compared impacts for the three time horizons, its judgments were synthesized across the selected time horizons. Note that when synthesizing judgments across voting interests and time horizons, all panelists were assigned equal importance, while the short, medium, and long-term time horizons were assigned by the panel to carry $24 \%, 31 \%$, and $45 \%$ of the weight, respectively.

The environmental impact importance weights developed through application of the AHP technique at the facilitated BEES Stakeholder Panel event are shown in Table 4-6. These weights reflect a synthesis of panelists' perspectives across all combinations of stakeholder voting interest and time horizon. The weight set draws on each panelist's personal and professional understanding of, and value attributed to, each impact category. While the synthesized weight set may not equally satisfy each panelist's view of impact importance, it does reflect contemporary values in applying LCA to real world decisions. This synthesized BEES Stakeholder Panel weight set is offered as an option in BIRDS online.

The panel's application of the AHP process to derive environmental impact importance weights is documented in an appendix to Gloria, Lippiatt et al. (2007) and ASTM (2011). 
Table 4-6 Relative Importance Weights based on BEES Stakeholder Panel Judgments

\begin{tabular}{lr}
\hline Impact Category & $\begin{array}{r}\text { Relative Importance } \\
\text { Weight (\%) }\end{array}$ \\
\hline GWP & 29.9 \\
\hline Primary Energy Consumption & 10.3 \\
\hline HH Criteria Air & 9.3 \\
\hline HH Cancer & 8.2 \\
\hline Water Consumption & 8.2 \\
\hline Ecological Toxicity & 7.2 \\
\hline Eutrophication & 6.2 \\
\hline Land Use & 6.2 \\
\hline HH Non-cancer & 5.2 \\
\hline Smog Formation & 4.1 \\
\hline $\begin{array}{l}\text { Acidification } \\
\text { Panel weight has been redistributed by proportion among }\end{array}$ & 3.1 \\
\hline Ozone Depletion & 2.1 \\
\hline Note: Since BIRDS does not currently include an Indoor & \\
\hline
\end{tabular}

The three figures below display in graphical form the BEES Stakeholder Panel weights used in BIRDS. Figure 4-3 displays the synthesized weight set. Figure 4-4 displays the weights specific to panelist voting interest, and Figure 4-5 displays the weights specific to time horizon. The BIRDS user is free to interpret results using either of the weight sets displayed in Figure 4-4 and Figure 4-5 by entering them as a user-defined weight set. 

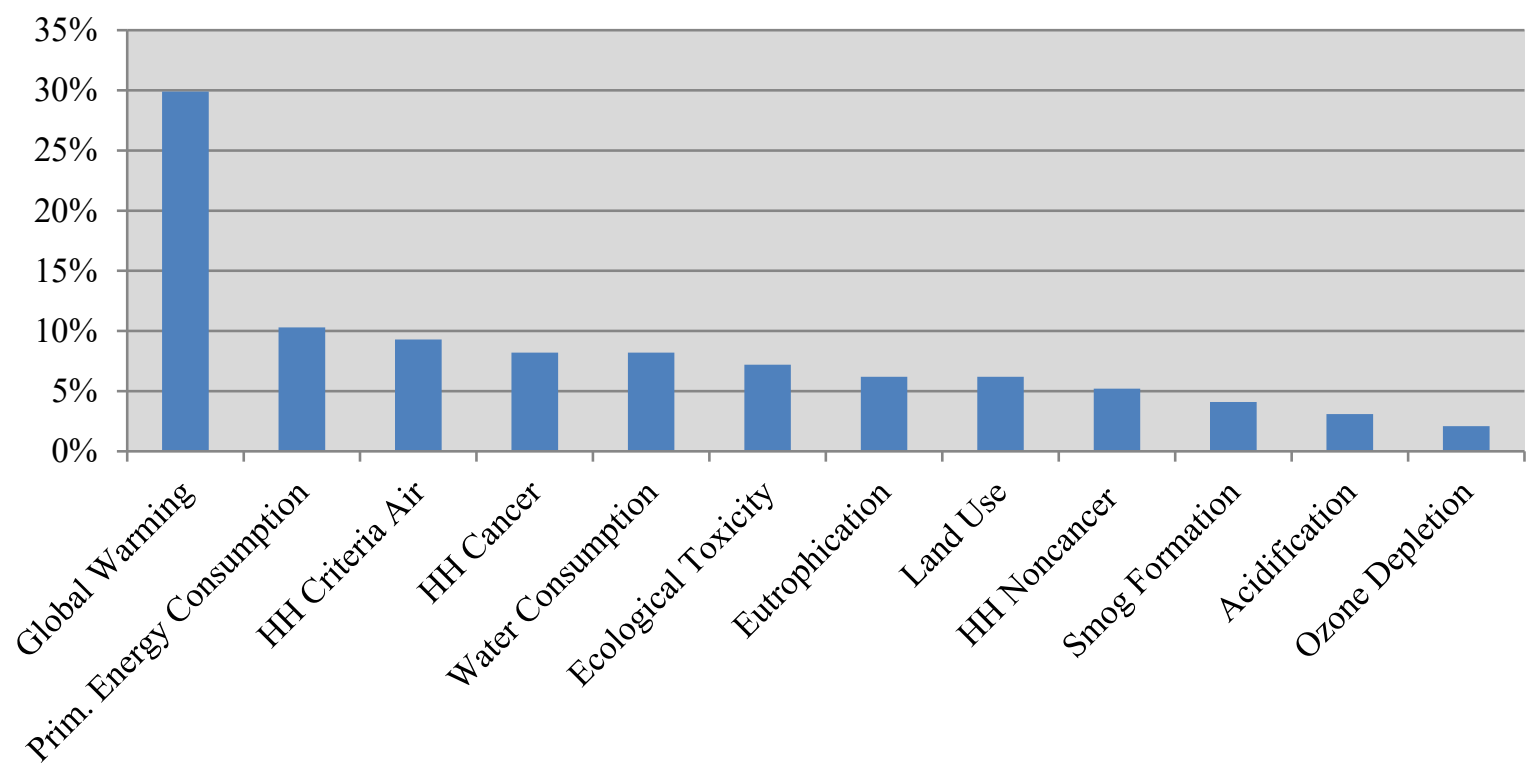

Impact Category

Figure 4-3 BEES Stakeholder Panel Importance Weights Synthesized across Voting Interest and Time Horizon

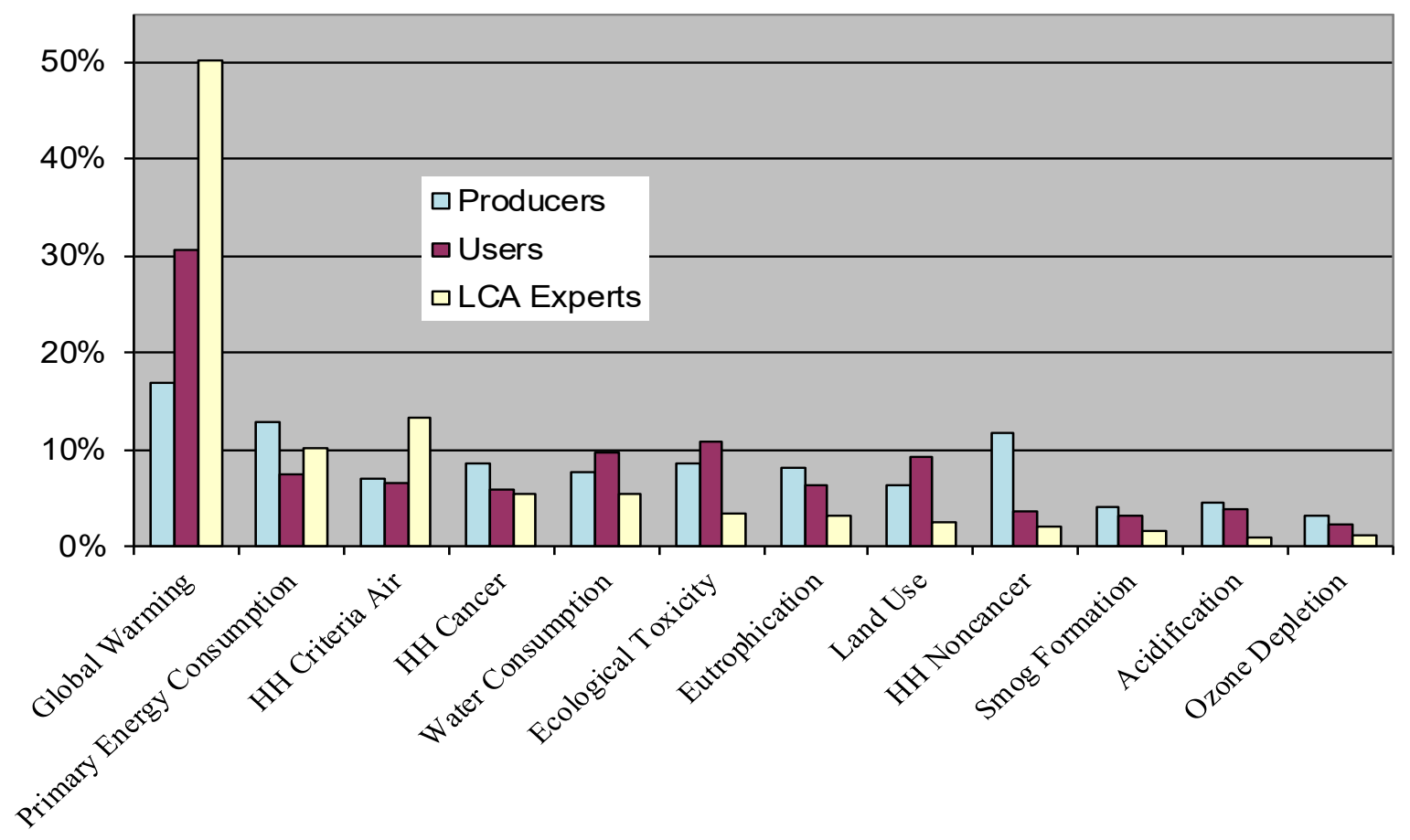

Figure 4-4 BEES Stakeholder Panel Importance Weights by Stakeholder Voting Interest 


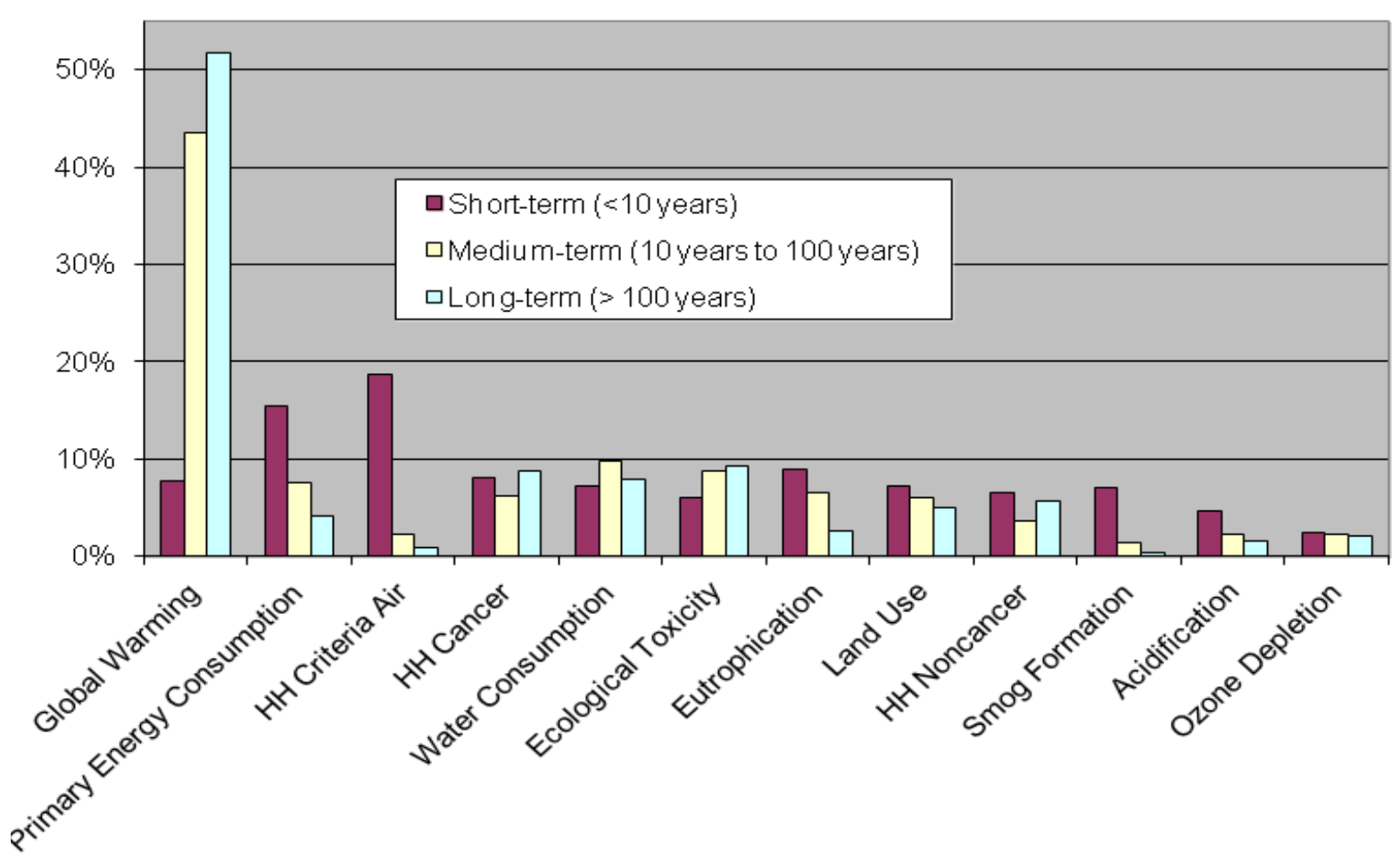

Figure 4-5 BEES Stakeholder Panel Importance Weights by Time Horizon

\subsection{BIRDS Residential Energy Technologies}

Since buildings have very long lives, operating energy efficiency has an important influence on their sustainability performance. Energy efficiency is largely driven by a building's energy technologies, but top-down inventory data are not readily available at this level of resolution. Therefore, BIRDS includes detailed LCI data for a range of energy technology packages that have been compiled at the traditional, bottom-up LCA level. These energy technology packages are used to match 480000 different building designs based on the NZERTF for Gaithersburg, MD. The bottom-up BIRDS data were developed under contract to NIST by Four Elements Consulting, LLC, of Seattle, Washington. Energy technologies include wall and ceiling insulation, windows, HVAC equipment, water heaters, lighting, and interior and exterior sealants.

\subsubsection{General Information Regarding the Energy Technology LCIs}

\subsubsection{Standards Used}

The LCAs in BIRDS have been built based on the principles and framework in the International Organization for Standardization (ISO) (2006a) and the guidelines specified in International Organization for Standardization (ISO) (2006b). 


\subsubsection{Primary and Secondary Data Sources}

Both primary data (collected directly from a manufacturing facility) and secondary data (publicly-available literature sources) can be used to build LCAs, and it is common to see a combination of both data types based on the level of disclosure organizations or companies prefer related to the information pertaining to their products. Sources of data on the energy technologies in BIRDS vary from one category to the next, and within categories themselves for the different products. Data were based on one or more of the following:

- Primary data from a group of companies and/or an industry association, compiled into an industry average product;

- Primary data on a product provided by one company;

- Secondary data that represent an average or typical product; and/or

- Secondary data that represent one product in a category.

For optimal data quality, the preference is to have the most representative data temporally, technologically, and geographically - on a product or system, so that the model produced most closely represents the product. But this is often not possible to achieve due to data constraints. It is also not always possible to have a data set that represents an entire category of products. For example, high quality, current, companyspecific data might be collected and used to build the LCA for a given product. Likewise, data for another product might be compiled from literature sources due to lack of other available data. In both cases, the LCI profiles may be used to represent the full product category, even though they may not be representative of all products within the category, based on market share, technology, geographical location, etc. The user should be aware of this limitation.

\subsubsection{Data Sources Used for the Background Data}

Secondary data have been applied to production of material inputs, production and combustion of fuels used for process energy, and transportation processes. The U.S. LCI Database (NREL 2012) and the ecoinvent v.2.2 database (Ecoinvent 2007) are the main sources of background data throughout the various life-cycle stages. Other sources of data were used where data were not available from the U.S. LCI Database or ecoinvent, and/or where they were deemed to be of better quality than these sources.

The following subsections describe modeling, assumptions, and data sources of the product life-cycle data. Data for the production of material inputs for each product are described in the subchapters since these may vary for different industries. The following data aspects are consistent for all products except where noted differently in the subchapters:

- All energy production, including production of fuels and conversion into energy and electricity production come from the U.S. LCI Database. 
- All transportation data come from the U.S. LCI Database.

- Whenever possible, where ecoinvent or other non-North American data sets were used, they were customized into North American processes by switching out foreign energy, electricity, transportation, and other processes for comparable North American based data sets from the U.S. LCI databases. Exceptions to this are noted.

- Data for parts forming (e.g., forming of metal parts and pieces, injection molding of plastic parts, etc.), are modeled with raw materials production. Most of these data come from ecoinvent.

\subsubsection{Wall and Ceiling Insulation}

The insulation categories considered for the residential walls and ceilings are presented in Table 4-7. BIRDS performance data for the insulation types were provided on the basis of $2.54 \mathrm{~cm}(1 \mathrm{in})$ or $0.09 \mathrm{~m}^{2}\left(1 \mathrm{ft}^{2}\right)$, which was then multiplied by the area and required thickness to meet the requirements of the home's design and energy code edition. Table 4-7 presents the thermal resistance in Rsi-value per-cm (R-value per in) for each.

\section{Table 4-7 Specified Insulation Types and R-Values}

\begin{tabular}{|c|c|c|}
\hline Insulation Type & $\begin{array}{c}\text { R-value (SI) } \\
\text { m }^{2} \mathrm{~K} / \mathrm{W} \text { per } 1 \mathrm{~cm}\end{array}$ & $\begin{array}{c}\text { R-value (IP) } \\
\mathbf{f t}^{2}{ }^{\circ} \mathbf{F} \text { hr/Btu per } 1 \text { in }\end{array}$ \\
\hline Kraft faced fiberglass blanket $-\mathrm{R}_{\mathrm{SI}}-2.3$ (R-13) & 0.26 & $\mathrm{R}-3.7$ \\
\hline Kraft faced fiberglass blanket - $\mathrm{R}_{\mathrm{SI}}-3.4$ (R-19) & 0.21 & $\mathrm{R}-3.0$ \\
\hline Blow-in cellulose - $\mathrm{R}_{\mathrm{SI}}-2.3$ (R-13) & 0.26 & $\mathrm{R}-3.7$ \\
\hline Blow-in cellulose - $\mathrm{R}_{\mathrm{SI}}-6.7$ (R-38) & 0.25 & $\mathrm{R}-3.5$ \\
\hline Spray polyurethane foam (open cell) & 0.25 & $\mathrm{R}-3.6$ \\
\hline Spray polyurethane foam (closed cell) & 0.42 & $\mathrm{R}-6.2$ \\
\hline Mineral wool blanket - $\mathrm{R}_{\mathrm{SI}}-2.6(\mathrm{R}-15)^{\text {Note } 1}$ & 0.30 & $\mathrm{R}-4.3$ \\
\hline Mineral wool blanket - $\mathrm{R}_{\mathrm{SI}^{-}}-4.1(\mathrm{R}-23)^{\text {Note } 1}$ & 0.30 & $\mathrm{R}-4.2$ \\
\hline XPS foam board & 0.35 & R-5. $0^{\text {Note } 2}$ \\
\hline Polyisocyanurate foam board & 0.46 & R-6.5 \\
\hline
\end{tabular}

Note 1: Thermal resistance values $\mathrm{R}_{\mathrm{SI}}-2.3$ (R-13) and $\mathrm{R}_{\mathrm{SI}}-3.4$ (R-19) are used for BIRDS wall insulation; mineral wool blankets have been modeled according to R-values more commonly offered for this insulation material (i.e., $\mathrm{R}_{\mathrm{SI}}-2.6(\mathrm{R}-15)$ and $\mathrm{R}_{\mathrm{SI}}-4.1$ (R-23)). For BIRDS, the data have been normalized to $\mathrm{R}_{\mathrm{SI}}-2.3(\mathrm{R}-13)$ and $\mathrm{R}_{\mathrm{SI}}-3.4(\mathrm{R}-19)$.

Note 2: See the XPS foam documentation (Section 4.5.2.5) regarding the increase of thermal resistance with increasing foam thickness. 
Figure 4-6 presents the general system boundaries for the insulation category as it is modeled for BIRDS.

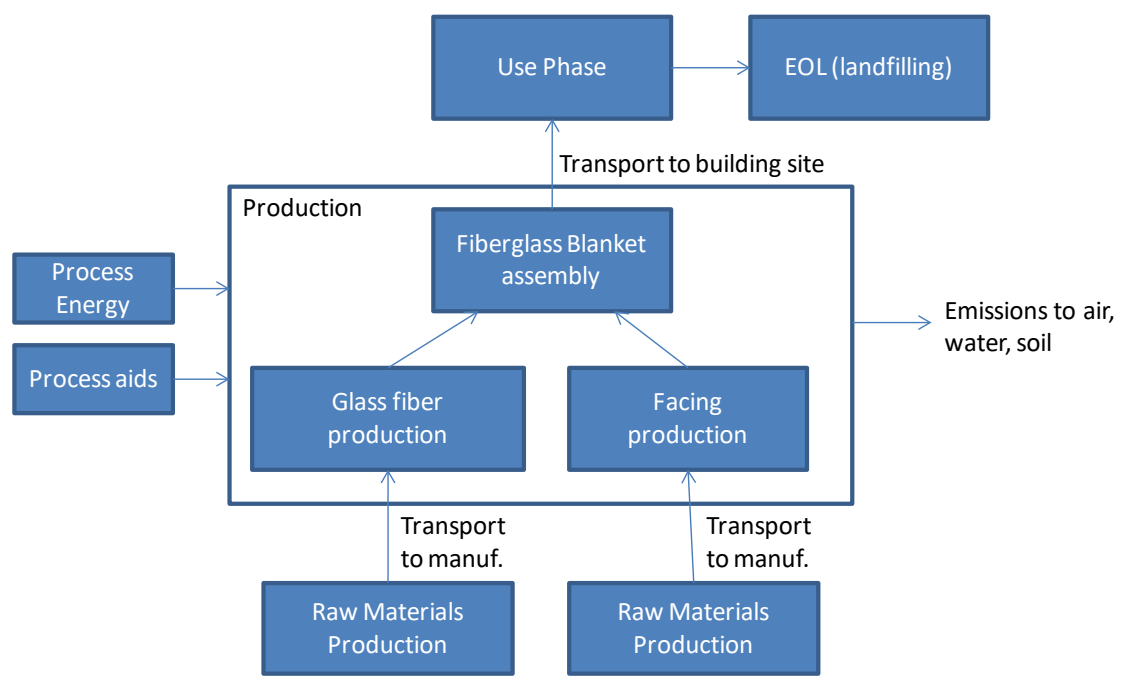

Figure 4-6 Insulation System Boundaries - Fiberglass Blanket Example

The modeling and assumptions for each type of insulation are presented in the following sections.

\subsubsection{Fiberglass Blanket}

Fiberglass blanket, or batt, insulation is made by forming spun-glass fibers into batts. At an insulation plant, the product feedstock is weighed and sent to a melting furnace. The raw materials are melted in a furnace at very high temperatures. Streams of the resulting vitreous melt are either spun into fibers after falling onto rapidly rotating flywheels or drawn through tiny holes in rapidly rotating spinners. This process shapes the melt into fibers. Glass coatings are added to the fibers that are then collected on conveyers. The structure and density of the product is continually controlled by the conveyer speed and height as it passes through a curing oven. The cured product is then sawn or cut to the required size. Off-cuts and other scrap material are recycled back into the production process.

Thermal resistance values of RsI-2.3 (R-13) and RsI-3.4 (R-19) are used for wall insulation, and Table 4-8 specifies fiberglass insulation by type and R-value. Most of the fiberglass insulation data is based on the model presented in the online documentation of the BEES software (NIST 2010). 
Table 4-8 Fiberglass Blanket Mass by Application

\begin{tabular}{|c|c|c|c|c|c|}
\hline Application & $\begin{array}{c}\text { Thickness } \\
\text { cm (in) }\end{array}$ & $\begin{array}{c}\text { Density } \mathbf{k g} / \mathrm{m}^{3} \\
\left(\mathbf{l b} / \mathbf{f t}^{3}\right)\end{array}$ & $\begin{array}{l}\text { Mass per } 1 \text { in } \\
\text { Functional Unit } \\
\text { kg/m } \mathbf{m}^{2}\left(o z / \mathbf{f t}^{2}\right)\end{array}$ & $\begin{array}{c}\text { R-Value per } \\
\text { Reference Flow } \\
\left(\mathbf{m}^{2} \mathrm{~K} / \mathrm{W} \text { per } 1 \mathrm{~cm}\right)\end{array}$ & $\begin{array}{c}\text { R-Value per } \\
\text { Reference Flow } \\
\left(\mathrm{ft}^{2}{ }^{\circ} \mathbf{F} \text { hr/Btu per } 1 \text { in }\right)\end{array}$ \\
\hline $\begin{array}{l}\text { Wall - } \mathrm{R}_{\mathrm{SI}}-2.3 \\
(\mathrm{R}-13)\end{array}$ & $8.9(3.5)$ & $12.1(0.76)$ & $0.31(1.01)$ & R-0.26 & R-3.7 \\
\hline $\begin{array}{l}\text { Wall - } \mathrm{R}_{\mathrm{SI}}-3.4 \\
(\mathrm{R}-19)\end{array}$ & $15.9(6.25)$ & $7.0(0.44)$ & $0.18(0.58)$ & $\mathrm{R}-0.21$ & R-3.0 \\
\hline
\end{tabular}

\subsection{Upstream Materials Production through Manufacturing}

Fiberglass insulation is made with a blend of sand, limestone, soda ash, and recycled glass cullet. Recycled window, automotive, or bottle glass is used in the manufacture of glass fiber; it accounts for $30 \%$ to $50 \%$ of the raw material input. The recycled content is limited by the amount of usable recycled material available in the market - not all glass cullet is of sufficient quality to be used in the glass fiber manufacturing process. The use of recycled material has helped to steadily reduce the energy required to produce insulation products. The raw materials used to produce fiberglass insulation are broken down by the glass and facing contents, shown in Table 4-9.

\section{Table 4-9 Fiberglass Insulation Constituents}

$\begin{array}{lc}\text { Glass Constituent } & \text { Mass Fraction (\%) } \\ \text { Soda Ash } & 9.0 \\ \text { Borax } & 12.0 \\ \text { Glass Cullet } & 34.0 \\ \text { Limestone } & 9.0 \\ \text { Phenolic resin (binder coating) } & 5.0 \\ \text { Sand } & 31.0 \\ \text { Total } & \mathbf{1 0 0} \\ \text { Facing } & \text { Mass Fraction (\%) } \\ \text { Kraft paper } & 25.0 \\ \text { Asphalt } & 75.0 \\ \text { Total } & \mathbf{1 0 0}\end{array}$


The production data for the soda ash, limestone, and phenol formaldehyde resin come from the U.S. LCI Database. The borax, glass cullet, and silica sand data come from ecoinvent. For the facing, Kraft paper data come from ecoinvent and the asphalt comes from U.S. LCI Database.

The raw materials are transported to the manufacturing plant via diesel truck. Materials are sourced domestically, and transportation distances range on average from $161 \mathrm{~km}$ (100 mi) to $805 \mathrm{~km}(500 \mathrm{mi})$.

The energy requirements for melting the glass constituents into fibers and drying off the completed blanket involve use of natural gas and electricity, shown in Table 4-10.

Table 4-10 Energy Requirements for Fiberglass Insulation Manufacturing

$\begin{array}{lc}\text { Energy Carrier } & \mathbf{M J} / \mathbf{k g}(\mathbf{B t u} / \mathbf{l b}) \\ \text { Natural Gas } & 1.99(857) \\ \text { Electricity } & 1.37(591) \\ \text { Total } & \mathbf{3 . 3 6}(\mathbf{1 ~ 4 4 8 )}\end{array}$

Besides combustion emissions from fuel usage at manufacturing, particulates are emitted at a rate of $2.38 \mathrm{~g} / \mathrm{kg}(4.76 \mathrm{lb} / \mathrm{ton})$ of bonded blankets and volatile organic compounds (VOCs) are emitted at a rate of $0.76 \mathrm{~g} / \mathrm{kg}(1.52 \mathrm{lb} / \mathrm{ton})$ of bonded blankets.

All waste produced during the cutting and blending process is either recycled into other insulation materials or added back into the glass mix. Thus, no solid waste is assumed to be generated during the production process.

\subsection{Transportation to the Building through End-of-Life}

Transportation of the insulation from the manufacturer to the building site is assumed to be an average of $805 \mathrm{~km}(500 \mathrm{mi})$ by heavy-duty diesel-fueled truck.

Installing fiberglass blanket insulation is primarily a manual process, with no energy or emissions included in the model. During installation, any waste material is added into the building shell where the insulation is installed - there is effectively no installation waste.

Fiberglass insulation has a functional lifetime of over 50 years so no replacement is needed during the 40 -year study period. How this product affects operating energy during the home's use phase is addressed in other sections of this report.

While fiberglass insulation is recyclable, it is assumed that it is disposed of in a landfill at end-of-life. End-of-life modeling includes transportation by heavy-duty diesel-fuel powered truck approximately $80 \mathrm{~km}(50 \mathrm{mi})$ to a construction and demolition $(\mathrm{C} \& \mathrm{D})$ landfill. Landfilled insulation is modeled based on ecoinvent end-of-life waste management process data. 


\subsubsection{Blown Cellulose Insulation}

Thermal resistance values of Rsi-3.4 (R-13) for a wall application and RsI-6.7 (R-38) for a ceiling application of blown cellulose have been used in BIRDS. The models for BIRDS are largely based on the blown cellulose in NIST (2010). Table 4-11 specifies blown cellulose insulation by type and R-value.

Table 4-11 Blown Cellulose Insulation by Application

\begin{tabular}{|c|c|c|c|c|c|}
\hline Application & $\begin{array}{c}\text { Thickness } \\
\text { cm (in) }\end{array}$ & $\begin{array}{c}\text { Density } \\
\mathrm{kg} / \mathrm{m}^{3} \\
\left(\mathbf{l b} / \mathbf{f t}^{3}\right)\end{array}$ & $\begin{array}{l}\text { Mass per } 1 \text { in } \\
\text { Functional Unit } \\
\mathbf{k g} / \mathbf{m}^{\mathbf{2}}\left(\mathbf{l b} / \mathbf{f t}^{\mathbf{2}}\right)\end{array}$ & $\begin{array}{c}\text { R-Value per } \\
\text { Reference Flow } \\
\left(\mathrm{m}^{2} \mathrm{~K} / \mathrm{W} \text { per } 1\right. \\
\mathrm{cm})\end{array}$ & $\begin{array}{c}\text { R-Value per } \\
\text { Reference Flow } \\
\left(\mathrm{ft}^{2}{ }^{\circ} \mathrm{F} \text { hr/Btu per } 1 \mathrm{in}\right)\end{array}$ \\
\hline $\begin{array}{l}\text { Wall }-\mathrm{R}_{\mathrm{SI}}-2.3 \\
(\mathrm{R}-13)\end{array}$ & $8.9(3.5)$ & $35.3(2.20)$ & $0.89(0.18)$ & $\mathrm{R}_{\mathrm{SI}-0.26}$ & $\mathrm{R}-3.7$ \\
\hline $\begin{array}{l}\text { Ceiling }-\mathrm{R}_{\mathrm{SI}}-6.7 \\
(\mathrm{R}-38)\end{array}$ & $\begin{array}{c}27.6 \\
(10.9)\end{array}$ & $27.2(1.70)$ & $0.69(0.14)$ & $\mathrm{R}_{\mathrm{SI}}-0.24$ & $R-3.5$ \\
\hline
\end{tabular}

\subsection{Upstream Materials Production through Manufacturing}

Cellulose insulation is essentially shredded, recovered wastepaper that is coated with fire retardants. Blown cellulose insulation is produced primarily from post-consumer wood pulp (newspapers), typically accounting for roughly $85 \%$ of the insulation by weight. Ammonium sulfate, borates, and boric acid are the fire retardants used most commonly and account for the other $15 \%$ of the cellulose insulation by weight. The mix of these materials is provided in Table 4-12; while the relative proportions of the fire retardants vary among manufacturers, it is assumed that they are mixed in equal proportions for BIRDS.

\section{Table 4-12 Cellulose Insulation Constituents}

\begin{tabular}{lc} 
Constituent & Mass Fraction (\%) \\
\hline Recovered Newspaper & 85 \\
Ammonium Sulfate & 7.5 \\
Boric Acid & 7.5 \\
Total & $\mathbf{1 0 0}$ \\
\hline
\end{tabular}

BIRDS recovered newspaper data includes impacts from wastepaper collection, sorting, and subsequent transportation to the insulation manufacturer. Since it is a recovered product, the impacts from upstream production of the pulp are not included in the system boundaries. Data for ammonium sulfate and boric acid come from ecoinvent. It is 
assumed that the raw materials are shipped $161 \mathrm{~km}(100 \mathrm{mi})$ to the manufacturing plant via diesel truck.

The manufacturing process includes shredding the wastepaper and blending it with the different fire retardants. It is assumed that the manufacturing energy is purchased electricity in the amount of $0.35 \mathrm{MJ} / \mathrm{kg}(150 \mathrm{Btu} / \mathrm{lb})$. Any waste produced during the production process is recycled back into other insulation materials. Therefore, no solid waste is generated during the production process.

\subsection{Transportation to the Building Site through End-of-Life}

Transportation of the insulation to the building site is modeled an assumed average of $805 \mathrm{~km}$ (500 mi) by heavy-duty diesel-fueled truck.

At installation, a diesel generator is used to blow the insulation material into the space. For one hour of operation, a typical $18 \mathrm{~kW}(25 \mathrm{hp})$ diesel engine can blow $818 \mathrm{~kg}$ (1800 lb) of insulation. The emissions and energy use for this generator are included in the system boundaries for this product. No other installation energy is required. Any waste material during installation is added into the building shell where the insulation is installed, so there is effectively no installation waste.

Cellulose insulation has a functional lifetime of over 50 years so no replacement is needed during the 40 year study period. How this product affects operating energy during the home's use phase is addressed in other sections of this report.

While cellulose insulation is mostly recyclable, it is assumed that all of the insulation is disposed of in a landfill at end-of-life. End-of-life modeling includes transportation approximately $80 \mathrm{~km}$ (50 mi) to a C\&D landfill. Landfilled insulation is modeled based on ecoinvent end-of-life waste management process data.

\subsubsection{Spray Polyurethane Foam Insulation}

Spray polyurethane foam (SPF) is an insulation and roofing material that is formulated at the building installation site using a combination of an isocyanate, or "A-side," with an equal volume of a polyol blend, or "B-side." For SPF, the A-side is a blend of monomeric and polymeric methylene diphenyl diisocyanate (pMDI). The B-side formulation varies based on formulator and desired properties, and includes at least five different types of chemical ingredients: polyols, blowing agents, flame retardants, catalysts, and surfactants. When the A and B side are mixed, it expands in place providing both insulation and an air barrier; some SPF types deliver other performance properties including a vapor retarder, water resistance and structural enhancement.

Two classifications for SPF insulation used in the U.S. construction industry are opencell (low-density) and closed-cell (medium-density) SPF. Open-cell has a nominal density ranging from $6.4 \mathrm{~kg} / \mathrm{m}^{3}$ to $11.1 \mathrm{~kg} / \mathrm{m}^{3}\left(0.4 \mathrm{lb} / \mathrm{ft}^{3}\right.$ to $\left.0.7 \mathrm{lb} / \mathrm{ft}^{3}\right) ; 7.9 \mathrm{~kg} / \mathrm{m}^{3}$ $\left(0.5 \mathrm{lb} / \mathrm{ft}^{3}\right)$ has been assumed for the LCA. Open-cell foam is formed using water as a reactive blowing agent. Water reacts with the A-side methylene diphenyl diisocyanate 
(MDI) to create carbon dioxide $\left(\mathrm{CO}_{2}\right)$ gas that expands the curing liquid into a cellular foam material. Thermal resistance per inch is in the range of $\mathrm{RSI}_{\mathrm{SI}}-0.25$ to $\mathrm{RSI}_{\mathrm{SI}}-0.28 \mathrm{per} \mathrm{cm}$ (R-3.6 to R-4.0 per inch); RsI-0.25 (R-3.6) has been assumed.

Closed-cell foam has a nominal density ranging from 27.0 to $36.5 \mathrm{~kg} / \mathrm{m}^{3}$ (1.7 to 2.3 $\left.\mathrm{lb} / \mathrm{ft}^{3}\right) ; 31.8 \mathrm{~kg} / \mathrm{m}^{3}\left(2.0 \mathrm{lb} / \mathrm{ft}^{3}\right)$ has been assumed. Fluorocarbon (physical) blowing agents are used to expand closed-cell foams: the fluorocarbon liquid in the B-side converts to a gas from the heat of the reaction to expand the cells. The low thermal conductivity fluorocarbon gas yields an R-value ranging from RsI- 0.07 to Rsi-0.08 per cm (R-5.8 to R6.8 per in); RsI-0.43 (R-6.2) has been assumed. Emissions from the Pentafluoropropane (HFC-245fa) were included in the LCA, and the assumptions around its release are stated later in this documentation.

The information provided in this summary is based on a comprehensive LCA study on SPF (PE International 2012). The quantitative data come mainly from a Spray Polyurethane Foam Alliance (SPFA) summary report (SPFA 2012) and SPFA's Environmental Product Declaration (EPD), both based on PE International (2012).

\subsection{Upstream Materials Production through Manufacturing}

SPF's A-side is MDI. The B-side is made up of a number of combinations and types of chemicals. Primary data for the year 2010 were collected from six formulation plants to attain an industry average. Table 4-13 provides the material constituent percentages of the B-side formulations (SPFA 2012). These data are assumed to be representative of SPF in the U.S., based on input and consensus by SPFA members. Nonetheless, these formulations are generic and thus do not represent one specific producer's formulation. 
Table 4-13 B-Side Formulation - Material Constituent Percentages

$\begin{array}{lcc}\text { Constituent } & \text { Low density (open } & \begin{array}{c}\text { Medium density } \\ \text { cell foam) \% }\end{array} \\ \text { Polyol - polyester } & \mathrm{n} / \mathrm{a} & 45.0 \\ \text { Polyol - Mannich } & 10.0 & 30.0 \\ \text { Polyol - compatibilizer } & 35.0 & \mathrm{n} / \mathrm{a} \\ \text { Polyol - polyether } & 25.0 & \mathrm{n} / \mathrm{a} \\ \text { Fire retardent - TCPP } & \mathrm{n} / \mathrm{a} & 4.0 \\ \text { Fire retardent - brominated } & 23.5 & 6.0 \\ \text { Blowing agent - reactive (de-ionized H2O) } & \mathrm{n} / \mathrm{a} & 2.0 \\ \text { Blowing agent - physical (HFC-245fa) } & 6.0 & 8.5 \\ \text { Catalyst - amine } & \mathrm{n} / \mathrm{a} & 3.0 \\ \text { Catalyst - metal } & 0.5 & 0.5 \\ \text { Surfactant - silicone } & \mathbf{1 0 0} & 1.0 \\ \text { Total } & & \mathbf{1 0 0}\end{array}$

The reference flows used for the original LCA were based on the functional unit defined by UL Environment (2011) Product Category Rules (PCR) on U.S. insulation: one square meter of foam provides an R-value of $1.00 \mathrm{~m}^{2} \mathrm{~K} / \mathrm{W}\left(5.68 \mathrm{~h} \cdot \mathrm{ft}^{2} \cdot{ }^{\circ} \mathrm{F} / \mathrm{Btu}\right)$. The specifications for the original LCA and the BIRDS LCA are shown together in Table 4-14. 
Table 4-14 SPF Insulation Reference Unit Parameters for Original and BIRDS LCAs

\begin{tabular}{|c|c|c|c|c|}
\hline & & Unit & $\begin{array}{c}\text { Low-density } \\
\text { Open-Cell }\end{array}$ & $\begin{array}{l}\text { Medium-density } \\
\text { Closed-Cell }\end{array}$ \\
\hline Foam R-Value & & $\begin{array}{c}\mathrm{m}^{2} \mathrm{~K} / \mathrm{W}\left(\mathrm{h} \cdot \mathrm{ft}^{2} \cdot{ }^{\circ} \mathrm{F} / \mathrm{Btu}\right) \text { per } \\
\mathrm{cm}(\text { per in })\end{array}$ & $0.25(3.6)$ & $0.43(6.2)$ \\
\hline \multirow[t]{4}{*}{ Original LCA } & Foam area & $\mathrm{m}^{2}\left(\mathrm{ft}^{2}\right)$ & $1.0(10.76)$ & $1.0(10.76)$ \\
\hline & Target R-value & $\mathrm{m}^{2} \mathrm{~K} / \mathrm{W}\left(\mathrm{h} \cdot \mathrm{ft}^{2} \cdot{ }^{\circ} \mathrm{F} / \mathrm{Btu}\right)$ & $1.00(5.68)$ & $1.00(5.68)$ \\
\hline & $\begin{array}{l}\text { Thickness per } \\
\text { reference unit }\end{array}$ & $\mathrm{cm}$ (in) & $4.0(1.58)$ & $2.3(0.92)$ \\
\hline & $\begin{array}{l}\text { Mass per } \\
\text { reference unit }\end{array}$ & $\mathrm{kg}(\mathrm{lb})$ & $0.59(1.31)$ & $1.16(2.55)$ \\
\hline \multirow[t]{4}{*}{ BIRDS LCA } & Foam area & $\mathrm{m}^{2}\left(\mathrm{ft}^{2}\right)$ & $0.09(1.0)$ & $0.09(1.0)$ \\
\hline & $\begin{array}{l}\text { R-value per } \mathrm{cm} \\
\text { (per in) }\end{array}$ & $\mathrm{m}^{2} \mathrm{~K} / \mathrm{W}\left(\mathrm{h} \cdot \mathrm{ft}^{2} \cdot{ }^{\circ} \mathrm{F} / \mathrm{Btu}\right)$ & $0.25(3.6)$ & $0.43(6.2)$ \\
\hline & $\begin{array}{l}\text { Thickness per } \\
\text { reference unit }\end{array}$ & $\mathrm{cm}$ (in) & $2.54(1.0)$ & $2.54(1.0)$ \\
\hline & $\begin{array}{l}\text { Mass per } \\
\text { reference unit }\end{array}$ & $\mathrm{kg}(\mathrm{lb})$ & $0.035(0.077)$ & $0.117(0.26)$ \\
\hline
\end{tabular}

Based on the percentages of the B-side material constituents (presented in Table 4-13) and the mass per reference unit for the BIRDS LCA, the masses of materials in the foam shown in Table 4-15 were modeled for BIRDS. The quantities of the pMDI were calculated based on SPFA (2012), which provided the masses of A-side and B-side from a drum set at installation. 
Table 4-15 Material Constituents for Open-Cell and Closed-Cell SPF Insulation

\begin{tabular}{|c|c|c|c|c|}
\hline \multirow{2}{*}{ Constituent } & \multicolumn{2}{|c|}{$\begin{array}{c}\text { Low Density } \\
\text { (Open-Cell) Foam }\end{array}$} & \multicolumn{2}{|c|}{$\begin{array}{c}\text { Medium Density } \\
\text { (Closed-Cell) Foam }\end{array}$} \\
\hline & kg & lb & kg & lb \\
\hline Polyol - polyester & $\mathrm{n} / \mathrm{a}$ & $\mathrm{n} / \mathrm{a}$ & 0.026 & 0.057 \\
\hline Polyol - Mannich & $\mathrm{n} / \mathrm{a}$ & $\mathrm{n} / \mathrm{a}$ & 0.017 & 0.038 \\
\hline Polyol - compatibilizer & 0.002 & 0.004 & $\mathrm{n} / \mathrm{a}$ & $\mathrm{n} / \mathrm{a}$ \\
\hline Polyol - polyether & 0.006 & 0.013 & $\mathrm{n} / \mathrm{a}$ & $\mathrm{n} / \mathrm{a}$ \\
\hline Fire retardent - TCPP & 0.004 & 0.009 & 0.002 & 0.005 \\
\hline Fire retardent - Brominated & $\mathrm{n} / \mathrm{a}$ & $\mathrm{n} / \mathrm{a}$ & 0.003 & 0.008 \\
\hline Blowing agent - reactive (deionized $\mathrm{H} 2 \mathrm{O}$ ) & 0.004 & 0.009 & 0.001 & 0.003 \\
\hline Blowing agent - physical (HFC-245fa) & $\mathrm{n} / \mathrm{a}$ & $\mathrm{n} / \mathrm{a}$ & 0.005 & 0.011 \\
\hline Catalyst - amine & 0.001 & 0.002 & 0.002 & 0.004 \\
\hline Catalyst - metal & $\mathrm{n} / \mathrm{a}$ & $\mathrm{n} / \mathrm{a}$ & 0.0003 & 0.001 \\
\hline Surfactant - silicone & $\mathrm{n} / \mathrm{a}$ & $\mathrm{n} / \mathrm{a}$ & 0.001 & 0.001 \\
\hline pMDI - A-Side & 0.018 & 0.040 & 0.060 & 0.131 \\
\hline Total & 0.035 & 0.077 & 0.117 & 0.258 \\
\hline
\end{tabular}

Data for the MDI comes from the U.S. LCI Database. Data for the polyester polyol comes from PE International (2010). Due to lack of other available data, proxies were used for the other polyols: polyether polyol was used for the Mannich polyol and ethylene glycol was used for compatibilizer polyol. Both come from the U.S. LCI Database.

Data for Tris(2-chloroisopropyl) phosphate (TCPP) are U.S. compiled from PE International (2012). Due to lack of specific data on the brominated fire retardant, ecoinvent's data set on diphenyl ether compounds was used as a proxy, since brominated fire retardants may be part of a group called polybrominated diphenyl ethers (PBDEs).

Deionized water-blowing agent data come from ecoinvent. Data for the HFC-245fa are based on stoichiometry and information from McCulloch (2009). Dimethylamine from ecoinvent was used for the amine catalyst, and the silicone surfactant was modeled using tetrachlorosilane as a proxy. Both these data sets come from ecoinvent. No data were available to include the metal catalyst. 
Transport distances and modes of transportation of raw materials to the formulation plants were provided in the original LCA; these distances were used in the BIRDS LCA but are not included in this text due to non-disclosure requests.

Weighted average process energy data from the six formulation sites were provided in Table 3.1 of PE International (2012). Data included electric and other fuel energy sources, waste quantities and their fates, packaging in steel drums, plastic drums and totes, plastic wrap, and pallets, plus direct process emissions from foam reactions. These data were included in the BIRDS LCA but are not provided in this summary to protect confidentiality.

\subsection{Transportation to the Building Site through End-of-Life}

According to PE International (2012), transportation to the building site of the A- and Bside drums is modeled as a weighted industry average of $1287 \mathrm{~km}(800 \mathrm{mi})$ by heavyduty diesel-fueled truck.

On-site application is nearly identical for all high-pressure SPF materials. The A- and Bside chemicals are delivered to the SPF contractor in pairs (sets) of 208-liter (55-gal) drums from the formulator. These unpressurized drum sets are stored at the contractor's facility at room temperature conditions until taken to the jobsite in a spray rig.

At the jobsite, the chemicals are heated and pressurized by specialized equipment. The chemicals are aerosolized by a spray gun and combined by impingement mixing during application. Weighted average data from six installation contractors from across North America were provided in Table 3.3 of PE International (2012). Data included electricity, diesel fuel, and waste materials. These data were included in BIRDS but are not provided in this summary to protect confidentiality. According to the UL Environment (2013) EPD, it is assumed that $50 \%$ of the original HFC-245fa blowing agent in the closed-cell foam will stay with the product. The remaining original amount of the blowing agent is released according to the EPD as follows:

- $10 \%$ emitted at installation;

- $24 \%$ emitted over its lifetime in the building;

- $16 \%$ emitted at end-of-life.

SPF insulation has a functional lifetime of 60 years so no replacement is needed during the BIRDS' 40-year study period. Installed SPF insulation normally requires no maintenance and has no impacts associated with it besides the release of blowing agent as mentioned above. How insulation in the building affects operating energy during the use phase is addressed in other sections of this report.

It is assumed that SPF insulation is disposed of in a landfill at end-of-life. The foam is inert in the landfill, except for the release of the HFC-245fa, as stated above. End-of-life modeling includes transportation by heavy-duty diesel-fuel powered truck approximately 
$80 \mathrm{~km}(50 \mathrm{mi})$ to a C\&D landfill. Insulation in a landfill is modeled based on ecoinvent end-of-life waste management process data.

\subsubsection{Mineral Wool Blanket Insulation}

Mineral wool insulation is made by spinning fibers from natural rock like diabase or basalt (rock wool) or iron ore blast furnace slag (slag wool). Rock wool and slag wool are manufactured by melting the constituent raw materials in a cupola. A molten stream is created and poured onto a rapidly spinning wheel or wheels. The viscous molten material adheres to the wheels and the centrifugal force throws droplets of melt away from the wheels, forming fibers. A binder, used to stabilize the fibers, and a de-dusting agent to reduce free, airborne wool during use, are applied during this process. The material is heated to cure the binder and stabilize the material, and is then cooled. The blankets are then cut to size and packaged. A portion of the data on mineral wool insulation come from NIST (2010).

Thermal resistance values of $\mathrm{R}_{\mathrm{SI}}-2.3$ (R-13) and $\mathrm{R}_{\mathrm{SI}}-3.4$ (R-19) are used in BIRDS for wall insulation but data used for this LCA have been modeled according to thermal resistances more commonly offered for mineral wool blankets (i.e., Rsi-2.6 (R-15) and $\mathrm{R}_{\mathrm{SI}}-4.1$ (R-23)) for each of comparison. Table 4-16 specifies mineral wool blanket insulation by type and R-value (ROXUL 2013).

Table 4-16 Mineral Wool Blanket Mass by Application

\begin{tabular}{|c|c|c|c|c|}
\hline Application & $\begin{array}{l}\text { Thickness } \\
\text { cm (in) }\end{array}$ & $\begin{array}{c}\text { Density } \\
\mathrm{kg} / \mathrm{m}^{3}\left(\mathrm{lb} / \mathrm{ft}^{3}\right)\end{array}$ & $\begin{array}{l}\text { Mass per } 1 \text { in } \\
\text { Functional Unit } \\
\mathbf{k g} / \mathbf{m}^{\mathbf{2}}\left(\mathbf{l b} / \mathbf{f t}^{2}\right)\end{array}$ & $\begin{array}{c}\text { R-Value per } \\
\text { Reference Flow } \\
\mathbf{m}^{2} \mathbf{K} / \mathbf{W} \text { per } \mathrm{cm} \\
\left(\mathbf{h} \cdot \mathbf{f t}^{2} \cdot{ }^{\circ} \mathbf{F} / \text { Btu per in }\right)\end{array}$ \\
\hline Wall - $\mathrm{R}_{\mathrm{SI}}-2.6$ (R-15) & $8.9(3.5)$ & $31.5(2.0)$ & $0.074(0.16)$ & $0.30(4.3)$ \\
\hline Wall - $\mathrm{R}_{\mathrm{SI}}-4.1$ (R-23) & $14.0(5.5)$ & $34.3(2.1)$ & $0.081(0.18)$ & $0.30(4.2)$ \\
\hline
\end{tabular}

\subsection{Upstream Materials Production through Manufacturing}

Mineral wool can be manufactured using slag wool or rock wool. Some products contain both materials; about $80 \%$ of North American mineral wool is manufactured using iron ore slag. The binder is modeled as phenol formaldehyde resin. Quantities of resin vary for different manufacturers and performance characteristics; eight percent was modeled for BIRDS. Additionally, a small amount of mineral oil was modeled as added to seal the surface against dust production (U.K. Department for Environment 2008). Table 4-17 presents the weighted mix of the different types of mineral wool feedstock representing production in North America, plus the additional materials used in blankets. 
Table 4-17 Mineral Wool Insulation Constituents

\begin{tabular}{lc} 
Constituent & Mass Fraction (\%) \\
\hline Diabase Rock/Basalt & 20.2 \\
Iron Ore Slag & 71.5 \\
Phenol formaldehyde resin & 8.0 \\
Mineral oil & 0.3 \\
Total & $\mathbf{1 0 0}$ \\
\hline
\end{tabular}

Data for rock mining and grinding come from ecoinvent. Slag is produced during steel production, when molten iron and slag are produced together in the blast furnace. The slag is recovered and can be used to produce mineral wool, as an additive to cement, etc. For mineral wool, the production of slag is considered to be environmentally "free" of upstream impacts. However, the LCA accounts for the transportation to fiber production and the processing into fiber. The data for phenol formaldehyde resin and mineral oil come from the U.S. LCI database.

The raw materials are transported to the manufacturing plant via diesel truck. Materials are sourced domestically, and transportation distances range on average from $161 \mathrm{~km}$ (100 mi) to $805 \mathrm{~km}(500 \mathrm{mi})$.

The energy requirements for melting the product constituents into fibers and drying of the fibers involve a mixture of coke and electricity. The energy demands are outlined in Table 4-18 (NIST 2010).

\section{Table 4-18 Energy Requirements for Mineral Wool Insulation Manufacturing}

$\begin{array}{lc}\text { Energy Source } & \text { MJ/kg (Btu/lb) } \\ \text { Coke } & 6.38(2740) \\ \text { Electricity } & 1.0(430) \\ \text { Total } & \mathbf{7 . 3 8 ( 3 1 7 0 )}\end{array}$

The manufacturing process generates air emissions from energy use, particulates and fluorides during melting and spinning of the mineral feedstocks, and phenol and formaldehyde during melting and binding. These emissions are included in the model. All waste produced during the production process is either recycled into other insulation materials or added back into the melt. Therefore, no solid waste is generated during production. 


\subsection{Transportation to the Building Site through End-of-Life}

Transportation of the insulation to the building site is modeled an assumed average of $805 \mathrm{~km}(500 \mathrm{mi})$ by heavy-duty diesel-fueled truck. Installation is primarily a manual process; no energy or emissions are included in the model. During installation, any waste material is added into the building shell where the insulation is installed - there is effectively no installation waste.

Mineral wool insulation has a functional lifetime of over 50 years so no replacement is needed during the 40 -year study period. How this product affects operating energy during the home's use phase is addressed in other sections of this report.

While mineral wool insulation may be recyclable, it is assumed that it is disposed of in a landfill at end-of-life. End-of-life modeling includes transportation by heavy-duty dieselfuel powered truck approximately $80 \mathrm{~km}(50 \mathrm{mi})$ to a $C \& D$ landfill. Landfilled insulation is modeled based on ecoinvent end-of-life waste management process data.

\subsubsection{XPS Foam Insulation}

Extruded Polystyrene (XPS) foam insulation has been modeled for the residential exterior wall. Type IV and Type XPS may be used for residential applications; the data in this document is representative of Type IV XPS, which has a typical average density of $26.2 \mathrm{~kg} / \mathrm{m}^{3}\left(1.63 \mathrm{lb} / \mathrm{ft}^{3}\right)$. The foam has the following R-values, depending on thickness: ${ }^{6}$

- $\quad 2.5 \mathrm{~cm}(1 \mathrm{in}): \mathrm{RsI}=0.9(\mathrm{R}=5.0)$

- $5.1 \mathrm{~cm}(2 \mathrm{in}): \mathrm{R}_{\mathrm{SI}}=1.9(\mathrm{R}=10.6)$

- $\quad 7.6 \mathrm{~cm}(3 \mathrm{in}): \mathrm{R}_{\mathrm{SI}}=2.9(\mathrm{R}=16.2)$

- $10.2 \mathrm{~cm}(4 \mathrm{in}): \mathrm{R}_{\mathrm{SI}}=3.9(\mathrm{R}=22.0)$

\subsection{Upstream Materials Production through Manufacturing}

Extruded Polystyrene Foam Association (XPSA) member companies provided representative industry average production data on XPS foam boards. XPSA represents the three largest producers in North America and accounts for over $95 \%$ of XPS products produced and sold. Table 4-19 provides a 2010 representative average of the raw material and processing energy inputs and process outputs to produce one $\mathrm{kg}$ of XPS foam board.

The table presents the current representative blowing agent assumptions for XPS. It should be noted that HFCs began to replace 1-Chloro-1, 1-difluoroethane (HCFC-142b) as the principal blowing agent in 2009, as the industry complied with U.S. EPA and Environment Canada ODS phase-out regulations requiring the XPS sector to discontinue HCFC use by the end of 2009. By 2010, all XPSA members had converted to non-HCFC blowing agents and have been using only HFC materials ever since.

\footnotetext{
${ }^{6}$ Extruded Polystyrene Foam Association (XPSA) website, found at http://www.xpsa.com. Values are based on a round-robin study in 2003 using the CAN/ULC S770-00 LTTR standard.
} 


\section{Table 4-19 XPS Foam Board Production Data}

\begin{tabular}{llcc} 
Inputs & & Quantity per kg & Quantity per lb \\
Blowing agents & HFC-134a & $0.060 \mathrm{~kg}$ & $0.060 \mathrm{lb}$ \\
& HFC-152a & $0.017 \mathrm{~kg}$ & $0.017 \mathrm{lb}$ \\
& $\mathrm{CO}_{2}$ & $0.012 \mathrm{~kg}$ & $0.012 \mathrm{lb}$ \\
Solid additives & PS resin & $0.907 \mathrm{~kg}$ & $0.907 \mathrm{lb}$ \\
& Additives & $0.018 \mathrm{~kg}$ & $0.018 \mathrm{lb}$ \\
Energy & Electricity & $1.00 \mathrm{kWh}$ & $0.454 \mathrm{kWh}$ \\
Outputs & & & \\
Air & HFC-134a & $0.0105 \mathrm{~kg}$ & $0.0105 \mathrm{lb}$ \\
& HFC-152a & $0.0029 \mathrm{~kg}$ & $0.0029 \mathrm{lb}$ \\
Waste & Waste & $1.0 \mathrm{E}-4 \mathrm{~kg}$ & $1.0 \mathrm{E}-4 \mathrm{lb}$ \\
\hline
\end{tabular}

The additives in the table include the flame retardant widely used in all polystyrene foams (hexabromocyclododecane (HBCD)) and colorants or dyes/pigments used to produce the characteristic color of each XPSA member's foam. Additives may also include a nucleation control agent, process lubricant, acid scavenger, or others.

The blowing agent conversion/trim losses during manufacturing are assumed to be on average $17.5 \%$ for North American XPS foam production (Intergovernmental Panel on Climate Change (IPCC) 2005). All of the polystyrene trim waste at the manufacturing plant is reused internally in the process. Only a very small amount of foam and other materials are occasionally sent off-site for disposal in a landfill.

Data for polystyrene come from the U.S. LCI Database. Data for all three blowing agents and some of the additives come from ecoinvent. Data were not available for all of the additives; where data were not available proxy data were implemented.

All the raw materials are produced in the U.S., and most of the raw materials are centrally located, as are the XPS manufacturer's largest plants. The estimated weighted average distance from the main suppliers to the majority of XPS manufacturing plants is $805 \mathrm{~km}$ (500 mi) for polystyrene, Tetrafluoroethane (HFC-134a), flame retardant, and $\mathrm{CO}_{2}$. 1,1Difluoroethane (HFC-152a) and other additives are transported an average distance of $1609 \mathrm{~km}(1000 \mathrm{mi})$ to manufacturing plants. All but the blowing agents and polystyrene are transported by diesel truck; the blowing agents and polystyrene are transported by rail. 


\subsection{Transportation to the Building Site through End-of-Life}

Transportation of the insulation to the building site is modeled as $563 \mathrm{~km}$ (350 mi), an average factoring in the various plants around the United States. Transportation is by heavy-duty diesel truck.

Foam boards are installed with installation tape, but tape is excluded since it is considered negligible. Scrap XPS foam board generated at installation is assumed to be 2 $\%$ of the total, consistent with other foam products in this category. While the product may be recyclable, it is modeled as being sent to a landfill $32 \mathrm{~km}$ (20 mi) from the building site. Data for the landfill come from waste management datasets in ecoinvent. Blowing agent escape during installation is insignificant. Minimal cutting to size on the jobsite is done and, even then, a sharp tool is typically used so that very few cells are opened.

XPS insulation has a functional lifetime of over 40 years so no replacement is needed during the 40-year study period. How insulation in the buildings affects operating energy during the prototype buildings' use phase is addressed in other sections of this report.

The diffusion of HFC-134a from XPS during use is $0.75 \%+/-0.25 \%$ per (Intergovernmental Panel on Climate Change (IPCC) 2005). The blowing agent emission loss during the use phase is complex and non-linear but can be represented for simplicity as a linear function after the first year. The rate is a function of the product thickness, properties (density, cell size, skins), blowing agent type(s) and transport properties (solubility, diffusion coefficient), and the installed application details (mean temperature, permeability of applied facings). The diffusion rate of HFC-152a is $15 \%$ per year (Intergovernmental Panel on Climate Change (IPCC) 2005).

Reuse of the foam is possible after building decommissioning, but the model assumes that at end-of-life the foam is disposed of in a landfill. End-of-life modeling includes transportation by heavy-duty diesel-fuel powered truck approximately $80 \mathrm{~km}(50 \mathrm{mi})$ to a C\&D landfill. Landfilled insulation is modeled based on ecoinvent end-of-life waste management process data. For a typical North America building demolition followed by disposal in a landfill, it is reasonable to assume an initial blowing agent end-of-life loss of $20 \%$ followed by annual losses of $1 \%$ (United Nations Environment Programme (UNEP) 2005).

\subsubsection{Polyisocyanurate Foam Insulation}

Polyisocyanurate (polyiso) foam insulation has been modeled for the exterior wall application. The thermal resistance value for wall polyiso board is 6.5 which includes its impermeable board facer. This R-value is based on a 6-month accelerated aging test and was provided by representatives at Bayer MaterialScience ${ }^{7}$. The foam has a wet, or pre-

\footnotetext{
${ }^{7}$ Verbal communication with Bayer MaterialScience representatives, July 2013.
} 
yield, density of $29.2 \mathrm{~kg} / \mathrm{m}^{3}\left(1.82 \mathrm{lb} / \mathrm{ft}^{3}\right)$. The final product, which includes the weight of the facers, has a nominal density of $32.0 \mathrm{~kg} / \mathrm{m}^{3}\left(2.0 \mathrm{lb} / \mathrm{ft}^{3}\right)$.

\subsection{Upstream Materials Production through Manufacturing Upstream Materials Production}

Cradle-to-gate data on production through manufacturing is based on a 2010 study performed for the Polyisocyanurate Insulation Manufacturers Association (PIMA) (Bayer MaterialScience 2008). The scope of this study included collecting and compiling mostly 2007 production data from the six PIMA member companies and compiling it into an industry average polyiso insulation board. Process energy data came from 29 out of 31 polyiso plants in the U.S. and Canada, representing approximately $94 \%$ of production in those geographies.

The chemicals to produce polyiso foam make up an "A" side (MDI) and a "B" side (polyester polyol with various additives such as catalysts, surfactants and flame retardants) plus a blowing agent (pentane). Table 4-20 presents the raw material inputs associated with polyiso foam production (Bayer MaterialScience 2011), provided on the basis of $2.54 \mathrm{~cm}(1 \mathrm{in})$ in thickness.

\section{Table 4-20 Raw Material Inputs to Produce Polyiso Foam}

$\begin{array}{lccc}\text { Inputs } & \begin{array}{c}\text { \% in foam } \\ \mathbf{2 . 5 4} \mathbf{~ c m} \text { thick }\end{array} & \begin{array}{r}\mathbf{l b ~ p e r ~} \mathbf{1} \mathbf{~ t}^{2}, \\ \mathbf{1} \text { in thick }\end{array} \\ \text { MDI } & 55.5 & 0.0382 & 0.0842 \\ \text { Polyester Polyol } & 31 & 0.0213 & 0.0470 \\ \text { TCPP } & 3.4 & 0.0023 & 0.0051 \\ \text { Catalyst K15 } & 1.4 & 0.0010 & 0.0022 \\ \text { Catalyst PC46 } & 0.16 & 1.38 \mathrm{E}-04 & 0.0003 \\ \text { Catalyst PV } & 0.08 & 6.90 \mathrm{E}-05 & 0.0002 \\ \text { Surfactant } & 0.63 & 5.51 \mathrm{E}-04 & 0.0012 \\ \text { Pentane (blowing agent) } & 7.5 & 0.0052 & 0.0115 \\ \text { Process water } & 0.1 & 0.0001 & 0.0002 \\ \end{array}$

The MDI data come from the U.S. LCI Database. Data for the polyester polyol comes from an eco-profile study of aromatic polyester polyols (PE International 2010). Data for TCPP are U.S. data compiled from literature sources (PE International 2011). Pentane data come from ecoinvent. No data were available to include the three catalysts or 
silicone surfactant; they total $2.3 \%$ of the total input, so a total of $97.7 \%$ of the inputs were included in the model.

Polyiso wall applications normally use aluminum Kraft paper (foil) for the facer. The foil facer raw materials include paper, aluminum foil, adhesives and coatings, and has a mass of $0.098 \mathrm{~kg} / \mathrm{m}^{2}\left(0.02 \mathrm{lb} / \mathrm{ft}^{2}\right)$ (Bayer MaterialScience 2008). Data on material composition come from a material safety data sheet (MSDS). Based on this limited data source, the facer is modeled as $77 \%$ foil and $23 \%$ Kraft (Atlas Roofing Corporation 2012). Data for foil is modeled as 50/50 primary and secondary aluminum from the U.S. LCI Database, plus sheet rolling (ecoinvent). Data for Kraft paper come from ecoinvent.

Raw materials are transported to the manufacturing plant via diesel truck or rail. The following distances and modes of transport were modeled:

- MDI: $2414 \mathrm{~km}$ (1500 mi) by rail;

- Polyester polyol: $1384 \mathrm{~km}$ (860 mi) by rail (90\%), $1384 \mathrm{~km}(860 \mathrm{mi})$ by truck $(10 \%)$;

- Pentane: 2414 km (1 $500 \mathrm{mi})$ by truck;

- Remaining materials: 1609 km (1 $000 \mathrm{mi})$ by truck.

\section{Manufacturing}

According to (Bayer MaterialScience 2011), polyiso plants consume primarily electricity and natural gas used to operate the laminator and associated operations support equipment, such as thermal oxidizers, storage areas, packaging machines, raw material pumps, offices, etc. A small amount of propane is used for fork lift trucks. Table 4-21 presents energy inputs and process outputs to produce 1 board-foot of foam, or $0.09 \mathrm{~m}^{2}(1$ $\mathrm{ft}^{2}$ ) of $2.54 \mathrm{~cm}$ ( 1 in) thick polyiso foam.

\section{Table 4-21 Energy Inputs and Process Outputs for 1 Board-Foot Polyiso Foam}

$\begin{array}{lcc}\text { Energy inputs } & \text { Unit } & \text { Quantity } \\ \text { Electricity } & \mathrm{MJ}(\mathrm{kWh}) & 0.0497(0.0138) \\ \text { Nat gas } & \mathrm{MJ}(\mathrm{Btu}) & 0.0913(86.55) \\ \text { Propane } & \mathrm{kg}(\mathrm{lb}) & 0.00015(0.00031) \\ \text { Outputs } & \text { Unit } & \text { Quantity } \\ \text { Pentane to air } & \mathrm{kg}(\mathrm{lb}) & 0.00013(0.00030) \\ \text { Waste scrap } & \text { board-foot } & 0.01\end{array}$

Based on review with polyiso plant manufacturers, approximately $2.5 \%$ of the pentane added to the foam is lost to air during manufacturing. Depending on the plant and local 
regulatory requirements, pentane is emitted directly to the atmosphere or to a thermal oxidizer for combustion. Only 13 plants out of 31 use thermal oxidizers to combust the pentane emissions. Since the majority of polyiso plants in North America do not use thermal oxidizers, the pentane is modeled as going directly to atmosphere (Bayer MaterialScience 2011).

Transportation and disposal of manufacturing waste scrap was modeled as going to an industrial landfill. It is assumed that a landfill for such non-hazardous waste is within 32 $\mathrm{km}$ (20 mi) of the polyiso plant.

\subsection{Transportation to the Building Site through End-of-Life}

Transportation to the building site is modeled as $400 \mathrm{~km}(250 \mathrm{mi})$ by heavy-duty diesel truck (Bayer MaterialScience 2011).

Installation tape is used but is excluded since it is considered negligible. Scrap polyiso generated at installation is assumed to be $2 \%$ of the total, consistent with other foam products in this category. While the product may be recyclable, it is modeled as being sent to a landfill $32 \mathrm{~km}(20 \mathrm{mi})$ from the building site. Data for the landfill come from waste management datasets in ecoinvent. Pentane release at installation is negligible.

Polyiso insulation has a functional lifetime of over 40 years so no replacement is needed during the 40 year study period. How insulation in the buildings affects operating energy during the prototype buildings' use phase is addressed in other sections of this report.

Polyiso insulation is modeled as disposed of in a landfill at end-of-life. End-of-life modeling includes transportation by heavy-duty diesel truck approximately $80 \mathrm{~km}(50$ mi) to a C\&D landfill. Landfilled insulation is modeled based on ecoinvent end-of-life waste management process data. According to Bayer MaterialScience (2011), $50 \%$ of the total pentane in the product will have been released by end-of-life and $50 \%$ remains in the product.

\subsubsection{Windows}

\subsubsection{Introduction}

The BIRDS residential tool evaluates double hung and casement windows with specifications complying with different energy code editions. Table 4-22 provides the Ufactor and solar heat gain coefficients (SHGCs) used to address different climate zone and code edition requirements, plus the window characteristics and frame type modeled for each. The window that is the closest match to the thermal performance of the window options in BIRDS is used as a basis for calculating the window LCIA data. 
Table 4-22 Window Specifications

\begin{tabular}{|c|c|c|c|}
\hline $\begin{array}{c}\text { U-Factor } \\
\mathbf{W} / \mathbf{m}^{2} \cdot \mathbf{K} \\
\left(\mathbf{B t u} / \mathbf{f t}^{2} \cdot \mathbf{F} \cdot \mathbf{h}\right)\end{array}$ & SHGC & Window characteristics & $\begin{array}{c}\text { Frame Type for } \\
\text { Double Hung and } \\
\text { Casement Windows }\end{array}$ \\
\hline $1.99(0.35)$ & No Req. & 2 window panes, low-e coating, argon gas & Wood-clad frame \\
\hline $2.27(0.4)$ & No Req. & 2 window panes, low-e coating, argon gas & Vinyl frame \\
\hline $2.56(0.45)$ & No Req. & 2 window panes, tint & Wood-clad frame \\
\hline $2.84(0.5)$ & 0.3 & 2 window panes, tint & Wood-clad frame \\
\hline $2.84(0.5)$ & No Req. & 2 window panes, tint & Wood-clad frame \\
\hline $3.12(0.55)$ & No Req. & 2 window panes, tint & Wood-clad frame \\
\hline $3.41(0.6)$ & No Req. & 2 window panes, low-e coating, argon gas & Aluminum frame \\
\hline $3.69(0.65)$ & 0.3 & 2 window panes, low-e coating, argon gas & Aluminum frame \\
\hline $3.69(0.65)$ & 0.4 & 2 window panes, tint & $\begin{array}{l}\text { Aluminum frame, } \\
\text { thermal break }\end{array}$ \\
\hline $3.69(0.65)$ & No Req. & 2 window panes, low-e coating, argon gas & Aluminum frame \\
\hline $4.26(0.75)$ & 0.4 & 1 window pane, tint & Wood-clad frame \\
\hline $4.26(0.75)$ & No Req. & 1 window pane, no coating & Wood-clad frame \\
\hline $5.11(0.9)$ & No Req. & 1 window pane, tint & Wood-clad frame \\
\hline $6.81(1.2)$ & 0.3 & 1 window pane, low-e coating, tint & Aluminum frame \\
\hline $6.81(1.2)$ & 0.4 & 2 window panes, low-e coating, tint & Aluminum frame \\
\hline $6.81(1.2)$ & No Req. & 1 window pane, no coating & Aluminum frame \\
\hline
\end{tabular}

The compilation of window characteristics and frame types come from a variety of sources, including an online residential window selection tool ${ }^{8}$ and individuals in industry. In reality there are many possible window assembly possibilities (combination of frame material, glass in-fill, and operability) for residential structures in any climate zone. Multiple window assembly options can be nearly identical in performance. The window assembly types presented in Figure 4-7 represent one of many options available to meet each U-SHGC combination. As such, the window assemblies presented here are not endorsed or preferred over any other type of window assembly for a residential home.

BIRDS environmental performance data for the windows category was provided per 0.09 $\mathrm{m}^{2}\left(1 \mathrm{ft}^{2}\right)$ of a typical or common size of residential window. Since data were collected

\footnotetext{
${ }^{8}$ Efficient Windows Collaborative tool, found at http://www.efficientwindows.org/selection.cfm.
} 
on a full window basis, windows were modeled as full windows and then normalized to $0.09 \mathrm{~m}^{2}\left(1 \mathrm{ft}^{2}\right)$. Figure 4-7 presents the general system boundaries for the window category as it is modeled for BIRDS.

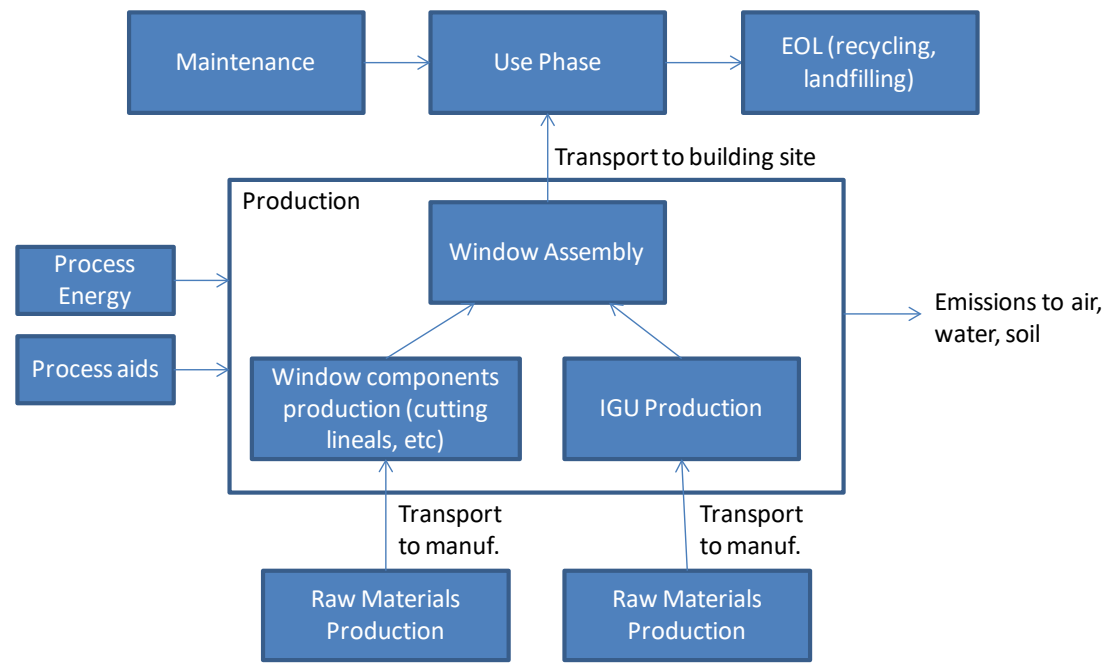

Figure 4-7 Windows System Boundaries

The next sections present the modeling and assumptions for the assemblies of wood clad, vinyl, aluminum, and aluminum with thermal break frames, for casement and double hung windows.

\subsubsection{Casement Windows Bill of Materials}

One North American manufacturer of residential windows provided primary data on wood clad, aluminum, and vinyl casement windows. Data were based on 2012 production, and material data were based on averaged information for all final assembly facilities located in North America. A generic casement window was modeled for each frame type, and the weight of each component was averaged between the plants. The data for the casement windows include:

- Frame and sash - quantities of each material;

- Insulated glass unit (IGU), including quantities and type(s) of glass, spacer, sealants, and gas if applicable;

- Hardware, weatherstrip, fasteners, and other components - quantities and types of each material.

Table 4-23, Table 4-24, and Table 4-25 provide dimensions and masses of the main parts of the casement windows. Due to the proprietary nature of the data, the details of the specific windows have been removed. Note that a thermal break is a material that separates the interior and exterior of a metal frame. The low thermal conductivity of the thermal break material reduces temperature transfer, making the metal window more energy efficient. 
Table 4-23 Dimensions and Main Parts of the Wood Clad Casement Window

$\begin{array}{llcc}\text { Description } & \text { Units } & \text { Single pane } & \text { Double pane } \\ \text { Dimension of the window } & \mathrm{m}^{2}\left(\mathrm{ft}^{2}\right) & 1.0(10.76) & 1.0(10.76) \\ \text { Weight of the finished sealed unit } & \mathrm{kg}(\mathrm{lb}) & 17.9(39.4) & 23.4(51.6) \\ \text { Wood and extruded aluminum (frame) } & \mathrm{kg}(\mathrm{lb}) & 10.4(22.9) & 10.4(22.9) \\ \text { IGU } & \mathrm{kg}(\mathrm{lb}) & 5.0(11)^{*} & 10.5(23.2) \\ \text { Other components } & \mathrm{kg}(\mathrm{lb}) & 2.5(5.5) & 2.5(5.5) \\ \text { * only glass } & & & \end{array}$

Table 4-24 Dimensions and Main Parts of the Aluminum Casement Window

\begin{tabular}{lcccc} 
Description & Units & Single pane & Double pane & $\begin{array}{c}\text { Double pane w/ } \\
\text { thermal break }\end{array}$ \\
Dimension of the window & $\mathrm{m}^{2}\left(\mathrm{ft}^{2}\right)$ & $1.0(10.76)$ & $1.0(10.76)$ & $1.0(10.76)$ \\
Weight of the finished sealed unit & $\mathrm{kg}(\mathrm{lb})$ & $16.4(36.2)$ & $20.9(46.1)$ & $21.6(47.6)$ \\
Extruded aluminum (frame) & $\mathrm{kg}(\mathrm{lb})$ & $9.7(21.4)$ & $9.7(21.4)$ & $9.7(21.4)$ \\
IGU & $\mathrm{kg}(\mathrm{lb})$ & $3.9(8.6)^{*}$ & $8.4(18.5)$ & $8.4(18.5)$ \\
Other components & $\mathrm{kg}(\mathrm{lb})$ & $2.8(6.2)$ & $2.8(6.2)$ & $3.6(7.9)$ \\
* only glass & & & & \\
\hline
\end{tabular}

Table 4-25 Dimensions and Main Parts of the Vinyl Casement Window

$\begin{array}{lcc}\text { Description } & \text { Units } & \text { Double pane } \\ \text { Dimension of the window } & \mathrm{m}^{2}\left(\mathrm{ft}^{2}\right) & 1.0(10.76) \\ \text { Weight of the finished sealed unit } & \mathrm{kg}(\mathrm{lb}) & 20.1(44.4) \\ \text { Vinyl (frame) } & \mathrm{kg}(\mathrm{lb}) & 8.0(17.6) \\ \text { IGU } & \mathrm{kg}(\mathrm{lb}) & 10.0(22.1) \\ \text { Other components } & \mathrm{kg}(\mathrm{lb}) & 2.1(4.6)\end{array}$




\subsubsection{Double Hung Window Bill of Materials}

One North American manufacturer of residential windows provided primary data on wood clad double hung windows. Data were based on 2011 North American production, and material data were based on a typical construction of an average sized window. The data for double hung windows include:

- Frame and sash - quantities of each material;

- Insulated glass unit (IGU), including quantities and type(s) of glass, spacer, sealants, and gas if applicable;

- Weatherstrip, fasteners, coatings, and other components - quantities and types of each material, where applicable.

Table 4-26, Table 4-27, and Table 4-28 provide dimensions and masses of the main parts of the double hung windows modeled for BIRDS. Due to the proprietary nature of the data, the details of the specific windows have been removed. Note that data for the aluminum frame windows are based on extrapolation from casement windows data. The mass of framing material per linear foot of the casement's frame was used to calculate the estimated mass of that material in a double-hung window frame, using the perimeters of the double hung window. The same was done for the IGU sealants and spacer, using the perimeters of the IGUs. To estimate other IGU materials and glass, the glass area was used. Most of the casement hardware was removed from the data set. The resulting double hung window is therefore comprised of estimated data. Data for the vinyl windows are based on extrapolations as described above.

Table 4-26 Dimensions and Main Parts of the Wood Clad Double Hung Window

\begin{tabular}{|c|c|c|c|}
\hline Description & Units & Single pane & Double pane \\
\hline Dimension of the window & $\mathrm{m}^{2}\left(\mathrm{ft}^{2}\right)$ & $1.3(14.0)$ & $1.3(14.0)$ \\
\hline Weight of the finished sealed unit & $\mathrm{kg}(\mathrm{lb})$ & $35.0(77.2)$ & $43.8(96.5)$ \\
\hline Wood and extruded aluminum (frame) & $\mathrm{kg}(\mathrm{lb})$ & $24.7(54.4)$ & $24.7(54.4)$ \\
\hline IGU & $\mathrm{kg}(\mathrm{lb})$ & $6.2(13.7)^{*}$ & $15.0(33.0)$ \\
\hline Other components & $\mathrm{kg}(\mathrm{lb})$ & $4.1(9.1)$ & $4.1(9.1)$ \\
\hline
\end{tabular}

* only glass 
Table 4-27 Dimensions and Main Parts of the Aluminum Double Hung Window

\begin{tabular}{lcccc} 
Description & Units & Single pane & Double pane & $\begin{array}{c}\text { Double pane } \\
\text { w/ thermo-br }\end{array}$ \\
Dimension of the window & $\mathrm{m}^{2}\left(\mathrm{ft}^{2}\right)$ & $1.3(14.0)$ & $1.3(14.0)$ & $1.3(14.0)$ \\
Weight of the finished sealed unit & $\mathrm{kg}(\mathrm{lb})$ & $20.8(45.9)$ & $25.4(56.0)$ & $26.7(58.9)$ \\
Extruded aluminum (frame) & $\mathrm{kg}(\mathrm{lb})$ & $15.6(34.4)$ & $15.6(34.4)$ & $15.6(34.4)$ \\
IGU & $\mathrm{kg}(\mathrm{lb})$ & $4.0(8.8)^{*}$ & $8.6(19.0)$ & $8.6(19.0)$ \\
Other components & $\mathrm{kg}(\mathrm{lb})$ & $1.2(2.7)$ & $1.2(2.7)$ & $2.5(5.5)$ \\
\hline * only glass & & & &
\end{tabular}

\section{Table 4-28 Dimensions and Main Parts of the Vinyl Double Hung Window}

$\begin{array}{lcc}\text { Description } & \text { Units } & \text { Double pane } \\ \text { Dimension of the window } & \mathrm{m}^{2}\left(\mathrm{ft}^{2}\right) & 1.3(14.0) \\ \text { Weight of the finished sealed unit } & \mathrm{kg}(\mathrm{lb}) & 23.6(52.0) \\ \text { Vinyl (frame) } & \mathrm{kg}(\mathrm{lb}) & 12.9(28.4) \\ \text { IGU } & \mathrm{kg}(\mathrm{lb}) & 10.2(22.5) \\ \text { Other components } & \mathrm{kg}(\mathrm{lb}) & 0.5(1.1)\end{array}$

\subsubsection{Production Data for the Materials}

Greater than $99 \%$ of the mass of materials in each window were included and modeled for these window systems. While data in the tables represent masses of materials in the finished windows, manufacturers quantified amounts of unusable (i.e. waste) materials and materials recovered, recycled, or reused, including wood and extruded aluminum. Manufacturers noted which materials were reused, recycled, landfilled, or disposed of in another way. Where materials were reused or recycled, the production of that overage was not included in the model. Where material was landfilled or incinerated, the overage was included with the window model and the appropriate waste disposal treatment method was modeled. Some of the information used for the windows modeling was supplemented by Salazar (2007).

Supplier distances to the manufacturing or assembly plant were provided by the manufacturers. Modes of transportation included heavy-duty diesel-fueled truck, ocean 
freighter and rail. The appropriate distances and modes were modeled as such, using data from the U.S. LCI Database. Where transport distances were not given for smaller contributing materials, an average of $965 \mathrm{~km}$ (600 mi) was modeled as transported by diesel truck.

Window frame raw materials. The wood clad frame consists of planed, kiln-dried lumber and extruded aluminum profile. The wood part of the frame is modeled as having equal amounts of planed, kiln-dried wood from the Southeast and Pacific Northwest using data from the U.S. LCI Database. The aluminum profile is modeled as $50 \%$ primary and $50 \%$ secondary aluminum, and uses data from the U.S. LCI Database. Data for extrusion come from an average of primary data from one window manufacturer and ecoinvent. The thermal break (used in the aluminum windows only) is made up of glassreinforced polyamide, using data from ecoinvent, and polyurethane (PUR) resin, using data from U.S. LCI Database and ecoinvent. Where applicable, stains and external coatings were modeled. The paint and primer are modeled as alkyd oil based, and stain is assumed to be latex-based; these data are built using ecoinvent data sets.

IGU raw materials. The data for float glass come from ecoinvent and is based on early 2000's European processes and technologies. Due to the lack of available data on U.S. float glass production, older European data were implemented. Processes in the data set include melting, cullet addition, forming (on a float bath), annealing by cooling in an oven (know as a lehr), cutting of the glass, and storage. While this data set may not be representative of current U.S. production, it has been customized using U.S. energy and transportation data sets. Also, some transportation impacts have been removed, including transport between manufacturing plants and coating facilities, which, according to U.S. windows industry representatives, exists for European operations but not for U.S. operations. The next version of BIRDS hopes to have more representative data on glass production.

The spacer, which separates the two panes of glass, can be made of an array of materials, including aluminum, stainless steel, and tin-plated steel. A hypothetical mix of equal parts of these three materials was used. Salazar (2007) reported a loss of approximately $10 \%$ of the spacer; this has been factored in to the model. However, the loss is recycled and is, therefore, not waste. The inner primary sealant, commonly polyisobutylene (PIB), is used to prevent leakage of the argon gas as well as penetration of water vapor into the space between the panes. An assumption of 50/50 polysulphide polymer and polyurethane as secondary sealants were implemented. The desiccant in the spacer, a silicone based product, is used to absorb moisture. Salazar (2007) reported a loss of approximately $0.7 \%$ of the desiccant and this has been factored into the model. Salazar (2007) reported an escape of argon when the cavity is flushed prior to being sealed approximately $95 \%$ more than the quantity in the finished unit. The manufacturers did not provide data on material losses. Since it is unknown if the reported quantity of escaped argon is high or low, a $50 \%$ escape is assumed for this model. 
Aluminum and PUR data come from the U.S. LCI Database. Data for all other IGU materials come from ecoinvent. Synthetic rubber is used as a general proxy for PIB.

Other components raw materials. The jambliner, or the lining between the window sash and frame, is modeled as polyvinyl chloride (PVC). Data for PVC resin comes from the U.S. LCI Database and extrusion data come from ecoinvent. Other components may include a combination of clips, gaskets, hardware, weatherstrip, and sealant. Clips, and gaskets are modeled as PVC and rubber parts. The sealant is assumed to be siliconebased. U.S. LCI Database provided the production data for PVC while the ecoinvent database provided the data for the remaining materials. Weatherstrip is described in section XXX.

Hardware is custom ordered and may vary with the window. For BIRDS, a hypothetical mix of equal parts of stainless steel, cold rolled steel, and bronze has been modeled. The steel in screws and other steel parts are based on data from the World Steel Association (2011), with steel profiles customized to the U.S. using the U.S. electricity grid; steel product manufacturing, i.e. parts forming, data come from ecoinvent. Stainless steel is modeled from a chromium steel (18/8 grade) stainless steel data set from ecoinvent with a steel product manufacturing data set to account for part forming. Bronze data come from ecoinvent.

Coatings. Low-emissivity (low-E) coatings and tinted windows have been included in the windows modeling to meet different performance characteristics of the windows. Coatings are used to improve the insulation properties of the glass by reflecting visible light and infrared radiation. The BIRDS Low-E coating is modeled using the coating details of ecoinvent's "flat glass, coated" data set as a starting point. The technology used at the particular plant is based on a cathodic sputtering technology which involves depositing thin silver and other layer(s) on the glass. According to the ecoinvent documentation, the raw materials used for sputtering are bismuth, silver and nickelchrome. The quantity of $1.19 \mathrm{E}-4 \mathrm{~kg}(2.62 \mathrm{E}-4 \mathrm{lb})$ metals per $\mathrm{kg}$ was divided into three to account for $1 / 3$ nickel, $1 / 3$ chromium, and $1 / 3$ silver. These data are approximate.

Tint is obtained by adding small amounts of metal oxides during glass manufacturing, coloring the glass uniformly. For BIRDS, iron oxide has been assumed to be the mineral additive for the tint, and it is modeled as applied at an assumed proportion of $0.1 \%$ of the glass weight.

\subsubsection{Manufacturing}

Manufacturing data is representative of the year 2011 based on total windows manufactured that year. Data include process energy and water consumption. Electricity was reported for material preparation and window assembly, and natural gas was reported for heating and drying ovens. The facility totals were normalized to one window. These data are an average and not specific for the exact window(s) being modeled. For 
confidentiality purposes, the data are not shared in this documentation, however, they have been included in the models for all of the window types.

\subsubsection{Transportation to the Building Site, Use and Maintenance}

Transportation of the window to the building site is modeled an average of $805 \mathrm{~km}$ (500 mi) by heavy-duty diesel fuel-powered truck.

Installing windows is primarily a manual process; no energy or emissions are included in the model. Windows come to the construction site fully assembled and custom-ordered to fit so there is generally no installation waste.

Maintenance of the windows includes weatherstripping and sealing. Weatherstrip is modeled as a thermoplastic elastomer. Data for the thermoplast, as ethylene propylene diene monomer (EPDM) rubber, come from ecoinvent (as synthetic rubber). For BIRDS, an EPDM weatherstrip has been modeled in the amount of $0.0064 \mathrm{~kg}$ per $0.3 \mathrm{~m}(0.014 \mathrm{lb}$ per $\mathrm{ft}$ ). Weatherstrip is assumed to perform at its optimal level an average of 7.5 years (Vigener and Brown 2012), so is modeled as replaced every 7.5 years. Different perimeter sealants can be used for different applications. For BIRDS, an acrylic latex sealant with silicone has been modeled in the amount of $0.029 \mathrm{~kg}$ per $\mathrm{m}(0.31 \mathrm{oz}$ per $\mathrm{ft})$, which is based on a $0.47 \mathrm{~cm}$ (0.19 in) diameter bead (DAP 2011). Data for the sealant is described in Section 4.5.7 and is modeled as being replaced every 15 years (Vigener and Brown 2012).

Other maintenance, such as glass and/or window frame cleaning, frame repainting or recoating, hardware adjustment or replacement, are not included in the analysis. All operational energy-related aspects of the window are addressed in other sections of this report.

The windows are modeled as having a lifetime of 30 years. Lifetime was set based on Earthsure's (2013) draft window industry PCR, even though it is acknowledged that realistically, the lifetime of windows can vary (based on frame type, weather conditions, maintenance, etc.), and that often windows have a longer service life than 30 years.

\subsubsection{End-of-Life}

Wood clad and vinyl windows are modeled as landfilled at end-of-life. The frame of the aluminum window is modeled as recycled at end-of-life, and the " $0-100$ recycling methodology" has been applied. For this methodology, system expansion is applied; the production of the same amount of virgin aluminum that is in the frame is subtracted out of the system, crediting the system with an avoided burden based on the reduced requirement for virgin material production in the next life-cycle. Likewise, recycled content in the aluminum adds some of the burden to the product system in order to share the burden with the previous life-cycle. The "0-100 recycling methodology" is applied to valuable metal recovery in other product categories as well. For more information on the "0-100 recycling methodology" approach to modeling metals at end-of-life, see Atherton 
(2007) and World Steel Association (2011). The remaining parts of the window, including the IGU, are disposed of in a landfill.

End-of-life modeling includes transportation by diesel-fuel powered truck approximately $80 \mathrm{~km}(50 \mathrm{mi})$ to a $\mathrm{C} \& \mathrm{D}$ landfill or to recycling. The portions of the window going to landfill are modeled based on ecoinvent end-of-life waste management process data.

\subsubsection{HVAC}

Residential BIRDS evaluates air conditioning systems and gas furnaces. BIRDS environmental performance data for these was provided on a per-unit (or per-system) basis as well as electric furnaces for future updates of the BIRDS new residential database. Figure 4-8 presents the general system boundaries for these as they are modeled for BIRDS.

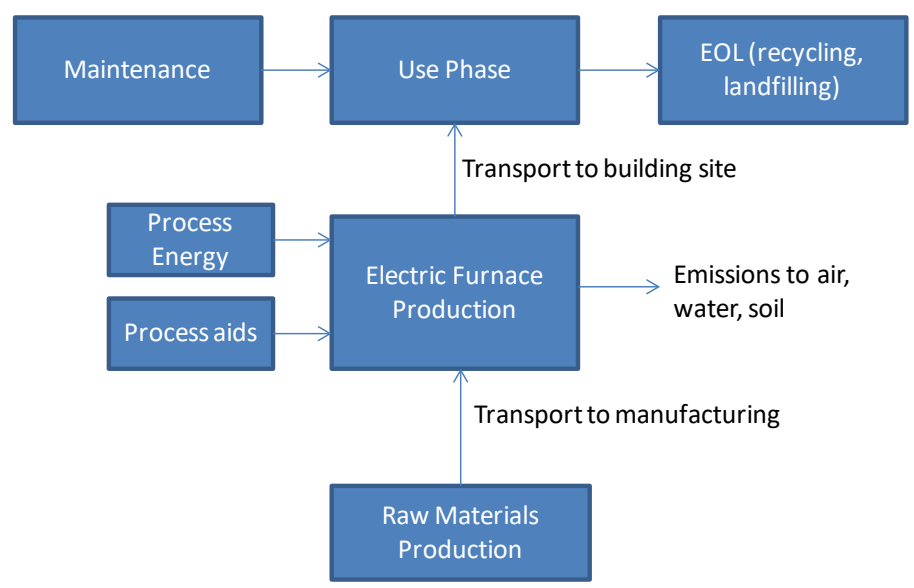

Figure 4-8 HVAC System Boundaries - Electric Furnace Example

\subsubsection{Natural Gas and Electric Furnaces}

\subsection{Upstream Materials Production through Manufacturing}

LCA practitioners often seek bill of materials data when conducting life-cycle assessments. However, there was no bill of materials data available for residential furnaces so proxy data were used. Athena Sustainable Materials Institute (2003) provided teardown data for a medium efficiency Lennox sealed combustion furnace, manufactured in 1985. These data were used with adjustments. The mass of the Lennox, $91 \mathrm{~kg}(200 \mathrm{lb})$, was normalized to the mass of an efficient natural gas furnace currently available on the market that weighs approximately $56 \mathrm{~kg}(124 \mathrm{lb})^{9,10}$. These data were supplemented by Yang, Zmeureanu et al. (2008), which provided data for a blower motor, replacing that of

\footnotetext{
${ }^{9}$ Weight of the Standard Rheem Classic $95 \%$ efficiency natural gas furnace (RGRC-07-RBGS) from Rheem Classic Series, Upflow Gas Furnaces, Physical Data and Specifications, Form No. G11-527, p.4. ${ }^{10}$ This source states a total shipping weight of $62.1 \mathrm{~kg}(137 \mathrm{lb})$. The mass of the equipment itself was assumed to be $91 \%$ of the total weight, based on other Rheem product published weights relative to their shipping materials.
} 
the older Lennox, to account for the more efficient furnace. Table 4-29 provides the materials in the natural gas furnace; the notes column identifies the adjustments made.

\section{Table 4-29 Natural Gas Furnace Bill of Materials}

\begin{tabular}{|c|c|c|c|}
\hline \multirow[b]{2}{*}{ Material } & \multicolumn{2}{|c|}{ Mass } & \multirow[b]{2}{*}{ Notes } \\
\hline & kg & lb & \\
\hline Aluminum & 1.02 & 2.25 & $\begin{array}{l}\text { Yang (2008) air blower data, replacing the Al in } \\
\text { Athena (2003) }\end{array}$ \\
\hline Brass & 0.05 & 0.11 & \\
\hline Ceramic & 0.04 & 0.08 & \\
\hline Circuit board, transistors & 0.05 & 0.11 & \\
\hline Copper & 2.20 & 4.85 & $\begin{array}{l}\text { Yang (2008) air blower data, replacing the } \mathrm{Cu} \\
\text { in Athena (2003) }\end{array}$ \\
\hline $\begin{array}{l}\text { Fiberglass insulation (foil- } \\
\text { lined) }\end{array}$ & 0.27 & 0.60 & \\
\hline Galvanized Steel & 21.86 & 48.19 & Steel paired down to meet the Rheem weight \\
\hline PET & 0.38 & 0.83 & \\
\hline PVC & 0.45 & 0.99 & \\
\hline Powder coating & 0.19 & 0.42 & \\
\hline Rubber & 0.02 & 0.04 & \\
\hline Steel & 29.79 & 65.66 & $\begin{array}{l}\text { Yang (2008) air blower and Athena (2003). } \\
\text { Steel paired down to meet the Rheem weight }\end{array}$ \\
\hline Total & 56.3 & 124.1 & \\
\hline
\end{tabular}

For the electric furnace, the mass of the Lennox was normalized down to the mass of the electric furnace in BIRDS, a unit currently on the market. ${ }^{11}$ Data for the blower motor were provided by Yang, Zmeureanu et al. (2008). Table 4-30 presents the bill of materials with data adjustments.

\footnotetext{
${ }^{11}$ Rheem Air Handlers, Form No. H11-524 REV. 8, Unit Dimensions \& Weights, p.4, model 4221/4821.
} 
Table 4-30 Electric Furnace Bill of Materials

\begin{tabular}{|c|c|c|c|}
\hline \multirow[b]{2}{*}{ Material } & \multicolumn{2}{|c|}{ Mass } & \multirow[b]{2}{*}{ Notes } \\
\hline & kg & lb & \\
\hline Aluminum & 1.02 & 2.25 & Yang (2008), replacing the $\mathrm{Al}$ in Athena (2003) \\
\hline Brass & 0.05 & 0.11 & \\
\hline Ceramic & 0.04 & 0.08 & \\
\hline Circuit board, transistors & 0.05 & 0.11 & \\
\hline Copper & 2.20 & 4.85 & Yang (2008), replacing the $\mathrm{Cu}$ in Athena (2003) \\
\hline $\begin{array}{l}\text { Fiberglass insulation (foil- } \\
\text { lined) }\end{array}$ & 0.27 & 0.60 & \\
\hline Galvanized Steel & 34.04 & 75.04 & Steel paired down to meet the Rheem weight \\
\hline PET & 0.38 & 0.83 & \\
\hline PVC & 0.45 & 0.99 & \\
\hline Powder coating & 0.32 & 0.71 & $\begin{array}{l}\text { Model assumes } 0.095 \mathrm{~kg} \text { powder per } \mathrm{m}^{2} \text { (from } \\
\text { ecoinvent) }\end{array}$ \\
\hline Rubber & 0.02 & 0.04 & \\
\hline Steel & 29.17 & 64.31 & $\begin{array}{l}\text { Yang (2008) air blower and Athena (2003). Steel } \\
\text { paired down to meet the Rheem weight }\end{array}$ \\
\hline Total & 68.00 & 149.9 & \\
\hline
\end{tabular}

The steel is assumed to be cold-rolled; this and the galvanized steel come from World Steel Association (2011). Aluminum is modeled as a 50/50 mix of primary and secondary extruded aluminum using data from the U.S. LCI Database. Data for copper come from International Copper Association (ICA) (2012). Data for PET and PVC come from the US LCI database. Ecoinvent provided the data for brass, ceramics, integrated circuit boards, rubber (as synthetic rubber), and powder coating. The fiberglass insulation was modeled as described in the insulation section of this report.

Raw materials are modeled as transported to the manufacturing plant via diesel truck an assumed average distance of $805 \mathrm{~km}(500 \mathrm{mi})$.

Because no manufacturing data were available for residential furnaces, an ecoinvent data set for a 10-kW (34-MBH) oil boiler was used as a proxy (Ecoinvent 2007). The ecoinvent dataset description states that the $10 \mathrm{~kW}$ low- $\mathrm{NO}_{\mathrm{x}}$ or condensing boiler data may be applied for residential furnaces (Ecoinvent 2007). The production energy is stated 
to be estimated from a 1998 environmental report. Even though this proxy is considered not to be representative of current practice; however its use is considered sufficient for comparison purposes.

Table 4-31 shows data for a boiler of approximately $150 \mathrm{~kg}(331 \mathrm{lb})$. Since manufacturing the smaller units is assumed to require less energy, these data were normalized based on the total weights of the natural gas and electric furnaces.

\section{Table 4-31 Furnace Manufacturing}

\begin{tabular}{lc} 
Energy source & Quantity for 10 kW boiler \\
\hline Electricity, medium voltage, MJ (Btu) & $294(81.7)$ \\
Natural gas in industrial furnace, MJ (Btu) & $424(401874)$ \\
Light fuel oil in industrial furnace, MJ (Btu) & $236(223685)$ \\
Tap water, liter (gal) & $182(48)$
\end{tabular}

\subsection{Transportation to the Building Site through End-of-Life}

Transportation of the equipment to the building site is modeled as an assumed average of $644 \mathrm{~km}$ (400 mi) by heavy-duty diesel fuel-powered truck.

It is assumed that a qualified service technician comes to the building site to check and/or service the unit one time every three years to ensure optimal performance and lifetime. It is assumed that the qualified technician is within a $24 \mathrm{~km}$ (15 mi) service radius. This distance, driven in a gasoline-powered van, is allocated amongst other service visits, assuming that the same technician is making more than one service call during that trip. Assuming the technician makes 5 service calls in one day, one-fifth of the impacts from driving $24 \mathrm{~km}(15 \mathrm{mi})$ are allocated to the product, or $4.8 \mathrm{~km}(3 \mathrm{mi})$. Environmental flow data associated with the operation of the van comes from ecoinvent. Unplanned service visits (i.e., unanticipated issues that require a service technician) are not included in the model, assuming that the homeowner adequately follows the maintenance and care guidelines.

A lifetime of 16 years has been assumed for both gas and electric furnaces, based on the National Association of Home Builders (NAHB) Research Center (2007), a study on life expectancy of home components. ${ }^{12}$

At the end-of-life, it is assumed that the furnaces are sent for recycling to recover valuable metal using the "0-100 recycling methodology" discussed previously in Section 4.5.3.7. What cannot be recovered, i.e., any non-metallic parts, are modeled as landfilled, assuming a distance of $48 \mathrm{~km}$ (30 mi) to the land fill with transport via heavy-duty diesel

\footnotetext{
${ }^{12}$ NAHB (2007), Table 1, Section 15 gives furnaces a life expectancy range of 15 to 20 years.
} 
truck. The landfill is modeled based on ecoinvent end-of-life waste management process data.

\subsubsection{Residential Air Conditioners}

Residential air conditioners for BIRDS are modeled as split systems with outdoor and indoor components that provide a condenser and evaporative heat exchanger, respectively. BIRDS includes LCA data for 3-ton residential air conditioners with SEERs of $13,14,18$, and 21. SEER is defined by the Air Conditioning, Heating, and Refrigeration Institute (AHRI) as total heat removed from the conditioned space during the annual cooling season, expressed in Btu's, divided by the total electrical energy consumed by the air conditioner or heat pump during the same season, expressed in watthours (AHRI 2008). Eighteen SEER is considered to be a high rating relative to other models; based on informal discussions with industry members, only a small percentage of the market is currently at 18 SEER. An even smaller percentage is beyond 18 SEER, so 21 SEER is considered to be exceptionally high, providing an extremely efficient system.

\subsection{Upstream Materials Production through Manufacturing}

Bill of materials for the outside unit (condenser) shown in Table 4-32 came from De Kleine (2009). The condensing unit is based on a tear-down of a 3-ton, 10 SEER unit manufactured in approximately 2001. The components' materials were assumed by Four Elements, except where noted. 
Table 4-32 Condenser Unit Bill of Materials

\begin{tabular}{|c|c|c|c|c|}
\hline \multirow[b]{2}{*}{ Main Component } & \multicolumn{3}{|c|}{ Mass } & \multirow[b]{2}{*}{ Notes } \\
\hline & Material Breakdown & kg & $\mathbf{L b}$ & \\
\hline \multirow[t]{4}{*}{ Compressor } & Aluminum & 0.53 & 1.16 & \multirow{4}{*}{$\begin{array}{l}\text { Compressor breakdown from (Biswas and } \\
\text { Rosano 2011), Fig } 1 .\end{array}$} \\
\hline & Cast iron & 24.74 & 54.54 & \\
\hline & Copper & 1.32 & 2.90 & \\
\hline & Steel & 2.72 & 6.00 & \\
\hline \multirow[t]{2}{*}{ Coil Assembly } & Copper (tubing) & 3.95 & 8.71 & \multirow{2}{*}{$\begin{array}{l}\text { Approx. } 50 \% \text { copper tubing, } 50 \% \text { aluminum } \\
\text { fins. (De Kleine, 2009) }\end{array}$} \\
\hline & Aluminum (fins) & 3.95 & 8.71 & \\
\hline \multirow[t]{3}{*}{ Fan Motor } & Copper wire & 1.08 & 2.37 & \multirow{3}{*}{$\begin{array}{l}\text { Assumed to have a composition of } 25 \% \text { copper } \\
\text { wire, } 72 \% \text { steel, and } 3 \% \text { polyamide } \\
\text { (De Kleine } 2009 \text { ) }\end{array}$} \\
\hline & Steel & 3.10 & 6.83 & \\
\hline & Polyamide & 0.13 & 0.28 & \\
\hline Unit Wall & Galvanized steel & 3.10 & 6.83 & \\
\hline Base & Galvanized steel & 2.70 & 5.95 & \\
\hline Top Cover & Galvanized steel & 1.90 & 4.19 & \\
\hline Fan Guard & Stainless steel & 1.60 & 3.53 & \\
\hline \multirow{2}{*}{$\begin{array}{l}\text { Refrigerant Line } \\
\text { service valve }\end{array}$} & Brass (service valves) & 0.75 & 1.65 & \\
\hline & Rubber & 0.25 & 0.55 & \\
\hline Wire Guard & Stainless steel & 0.80 & 1.76 & \\
\hline Fan Blade & Steel & 0.60 & 1.32 & \\
\hline Misc Fasteners & Steel & 0.30 & 0.66 & \\
\hline Capacitor & Sheet metal (steel) & 0.30 & 0.66 & \\
\hline \multirow[t]{2}{*}{ Relay Switch } & Copper wiring & 0.10 & 0.22 & \multirow{2}{*}{$\begin{array}{l}\text { Assumed to be } 50 \% \text { copper wiring and } 50 \% \\
\text { nylon polymer (De Kleine } 2009 \text { ) }\end{array}$} \\
\hline & Nylon polymer & 0.10 & 0.22 & \\
\hline Copper Wiring & Copper wire & 0.20 & 0.44 & \\
\hline Total & & 54.20 & 119.49 & \\
\hline
\end{tabular}


De Kleine's teardown was for a SEER 10 unit, but the bill of materials for the higher SEERs were required for his study. To do this, De Kleine created a weight function using survey data and manufacturer specification sheets on condenser units from several different brands ranging in efficiency from 10 SEER to 18 SEER and ranging in capacity from 1.5 tons to 5 tons of cooling. This weight function was used to calculate the mass of each of the condenser units in BIRDS as follows, enabling the adjustment of the bill of materials to the different masses as shown in Table 4-33. See De Kleine (2009) for more detail.

\section{Table 4-33 Condenser Unit Masses}

$\begin{array}{lccccc} & \text { SEER 10 } & \text { SEER 13 } & \text { SEER 14 } & \text { SEER 18 } & \text { SEER 21 } \\ \text { Factor } & 1 & 1.36 & 1.49 & 1.98 & 2.34 \\ \begin{array}{l}\text { Mass in kg } \\ \text { (lb) }\end{array} & 54.2(119.5) & & & & \\ & & 74.1(163.5) & 80.8(178.1) & 107.4(236.7) & 127.3(280.7)\end{array}$

These values corresponded with De Kleine (2009), and are consistent with manufacturers' products of the same SEER ratings.

The evaporator coil indoor unit was modeled as being housed in the electric furnace. De Kleine (2009) approximated the inside coil assembly for a 13 SEER system to weigh 15.9 $\mathrm{kg}(35 \mathrm{lb})$ and be composed of $50 \%$ copper tubing and $50 \%$ aluminum fins. The refrigerant line, connecting the outdoor and indoor units, was modeled as 20 feet of copper tubing weighing $4.5 \mathrm{~kg}(9.9 \mathrm{lb})$ (De Kleine 2009). The air conditioning system uses R-410a refrigerant, and data for the quantity of refrigerant used in each of the SEERs studied (shown in Table 4-34) was calculated using refrigerant mass function developed by De Kleine (2009).

\section{Table 4-34 Refrigerant Quantities}

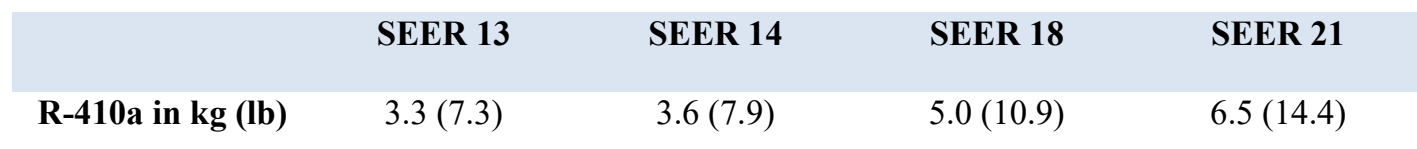

The steel data, assumed to be cold-rolled, and the galvanized steel data come from the World Steel Association (2011). Aluminum is modeled as a 50/50 mix of primary and secondary extruded aluminum using data from the U.S. LCI Database. Data for copper tube, sheet, and wire come from International Copper Association (ICA) (2012). Ecoinvent provided the data for the cast iron, stainless steel, brass, rubber (as synthetic rubber), and polyamide. 
R-410a data are based on a 50/50 share of difluoromethane (R-32) and pentafluoroethane (R-125). Due to lack of available production data on both of these chemicals, proxies were implemented. Trifluoromethane (HFC-23) was used as a proxy for difluoromethane and 1,1,difluoroethane (HFC-152a) was used as a proxy for R-125. Note: while proxies were used for the production aspect of the chemicals, any release of these was based on the release of R-32 and R-125, not the proxy chemicals, so that ozone depletion impact remains zero and climate change potential impact is calculated appropriate to R-410a.

Raw materials are modeled as transported to the manufacturing plant via diesel truck an assumed average distance of $805 \mathrm{~km}$ (500 mi).

No manufacturing data were available for residential air conditioners, so as a proxy, an ecoinvent data set for a $10 \mathrm{~kW}(34 \mathrm{MBH})$ oil boiler was used. Since manufacturing the smaller units is assumed to require less energy and resources than the $150 \mathrm{~kg}(331 \mathrm{lb})$ boiler, these data were normalized based on the total weights of the air conditioners.

\subsection{Transportation to the Building Site through End-of-Life}

Transportation of the equipment to the building site is modeled assuming a heavy-duty, diesel-powered truck is used and an average distance of $1287 \mathrm{~km}(800 \mathrm{mi})$ is travelled. This distance was estimated by De Kleine (2009) and is based on five manufacturing locations of major residential air conditioner manufacturers.

It is assumed that a qualified service technician comes to the building site to check and service the unit every three years to ensure optimal performance and lifetime. It is assumed that the qualified technician is within a $24 \mathrm{~km}(15 \mathrm{mi})$ service radius. This distance is driven in a gasoline-powered van and is shared amongst other service visits for that technician, assuming that the same technician is making more than one service call during that trip. Assuming the technician makes 5 service calls in one day, one-fifth

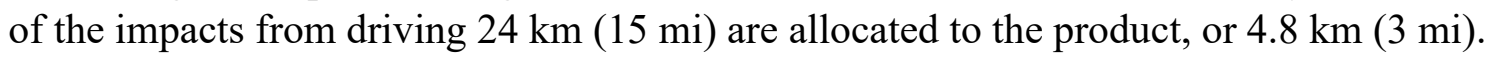
Data for a van come from ecoinvent. Unplanned service visits (i.e., unanticipated issues that require a service technician) are not included in the modeling assuming that the home owner adequately follows the maintenance and care guidelines.

A lifetime of 15 years has been assumed for the air conditioners (National Association of Home Builders (NAHB) Research Center 2007). During use, refrigerant is assumed to escape at a rate of $2 \%$ per year of the total refrigerant (De Kleine 2009). It is recharged every three years during the maintenance visit.

At the end-of-life, it is assumed that the air conditioners are sent for recycling to recover valuable metal using the " $0-100$ recycling methodology discussed previously in Section 4.5.3.7. What cannot be recovered, i.e., any non-metallic parts, are modeled as landfilled assuming a distance of $48 \mathrm{~km}$ (30 mi) to the landfill with transport via heavy-duty diesel truck. The landfill is based on ecoinvent waste management process data. A study prepared for Air-Conditioning, Heating, and Refrigeration Technology Institute (AHRTI) assumes an overall loss of $15 \%$ of the R-410a refrigerant (AHRTI 2011). This is based on 
"recovering $90 \%$ of the charge from $95 \%$ of the field units, but allowing for a $100 \%$ charge loss from about $5 \%$ of the field stock" (AHRTI 2011).

\subsubsection{Split System Heat Pump}

The Net-Zero Energy Residential Test Facility (NZERTF) uses a split system heat pump which can convert cooler outside air to warm inside air for heating, and vice versa for cooling. A split system is an air conditioner split by the air source condensing unit located on the outside of the building and an air handler inside the building. An air handler is an appliance used to condition and circulate air through a building as part of the building's HVAC system. The Aaon condensing unit (model CB-036) and corresponding heat pump air handler (model F1-036) are modeled in the NZERTF. By way of the reversible heap pump, the system provides cooling and heating with R-410A refrigerant. The refrigerant absorbs heat in the evaporator where it vaporizes, and releases heat where the refrigerant condenses, in the condenser. In heating mode, the outdoor coil serves as the evaporator, while the inside coil is the condenser. The refrigerant coming from the outdoor coil carries the thermal energy from outside air indoors. The indoor coil then transfers thermal energy to the indoor air, where it is distributed throughout the home by the air handler. In cooling mode, the cycle is reversed; similar to an air conditioner, the outdoor coil is the condenser and the indoor coil is the evaporator. In BIRDS, the split system heat pump's system boundaries are modeled as follows:

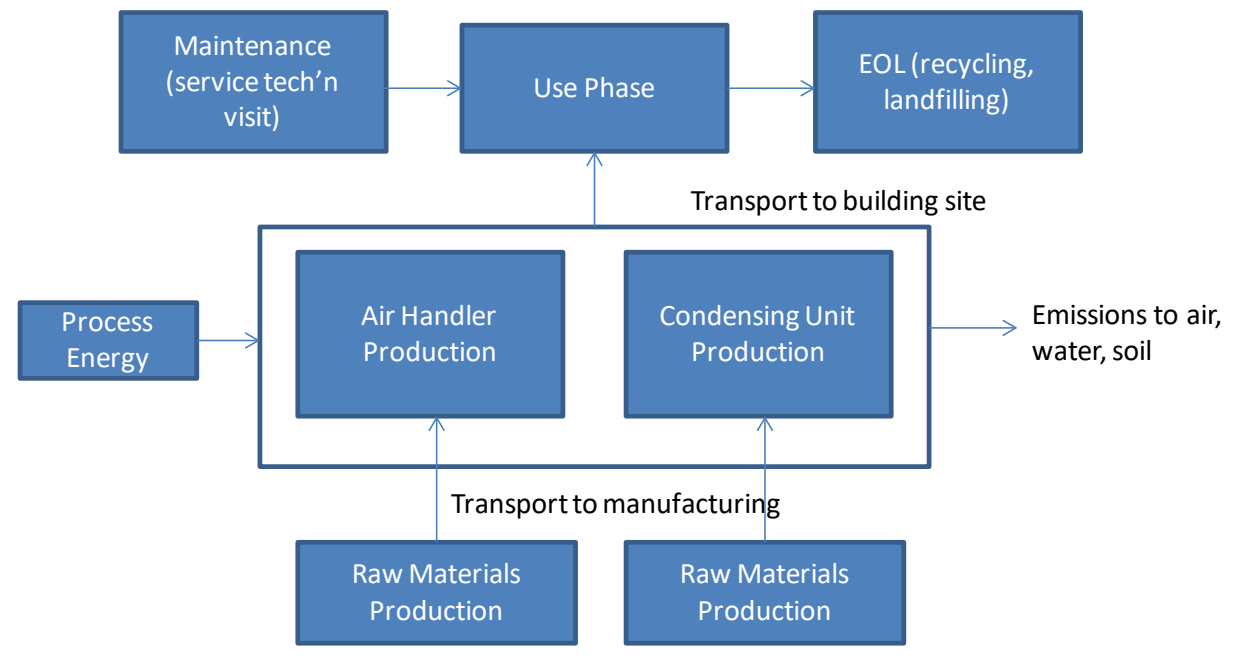

Figure 4-9 Split System Heat Pump System Boundaries

\subsection{Upstream Materials Production through Manufacturing}

Manufacturer-specific data was not available, so publicly-available sources of data were used as proxy and customized wherever possible using product specifications. Data for the bill of materials for the air handler comes from Nyman (2004) Table 2. ${ }^{13}$ The higher

\footnotetext{
${ }^{13}$ The data for the small air-handling unit (AHU) w/ wheel was used.
} 
mass of the air handler in Nyman (2004) - $691 \mathrm{~kg}(1523 \mathrm{lb})$ - was scaled down to the mass of the $58.5 \mathrm{~kg}$ (129 lb) Aaon unit, and data are as follows in Table 4-35:

Table 4-35 F1 Air Handler Bill of Materials

\begin{tabular}{lccrl}
\multicolumn{1}{c}{ Material Breakdown } & Kg & Lb & \multicolumn{1}{c}{$\%$} & Notes \\
Sheet metal and cast iron & 47.8 & 105.3 & $81.6 \%$ & Assume $75 \%$ is galv. \\
Mineral wool & 4.9 & 10.8 & $8.4 \%$ & steel, 25\% cast iron \\
Fiberglass & 0.5 & 1.1 & $0.9 \%$ & \\
Copper & 1.3 & 2.8 & $2.2 \%$ & \\
Aluminum & 4.0 & 8.8 & $6.8 \%$ & \\
Natural rubber & 0.1 & 0.1 & $0.1 \%$ & \\
Total --> & $\mathbf{5 8 . 5}$ & $\mathbf{1 2 9 . 0}$ & $\mathbf{1 0 0} \%$ & \\
& & & &
\end{tabular}

The galvanized steel comes from World Steel Association (2011). Aluminum is modeled as a 50/50 mix of primary and secondary extruded aluminum which come from the U.S. LCI Database. Data for copper tube comes from ICA (2012). Ecoinvent provided the data for the cast iron, glass fiber, mineral wool (as rock wool), and rubber.

No manufacturing data were available for the air handler, so as proxy, an ecoinvent data set for a $10 \mathrm{~kW}$ (34 MBH) oil boiler was used - see discussion above Table 4-35. Since manufacturing/assembling the smaller air handler is assumed to require less energy and resources than the $150 \mathrm{~kg}(331 \mathrm{lb})$ boiler, these data were scaled down on a mass basis.

For the condensing unit, the bill of materials for the residential air conditioner was used. Table 4-32 provides a detailed breakdown of components and materials for a 3-ton, 10 SEER condensing unit (De Kleine, 2009). The data in the table were increased by the 1.98 factor given in Table 4-33, to be more in line with the Aaon condensing unit, whose mass $(107.5 \mathrm{~kg}(237 \mathrm{lb})$ ) corresponds almost perfectly with the data in Table 4-33. It should be noted that the Aaon unit provides an air conditioning rating of up to 17.3 SEER, not the SEER 18 in the table (Aaon 2016). Per an Aaon sales representative, ${ }^{14}$ the system is charged with $5.5 \mathrm{~kg}(12.1 \mathrm{lb}) \mathrm{R}-410 \mathrm{a}$ refrigerant. Data sources for all the materials in the condenser are given below Table 4-34.

As mentioned earlier in this documentation, no manufacturing data were available for residential air conditioners. However, the modeling of the materials in the equipment includes processing these materials into usable parts, i.e., tubing, wire, and sheet metal. While this does not include processes like punching, shearing, forming parts and general final assembly-related processing, it likely accounts for most environmental impacts. This unknown quantity is difficult to quantify without understanding the processes at this product's final manufacturing/assembly plant.

\footnotetext{
${ }^{14}$ Phone correspondence with Aaon in June, 2014.
} 


\subsection{Transportation to the Building Site through End of Life}

Transportation of the equipment to the building site is modeled using an assumed average of $2414 \mathrm{~km}$ (1500 mi) by heavy-duty diesel fuel-powered truck.

The air handler uses a $50.8 \times 50.8 \times 2.54 \mathrm{~cm}(20 \times 20 \times 1 \mathrm{in})$ air filter that should be checked every 30 days and replaced or cleaned as necessary. Permanent type filters may be vacuumed and/or washed, and reinstalled when thoroughly dry. BIRDS includes a disposable air filter. An Aaon salesperson said that no specific filter is required and that it can be purchased locally. The filter that has been modeled for this system is a minimum efficiency reporting value (MERV) 11 filter, described in Table 4-39 and adjusted to 50.8 x $50.8 \mathrm{~cm}(20 \times 20$ in).

Maintenance includes a qualified service technician coming to the building site to check and service the unit every three years to ensure optimal performance and lifetime. It is assumed that the technician is within a $24 \mathrm{~km}(15 \mathrm{mi})$ service radius. This distance is driven in a gasoline-powered van and is shared amongst other service visits for that technician, if the same technician is making more than one service call during that trip. Assuming the technician makes 5 service calls in one day, one-fifth of the impacts from driving $24 \mathrm{~km}(15 \mathrm{mi})$ are allocated to the product, or $4.8 \mathrm{~km}(3 \mathrm{mi})$. Data for a van come from ecoinvent. Unplanned service visits (i.e., unanticipated issues that require a service technician) are not included in the model under the assumption that the system will run as designed given the homeowner adequately follows the maintenance and care guidelines.

Per Aaon, ${ }^{15}$ the air handler has a lifetime of $15 \mathrm{yrs}$ and the condensing unit has a lifetime of 16 yrs. These stated lifetimes are consistent with those listed in NAHB (2007) for those items. During use, refrigerant is assumed to escape at a rate of $2 \%$ per year. (De Kleine, 2009, Sec. 3.3). It is modeled as recharged every three years during the maintenance visit.

At the end of their life, it is assumed that the equipment is sent for recycling to recover valuable metal (see windows end-of-life in Section 4.5.3.7 for the recycling methodology used). What cannot be recovered is modeled as landfilled. A distance of $48 \mathrm{~km}$ (30 mi) to the landfill in a heavy-duty diesel truck has been modeled. The landfill is based on ecoinvent waste management process data. A study prepared for Air-Conditioning, Heating, and Refrigeration Technology Institute (AHRTI, 2011) assumes an overall loss of $15 \%$ of the R-410a refrigerant after decommissioning. This is based on "recovering 90 $\%$ of the charge from $95 \%$ of the field units, but allowing for a $100 \%$ charge loss from about $5 \%$ of the field stock". (AHRTI, 2011, p.12)

\subsubsection{Heat Recovery Ventilator}

One of the featured technologies in the Net-Zero Energy Residential Test Facility (NZERTF) is a heat recovery ventilator (HRV). An HRV moves stale, contaminated air outside while bringing in fresh air, all the while extracting the hot energy from the indoor

\footnotetext{
${ }^{15}$ Phone correspondence with Aaon in June, 2014.
} 
air and transferring it to the incoming air, so that there is little energy lost. HRV systems are especially important in newer, tightly sealed homes that do not have as much natural ventilation. The HRV unit modeled for the NZERTF and BIRDS is the Venmar EKO 1.5 HRV, a high-efficiency model that, per Venmar, uses high performance motors which enable it to significantly lower energy costs without affecting performance. The heat recovery core can retain up to $80 \%$ of a home's heating or cooling. ${ }^{16}$

In 2013, Venmar contributed data to BIRDS on the EKO 1.5 HRV, model 43900, to be used in the calculations in NZERTF and BIRDS. One HRV is evaluated in this system.

\subsection{Raw Material Production}

Venmar provided the detailed bill of parts and materials in the HRV system. The list of parts has been removed from this documentation to protect the proprietary nature of the data. Instead, the $22.6 \mathrm{~kg}(49.8 \mathrm{lb})$ unit's parts have been grouped in terms of likematerials, as presented in Table 4-36.

\section{Table 4-36 Venmar EKO 1.5 Bill of Materials}

$\begin{array}{lc}\text { Material } & \text { Percent in Product } \\ \text { Prepainted steel } & 41.3 \% \\ \text { Polypropylene (PP) } & 15.8 \% \\ \text { Motor: steel, alum, copper } & 12.0 \% \\ \text { Galvanized steel } & 8.1 \% \\ \text { Expanded polystyrene (EPS) foam } & 5.9 \% \\ \text { Aluminum } & 3.5 \% \\ \text { Steel, copper wire, leadwire } & 4.7 \% \\ \text { Polyvinyl chloride (PVC) } & 2.0 \% \\ \text { Acrylonitrile-butadiene-styrene copolymer (ABS) } & 1.7 \% \\ \text { Additional materials } & 5.0 \% \\ \text { Total } & \mathbf{1 0 0 \%}\end{array}$

Over $99 \%$ of the reported materials were included in the model. Data for prepainted steel comes from the World Steel (2011) dataset for Finished Cold Rolled Coil (FCRC). Per Venmar, the motor is made up of approximately $45 \%$ steel, $45 \%$ aluminum, and $10 \%$ copper. The steel is based on World Steel (2011) LCI data on finished cold rolled steel (FCRC). The aluminum used in the motor and other parts of the unit is extruded aluminum, using a mix of secondary and primary aluminum, and this data comes from the U.S. LCI Database. The copper sheet data comes from ICA (2012). World Steel's (2011) data on hot-dip galvanized (HDG) steel is used for the galvanized steel.

The EPS is used as insulation within the unit. Foam production data come from ecoinvent. While the foam data is European-based, the polystyrene (PS) resin within the dataset was switched out with the U.S. LCI dataset for PS resin production. The resins of

\footnotetext{
${ }^{16}$ Description of performance retrieved at: http://www.venmar.ca/110-air-exchangers-eko-1-5hrv.html\#!prettyPhoto
} 
Polypropylene (PP), Polyvinyl chloride (PVC), and Acrylonitrile-butadiene-styrene copolymer (ABS) come from the U.S. LCI Database.

Leadwire is tinned copper with PVC insulation. Copper wire (ICA (2012)) is assumed to make up $40 \%$ by mass, with the other $60 \%$ being the PVC.

Additional materials in the unit include: NBR foam (data for acrylonitrile and polymer foaming from ecoinvent); some electrical parts (from ecoinvent); high impact polystyrene (U.S. LCI Database), EPDM (modeled as synthetic rubber, from ecoinvent), and silicone sealant (based on data from ecoinvent).

The packaging, an additional $3.9 \mathrm{~kg}(8.7 \mathrm{lb})$, includes corrugated cardboard and cardboard ( $89 \%$ of packaging), EPS foam (10\%), and less than $1 \%$ each of steel, PVC, and low-density polyethylene (LDPE). The cardboard production data come from ecoinvent. The steel, PVC, and LDPE were not included in the model since, overall, they amounted to less than $0.01 \%$ of the total mass.

Transport distances and modes of transportation of the parts to Venmar's Drummondville, Quebec, facility were provided by Venmar. Most of the main suppliers are local, thus most the parts were reported to be within $100 \mathrm{~km}(62 \mathrm{mi})$. The parts within North America are modeled as transported by heavy-duty (combination) diesel-fueled truck. The few parts that come from Asia or Europe are modeled as transported by ocean freighter and heavy-duty truck. Data for the combination truck and ocean freighter come from the U.S. LCI database.

\subsection{Manufacturing}

Venmar's Drummondville, Quebec, facility produces HRVs and Energy Recovery Ventilators (ERVs) delivering airflow from $0.019 \mathrm{~m}^{3} / \mathrm{s}$ to $0.142 \mathrm{~m}^{3} / \mathrm{s}$ ( 40 cubic feet per minute (CFM) to $300 \mathrm{CFM}$ ). The Venmar facility is primarily an assembly plant: flat prepainted or galvanized steel sheet is transformed using an automated punching machine and hydraulic press brakes. Wiring in the units is connected. Most of the labor is manual assembly of components using either screw (pneumatic screwdrivers) or silicone for sealing parts. The facility is a "dry" assembly line. Thus, no water is used, nor is any solvent except for cleaning the working area and when a part or unit needs cleaning. Energy was reported on a full facility basis and has been normalized on a per-unit basis, as follows in Table 4-37:

\section{Table 4-37 HRV Production Energy Requirements}

\begin{tabular}{lll}
$\begin{array}{l}\text { Energy Source } \\
\text { Electricity } \\
\text { (hydroelectricity) }\end{array}$ & $\begin{array}{c}\text { Quantity } \\
8.7 \mathrm{kWh}\end{array}$ & $\begin{array}{l}\text { Notes } \\
\text { Lighting, hand tools, compressor, press brake and } \\
\text { automated punching machine, cooling and } \\
\text { computers. }\end{array}$ \\
Natural gas & $0.0278 \mathrm{MMbtu}$ & Heating \\
\hline
\end{tabular}


Data for the energy come from the U.S. LCI database. While solvent is used to clean areas or parts, its use, and any VOCs from this cleaning, are considered negligible and not included in the model. No waste or air emissions were reported.

\subsection{Transportation to the Building Site through End of Life}

For BIRDS, which accounts for transport to customers throughout North America, a transportation distance of the unit to installation was modeled as $2414 \mathrm{~km}$ (1 $500 \mathrm{mi}$ ). Transportation is done by heavy-duty (combination) diesel-fueled truck, and these data come from the U.S. LCI Database. Modeling the customer driving to a store to purchase and bring the unit home is not included for the first purchase, with the assumption that this unit is installed when the home is built, so the unit is delivered by the builder (in a truck or van).

For maintenance, HRVs should undergo simple maintenance procedures, including cleaning the unit and filters, about every six months. This can be done by the homeowner.

The lifetime is expected to be 20 or more years, based on the stated lifetime of an HRV in NAHB (2007), Table 1, Sec. 15. At the end of life, it is assumed that the HRV is sent for recycling to recover valuable metal (see windows end of life in Section 4.5.3.7 for the recycling methodology used). The non-metal parts are modeled as landfilled. A distance of $48 \mathrm{~km}(30 \mathrm{mi})$ to the landfill in a heavy-duty diesel truck has been modeled. The landfill is based on ecoinvent waste management process data.

\subsubsection{Whole House Dehumidifier}

One of the energy technologies employed by the Net-Zero Energy Residential Test Facility (NZERTF) is a whole-house ventilating dehumidifier. Data for the Ultra-Aire Whole-House Ventilating Dehumidifier (model $70 \mathrm{H}$ ) was used in the calculations in NZERTF and BIRDS. With a capacity of 70 pints/day, the Ultra-Aire $70 \mathrm{H}$ is designed to provide moisture control and air filtration for an area of up to $1800 \mathrm{sq}$. $\mathrm{ft}$. It has a MERV rating of 11. Ultra-Aire contributed the data on the $70 \mathrm{H}$; one dehumidifier is evaluated in this system.

\subsection{Upstream Material Production}

Ultra-Aire provided the material composition of the dehumidifier in terms of percentage of materials, along with functions and/or parts of the main components. These data were used to construct a bill of materials, shown in Table 4-38. 
Table 4-38 Ultra-Aire 70H Whole-House Ventilating Dehumidifier Bill of Materials

\begin{tabular}{lccl} 
& \multicolumn{2}{c}{ Mass } & \\
Material & Lb & Kg & Notes \\
Steel & 37.7 & 17.1 & Housing, motors, and fasteners. \\
Copper & 7.7 & 3.5 & Refrigerant tubing, motor windings, wiring \\
High density & & & \\
polyethylene (HDPE) & 1.65 & 0.75 & Drain pan (assumed HDPE). \\
Polyvinyl Chloride & & & \\
(PVC) & 1.1 & 0.5 & Electrical components, duct collars \\
Rubber & 1.1 & 0.5 & Seals and trim. \\
Foam insulation & 1.65 & 0.75 & Assumed expanded polystyrene (EPS) foam \\
Aluminum & 2.75 & 1.25 & Heat exchanger fins \& plates \\
R410a refrigerant & 0.81 & 0.37 & Actual quantity reported to be in a new unit. \\
Compressor oil & 0.55 & 0.25 & \\
Total & $\mathbf{5 5 . 0 1}$ & $\mathbf{2 4 . 9 7}$ & \\
\hline
\end{tabular}

Data for steel come from World Steel Association (2011). Data for the copper tubing and copper wiring come from ICA (2012). The data for the HDPE and PVC come from the U.S. LCI Database. The rubber comes from the ecoinvent database, as does the "foaming" process for the EPS insulation. The U.S. LCI Database supplied the data for production of the PS resin in the EPS. Aluminum is modeled as a 50/50 mix of primary and secondary extruded aluminum and comes from the U.S. LCI Database. The compressor oil was modeled as lubricating oil, which comes from the U.S. LCI database.

The Ultra-Aire $70 \mathrm{H}$ uses $\mathrm{R} 410 \mathrm{a}$ in its refrigeration system to remove heat and moisture from incoming air and add heat to the air that is discharged. The R410a data is discussed in text following Table 4-34.

The transportation distance of components to the assembly plant in Madison, WI was assumed to be on average $805 \mathrm{~km}(500 \mathrm{mi})$, assuming some of the larger parts are relatively local and smaller parts may be transported greater distances. Transport is modeled as heavy-duty (combination) diesel-fueled truck. Data for the combination truck come from the U.S. LCI Database.

\subsection{Manufacturing}

Components, materials, and sub-assemblies are shipped to Ultra-Aire's Madison, WI, facility. The dehumidifier is assembled in batches on an assembly line in the plant dedicated to the product platform. The product is primarily assembled by hand with a few assembly stations utilizing automation. The finished product is held in and shipped from Ultra-Aire's distribution center that adjoins the plant. It is assumed that some electricity is used and that there are probably some ancillary materials, such as solvents or degreasers for cleaning the working area or perhaps parts or units. No manufacturing data were provided for this equipment but proxy data on electricity use for assembly of a similar size of HVAC equipment was used. 


\subsection{Transportation to the Building Site through End of Life}

Transportation distance of the unit to installation was modeled as $1368 \mathrm{~km}$ (850 mi), based on Ultra-Aire's average shipping distance to customers in North America.

Transportation is modeled as heavy-duty diesel-fueled truck, and these data come from the U.S. LCI Database.

A lifetime of 19 years was modeled based on a recent analysis by the U.S. Department of Energy (DOE) that determined whole house dehumidifiers to have a 19-year life. (DOE, 2015, Table 8.2.25) This longer life finding is fairly consistent with Ultra-Aire whole house dehumidifiers; Ultra-Aire introduced this product line in 1996 and, anecdotally speaking, there are originals still in use.

The only maintenance that needs to be done is to regularly inspect it and clean or replace the air filter. Seasonal maintenance should include drain line inspection/cleaning. The unit uses a MERV-11 (or optionally MERV-14) filter, and it is recommended by the manufacturer that the filter be replaced every 3-6 months. The replacement of the MERV 11 filter every six months was included in the model, and included the homeowner trip to the store as well as the mass of the materials in the filter. The bill of materials of the MERV 11 filter was obtained by purchasing a MERV 11 media filter of size $22.9 \times 27.9$ $\mathrm{x} 2.54 \mathrm{~cm}(9 \times 11 \times 1 \mathrm{in})(\mathrm{P} / \mathrm{N} 4030671)$, then disassembling it and weighing the parts. The bill of materials was compiled as follows in Table 4-39:

\section{Table 4-39 MERV-11 Filter Bill of Materials}

\begin{tabular}{lccl}
\multicolumn{2}{c}{ Mass } & & \\
Part and/or Material & Lb & G & Notes \\
Plastic stretch wrap (packaging) & 0.002 & 1.0 & LDPE \\
Cardboard "frame" & 0.08 & 37.0 & Bleached \\
Rubber/plastic in the pleats & 0.12 & 55.0 & 11 rows, 5 g per row \\
Synthetic fiber & 0.075 & 34.0 & Assume PET \\
Total & $\mathbf{0 . 2 8}$ & $\mathbf{1 2 7}$ & \\
\hline
\end{tabular}

The data for the LDPE comes from the U.S. LCI Database, and ecoinvent provides the data for the cardboard. The plastic in the pleats is modeled as polypropylene. The synthetic fiber was modeled as a spun-bonded polyethylene terephthalate (PET). The PET comes from the U.S. LCI Database, and the data for the spunbonding process -0.76 $\mathrm{kWh}(2.73 \mathrm{MJ})$ per kg comes from EA (2011), Table 4.2. Filters are landfilled after they are replaced.

At the end of life of the dehumidifier, it is assumed that it is sent for recycling to recover valuable metal (see windows end of life in Section 4.5.3.7 for the recycling methodology used). The non-metal parts are modeled as landfilled. A distance of $48 \mathrm{~km}$ (30 mi) to the landfill in a heavy-duty diesel truck has been modeled. The landfill is based on ecoinvent waste management process data. The model assumes most of the refrigerant is recovered at end of life. This is supported by a study prepared for Air-Conditioning, Heating, and Refrigeration Technology Institute (AHRTI) that assumes an overall loss of $15 \%$ of the 
R-410a refrigerant (based on "recovering $90 \%$ of the charge from $95 \%$ of the field units, but allowing for a $100 \%$ charge loss from about $5 \%$ of the field stock"). (AHRTI, 2011, p.12)

\subsubsection{Residential Water Heaters}

\subsubsection{Conventional and Tankless Water Heaters}

Conventional electric and gas-powered water heaters with 189-liter (50-gal) storage tanks were included in BIRDS. A Rinnai R75LSi gas tankless water heater was evaluated for use in the Net-Zero Energy Residential Test Facility (NZERTF). Per Rinnai, the tankless unit uses "up to 40 percent less energy than a traditional tank." ${ }^{17}$

\subsection{Upstream Materials Production through Manufacturing}

No manufacturer-specific data was available, so publicly-available sources of data were used as proxy. A comprehensive study on the eco-design of water heaters (VHK, 2007) was consulted for the bill of materials data for the water heaters in BIRDS.

Electric water heater. Table B.9 in VHK (2007) provided bills of materials for several electric water heaters; the heater with 200 L (53 gal) storage tank was used, as its size is closest to the $189 \mathrm{~L}$ (50 gal) needed for BIRDS. Since the Material Groups listed in Table B.9 were general, these data were supplemented by more detailed parts and materials provided by Table B.10 in VHK (2007) to develop the data shown in Table 4-40. Any assumptions made are noted.

\section{Table 4-40 Electric Water Heater Bill of Materials}

\begin{tabular}{|c|c|c|c|}
\hline \multirow[b]{2}{*}{ B.9 Material Group } & \multicolumn{2}{|c|}{ Mass } & \multirow[b]{2}{*}{ Parts, Materials \& Assumptions } \\
\hline & kg & lb & \\
\hline 3-Ferro & 40.5 & 89.2 & $\begin{array}{l}\text { Tank, mounting plate, screws. Tank assumed to be } \\
\text { stainless steel }\end{array}$ \\
\hline 2-TecPlastics & 1.5 & 3.3 & $\begin{array}{l}\text { Rubber gasket (assume } 25 \% \text { ), PVC pipe protection and } \\
\text { pipe collar, PVC thermal control (assume } 75 \% \text { ) }\end{array}$ \\
\hline 1-BlkPlastics - & 1.2 & 2.7 & Assume EPS insulation \\
\hline 7-Misc & 1.2 & 2.7 & $\begin{array}{l}\text { Portion of the Misc. category; part unknown. Assuming } \\
\text { packaging, based on Table B.10. Not included in this } \\
\text { analysis. }\end{array}$ \\
\hline 7-Misc & 0.3 & 0.7 & Portion of the Misc. category; Assume resistance heater \\
\hline 5-Coating & 3.1 & 6.7 & Assume enamel \\
\hline 4-Non-ferro & 0.2 & 0.5 & Assume copper \\
\hline 6-Electronics & 0.06 & 0.1 & Assume wiring, thermal control \\
\hline TOTAL & 48.1 & 106.0 & \\
\hline
\end{tabular}

\footnotetext{
${ }^{17}$ Rinnai product information retrieved from https://www.rinnai.us/tankless-water-heater. This was based on the average cost to run an electric tank water heater per the Department of Energy Average Energy Costs (www.doe.gov).
} 
Gas water heater. Bill of materials for the gas water heater and its storage tank shown in Table 4-41 are based on Table B.8 in VHK (2007), which contains materials for a generic water storage tank and the natural gas component of a water heater. Since a $189 \mathrm{~L}$ (50 gal) storage tank was not offered by VHK (2007), the data for the $150 \mathrm{~L}$ (39.6 gal) tank was scaled down on a mass basis. The data for the gas heating/storage component was left the same.

\section{Table 4-41 Gas Water Heater Bill of Materials}

\begin{tabular}{lccl} 
Parts & \multicolumn{2}{c}{ Mass } & Materials \\
Generic tank & kg & $\mathbf{~ b ~}$ & \\
Tank & 26.0 & 57.3 & Galvanized steel \\
Enamel & 4.7 & 10.3 & Enamel \\
Insulation & 9.1 & 20.0 & Rigid PUR foam \\
Mantle & 11.7 & 25.9 & Galvanized steel \\
Top/bottom & 0.3 & 0.6 & Polypropylene \\
Diptube & 2.1 & 4.7 & Galvanized steel \\
Fitting & 1.3 & 2.8 & Brass \\
Mounting & 0.6 & 1.4 & Galvanized steel \\
Subtotal & 55.8 & 122.9 & \\
Gas storage component & & & \\
Burner & 1.5 & 3.3 & Galvanized steel \\
H Ex & 3.5 & 7.7 & Galvanized steel \\
Flue parts & 2.7 & 6.0 & Galvanized steel \\
Gas valve & 1.4 & 3.1 & Aluminum diecast \\
Brass parts & 1.0 & 2.2 & Brass \\
Various steel parts & 41.0 & 90.4 & Galvanized steel \\
Subtotal & 51.1 & 112.7 & \\
Total & $\mathbf{1 0 6 . 9}$ & $\mathbf{2 3 5 . 6}$ & \\
\hline
\end{tabular}

Tankless water heater. Bill of materials for the $22.7 \mathrm{~kg}(50 \mathrm{lb})$ Rinnai R75LSi unit shown in Table 4-42 are derived from VHK (2007) Table B.6, which contains materials for instantaneous gas water heaters of varying power and weights. The basis for these data is the $20 \mathrm{~kW}$ gas-fired low temperature boiler evaluated in earlier VHK work on Methodology for the Ecodesign of Energy-using Products (MEEuP), corrected for typical product weights of gas instantaneous water heaters. ${ }^{18}$

\footnotetext{
${ }^{18}$ See VHK (2007) for more information.
} 
Table 4-42 Tankless Water Heater Bill of Materials

\begin{tabular}{lccc} 
Material & $\mathbf{k g}$ & $\mathbf{l b}$ & $\mathbf{\%}$ \\
Galvanized steel & 13.96 & 30.78 & $61.6 \%$ \\
Copper tube, sheet & 2.16 & 4.77 & $9.5 \%$ \\
ABS & 1.84 & 4.06 & $8.1 \%$ \\
Stainless steel, 18/8 coil & 1.36 & 2.99 & $6.0 \%$ \\
Die cast aluminum & 0.99 & 2.18 & $4.4 \%$ \\
Brass, CuZn38 cast & 0.83 & 1.83 & $3.7 \%$ \\
Cast Iron & 0.60 & 1.32 & $2.6 \%$ \\
Insulation ceramic, ferrite & 0.41 & 0.91 & $1.8 \%$ \\
Electronics, controller board & 0.35 & 0.76 & $1.5 \%$ \\
Others, not specified & 0.18 & 0.41 & $0.8 \%$ \\
Total & $\mathbf{2 2 . 6 8}$ & $\mathbf{5 0 . 0 0}$ & $\mathbf{1 0 0 . 0}$ \\
\hline
\end{tabular}

All steel and galvanized steel data come from World Steel Association (2011). Aluminum is modeled as a 50/50 mix of primary and secondary extruded aluminum which come from the U.S. LCI Database. Data for copper tube, sheet and wire come from ICA (2012). U.S. LCI Database provided the production data for ABS, PVC and PP. Ecoinvent provided the data for the stainless steel, brass, rubber (as synthetic rubber), EPS, PUR foam, enamel, and electronics. The unspecified "other" materials in the tankless water heater data amount to less than one percent; no assumptions were made as to the materials, so this mass was not accounted for in the model.

Raw materials are modeled as transported to the manufacturing plant via diesel truck an assumed average distance of $805 \mathrm{~km}$ (500 mi). Data come from the U.S. LCI Database.

No manufacturing data were available for residential water heaters, so as proxy, the ecoinvent data set for a $10 \mathrm{~kW}(34 \mathrm{MBH})$ oil boiler was used - see discussion above Table 4-31. Since manufacturing the smaller units is assumed to require less energy and resources than the $150 \mathrm{~kg}(331 \mathrm{lb})$ boiler, these data were scaled down based on the total weights of the water heaters.

\subsection{Transportation to the Building Site through End-of-Life}

Transportation of the water heaters to the building site is modeled using an assumed average of $644 \mathrm{~km}$ (400 mi) by heavy-duty diesel fuel-powered truck. The Rinnai tankless unit is modeled as transported $2414 \mathrm{~km}$ (1500 mi) by heavy-duty diesel fuelpowered truck. The difference is that the Rinnai unit is manufacture-specific so comes from one location, while the other water heaters are modeled as generic so are manufactured in many locations around the U.S., reducing the overall distance transported.

It is assumed that a qualified service technician comes to the building site to check and service the units every three years to ensure optimal performance and lifetime. It is assumed that the technician is within a $24 \mathrm{~km}$ (15 mi) service radius. This distance, driven in a gasoline-powered van, is shared amongst other service visits for that 
technician, assuming that the same technician is making more than one service call during that trip. Assuming the technician makes 5 service calls in one day, one-fifth of the impacts from driving $24 \mathrm{~km}(15 \mathrm{mi})$ are allocated to the product, or $4.8 \mathrm{~km}(3 \mathrm{mi})$. Data for a van come from ecoinvent. Unplanned service visits (i.e., unanticipated issues that require a service technician) are not included in the model under the assumption that the system will run as designed given the homeowner adequately follows the maintenance and care guidelines.

Lifetimes of 11 and 10 years have been assumed for the electric and gas-fired water heaters, respectively. (NAHB, 2007 Table 1, Section 1) The lifetime of the tankless water heater is modeled as 20 years. (NAHB, 2007, Table 1, Section 15) At the end-of-life, it is assumed that the water heaters are sent for recycling to recover valuable metal (see Section 4.5.3.7 for the recycling methodology used). What cannot be recovered is modeled as landfilled. A distance of $48 \mathrm{~km}(30 \mathrm{mi})$ to the landfill in a heavy-duty diesel truck has been modeled. The landfill is based on ecoinvent waste management process data.

\subsubsection{Heat Pump Water Heater}

The Net-Zero Energy Residential Test Facility (NZERTF) is equipped with a Rheem hybrid water heater. The water heater uses air source heat pump technology, extracting heat from warm air, intensifying the heat with a compressor, delivering the heat to the water, and exhausting the cooler air. It is an efficient way to heat water because it uses ambient air temperature to do much of the work. Manufacturer-specific data was not available, so publicly-available sources of data were used as proxy and customized wherever possible using product specifications. One heat pump water heater is evaluated in this system.

\subsection{Upstream Materials Production through Manufacturing}

A combination of electric water heater and air conditioner data from BIRDS was used. Adjustments were made to the bills of materials based on Rheem literature, including the addition of refrigerant, switching insulation quantities, and scaling the unit weights to the Rheem unit.

Rheem did not provide specific weight data for its hybrid heat pump water heater, so the weight was estimated based on information on other Rheem products. The heat pump water heater weight was assumed to be the same as a Rheem 50 gallon water heater; the heat pump part of the unit was calculated to be: total heat pump tank weight minus the electric water heater weight, as shown in Table 4-43: 
Table 4-43 Heat Pump Water Heater Weight Estimation

\begin{tabular}{|c|c|c|c|}
\hline Unit & kg & Lb & Notes \\
\hline Rheem Model HP50ES 50 gallon heat pump tank & 89.3 & 197.0 & \\
\hline $\begin{array}{l}\text { Rheem model RHE PRO52-2 } 50 \text { gallon electric } \\
\text { tank }\end{array}$ & 41.2 & 90.8 & $\begin{array}{l}\text { Shipping weight only was given, so } \\
\text { this represents a portion of the total. }\end{array}$ \\
\hline Assumed weight of heat pump part of unit & 48.2 & 106.2 & \\
\hline Assumed weight of hot water tank & 41.2 & 90.8 & $\begin{array}{l}\text { Assumed to be same weight as the } \\
\text { Rheem RHE PRO52-2 }\end{array}$ \\
\hline
\end{tabular}

The bills of materials are described in terms of the individual components. Data for the Rheem hot water tank portion was based on VHK (2007) Table B.9 electric water heater data. Data for the $200 \mathrm{~L}$ (53 gal) storage tank was used as its size closely aligns with the Rheem's 189 L (50 gal) capacity. As was done for the generic water heater chapter earlier in this document, the data were supplemented by more detailed parts and materials provided by VHK (2007) Table B.10 materials' quantities, especially those over $1 \%$ weight by mass, have been adjusted to meet the weight of the Rheem unit. Any assumptions made are noted in Table 4-44.

\section{Table 4-44 Rheem Hot Water Tank Portion Bill of Materials}

\begin{tabular}{|c|c|c|c|}
\hline \multicolumn{3}{|c|}{ Mass } & \multirow[b]{2}{*}{ Parts, Materials \& Assumptions } \\
\hline B.9 Material Group & Kg & $\mathbf{L b}$ & \\
\hline 3-Ferro & 35.36 & 77.96 & $\begin{array}{l}\text { Tank, mounting plate, screws. Tank assumed to be } \\
\text { stainless steel }\end{array}$ \\
\hline 2-TecPlastics & 0.32 & 0.71 & Rubber gasket \\
\hline 2-TecPlastics & 1.02 & 2.25 & $\begin{array}{l}\text { PVC pipe protection and pipe collar, PVC thermal control } \\
\text { Previously EPS insul. This tank insulated with } 21 / 2 "\end{array}$ \\
\hline $\begin{array}{l}\text { 1-BlkPlastics - } \\
\text { Insulation }\end{array}$ & 1.21 & 2.68 & $\begin{array}{l}\text { polyol-based non-CVC foam insulation. }{ }^{19} \text { Polyol modeled } \\
\text { as PUR rigid foam insulation (density } 36.8 \mathrm{~kg} / \mathrm{m} 3 \text { ). }\end{array}$ \\
\hline 7-Misc & 0.30 & 0.66 & Portion of the Misc. category; Assume resistance heater \\
\hline 5-Coating & 2.67 & 5.89 & Assume enamel \\
\hline 4-Non-ferro & 0.24 & 0.54 & Assume copper \\
\hline 6-Electronics & 0.06 & 0.13 & Assume copper wiring, thermal control \\
\hline TOTAL --> & 41.20 & 90.82 & \\
\hline
\end{tabular}

Data for the Rheem heat pump portion was based on the bill of materials for the condensing unit described in the air conditioner subchapter of this report (Section Error! Reference source not found.). The unit is based on a tear-down of a 3-ton, 10 SEER unit. The quantities of materials have been scaled down to the weight of the Rheem unit, and some materials have been added, under Notes in Table 4-45.

\footnotetext{
${ }^{19}$ Based on communications with a Rheem technical support person via phone.
} 
Table 4-45 Rheem Heat Pump Portion Bill of Materials

\begin{tabular}{|c|c|c|c|c|}
\hline \multicolumn{5}{|c|}{ Mass } \\
\hline Main Component & Material Breakdown & Kg & Lb & Notes \\
\hline \multirow[t]{4}{*}{ Compressor } & Aluminum & 0.45 & 0.99 & \multirow{4}{*}{$\begin{array}{l}\text { Compressor breakdown from Biswas (2011) } \\
\text { Fig } 1 .\end{array}$} \\
\hline & Cast iron & 21.20 & 46.73 & \\
\hline & Copper & 1.13 & 2.49 & \\
\hline & Steel & 2.33 & 5.14 & \\
\hline \multirow[t]{2}{*}{ Coil Assembly } & Copper (tubing) & 3.38 & 7.46 & \multirow{2}{*}{$\begin{array}{l}\text { Approx } 50 \% \text { copper tubing, } 50 \% \text { aluminum } \\
\text { fins. (De Kleine, 2009, Sec. } 3.1 .4 \text { ) }\end{array}$} \\
\hline & Aluminum (fins) & 3.38 & 7.46 & \\
\hline \multirow[t]{3}{*}{ Fan Motor } & Copper wire & 0.92 & 2.03 & \multirow{3}{*}{$\begin{array}{l}\text { Assumed to have a composition of } 25 \% \text { copper } \\
\text { wire, } 72 \% \text { steel, and } 3 \% \text { polyamide (De } \\
\text { Kleine, 2009, Sec. 3.1.4) }\end{array}$} \\
\hline & Steel & 2.65 & 5.85 & \\
\hline & Polyamide & 0.11 & 0.24 & \\
\hline Unit Wall & Galvanized steel & 2.66 & 5.86 & \\
\hline Base & Galvanized steel & 2.31 & 5.10 & \\
\hline Top Cover & Galvanized steel & 1.63 & 3.59 & \\
\hline Fan Guard & Stainless steel & 1.60 & 3.53 & \\
\hline \multirow{2}{*}{$\begin{array}{l}\text { Refrigerant Line } \\
\text { service valve }\end{array}$} & Brass (service valves) & 0.75 & 1.65 & \\
\hline & Rubber & 0.25 & 0.55 & \\
\hline Wire Guard & Stainless steel & 0.80 & 1.76 & \\
\hline Fan Blade & Steel & 0.60 & 1.32 & \\
\hline Misc Fasteners & Steel & 0.30 & 0.66 & \\
\hline Capacitor & Sheet metal (steel) & 0.30 & 0.66 & \\
\hline \multirow[t]{2}{*}{ Relay Switch } & Copper wiring & 0.10 & 0.22 & \multirow{2}{*}{$\begin{array}{l}\text { Assumed to be } 50 \% \text { copper wiring and } 50 \% \\
\text { nylon polymer (De Kleine, 2009, Sec. } 3.1 .4 \text { ) }\end{array}$} \\
\hline & Nylon polymer & 0.10 & 0.22 & \\
\hline Copper Wiring & Copper wire & 0.20 & 0.44 & \\
\hline Refrigerant & $\mathrm{R} 410 \mathrm{~A}$ & 0.68 & 1.49 & Added here. Data from Rheem tech support \\
\hline Powder coating & steel powder coating & 0.35 & 0.77 & $\begin{array}{l}\text { Added here based on assumption that the basic } \\
\text { volume of the appliance is powder coated. } \\
\text { Assumes } 0.095 \mathrm{~kg} / \mathrm{m} 2 \text {, per Ecoinvent powder } \\
\text { coating process. }\end{array}$ \\
\hline Total & & 48.18 & 106.23 & \\
\hline
\end{tabular}

The steel, assumed to be cold-rolled, and the galvanized steel come from World Steel Association (2011). Aluminum is modeled as a 50/50 mix of primary and secondary extruded aluminum which come from the U.S. LCI Database. Data for copper tube, sheet, and wire come from ICA (2012). U.S. LCI Database provided the production data for PVC and PP. Ecoinvent provided the data for the cast iron, stainless steel, brass, rubber (as synthetic rubber), polyamide, enamel, and powder coating. The R410a data is discussed in text following Table 4-34.

Raw materials are modeled as transported to the manufacturing plant via diesel truck an assumed average distance of $805 \mathrm{~km}$ (500 mi).

No manufacturing data were available for this unit, so as proxy, the ecoinvent data set for a $10 \mathrm{~kW}$ (34 MBH) oil boiler was used - see discussion above Table 4-31. Since 
manufacturing the smaller units is assumed to require less energy and resources than the $150 \mathrm{~kg}(331 \mathrm{lb})$ boiler, these data were scaled down based on the total weight of the Rheem water heater.

\subsection{Transportation to the Building Site through End-of-Life}

Transportation to the building site is modeled using an assumed average of $2414 \mathrm{~km} \mathrm{(1}$ $500 \mathrm{mi}$ ) by heavy-duty diesel fuel-powered truck, assuming that one Rheem facility is manufacturing / assembling this particular unit.

Per a wholesaler of Rheem appliances, the water heater should be inspected for damaged components at least annually by a qualified service technician. ${ }^{20}$ Thus, a qualified service technician is assumed to come to the home annually to ensure optimal performance and lifetime. It is assumed that the technician is within a $24 \mathrm{~km}(15 \mathrm{mi})$ service radius. This distance, driven in a gasoline-powered van, is shared amongst other service visits for that technician, if the same technician is making more than one service call during that trip. Assuming the technician makes 5 service calls in one day, one-fifth of the impacts from driving $24 \mathrm{~km}(15 \mathrm{mi})$ are allocated to the product, or $4.8 \mathrm{~km}(3 \mathrm{mi})$. Data for a van come from ecoinvent. Unplanned service visits (i.e., unanticipated issues that require a service technician) are not included in the model under the assumption that the system will run as designed given the homeowner adequately follows the maintenance and care guidelines.

Given that the unit comes sealed and pre-charged with refrigerant, it is assumed that there are no refrigerant leaks during the life of the unit.

A lifetime of 15 years has been assumed for the Rheem unit, accounting for a 16-yr lifetime of a heat pump and relatively shorter lifetime of an electric water heater (11 yrs). (NAHB, 2007, Table 1, Section 1) At the end of life, it is assumed that the unit is sent for recycling to recover valuable metal (see Section 4.5.3.7 for the recycling methodology used). What cannot be recovered is modeled as landfilled. Given its small charge, it is assumed that the refrigerant is not recovered at end of life. A distance of $48 \mathrm{~km}(30 \mathrm{mi})$ to the landfill in a heavy-duty diesel truck has been modeled. The landfill is based on ecoinvent waste management process data.

\subsubsection{Lighting}

Three lighting alternatives were included in BIRDS: incandescent, compact fluorescent lamp (CFL), and light-emitting diode (LED). These were calculated on a per one $\mathrm{W} / \mathrm{h}$ basis so that BIRDS could calculate the energy needed for lighting based on time used. Figure 4-10 presents the lighting system boundaries for a CFL example.

\footnotetext{
${ }^{20}$ Email communication with Justin U, Gensco wholesaler of HVAC products in the western US, 24 January 2013.
} 


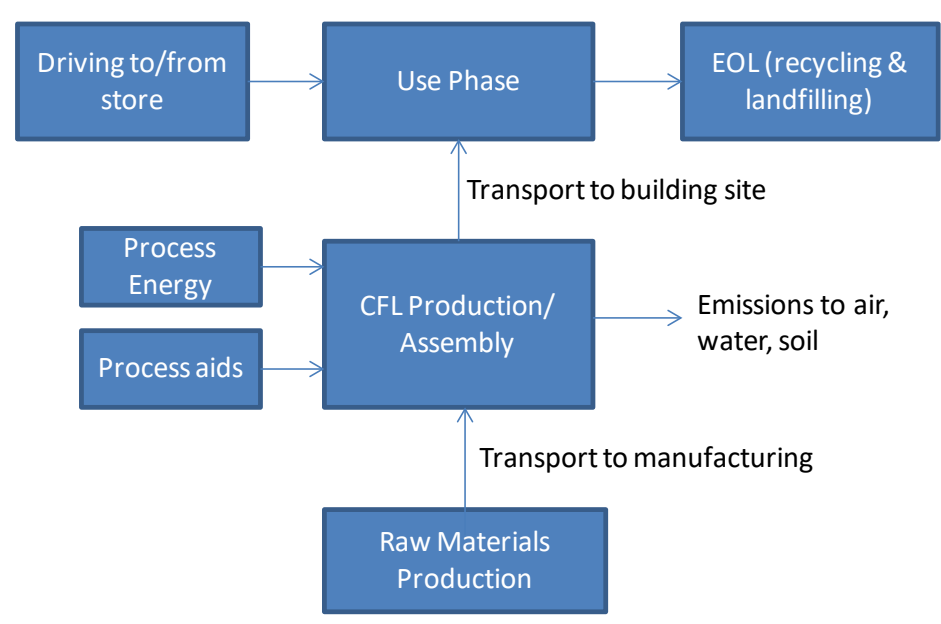

Figure 4-10 Lighting System Boundaries - CFL Example

In order to model the lighting alternatives on the basis of functional equivalency, the model must account for an equivalent or comparable lumen output, i.e., measure of brightness. The lighting characteristics from Energy Efficiency and Renewable Energy (EERE) (2012) were used to define the BIRDS' lighting systems' functional equivalency. Table 4.1 in Energy Efficiency and Renewable Energy (EERE) (2012), reproduced in part in Table 4-46, summarizes the average characteristics of the lamps analyzed within existing lighting LCA literature (at the time) in terms of lumen output, wattage, and lifetime. For the continuously-improving LED technology, a lumen output available in 2011 was used, which was higher than lumens from earlier studies.

Table 4-46 Performance of Lighting Technologies in BIRDS

\begin{tabular}{lcccc} 
Lamp Type & Watts & Lumens & $\begin{array}{c}\text { Operating } \\
\text { Lifetime (hr) }\end{array}$ & $\begin{array}{c}\text { Number of Equiv. } \\
\text { Systems }\end{array}$ \\
\hline Incandescent & 60 & 900 & 1000 & 25 \\
CFL & 15 & 900 & 8500 & 2.9 \\
LED (2011) & 12.5 & 800 & 25000 & 1 \\
\hline
\end{tabular}

\subsubsection{Upstream Materials Production through Manufacturing}

The bills of materials for all three alternatives come from U.K. Department for Environment (2009). These bills of materials are based on Ramroth (2008) but with more detail/aggregation provided.

\subsection{Incandescent}

The bill of materials shown in Table 4-47 is based on a $100 \mathrm{~W}$ (soft white) incandescent bulb manufactured by General Electric. Other sources provided data available for $60 \mathrm{~W}$ 
incandescent bulbs ${ }^{21}$, but Table B-12 of U.K. Department for Environment (2009) was used since its data is based on a detailed tear-down for a widely available product.

Furthermore, when factoring in use phase energy, the BOM differences between $60 \mathrm{~W}$ and $100 \mathrm{~W}$ are negligible.

Table 4-47 Incandescent Light Bulb Bill of Materials

\begin{tabular}{|c|c|c|c|}
\hline Parts and Materials & \multicolumn{2}{|c|}{ Mass } & \multirow[t]{2}{*}{ Notes } \\
\hline Ballast & $\mathbf{g}$ & lb & \\
\hline Black glass insulation & 2.0 & $4.4 \mathrm{E}-3$ & Modeled as foam glass \\
\hline Internal filler & 1.0 & $2.2 \mathrm{E}-3$ & Modeled as foam glass \\
\hline \multicolumn{4}{|l|}{ Lamp } \\
\hline Tin plate base & 2.0 & $4.4 \mathrm{E}-3$ & \\
\hline Tungsten filament & $2.0 \mathrm{E}-2$ & $4.4 \mathrm{E}-5$ & Modeled as chromium \\
\hline Internal glass & 2.0 & $4.4 \mathrm{E}-3$ & Modeled as borosilicate glass tube \\
\hline \multicolumn{4}{|l|}{ Lens } \\
\hline Globe (glass) & 20.0 & $4.4 \mathrm{E}-2$ & Modeled as borosilicate glass tube \\
\hline \multicolumn{4}{|l|}{ Packaging } \\
\hline Corrugated board & 4.0 & $8.8 \mathrm{E}-3$ & \\
\hline Total & 31.0 & $6.8 \mathrm{E}-2$ & \\
\hline
\end{tabular}

The data sets used to model the incandescent system's parts and materials come from ecoinvent. U.K. Department for Environment (2009) used proxy data for materials not available in ecoinvent or other publicly-available data or databases. These proxies were also used for BIRDS, and are indicated in the table notes. Raw materials are modeled as transported to the manufacturing plant via diesel truck an assumed average distance of $805 \mathrm{~km}$ (500 mi).

No manufacturing data were available, but the parts forming (wire drawing, injection molding, extrusion, etc.) have been included with the upstream raw materials, accounting for at least some of the production energy.

${ }^{21}$ See, for example, Parsons (2006). 


\subsection{Compact Fluorescent Lamp (CFL)}

The bill of materials in Table 4-48 is based on a 23 W Philips Marathon Mini CFL. Other data were available for an $18 \mathrm{~W} \mathrm{CFL}^{22}$ which might have been preferable in terms of wattage identified in Table 4-48, but Tables B.10-B.11 of U.K. Department for

Environment (2009) were used since the tear-down was quite detailed and for a widely available product. Furthermore, the difference in mass between the two sources was $3 \%$ to $5 \%$, with a similar bill of materials. Factoring in use phase energy, this difference becomes negligible.

${ }^{22}$ Ibid. 
Table 4-48 CFL Bill of Materials

\begin{tabular}{|c|c|c|c|}
\hline Parts and Materials & & & Notes \\
\hline Ballast & g & lb & \\
\hline PUR foam (rigid) & 3.0 & $6.6 \mathrm{E}-3$ & \\
\hline Plastic base (Polyvinyl chloride, PVC) & 17.0 & $3.7 \mathrm{E}-2$ & \\
\hline Printed wiring board & 4.0 & $8.8 \mathrm{E}-3$ & \\
\hline Printed board assembly (PBA) - & & & \\
\hline Polypropylene (PP) caps & 4.0 & $8.8 \mathrm{E}-3$ & \\
\hline PBA- inductor (cast iron) & 7.0 & $1.5 \mathrm{E}-2$ & \\
\hline PBA- inductor (copper) & 4.5 & $9.9 \mathrm{E}-3$ & \\
\hline PBA - transistor (ABS copolymer) & 1.0 & $2.2 \mathrm{E}-3$ & \\
\hline PBA - transistor (Aluminum) & 3.5 & $7.7 \mathrm{E}-3$ & \\
\hline PBA - resistors, diodes, HV capacitor & 1.0 & $2.2 \mathrm{E}-3$ & $\begin{array}{l}\text { Modeled as a logic type } \\
\text { integrated circuit }\end{array}$ \\
\hline PBA - torus magnet (cast iron) & 1.0 & $2.2 \mathrm{E}-3$ & \\
\hline
\end{tabular}

\section{Lamp}

Electrode assembly - mercury gas

4.0 E-3

8.8 E-6

Electrode assembly - chromium

2.0

4.4 E-3

Copper pins

2.0

4.4 E-3

Tin base plate

5.0

$1.1 \mathrm{E}-2$

Black glass insulation

5.0

1.1 E-2

Modeled as foam glass

\section{Lens}

Glass tube

34.0

Modeled as borosilicate

\section{Packaging}

Corrugated board

4.0

8.8 E-3

Total

98.0

2.2 E-1

The U.S. LCI Database provided data for the polyvinyl chloride base, polypropylene caps, acrylontrile-butadiene-styrene (ABS) copolymer transistor, and aluminum (as an 
average mix of primary and secondary aluminum). Data for copper sheet and wire come from International Copper Association (ICA) (2012). The remaining data sets come from ecoinvent. U.K. Department for Environment (2009) used proxy data for materials and/or parts not available in ecoinvent or other publicly-available data or databases. These proxies were also used for BIRDS, and are indicated in the table notes. Raw materials are modeled as transported to the manufacturing plant via diesel truck an assumed average distance of $805 \mathrm{~km}(500 \mathrm{mi})$.

No manufacturing data were available, but the parts forming (wire drawing, injection molding, extrusion, etc.) and manufacture of the individual electronics components have been included with the upstream raw materials, accounting for at least some of the production energy. For assembly, U.K. Department for Environment (2009) used data provided by ecoinvent - assembly of an LCD screen - which the authors determined to be a suitable proxy for CFL manufacturing. According to U.K. Department for Environment (2009), this surrogate was selected because an LCD screen is also a complex electrical product, involving circuits and components that are assembled, and the impacts were expressed on a per $\mathrm{kg}$ basis so the assembly of the lighting systems could be modeled based on their respective weights. This was a conservative assumption on the part of U.K. Department for Environment (2009) Four Elements tested this assumption with sensitivity analysis, which showed that it did not make a significant difference to the overall results. BIRDS used this same assumption, applying the assembly data to a $98.0 \mathrm{~g}(0.22 \mathrm{lb})$ system.

\subsection{Light-Emitting Diode (LED)}

The integrated LED system from Table B.2 and Table B.3 in U.K. Department for Environment (2009) was modeled, giving the LED system the opportunity to be retrofitted into existing lighting infrastructure. The LED inventory shown in Table 4-49 factored in 10 LED die. 
Table 4-49 LED Bill of Materials

\begin{tabular}{|c|c|c|c|}
\hline \multirow{2}{*}{$\begin{array}{l}\text { Parts and Material } \\
\text { Ballast }\end{array}$} & \multicolumn{2}{|c|}{ Mass } & \multirow[t]{2}{*}{ Notes } \\
\hline & g & $\mathbf{l b}$ & \\
\hline PUR foam (rigid) & 3.0 & $6.6 \mathrm{E}-3$ & \\
\hline Inductor (cast iron) & 6.0 & $1.3 \mathrm{E}-2$ & \\
\hline Inductor $(\mathrm{Cu})$ & 4.0 & $8.8 \mathrm{E}-3$ & \\
\hline Zener Diodes & 0.1 & $2.2 \mathrm{E}-4$ & Modeled as an unspecified diode \\
\hline Capacitors (aluminum) & 5.0 & $1.1 \mathrm{E}-2$ & \\
\hline Resistor & 10.0 & $2.2 \mathrm{E}-2$ & \\
\hline Transistor & 3.0 & $6.6 \mathrm{E}-3$ & \\
\hline PCB (aluminum machined tooled block) & 100.0 & $2.2 \mathrm{E}-1$ & Modeled as aluminum \\
\hline Wiring $(\mathrm{Cu})$ & 2.0 & 4.4 E-3 & \\
\hline Solder paste (used for electronics) & 1.0 & $2.2 \mathrm{E}-3$ & \\
\hline Polypropylene (PP) housing & 35.0 & $7.7 \mathrm{E}-2$ & \\
\hline Integrated circuit & 1.0 & $2.2 \mathrm{E}-3$ & \\
\hline Polyethylene terephthalate (PET) film & 2.0 & 4.4 E-3 & \\
\hline \multicolumn{4}{|l|}{ Lamp } \\
\hline Black glass insulation & 6.0 & $1.3 \mathrm{E}-2$ & Modeled as foam glass \\
\hline Tinplate base & 3.0 & $6.6 \mathrm{E}-3$ & Modeled as a low-alloyed steel \\
\hline Copper pins & 0.1 & $2.2 \mathrm{E}-4$ & \\
\hline Base contacts $(\mathrm{Cu})$ & 0.4 & $8.8 \mathrm{E}-4$ & \\
\hline Base contacts (solder paste for electronics) & 0.2 & $4.4 \mathrm{E}-4$ & \\
\hline Plastic base (PVC) & 16.0 & $3.5 \mathrm{E}-2$ & \\
\hline Light emitting diodes (LED, 10 total) & 19.0 & $4.2 \mathrm{E}-2$ & \\
\hline \multicolumn{4}{|l|}{ Lens } \\
\hline Glass & 20.0 & 4.4 E-2 & Modeled as borosilicate glass tube \\
\hline Coating (aluminum) & 1.0 & $2.2 \mathrm{E}-3$ & \\
\hline \multicolumn{4}{|l|}{ Packaging } \\
\hline Corrugated board & 3.0 & $6.6 \mathrm{E}-3$ & \\
\hline Total & 240.8 & $5.3 \mathrm{E}-1$ & \\
\hline
\end{tabular}

The U.S. LCI Database provided data for the PVC base, PP housing, PET film, and aluminum (as average production mix). Data for copper sheet and wire come from International Copper Association (ICA) (2012). The remaining data sets, including the production of the LEDs, come from ecoinvent. U.K. Department for Environment (2009) 
used proxy data for materials not available in ecoinvent or other publicly-available data or databases. These proxies were also used for BIRDS, and are indicated in the table notes. Raw materials are modeled as transported to the manufacturing plant via diesel truck an assumed average distance of $805 \mathrm{~km}$ (500 mi).

Data for LED die manufacturing comes from OSRAM Opto Semiconductors GmbH. (2009). Primary data were collected on the two main process stages to produce OSRAM's Golden Dragon Plus: the front end, where the $1 \mathrm{~mm}^{2}\left(1.6 \mathrm{E}-3 \mathrm{in}^{2}\right)$ semiconductor chip is fabricated, and back end, where the chip is contacted and packaged. See OSRAM Opto Semiconductors GmbH. (2009), pp.9-11, for more qualitative detail and schematics on the manufacture of the LED. Figure 6 in OSRAM Opto Semiconductors GmbH. (2009) presents the primary energy to produce one LED: approximately $0.41 \mathrm{kWh}$. Given that the other categories of data in the figure include materials production, an assumption was made that "common consumption" is energy at manufacturing, amounting to approximately $0.27 \mathrm{kWh}$ per LED, or $2.7 \mathrm{kWh}$ for 10 LEDs. No other manufacturing data could be gleaned from this study, but the ecoinvent data set on assembly of an LCD screen was used for assembly (see above discussion), and parts forming data were applied to other parts and materials listed in the table.

\subsubsection{Transportation to the Building Site through End-of-Life}

A number of the LCA studies mentioned China or Asia in general as being the main manufacturing location for incandescents. For their study, Energy Efficiency and Renewable Energy (EERE) (2012), p.32, assumed that an incandescent lamp is either manufactured in the northeastern U.S. or Shanghai, China, while also acknowledging that production occurs all over the world. BIRDS assumed $25 \%$ of production of incandescents to be produced in the northeast U.S., and $75 \%$ in Shanghai, China.

BIRDS modeled CFLs as manufactured in China (Parsons 2006, Ramroth 2008, U.K. Department for Environment 2009, Energy Efficiency and Renewable Energy (EERE) 2012).

Energy Efficiency and Renewable Energy (EERE) (2012) stated that LED lighting market is highly fragmented, with several firms focusing on a specific part within the LED supply chain (this was seen with OSRAM Opto Semiconductors GmbH. (2009)). BIRDS adopted EERE's approach to simplifying the sourcing logistics as follows: "the complete LED package is produced in Taiwan and then is assembled into the finished LED lamp product in Taiwan or the United States. In the second scenario, LED packages are produced in Taiwan and then shipped to the southeast region of the U.S. where they are assembled into complete LED lamp products" (Energy Efficiency and Renewable Energy (EERE) 2012).

For Asia manufacturing, transportation includes the ocean freighter transport to a port in California, plus heavy duty diesel truck an assumed $2414 \mathrm{~km}(1500 \mathrm{mi})$, an average distance traveled from California to other parts of the United States. For U.S. 
manufacturing, transport is modeled an assumed average of $2414 \mathrm{~km}$ (1500 mi) by heavy-duty diesel fuel-powered truck. Intermediate transportation (i.e., from LED production to lamp assembly) is also included.

For every light bulb purchased and needing to be replaced, customer driving to and from the retail store has been included.

How these lighting systems affect operating energy during the home's use phase is addressed in other sections of this report.

At end-of-life, each of the lighting alternatives was modeled as $20 \%$ recycling (and material recovery), and $80 \%$ landfill. A distance of $48 \mathrm{~km}$ (30 mi) traveled via a heavyduty diesel truck to the landfill or recycler has been assumed for waste and recycling transport.

\subsubsection{Sealants}

LCAs of an interior and exterior sealant have been included in BIRDS. The interior sealant is modeled as an aluminum foil-backed multi-purpose tape designed for taping joints and seams against moisture and vapor on ductwork. The exterior sealant, an acrylic latex caulk with silicone, is used to minimize air infiltration around windows, door frames, and other areas on the building envelope. The LCAs are based on one linear foot of each type of sealant (boundaries shown in Figure 4-11).

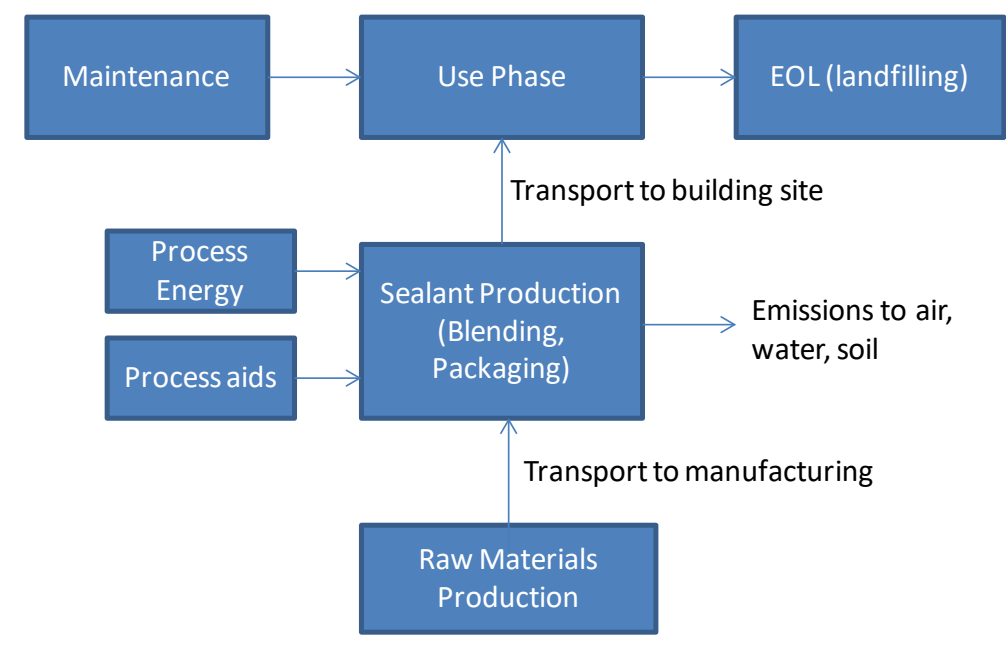

Figure 4-11 Sealants System Boundaries - Exterior Sealant Example

Both types of sealants have been modeled based on products that are readily available and whose published product literature provided sufficient data to model their production without the need to make too many assumptions. It should be reminded that there are many products on the market that can perform the same sealing functions, and that the products described herein are not considered endorsements. 


\subsubsection{Upstream Materials Production through Manufacturing}

\subsection{Ductwork Sealant}

The ductwork sealant modeled for BIRDS is modeled as a multi-purpose foil-backed tape. The 0.13-mm (5.0-mil) thick tape contains three distinct layers: a 0.05-mm (2.0-mil) thick aluminum foil layer, a synthetic rubber layer for the adhesive, and an unbleached natural Kraft paper layer for the liner (Nashua Tape Products 2013). One roll of $46 \mathrm{~m}$ (151 ft) long by $48 \mathrm{~mm}(0.16 \mathrm{ft})$ wide tape, or $2.2 \mathrm{~m}^{2}\left(23.8 \mathrm{ft}^{2}\right)$ of tape, weighed $0.55 \mathrm{~kg}$ $(1.2 \mathrm{lb})$, or $3.64 \mathrm{~g}(0.13 \mathrm{oz})$ per linear foot. ${ }^{23}$ Based on this weight, the material components were broken down as shown in Table 4-50, with assumptions noted.

Table 4-50 Foil Tape Bill of Materials

\begin{tabular}{|c|c|c|c|}
\hline \multirow[t]{2}{*}{ Tape material } & \multicolumn{2}{|c|}{ Mass } & \multirow[t]{2}{*}{ Notes } \\
\hline & $\mathbf{g}$ & $\mathbf{o z}$ & \\
\hline Aluminum & 2.01 & 0.071 & Based on $0.05 \mathrm{~mm}(2.0 \mathrm{mil}) \&$ density of $2.7 \mathrm{~g} / \mathrm{cm}^{3}$ \\
\hline Unbleached Kraft & 0.16 & $5.8 \mathrm{E}-3$ & Assumed $10 \%$ of remaining weight \\
\hline Synthetic rubber & 1.39 & 0.049 & Assumed $85 \%$ of remaining weight \\
\hline Cardboard core & 0.08 & $2.9 \mathrm{E}-3$ & Assumed $5 \%$ of remaining weight \\
\hline LDPE* film (packaging) & negl. & negl. & \\
\hline Total & 3.64 & 0.13 & \\
\hline
\end{tabular}

Production data for the foil is modeled as 50/50 primary and secondary aluminum from the U.S. LCI Database, plus sheet rolling (ecoinvent). Data for the remaining materials were supplied by ecoinvent. Assembly of the tape was assumed to consist of layering and laminating the materials, rolling, and cutting. The electricity-only portion of the ecoinvent data set for "laminating foil (with an acrylic binder)" was used, which was reported as $0.0183 \mathrm{kWh} / \mathrm{m}^{2}\left(0.0017 \mathrm{kWh} / \mathrm{ft}^{2}\right)$ laminated. This value is likely underestimated since cutting and rolling are not included in this dataset.

\subsection{Exterior Sealant}

The exterior sealant was modeled based on composition information for an MSDS of a commonly used acrylic latex sealant with silicone (DAP 2005). The amount modeled for $0.3 \mathrm{~m}(1 \mathrm{ft})$ was calculated to be $28.9 \mathrm{~g} / \mathrm{m}(0.31 \mathrm{oz} / \mathrm{ft})$, based on a specific gravity of 1.65 , coverage of $17 \mathrm{~m}(56 \mathrm{ft})$ per $298 \mathrm{~cm}^{3}(10.1 \mathrm{fl} \mathrm{oz})$, and a bead diameter of $0.47 \mathrm{~cm}(0.19$ in) (DAP 2011). Since composition was provided in the customary percentage ranges, the

\footnotetext{
${ }^{23}$ Weight taken by Four Elements.
} 
quantities of each ingredient modeled were estimated based on best-guess assumptions (see Table 4-51).

\section{Table 4-51 Exterior Sealant Bill of Materials}

\begin{tabular}{lcccl} 
& \multicolumn{4}{c}{ Weight Percentage } \\
Components & Low \% & High \% & \% Modeled & Notes \\
Non-hazardous polymer & 10 & 30 & 30 & Acrylic polymer assumed \\
Water & 10 & 30 & 18 & "82 \% solids" (DAP 2011) \\
Calcium carbonate & 40 & 70 & 46 & \\
Phthalate ester & 1 & 5 & 3 & \\
Titanium dioxide & 0.1 & 1 & 0.55 \\
Ethylene glycol & 0.1 & 1 & 0.55 & \\
Crystalline silica & 0.1 & 1 & 1 & \\
Carbon black & 0 & 1.5 & 0.75 \\
Ammonia & & 0.01 & 0.01 \\
Formaldehyde & & 0.02 & 0.02 \\
Ethyl acrylate & & 0.009 & 0.009 \\
Acetaldehyde & & 0.002 & 0.002 \\
Acrylonitrile & & 0.0003 & 0.0003 \\
Total & & & $\mathbf{1 0 0}$ \\
\hline & & & &
\end{tabular}

The mass of the high density polyethylene (HDPE) squeeze tube packaging was calculated by subtracting the quantity of $10.1 \mathrm{fl} \mathrm{oz}$ sealant $(493 \mathrm{~g}(17.3 \mathrm{oz})$ ) from the weighed product $(539 \mathrm{~g}(19.0 \mathrm{oz}))$. Thus, HDPE amounted to $46 \mathrm{~g}(1.6 \mathrm{oz})$, or $2.7 \mathrm{~g} / \mathrm{m}$ $(0.029 \mathrm{oz} / \mathrm{ft})$.

The U.S. LCI Database provided production data for HDPE, calcium carbonate, and ethylene glycol. Ecobilan (2001) provided the inventory data on the phthalate ester, and ecoinvent provided the remaining data. Manufacturing data were limited; the electricityonly portion of an ecoinvent data set for acrylic filler production - likely mixing energy were used, which amounted to $1.8 \mathrm{E}-3 \mathrm{kWh} / \mathrm{kg}(1.6 \mathrm{E}-5 \mathrm{kWh} / \mathrm{ft})$.

Raw materials for both products are modeled as transported to the manufacturing plant via diesel truck an assumed average distance of $805 \mathrm{~km}$ (500 mi). 


\subsubsection{Transportation to the Building Site through End-of-Life}

Transportation of the equipment to the building site is modeled assuming an average of $483 \mathrm{~km}$ (300 mi) traveled via heavy-duty diesel fuel-powered truck.

The tape is assumed to be replaced every 10 years. The exterior sealant is modeled as being replaced every 15 years (Vigener and Brown 2012). At the end of each of their respective lives, it is assumed that they are landfilled. Data on the landfill is based on ecoinvent end-of-life waste management process data. A distance of $48 \mathrm{~km}(30 \mathrm{mi})$ to the landfill in a heavy-duty diesel truck has been assumed.

\subsubsection{Solar Photovoltaics}

Photovoltaics (PV) is the term used to describe the method of generating direct current electricity from solar energy. PV panels, or solar panels, are composed of solar cells that supply usable solar power. A PV inverter converts the direct current electricity produced by solar cells into an alternating current that can be utilized directly or transferred back to the electrical grid.

The Net-Zero Energy Residential Test Facility (NZERTF) has a 10.2 kW PV system. Thirty-two SunPower SPR-320E-WHT-U solar PV panels are installed on the roof of the NZERTF in four horizontal strings of eight panels each. Two strings are connected to a SunPower 5000m LUT inverter for a total of two inverters. Each SunPower $320 \mathrm{~W}$ solar panel has a $19.9 \%$ conversion efficiency (Sunpower 2013), has a mass of $18.6 \mathrm{~kg}$ (41 lb), 96 monocrystalline solar cells built on a solid copper foundation, black anodized material-based frame, and high transmission, tempered, anti-reflective glass.

The LCA for the BIRDS model includes one solar panel and one PV inverter; the total number of panels and inverters used by the NZERTF are multiplied within the BIRDS tool. Figure 4-12 presents the PV system boundaries. 


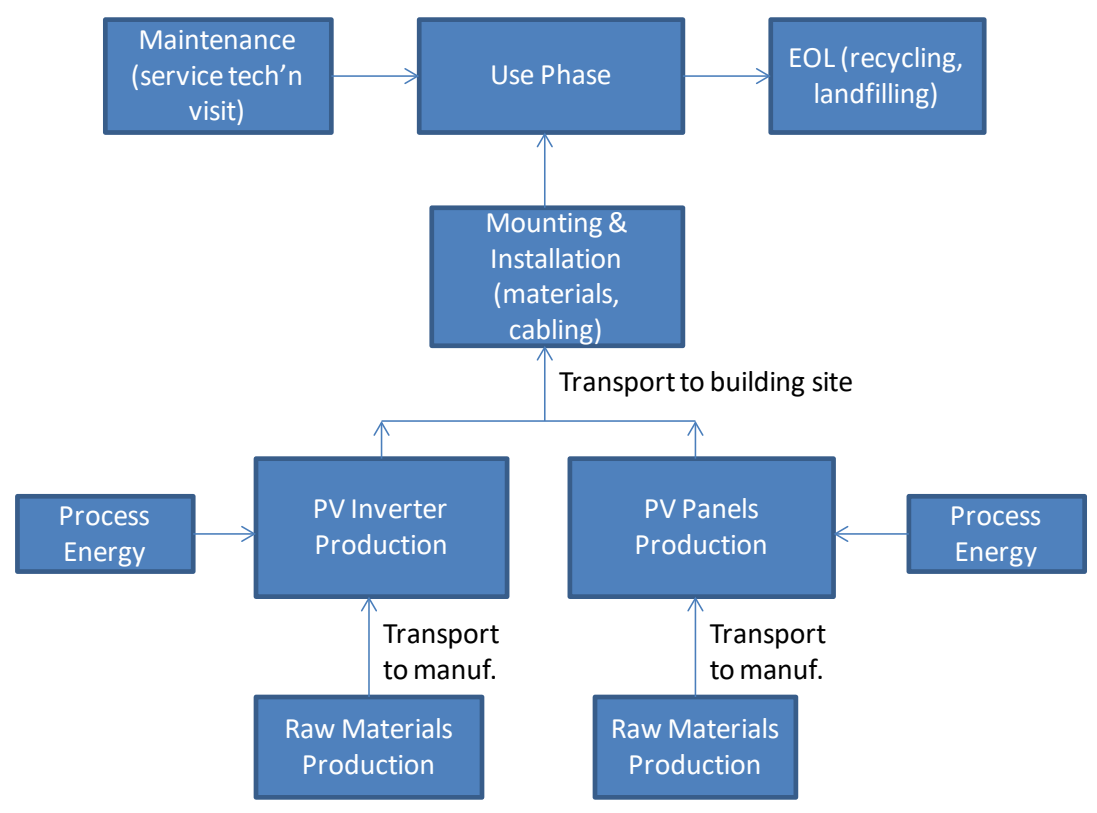

Figure 4-12 PV System Boundaries

\subsubsection{Upstream Materials Production through Manufacturing}

Manufacturer-specific data was not available, so publicly-available sources of data were used as a proxy. The inventories of the crystalline silicon PV panel, PV inverter, and associated cabling are based on research by Mariska De Wild and Erik Alsema (Fthenakis 2011). Ecoinvent data sets have been used to build the LCA model for BIRDS, adding additional elements to account for standard ecoinvent inventory and data quality requirements (Jungbluth 2007).

\subsubsection{Photovoltaic Panel}

The photovoltaic panel LCI data were provided by industry (not manufacturer-specific) and are a reliable representation of crystalline silicon module production technology for 2005/2006 and is based on Western Europe production. Due to the detailed bill of materials, the data are not presented in this report. However, Figure 4-13 is provided as a means to clarify the system boundaries and presents the processes that cover the monocrystalline Si PV panel (Fthenakis 2011).

For the BIRDS model, ecoinvent datasets that correspond to the information in Fthenakis (2011) were used. Since the data are based on Western Europe, wherever possible, data representing North American production were used to adjust the data to be more appropriate for North American conditions; U.S. LCI Database and other North American data sets were used to replace some of the process energy, transportation, and upstream materials data sets (e.g., framing materials, auxiliary materials, etc.). Detailed information is provided in the tables listed in Figure 4-13 and/or Jungbluth (2007). 


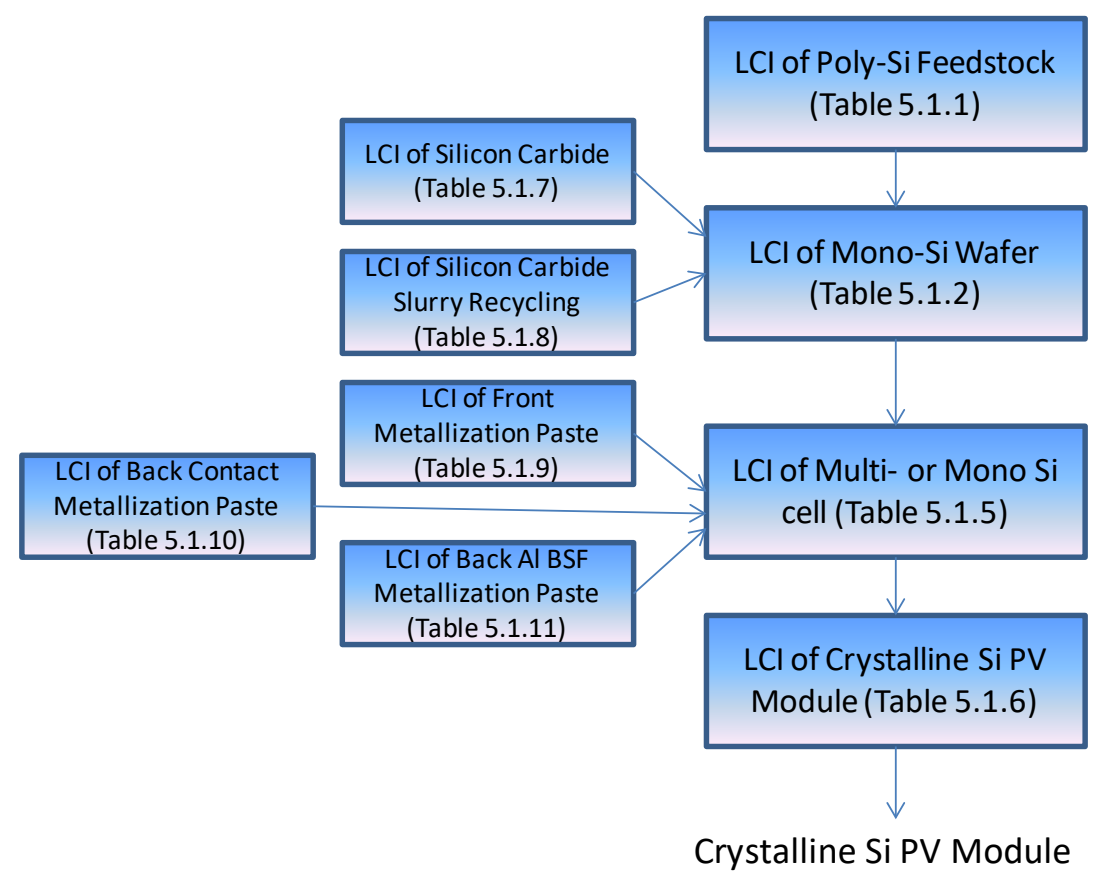

Figure 4-13 PV Module Data Sets

Even though the data in Fthenakis (2011) has been adjusted to North American conditions, there are still limitations to its use as a proxy for the SunPower panel, for example:

- SunPower PV panels have 96 solar cells while the IEA panels have 60 cells;

- SunPower PV panels are backed with a solid copper foundation while IEA panels are modeled as having back-contact metallization paste;

- The construction of the SunPower PV panels enables it to have a higher conversion efficiency than the " $14 \%$ " average efficiency of other monocrystalline silicon PV panels (Fthenakis (2011), p.31).

Because these differences cannot be reconciled with the manufacturer data, the model is more reflective of an industry average panel, and not customized to the SunPower unit.

\subsubsection{Photovoltaic Inverter}

The SunPower 5000m LUT PV inverter was modeled based on a tear-down of a $2500 \mathrm{~W}-\mathrm{AC}$ PV inverter. The SunPower inverter has a $5000 \mathrm{~W}$ continuous power output, and its $67 \mathrm{~kg}(148 \mathrm{lb})$ mass is approximately 3.6 times greater than the one featured in Fthenakis (2011). To make up for the difference in mass, the materials and parts presented in Fthenakis (2011) Table 5.5.1.4 were scaled up proportionally to the SunPower's mass. One exception is the scaling factor for the printed circuit board, which was doubled, assuming its weight is not directly proportional to its performance within the system. Note that Table 4-52 is simpler than the corresponding ecoinvent module which contains more detail on the transformers, wiring, packaging, etc. 
Table 4-52 SunPower 5000m LUT PV Inverter Bill of Materials

\begin{tabular}{lcccl} 
& $\mathbf{2 5 0 0} \mathbf{W}$ & \multicolumn{3}{c}{ SunPower $\mathbf{5 0 0 0} \mathbf{~ W}$} \\
Parts / Materials & $\mathbf{K g}$ & $\mathbf{K g}$ & $\mathbf{L b}$ & Notes \\
Steel & 9.8 & 37.2 & 82.0 & As casing \\
Aluminum & 1.4 & 5.3 & 11.7 & As casing \\
Transformers, wire- & & & & \\
wound & 5.5 & 20.9 & 46.0 & \\
Printed circuit board & 1.8 & 3.6 & 7.9 & \\
Total & $\mathbf{1 8 . 5}$ & $\mathbf{6 7 . 0}$ & $\mathbf{1 4 7 . 7}$ & \\
\hline
\end{tabular}

The steel data come from World Steel Association (2011). Aluminum is modeled as a 50/50 mix of primary and secondary extruded aluminum based on the U.S. LCI Database. The electronics data come from the ecoinvent database. Raw materials are modeled as transported to the manufacturing plant via diesel truck an assumed average distance of $805 \mathrm{~km}(500 \mathrm{mi})$ based on the U.S. LCI Database.

\subsubsection{Transportation to the Building Site through End of Life}

Transportation of the SunPower PV panels, the PV inverter, and mounting materials to the building site is modeled using an assumed average of $2414 \mathrm{~km} \mathrm{(1} 500 \mathrm{mi})$ by heavyduty diesel fuel-powered truck.

Specific mounting data were not available from SunPower literature, so the industry weighted-average materials and processes in Fthenakis (2011) Table 5.4.2 were used. The data are provided for $1 \mathrm{~m}^{2}\left(10.8 \mathrm{ft}^{2}\right)$ of a mounted PV module on a slanted roof. This was multiplied by 1.6 for the SunPower panel. Data for electrical cabling for module interconnection and AC-interface is provided in Fthenakis (2011) Table 5.5.1.1, and was modeled for on-roof installation as follows:

Table 4-53 Solar Panel Mounting Materials and Cabling

\begin{tabular}{lccl} 
Mounting Material & $\begin{array}{c}\text { kg per 1.6 } \\
\mathbf{m} 2\end{array}$ & $\begin{array}{c}\text { lb per } \mathbf{1 . 6} \\
\mathbf{~ m 2}\end{array}$ & Notes \\
Aluminum & 4.54 & 10.02 & plus section bar rolling \\
Corrugated board & 0.02 & 0.05 & \\
Polyethylene & 0.002 & 0.005 & \\
Polystyrene & 0.01 & 0.02 & \\
Low-alloyed steel & 2.40 & 5.29 & plus steel sheet rolling \\
Cabling Material & & & \\
Copper & 0.16 & 0.35 & $2.2 \mathrm{~m} \mathrm{DC}$ cable and $0.1 \mathrm{~m} \mathrm{AC}$ cable \\
Thermoplastic elastomer & 0.10 & 0.21 & \\
\hline
\end{tabular}

Copper wire data come from ICA (2012). U.S. LCI Database provided the data for the polyethylene and polystyrene. Data for the thermoplast, modeled as ethylene propylene diene monomer (EPDM) rubber, come from ecoinvent, as does the low-alloyed steel and corrugated board. 
It is assumed that a qualified service technician comes to the building site once annually to check the PV system to ensure optimal performance and lifetime. It is assumed that the technician is within a $24 \mathrm{~km}$ (15 mi) service radius. This distance, driven in a gasolinepowered van, is shared amongst other service visits for that technician, if the same technician is making more than one service call during that trip. Assuming the technician makes 5 service calls in one day, one-fifth of the impacts from driving $24 \mathrm{~km}(15 \mathrm{mi})$ are allocated to the product, or $4.8 \mathrm{~km}(3 \mathrm{mi})$. Data for a van come from ecoinvent. Unplanned service visits (i.e., unanticipated issues that require a service technician) are not included in the model under the assumption that the system will run as designed given the homeowner adequately follows the maintenance and care guidelines.

Over time, PV panels can degrade at a rate of one percent per year. The SunPower modules were found to degrade at a rate of 0.25 percent per year (Sunpower 2013). With a useful life defined as " 99 out of 100 panels operating at more than $70 \%$ of rated power," SunPower panel product literature to have a useful life of 40-years (Sunpower (2013) and Sunpower (2013)). The Solar Energy Industries Association (SEIA) states that the lifespan of PV panels can last from 20 to 30 years (SEIA 2015) and BIRDS models them as 30 years; while product literature indicates a longer lifetime, SunPower provides 25 years in its warranty. SEIA (2015) states a lifetime of 10 years for the inverter; this is supported by the 10 -year warranty provided by SunPower for the $5000 \mathrm{~m}$ LUT (Sunpower 2013).

At end of life, materials from PV panels are assumed to be sent for recycling for material recovery. The recycling process for silicon based modules can be described as follows: "For silicon-based modules, aluminum frames and junction boxes are dismantled manually.... The module is subsequently crushed and its several components are separated, allowing recovering up to $80 \%$ of the panel. ${ }^{24}$ An LCA screening study by Fraunhofer (2012) demonstrated that valuable materials like aluminum frames, copper, and glass cullet can be successfully recovered at a flat glass recycling facility. At the time of this writing, in the U.S., recycling of PV panels is not mandated. However, it is expected that as recycling of PV panels becomes a streamlined operation and as PV panels begin to exceed their useful lives, recycling will be industry standard practice. Note that PV panels are required to be recycled in the EU today. ${ }^{25}$

A distance of $48 \mathrm{~km}(30 \mathrm{mi})$ to the landfill or a recycler in a heavy-duty diesel truck has been modeled. The landfill is based on ecoinvent waste management process data.

\subsubsection{Solar Thermal Water Heating}

\footnotetext{
${ }^{24}$ See: http://www.solarwaste.eu/collection-and-recycling/.

${ }^{25}$ In 2012, PV panels fell under the scope of the Directive on waste electrical and electronic equipment (WEEE), which means that producers of PV panels are required to fund collection, treatment, and recycling of WEEE and divert it from landfills.
} 
The Net-Zero Energy Residential Test Facility (NZERTF) is equipped with two closedloop solar water heating systems, only one of which is used during operation of the NZERTF. Each system uses two Heliodyne Gobi 406001 solar thermal panels or collectors and a solar storage tank with heat exchanger (the Helio-Pak or HPAK 016) attached. The system works as follows: solar fluid in the collector is heated by the sun and then pumped through the heat exchanger which then heats the water in the storage tank. The solar fluid circulates back to the collector, where it is then reheated by the sun. The solar storage tanks are equipped with a backup electrical heating element when the sun is not able to provide energy.

The LCA for the BIRDS model includes two collectors, one heat exchanger, and tone of he two water storage tanks used for the two systems, either the $303 \mathrm{~L}$ ( 80 gal) or $454 \mathrm{~L}$ (120 gal) tank. One Gobi 406001 collector has a gross area of $2.5 \mathrm{~m}^{2}\left(26.9 \mathrm{ft}^{2}\right)$ and a mass of $33.5 \mathrm{~kg}(74 \mathrm{lb})$. The number of collectors and auxiliary equipment needed for any given performance requirement in BIRDS are multiplied within BIRDS.

Figure 4-14 presents the system boundaries for the solar water heating system.

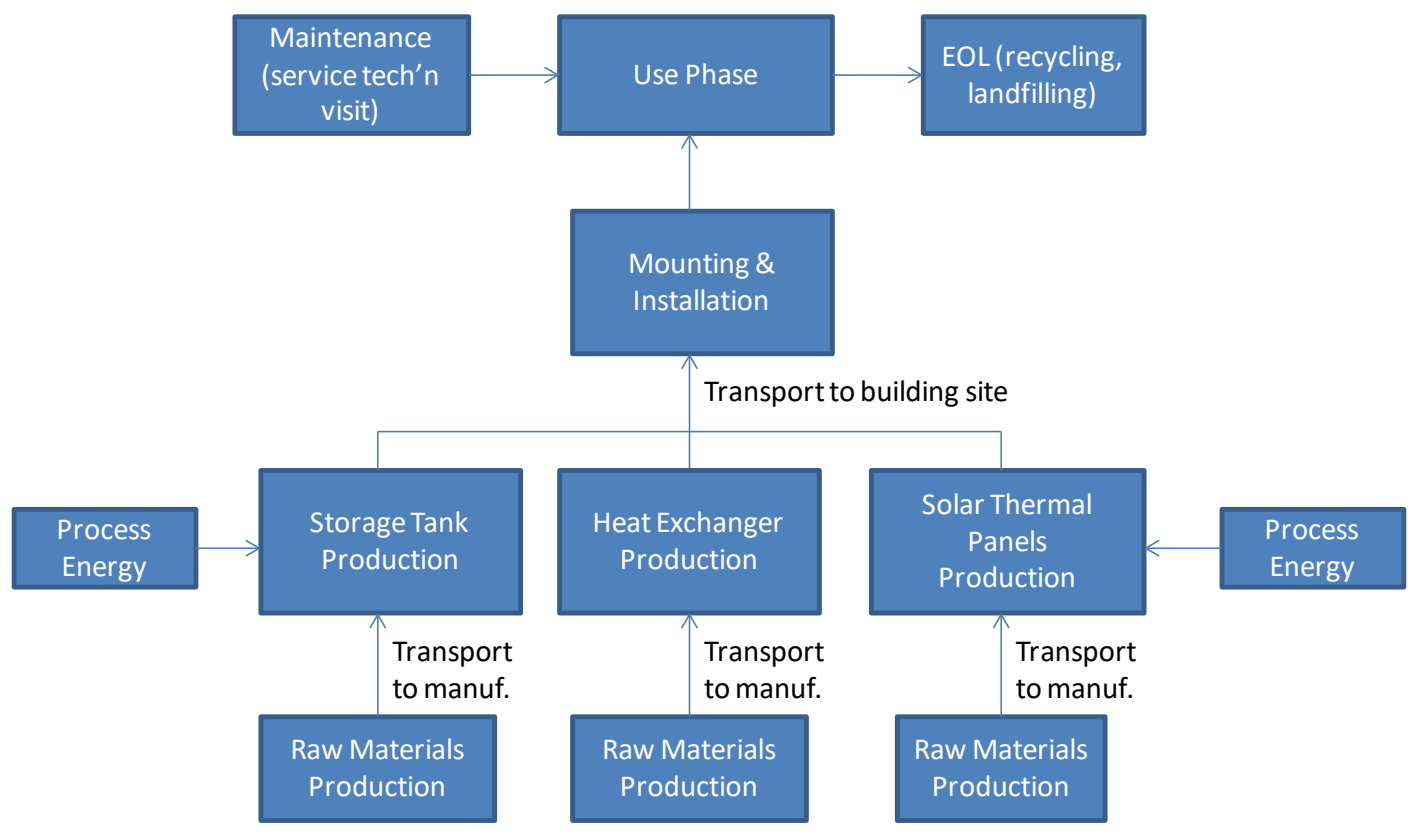

Figure 4-14 Solar Water Heating System Boundaries

\subsubsection{Upstream Materials Production through Manufacturing}

\subsection{Solar Collector Panels}

Manufacturer-specific data was not available, so publicly-available sources of data were used as a proxy and customized wherever possible using product specifications. Data for the solar collector comes from ecoinvent and is described in Stucki (2012) and Jungbluth (2007). The data cover the assembly of a flat plate collector with a copper absorber coated with a black chrome coating. Data are based on Swiss production in 2002 and 
include materials, water use, and production energy. One collector has an active area of $2.72 \mathrm{~m}^{2}\left(29.3 \mathrm{ft}^{2}\right)$ and an empty weight of $52 \mathrm{~kg}(115 \mathrm{lb})$. The technology is considered by ecoinvent to still be current. Some North American datasets and U.S. energy datasets from the U.S. LCI database were used to customize the European geography to more North American conditions. Nevertheless, the older data and the relatively smaller size of the ecoinvent collector are limitations to the data.

The data in Stucki (2012) is copyrighted so the bill of materials cannot be recreated here, but the interested reader is encouraged to go to the source or download the inventory datasets which are produced in EcoSpold1 format, at www.lc-inventories.ch, or found within ecoinvent.

\subsection{Heat Transfer Liquid}

The closed-loop solar system requires $2.2 \mathrm{~L}$ ( 0.6 gal) of heat transfer liquid consisting of $40 \%$ to $50 \%$ inhibited propylene glycol (Dyn-o-flo HD) and water. The mixture was modeled using $45 \%$ propylene glycol and $55 \%$ water. ((HPAK No Date) Table 1.5).

\subsection{Heat Transfer Appliance}

No data were available on the HPAK or similar apparatus so the $24.9 \mathrm{~kg}(55 \mathrm{lb})$ bill of materials was estimated using a combination of published Heliodyne information on parts and materials in drawings, technical specifications Heliodyne (No Date), and the Heliodyne HPAK installation guide, as follows in Table 4-54:

\section{Table 4-54 HPAK Bill of Materials}

\begin{tabular}{lcccl} 
Material & $\mathbf{\%}$ & $\mathbf{K g}$ & $\mathbf{l b}$ & Notes \\
Steel & $46.0 \%$ & 11.5 & 25.3 & \\
Copper & $30.0 \%$ & 7.48 & 16.5 & \\
Acrylic & $8.0 \%$ & 2.00 & 4.4 & $\begin{array}{l}\text { polymethyl methacrylate, for acrylic } \\
\text { (PMMA) (cover) }\end{array}$ \\
EPDM rubber & & & & Insulation by Armaflex \\
insulation & $7.0 \%$ & 1.75 & 3.85 & \\
Bronze & $5.0 \%$ & 1.25 & 2.75 & \\
Expanded PP foam & $3.0 \%$ & 0.75 & 1.65 & Casing \\
EPDM & $1.0 \%$ & 0.25 & 0.55 & Other parts \\
Total & $\mathbf{1 0 0 . 0 \%}$ & $\mathbf{2 4 . 9}$ & $\mathbf{5 5 . 0}$ & \\
\hline
\end{tabular}

The steel, assumed to be galvanized, comes from (World Steel Association 2011). Data for copper tube and wires come from (ICA 2012). U.S. LCI Database provided the production data for polymethyl methacrylate (PMMA, for acrylic) and polypropylene (PP). The PP foaming process comes from ecoinvent. Ecoinvent provided the data for the bronze and the ethylene propylene diene monomer (EPDM) rubber.

No manufacturing data was available for this type of appliance. However, the modeling of the upstream materials includes processing into usable parts, e.g., copper tubing. While this does not include full forming of parts and general final assembly, it likely accounts for most environmental impacts. Nonetheless, this uncertainty in impact is difficult to 
quantify without understanding the processes at this product's final manufacturing/assembly plant.

\subsection{Solar Water Tanks}

The Heliodyne storage tanks consider the solar storage components along with an electric component for auxiliary or backup heating. ((VHK) 2007) provided these data; Table 4-55 uses data extrapolated from ((VHK) 2007) Table B.9; the data for the $200 \mathrm{~L}$ (53 gal) storage tank was scaled up and the solar components from ((VHK) 2007) Table 3.2 were incorporated into the materials list to meet the total published weights of the Heliodyne units. As described in a previous chapter, since the material groups listed in ((VHK) 2007) Table B.9 were general, these data have been supplemented by more detailed parts and materials provided by ((VHK) 2007) Table B.10. Assumptions made are noted. Data for the materials are described in the subchapter on hot water heaters.

\section{Table 4-55 Heliodyne Solar Water Storage Tanks Bill of Materials}

\begin{tabular}{|c|c|c|c|c|c|}
\hline & \multicolumn{2}{|c|}{ 80-gal } & \multicolumn{2}{|c|}{ 120-gal } & \multirow[b]{2}{*}{ Parts, Materials \& Assumptions } \\
\hline $\begin{array}{l}\text { B.9 Material } \\
\text { Group }\end{array}$ & kg & lb & kg & lb & \\
\hline 3-Ferro & 84.7 & 186.8 & 124.4 & $\begin{array}{rr}274.3 & \mathrm{~T} \\
& \mathrm{~s} \\
\end{array}$ & $\begin{array}{l}\text { Tank, mounting plate, screws. Tank assumed to be } \\
\text { stainless steel }\end{array}$ \\
\hline 2-TecPlastics & 3.1 & 6.9 & 4.6 & 10.2 & $\begin{array}{l}\text { Rubber gasket (assume } 25 \% \text { ), PVC pipe protection and } \\
\text { pipe collar, PVC thermal control (assume } 75 \% \text { ) }\end{array}$ \\
\hline 1-BlkPlastics - & & & & & Assume EPS insulation \\
\hline & 2.5 & 5.5 & 3.7 & 8.1 & \\
\hline 7-Misc & 2.5 & 5.5 & 3.7 & 8.1 & $\begin{array}{l}\text { Portion of the Misc. category; part unknown. Assuming } \\
\text { packaging, based on Table B.10. Not included in this } \\
\text { analysis. }\end{array}$ \\
\hline 7-Misc & 0.6 & 1.4 & 0.9 & 2.0 & Portion of the Misc. category; Assume resistance heater \\
\hline 5-Coating & 6.5 & 14.3 & 9.5 & 21.0 & Assume enamel \\
\hline 4-Non-ferro & 0.4 & 0.9 & 0.6 & 1.4 & Assume copper \\
\hline 6-Electronics & 0.1 & 0.3 & 0.2 & 0.4 & Assume wiring, thermal control \\
\hline Solar Storage $P$ & rts and & Gaterial & ased on & Table 3.2) & \\
\hline Feed Pump & 3.8 & 8.3 & 5.0 & 11.0 & Stainless steel (assumption) \\
\hline Heat exchanger & - & - & - & - & $\begin{array}{l}\text { This line item removed as the Heliodyne system } \\
\text { uses an external heat exchanger (HPAK) }\end{array}$ \\
\hline 3-way valve & 1.5 & 3.3 & 2.0 & 4.4 & Aluminum diecast (assumption) \\
\hline Piping & 3.0 & 6.6 & 4.0 & 8.8 & Copper (assumption) \\
\hline TOTAL --> & 108.8 & 239.8 & 158.6 & 349.7 & \\
\hline
\end{tabular}

No manufacturing data were available for these tanks, so as a proxy, the same data used for the water heaters in this documentation was used for this tank. 


\subsubsection{Transportation to the Building Site through End of Life}

Transportation of the Heliodyne solar heating system to the building site is modeled using an assumed average of $2414 \mathrm{~km}(1500 \mathrm{mi})$ by heavy-duty diesel fuel-powered truck.

The installation of the solar thermal collectors accounts for mounting the solar panels on a slanted roof and installation of copper pipes. Collectors can be mounted flush against the roof using steel clips and hardware, or rack-mounted using aluminum channel shoes and legs. For the NZERTF, the collectors are assumed to be flush on the roof, and it is assumed that $1.4 \mathrm{~kg}(3.0 \mathrm{lb})$ of stainless steel hardware is used per collector. Data for stainless steel come from ecoinvent, and (ICA 2012) provides the data for the copper pipes. Copper pipes need only be installed one time during the 40 -year study period, as once installed, they are re-used for other solar collector replacements.

It is assumed that a qualified service technician comes to the building site once annually to check the system and ensure optimal performance and lifetime. During maintenance, the heat transfer liquid is tested for freeze protection and correct $\mathrm{pH}$ level. It is assumed that the liquid is replaced every 10 years. After use, it is sent to a municipal wastewater treatment. It is assumed that the technician is within a $24 \mathrm{~km}(15 \mathrm{mi})$ service radius. This distance, driven in a gasoline-powered van, is shared amongst other service visits for that technician, if the same technician is making more than one service call during that trip. Assuming the technician makes 5 service calls in one day, one-fifth of the impacts from driving $24 \mathrm{~km}(15 \mathrm{mi})$ are allocated to the product, or $4.8 \mathrm{~km}(3 \mathrm{mi})$. Data for a van come from ecoinvent. Unplanned service visits (i.e., unanticipated issues that require a service technician) are not included in the model under the assumption that the system will run as designed given the homeowner adequately follows the maintenance and care guidelines.

The solar collectors are modeled as having a 20-year lifetime, based on product literature. At end of life, they are assumed to be recycled (see discussion in the PV chapter). A lifetime of 10 years has been assumed for the Helio-Pak, based on the warranty. ((Heliodyne No Date), Sec.7). Lifetimes of 11 years have been assumed for the solar water heaters. ((National Association of Home Builders (NAHB) Research Center 2007), Table 1, Section 1) At the end of life, it is assumed that these pieces of equipment are sent for recycling to recover valuable metal (see Section 4.5.3.7 for the recycling methodology used). What cannot be recovered is modeled as landfilled. A distance of 48 $\mathrm{km}$ (30 mi) to the landfill in a heavy-duty diesel truck has been modeled. The landfill is based on ecoinvent waste management process data. 


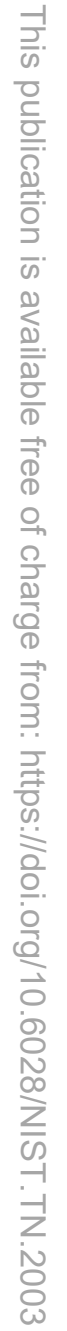




\section{Economic Performance Measurement}

When a decision maker wants a dollar measure of cost-effectiveness and cash flows are primarily costs, the most appropriate method for measuring the economic performance of a building is LCC (Fuller and Petersen 1996, ASTM 2012). BIRDS follows the ASTM International standard method for LCC of building-related investments (ASTM 2010), which involves calculating a present value of a cost by discounting its future value into Year 0, 2018 for the current version of BIRDS, dollars based on the year the cost occurs and the assumed discount rate. The formulas and discount factors used to calculate the present values will vary depending on the type of cost. The different cost types and related formulas, discount factors, data sources, and adjustment factors are described below.

\subsection{First Cost}

In the case of LCC analysis of a building, the first costs of a building are the total costs realized at the point of transfer of ownership. In the case of a newly constructed house, these are the out-of-pocket costs at the time of the home purchase (in Year 0) such as down payment and closing costs. Many closing costs are similar regardless of the sale price of a home, so they are excluded from the analysis. The down payment is a function of two variables: the financing option selected by a home purchaser and the total construction costs of the house.

\subsubsection{Total Construction Costs}

Total construction costs include all of the costs associated with constructing a building in a particular location, such as contractor labor, materials, equipment, overhead, and profit. ${ }^{26}$ The approach used to estimate the total construction costs is to first estimate the costs of constructing a building to minimum levels of energy efficiency, referred to as the "baseline" building design, and then adding the incremental costs of increasing the energy efficiency performance of each building component to meet the desired building design for each of the 960000 building simulations. A baseline design was generated for each of the exterior wall finishes: wood siding and brick veneer.

The national average baseline building costs are estimated using RSMeans Online Square Foot Cost Estimator (SFCE) based on the basic characteristics and features of the NZERTF as described in Chapter 3 (RS Means 2015). Since the costs are in 2015 dollars, they are adjusted for inflation to 2018 dollars. A screenshot of the SFCE is shown in Figure 5-1. Two levels of construction quality (average and luxury) - based on architectural design and interior finishes - are considered in this initial version of the low-energy residential incremental improvements database.

\footnotetext{
${ }^{26}$ Does not include closing costs, such as realtor commissions.
} 


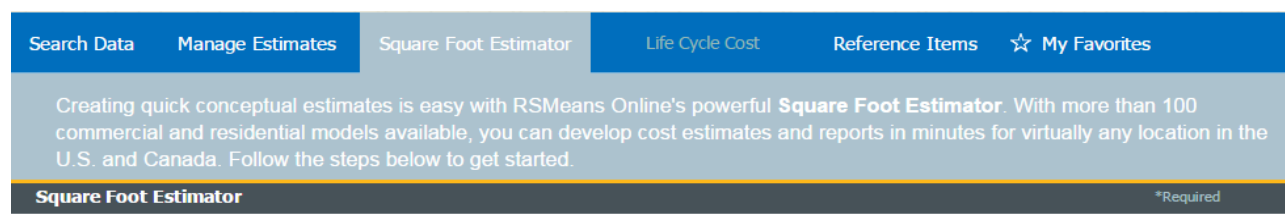

Estimate Header Information $\nabla$

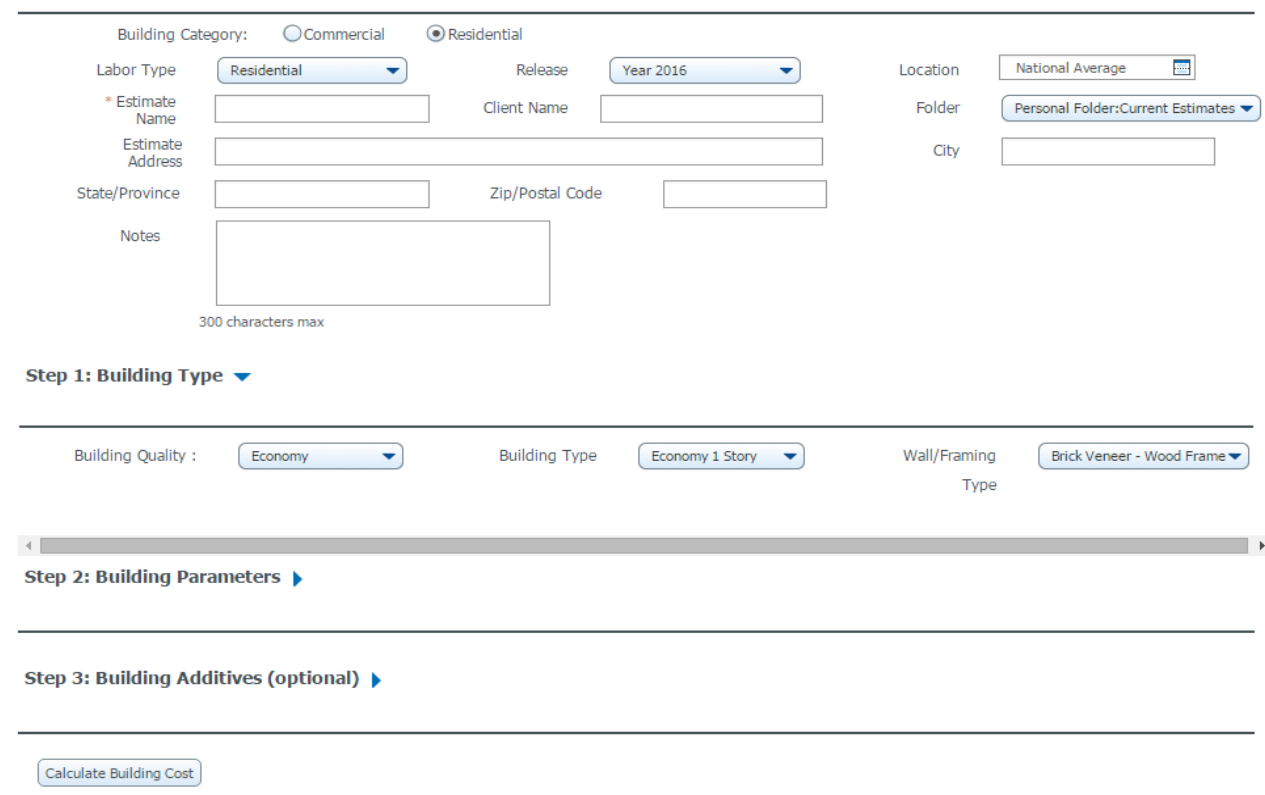

Figure 5-1 RS Means Online Square Foot Cost Estimator (SFCE)

Incremental national average cost data from Faithful+Gould (2012) and location-specific cost estimates from a NIST-contracted cost estimator (Kneifel 2016) and local solar photovoltaic installer quotes are used to add the cost of required energy efficiency measures to the baseline building costs to estimate the total first costs of a building design. The costs of 10 building components as defined in Chapter 3 - attic insulation, exterior wall insulation, foundation insulation, air sealant, windows, lighting, DHW heater, solar thermal system, HVAC system, and solar photovoltaic system - are adjusted to estimate the construction cost for the specific building design. All cost data is adjusted to 2017 dollars. The approaches to estimating the incremental costs of the alternative options for each building component will be discussed in greater detail in Section 5.1.3.

The location-specific construction costs for a building design are estimated by summing the costs of the baseline building $\left(C_{\text {NatAvg }}\right)$ and the changes in costs required to meet the prototype building design $\left(\Delta C_{x}\right)$. National average cost data for the HVAC and DHW systems were adjusted for location-related cost variation. Both the baseline building cost and component cost estimates are based on national average construction cost data, and must be adjusted with the city level cost indexes to control for local material and labor price variations in the 228 locations for which energy simulations are run. Two city construction cost indices are used to adjust for location-specific prices: $I_{F G}$ (Faithful+Gould 2011), a cost index developed along with the cost database and used to adjust the sum of the costs for the incremental building component costs and $I_{R S}$ (RS 
Means 2015), a cost index developed by RS Means for location specific adjustment for their cost databases and used to adjust the baseline building costs. The formula below shows the indexed construction cost $\left(C_{\text {Index }}\right)$ calculation.

$$
\begin{gathered}
C_{\text {Index }}=\left(C_{\text {NatAvg }}\right) * I_{R S}+\left(\Delta C_{\text {Wall }}\right)+\left(\Delta C_{\text {Attic }}\right)+\left(\Delta C_{\text {Foundation }}\right)+\left(\Delta C_{\text {Sealant }}\right) \\
+\left(\Delta C_{\text {Window }}\right)+\left(\Delta C_{\text {Lighting }}\right)+\left(\Delta C_{\text {Solar } P V}\right) \\
+\left[+\left(\Delta C_{D H W \text { Heater }}\right)+\left(\Delta C_{\text {Solar Thermal }}\right)+\left(\Delta C_{H V A C}\right)\right] * I_{F G}
\end{gathered}
$$

$\begin{array}{ll}\text { Where } C_{\text {Index }} & =\text { Indexed construction costs } \\ C_{\text {NatAvg }} & =\text { Baseline building construction costs } \\ \Delta C_{\text {Wall }} & =\text { Change in wall insulation costs } \\ \Delta C_{\text {Attic }} & =\text { Change in attic insulation costs } \\ \Delta C_{\text {Foundation }} & =\text { Change in foundation costs } \\ \Delta C_{\text {Sealant }} & =\text { Change in air sealing costs } \\ \Delta C_{\text {Window }} & =\text { Change in window costs } \\ \Delta C_{\text {Lighting }} & =\text { Change in lighting costs } \\ \Delta C_{D H W} \text { Heater } & =\text { Change in } \text { DHW Heater costs } \\ \Delta C_{\text {Solar Thermal }} & =\text { Change in Solar Thermal system costs } \\ \Delta C_{H V A C} & =\text { Change in HVAC system costs } \\ \Delta C_{\text {Solar Photovoltaic }} & =\text { Change in solar photovoltaic costs } \\ I_{R S} & =R S \text { Means city construction cost index } \\ I_{F G} & =\text { Faithful }+ \text { Gould city construction cost index }\end{array}$

Once the indexed construction costs of the building are calculated, it is necessary to adjust for the contractor fees, which include general conditions, overhead, and profit, by multiplying the costs by the "mark-up" rate $\left(I_{M}\right)$, assumed to be $15 \%$ based on the default value set within the SFCE.

$$
C_{\text {First }}=C_{\text {Index }} *\left(1+I_{M}\right)
$$

The marked-up, indexed construction costs are the total construction costs to a home purchaser for the specific building design in the location $\left(C_{\text {First }}\right)$ of interest, which is assumed to be Washington, D.C., the closest city in the cost index database to the NZERTF's actual location in Gaithersburg, MD.

\subsubsection{Purchase Financing}

The other key factor in estimating the total first costs to the home purchaser is the financing method in which the building is purchased. Few new home purchases are completed with a $100 \%$ cash payment. Instead most home purchasers use some form of loan financing, which can vary in the terms of the loan such as the interest rate of the loan, length of the loan, and amount of the loan that must be paid up-front (down payment). An all cash purchase makes the total first costs equal to the total construction costs. A financed purchase makes the total first costs equal to the down payment. At this point, the low-energy residential incremental improvements database includes two financing options: (1) $100 \%$ all cash and (2) a fixed rate loan with $20 \%$ down payment 
(80/20 loan). There are two reasons for considering an 80/20 loan in the analysis. First, it is the most common type of loan for home purchases. Second, a down payment of $20 \%$ or greater eliminates the need for any mortgage insurance, which simplifies the future mortgage payment calculations. The selected mortgage interest rate $(4.000 \%)$ was the Freddie Mac US average rate for 2019 (January 1 through October 10) for an 80/20 loan. There are a variety of other loan options available to home purchasers, including changes in interest rates over time and additional costs, which should be considered. Homebuyers can make down payments of $10 \%$ or less, but lower down payments tend to lead to higher interest rates. Borrowers can also pay additional money upfront to reduce their interest rate or to eliminate mortgage insurance in cases of a down payment less than $20 \%$. The most important of these and other factors will be incorporated into the lowenergy residential incremental improvements database in future versions of BIRDS. Although it is important to note that inclusion of all potential loan options given the wide variety of potential variables associated with a given home mortgage make it impossible to include all options.

\subsubsection{Building Components}

The incremental costs of increasing the energy performance of different building components are calculated primarily using a publicly available database developed for the Pacific Northwest National Laboratory (PNNL) (Faithful+Gould 2012) although some data points were developed by cost estimating firms through contracts with NIST (Kneifel 2016) and the solar photovoltaic cost data is obtained from a compilation of quotes from local contractors during 2018. The cost estimation approaches for each building component alternative, or energy efficiency measure (EEM), is described in this section. Cost data originated from 2012 to 2018 depending on the source and is inflated to 2018 dollars as needed using the national CPI.

\subsubsection{Baseline Building Components}

To estimate the incremental costs of each building component relative to the baseline, it is necessary to identify the baseline building components included in the baseline building costs to not over- or under-estimate total costs. Table 5-1 shows the baseline building components. In some cases, the baseline is the same as the least efficient alternative for a building component (e.g. air exchange rate) while in other instances it is less efficient than any of the alternatives considered in the database (e.g. windows). For the user's benefit, the cost of each baseline is included in the cost tables throughout this section to facilitate comparison to the alternatives given as options in BIRDS v3.0. 
Table 5-1 Baseline Building Assumptions

\begin{tabular}{|c|c|c|}
\hline \multicolumn{2}{|c|}{ Building Component } & Baseline \\
\hline Exterior Wall & $\begin{array}{l}\text { Framing } \\
\text { Insulation }\end{array}$ & $\begin{array}{c}\text { Typical } \\
\text { R-13 }\end{array}$ \\
\hline Basement Wall & $\begin{array}{l}\text { Wall } \\
\text { Slab }\end{array}$ & $\begin{array}{l}\mathrm{R}-0 \\
\mathrm{R}-0\end{array}$ \\
\hline Attic & $\begin{array}{l}\text { Roof } \\
\text { Ceiling }\end{array}$ & $\begin{array}{c}\text { R-0 } \\
\text { R-30 }\end{array}$ \\
\hline Windows & U-factor* & $6.84(1.2)$ \\
\hline & SHGC & No Requirement \\
\hline Air Exchange Rate & $\mathrm{ACH}_{50}$ & 7.0 \\
\hline Lighting & Fraction Efficient & Typical \\
\hline Heating and Cooling & System & 3 Ton Heat Pump \\
\hline & Efficiency & SEER 13 / HSPF 7.7 \\
\hline Mechanical Ventilation & & No Requirement \\
\hline Water Heater & Efficiency & 0.90 \\
\hline Solar Thermal & & None \\
\hline Solar Photovoltaic & & None \\
\hline
\end{tabular}

\subsubsection{Building Envelope Components}

The building envelope accounts for 5 of the 10 building components that change across the 960000 building designs. The thermal performance of the wall, attic, and foundation assemblies is changed by altering the materials in those assemblies, such as the framing and insulation. The installed costs associated with these changes are estimated based on per unit of area (e.g. wall area) (Kneifel 2016). The costs are in 2016 dollars and are inflated to 2018 dollars using a CPI Inflator.

There are five exterior wall assembly options based on requirements defined in different editions of the IECC and the specifications of the NZERTF as defined in Section 3.2. Note that the exterior wall finish can be excluded in this estimate because the cost differences between the two are accounted for in the baseline building cost estimate. Installed assembly cost per unit of surface area based on different framing approaches and insulation levels based on IECC requirements (Kneifel 2016). For wall assemblies that require additional insulation (Option 4 and Option 5), the additional installed costs per unit area of the insulation is added to the per unit area costs of the assembly to get the total cost of the assembly. The difference between the building design's wall assembly costs and the baseline wall assembly costs (Option 1) is the change in wall assembly costs per unit of surface area. The change in the cost per unit area is multiplied by the amount of exterior wall area to get the total change in costs of the wall assembly relative to the baseline building design $\left(\Delta C_{\text {Wall }}\right)$. 
Table 5-2 Wall, Attic, and Foundation Costs $\left(\$ / \mathbf{f t}^{2}\right)$

(a)

\begin{tabular}{|l|r|r|r|r|r|r|}
\hline \multicolumn{1}{|c|}{ Constructions } & \multicolumn{1}{|c|}{ Baseline } & \multicolumn{1}{|c|}{ Option 1 } & Option 2 & Option 3 & \multicolumn{1}{c|}{ Option 4 } & \multicolumn{1}{c|}{ Option 5 } \\
\hline Exterior & 7.46 & 8.75 & 10.03 & 8.45 & 9.20 & 9.94 \\
\hline
\end{tabular}

(b)

\begin{tabular}{|rc|r|r|r|r|r|}
\hline \multicolumn{2}{|c|}{ Constructions } & Baseline & Option 1 & Option 2 & Option 3 & Option 4 \\
\hline \multirow{2}{*}{ Basement } & Wall & 0.00 & 3.18 & 3.98 & 7.86 & 7.86 \\
& Slab & 0.00 & 0.00 & 0.00 & 0.00 & 3.89 \\
\hline
\end{tabular}

(c)

\begin{tabular}{|c|c|c|c|c|c|c|c|}
\hline \multicolumn{2}{|c|}{ Constructions } & Baseline & Option 1 & Option 2 & Option 3 & Option 4 & Option 5 \\
\hline \multirow[t]{2}{*}{ Attic } & Roof & 0.00 & 0.00 & 0.00 & 3.00 & 5.03 & 7.98 \\
\hline & Ceiling & 1.90 & 2.41 & 3.11 & 0.00 & 0.00 & 0.00 \\
\hline
\end{tabular}

The basement foundation alternatives are a combination of two assemblies, the wall assembly and floor/slab assembly, which vary in terms of the amount of rigid insulation installed in each. There are four design options defined in Section 3.2, two of which are based on IECC requirements and include insulation in the wall assembly only, and two based on the NZERTF specifications that includes additional insulation in the wall assembly and under the basement floor/slab. The difference between the building design's foundation costs per unit area and that of the baseline costs (Option 1) shown in Table 5-2 is the change in basement foundation costs per unit area. The change in per unit installed costs for the basement wall and floor/slab are multiplied by the associated area, and then added together to get the change in foundation costs $\left(\Delta C_{\text {Foundation }}\right)$.

The thermal performance of the attic assembly considers two approaches to insulating the space. Common construction practice is to treat the attic as unconditioned space and cellulose is blown onto the attic floor while the NZERTF treats the attic as conditioned space, with no insulation between the attic and $2^{\text {nd }}$ floor while incorporating insulation into the roof assembly. The baseline and Option 1 and Option 2 use the first approach, for which the cost per unit of area is multiplied by the attic floor area to calculate the roof assembly costs. Option 3, Option 4, and Option 5 (NZERTF) use the second approach, for which the costs per unit of area is multiplied by the roof area to calculate the roof assembly costs. The difference between the building design's attic assembly costs and the baseline attic assembly costs (Option 1) is the total change in costs of the attic assembly relative to the baseline building design $\left(\Delta C_{A t t i c}\right)$.

The overall thermal performance of the building envelope is dependent on the air leakage rate of the building envelope. The air leakage rate defined in IECC as well as the performance of the NZERTF are based on air changes per hour estimated using a blower door test at $50 \mathrm{~Pa}\left(\mathrm{ACH}_{50}\right)$. Table 5-3 maps the cost per unit of area to the IECC requirements of $3.0 \mathrm{ACH}_{50}$ and 7.0 $\mathrm{ACH}_{50}$, and extrapolates those data points to estimate the cost of meeting the NZERTF performance of $0.63 \mathrm{ACH}_{50}$ using data from the NIST contract estimates (Kneifel 2016) and inflating from 2016 to 2018 dollars. Additional 
blower door tests are assumed to be required to ensure that the air leakage rate is reduced to the target $\mathrm{ACH}_{50}$ levels shown in Table 5-3.

Table 5-3 Air Leakage Rates and Costs

\begin{tabular}{|c|c|c|c|c|}
\hline ACHNaT & ACH50 & $\begin{array}{c}\text { Blower } \\
\text { Door Tests }\end{array}$ & Cost Per ft ${ }^{2}$ & $\begin{array}{c}\text { Testing } \\
\text { Costs }\end{array}$ \\
\hline Baseline & 7.00 & 1 & 0.00 & 297 \\
\hline$>0.35$ & 7.00 & 1 & 0.00 & 297 \\
\hline$<0.15$ & 3.00 & 2 & 1.30 & 594 \\
\hline NZERTF & 0.63 & 3 & 3.37 & 891 \\
\hline Conversion: Cost Per $\mathrm{m}^{2}=10.76391 *$ Cost Per $\mathrm{ft}^{2}$ \\
\hline
\end{tabular}

The cost data for windows is based on the cost per unit of area for double hung windows in the National Residential Efficiency Measures Database (((NREL) 2016)). The cost data is used to create a function of the U-factor and solar heat gain coefficient (SHGC) combination, which is then used to estimate the cost per unit of area for an array of U-factor/SHGC combinations shown in Table 5-4.

\section{Table 5-4 Window Costs $\left(\right.$ Per $\left.\mathrm{ft}^{2}\right)$}

\begin{tabular}{|l|c|c|c|c|c|c|}
\hline Cost & Baseline & Option 1 & Option 2 & Option 3 & Option 4 & Option 5 \\
\hline Option & 28.65 & 33.22 & 35.30 & 37.81 & 46.59 & 79.18 \\
\hline \multicolumn{7}{|l}{ Conversion: Cost Per $\mathrm{m}^{2}=10.76391$ * Cost Per ft ${ }^{2}$} \\
\hline
\end{tabular}

\subsubsection{Building System Components}

The building lighting, HVAC and DHW systems account for 5 building components that can be varied across the 960000 building designs. The installed costs associated with these changes are provided in Faithful+Gould (2012) and are estimated on a per system basis except for lighting, which is estimated on a per-watt basis. All cost data is inflated to 2018 dollars.

The fraction of hard-wired lighting that is high efficiency is adjusted to meet each IECC edition's requirements and the NZERTF specifications. The baseline lighting from Hendron and Engebrecht (2010) is assumed for IECC editions with no lighting requirement (see Section 3.4 for details). Due to the significant drop in the price of light emitting diode (LED) bulbs, the cost of lighting is estimated using the cost data for comparable incandescent and LED bulbs $(60 \mathrm{~W}$ at $\$ 1 / \mathrm{bulb}$ and $9 \mathrm{~W}$ at $\$ 1.50 / \mathrm{bulb}$, respectively) collected from multiple construction supply companies. These costs are converted into a normalized cost per watt using incandescent wattage as the basis for the 
normalization to allow for simple cost change estimates based on wattage values. Total lighting cost estimates are shown in Table 5-5.

\section{Table 5-5 Lighting Costs}

\begin{tabular}{|l|c|c|c|c|}
\hline \multirow{2}{*}{$\begin{array}{l}\text { Lighting } \\
\text { Costs (\$) by } \\
\text { Alternative }\end{array}$} & $\begin{array}{c}|c| \\
\text { Baseline/ } \\
\text { 2003/2006 }\end{array}$ & $\mathbf{2 0 0 9}$ & $\mathbf{2 0 1 2 / 2 0 1 5}$ & NZERTF \\
\cline { 2 - 5 } & $\mathbf{3 4 \%}$ & $\mathbf{5 0 \%}$ & $\mathbf{7 5 \%}$ & $\mathbf{1 0 0 \%}$ \\
\hline Total & 16.70 & 19.64 & 24.48 & 27.71 \\
\hline Incandescent & 3.81 & 2.31 & 0.96 & 0.00 \\
\hline LED & 20.52 & 21.95 & 25.44 & 27.71 \\
\hline
\end{tabular}

The HVAC equipment includes two components, the heating and cooling equipment and mechanical ventilation. The ductwork for the heating and cooling system is assumed to be incorporated into the baseline building design. There are currently two levels of efficiency available for the heating and cooling equipment for each fuel type. Both of the all-electric systems use an air-to-air heat pump with electric supplemental heat. The HVAC systems with natural gas-fired heating include a central air conditioner and a gas furnace. Each system may have different mechanical ventilation requirements dependent on the air leakage rate and whether an HRV system is installed. The capacity of the HVAC equipment varies based on the thermal load for a given building design, which impacts the cost of the system. Installed costs for the heat pump and air conditioners (1.5, $2.0,2.5,3.0,4.0$, or 5.0 ton) as well as the furnaces $(40 \mathrm{MBH}$ to $50 \mathrm{MBH}, 60 \mathrm{MBH}$ to 64 $\mathrm{MBH}, 78 \mathrm{MBH}$ to $80 \mathrm{MBH}$, and $96 \mathrm{MBH}$ to $100 \mathrm{MBH}$ ) are selected based on the closest match to the "autosized" system in the $E+$ simulation. Table 5-6 shows the costs of the two system designs assuming a 3.0-ton heat pump or air conditioning unit, which is the size of the baseline system.

\section{Table 5-6 HVAC Equipment Costs (3 Ton)}

\begin{tabular}{|l|c|c|c|}
\hline & \multicolumn{3}{|c|}{ Heating System } \\
\cline { 2 - 4 } & Baseline & $\begin{array}{c}\text { Standard } \\
\text { Efficiency }\end{array}$ & $\begin{array}{c}\text { NZERTF } \\
\text { System }\end{array}$ \\
\hline Heat Pump & 4000 & 4000 & 5478 \\
\hline AC with Gas Furnace & 0 & 2846 & 5276 \\
\hline Outdoor Air/HRV & 0 & $753 *$ & 3965 \\
\hline * If Outdoor Air is Required & \\
\hline
\end{tabular}

The less efficient system is designed to meet current "standard practice" efficiency levels, SEER 13 for cooling (heat pump or central air conditioner) and HSPF 7.7 for heating with heat pump and $\mathrm{EF}=0.80$ for natural gas-fired furnace. The dedicated outdoor air ventilation component of the HVAC system varies depending on the air leakage rate of the building envelope. IECC requirements state that a building with air leakage of less than $3 \mathrm{ACH}_{50}$ is required to have dedicated outdoor air ventilation to adhere to $A S H R A E$ 62.2-2010. As a result, only building designs with the less efficient system and an air 
leakage rate of $3 \mathrm{ACH}_{50}$ or less will have a dedicated outdoor air component to the HVAC system. Building designs with an air leakage rate of $3 \mathrm{ACH}_{50}$ or lower and no dedicated outdoor air ventilation are not included in BIRDS because they do not meet ASHRAE 62.2 requirements. Building designs with an air leakage rate of $7 \mathrm{ACH}_{50}$ and dedicated outdoor air ventilation are not included in the database because IECC does not require mechanical ventilation. For designs with the higher efficiency system, the separate HRV system is always installed regardless of the air leakage rate. This assumption will lead to building designs with an air leakage rate of $7 \mathrm{ACH}_{50}$ to overventilate the building relative to the ASHRAE 62.2 requirements due to the air leakage. Regardless of the building design, the cost of including the ductwork for the mechanical ventilation of the less efficient system is considered negligible and is assumed to be zero (\$0) as is shown in Table 5-6.

The DHW system has four alternative designs as described in Section 3.7, and includes two separate components: a water heater and a solar thermal system. There are four water heater options available: electric and natural gas water heaters of federal minimum required efficiency, a heat pump water heater based on the NZERTF specifications, and a high efficiency natural gas water heater. The solar thermal system is either installed or not installed. The costs of these different components are independent and, therefore, can be treated as additive as shown in Table 5-7. The cost of the plumbing/piping from the water heater to the fixtures is assumed to be incorporated into the baseline costs.

Table 5-7 DHW Costs

\begin{tabular}{|c|c|c|c|c|c|c|c|}
\hline & \multicolumn{7}{|c|}{ DHW System } \\
\hline & Baseline & $\begin{array}{c}\text { Option } \\
\text { 1a }\end{array}$ & $\begin{array}{c}\text { Option } \\
1 \mathrm{~b}\end{array}$ & $\begin{array}{c}\text { Option } \\
2 a\end{array}$ & $\begin{array}{c}\text { Option } \\
2 b\end{array}$ & Option 3 & NZERTF \\
\hline $\begin{array}{l}\text { Water Heater - } \\
\text { Electric }\end{array}$ & 758 & 833 & $\mathrm{n} / \mathrm{a}$ & 833 & $\mathrm{n} / \mathrm{a}$ & $\mathrm{n} / \mathrm{a}$ & $\mathrm{n} / \mathrm{a}$ \\
\hline $\begin{array}{l}\text { Water Heater - } \\
\text { Natural Gas }(0.78)\end{array}$ & $\mathrm{n} / \mathrm{a}$ & $\mathrm{n} / \mathrm{a}$ & 757 & $\mathrm{n} / \mathrm{a}$ & $\mathrm{n} / \mathrm{a}$ & $\mathrm{n} / \mathrm{a}$ & $\mathrm{n} / \mathrm{a}$ \\
\hline $\begin{array}{l}\text { Water Heater - } \\
\text { Natural Gas }(0.90)\end{array}$ & $\mathrm{n} / \mathrm{a}$ & $\mathrm{n} / \mathrm{a}$ & $\mathrm{n} / \mathrm{a}$ & $\mathrm{n} / \mathrm{a}$ & 921 & $\mathrm{n} / \mathrm{a}$ & $\mathrm{n} / \mathrm{a}$ \\
\hline $\begin{array}{l}\text { Water Heater }- \text { Heat } \\
\text { Pump }\end{array}$ & $\mathrm{n} / \mathrm{a}$ & $\mathrm{n} / \mathrm{a}$ & $\mathrm{n} / \mathrm{a}$ & $\mathrm{n} / \mathrm{a}$ & $\mathrm{n} / \mathrm{a}$ & 1944 & 1944 \\
\hline Solar Thermal System & $\mathrm{n} / \mathrm{a}$ & $\mathrm{n} / \mathrm{a}$ & $\mathrm{n} / \mathrm{a}$ & 5866 & 5866 & $\mathrm{n} / \mathrm{a}$ & 5866 \\
\hline Total & 758 & 833 & 757 & 6699 & 6787 & 1944 & 7810 \\
\hline
\end{tabular}

The solar photovoltaic system cost data has been updated from average cost per watt estimates using quotes from local solar PV installers to using a cost function (fixed and marginal cost components) based on 2018 installer quote data. The installed cost for the system installed on the NZERTF is estimated to be $\$ 1611$ in fixed costs and $\$ 2.67 / \mathrm{W}$ in marginal costs per watt. The cost function leads to lower incremental costs from installing a larger system. Given the trend of consistently decreasing solar PV installation costs, this is likely a conservative estimate (high) for the cost of installing a solar photovoltaic system. 


\subsection{Future Costs}

Future building costs include the maintenance, repair, and replacement (MRR) costs as well as operating energy-related costs of electricity and natural gas consumption. The total present value of future costs $\left(C_{\text {Future }}\right)$ is the sum of present value location-indexed MRR costs $\left(C_{M R R}\right)$ and present value energy costs (sum of electricity costs $\left(C_{\text {Elect }}\right)$ and natural gas costs $\left.\left(\left(C_{G a s}\right)\right)\right)$ based on location-specific energy prices and projections, as shown in the following equation:

$$
C_{\text {Future }}=C_{\text {MRR }}+C_{\text {Elect }}+C_{\text {Gas }}
$$

Each of these is discussed below.

\subsubsection{Operating Energy}

Energy consumption may include both electricity and natural gas. Half of the building designs are $100 \%$ electricity because both space and water heating needs are met with equipment that runs on electricity. ${ }^{27}$ The other half are heated using natural gas with equipment that would have similar performance to that installed in the NZERTF.

The sum of the electricity and natural gas use predicted by each building design's energy simulation is used as the annual energy use of the building for each year of the selected study period. A key assumption is that the MRR of building components maintains the level of energy consumption predicted by the E+ simulation model. The electricity production predicted by the simulation model is used as a basis for the solar PV system performance, with a linear annual production degradation rate of $0.5 \%$ over the its lifetime. With a constant consumption and decreasing production, net energy consumption increases slightly year-over-year as the solar photovoltaic system degrades.

For some building designs in the database, a building would exhibit negative annual consumption resulting from the combination of lower energy consumption from energy efficiency measures and electricity production from the solar photovoltaic system. Due to the design of a state's net metering program, the cost to the homeowner of consuming electricity may not be the same as the value earned from producing electricity. Based on a local utility's rate schedule, the estimated cost of consuming electricity including all charges, taxes, and fees is assumed to be $13.45 \phi / \mathrm{kWh}$ (average cost) while the value of excess production is assumed to be $7.3 \mathrm{k} / \mathrm{kWh}$, which is the generation charge for one $\mathrm{kWh}$ of electricity. As a result, each unit of excess production is worth less than half of the value of a unit reduction in consumption, which encourages sizing a solar photovoltaic system to exactly match annual electricity production to annual electricity consumption. Along with per unit costs of electricity, there is also an assumed monthly fixed fee of $\$ 7.96$ (including Gross Receipts tax), which aggregates to $\$ 95.52$ annually. Natural gas prices are estimated using a flat marginal rate of $\$ 0.415 / \mathrm{m}^{3}\left(\$ 11.75 / 1000 \mathrm{ft}^{3}\right)$, the average price for residential customers in Maryland for 2018. Given that these

\footnotetext{
${ }^{27}$ The assumption of $100 \%$ all electric equipment is based on the design of the NZERTF.
} 
electricity and natural gas prices are based on rate schedules for 2018, electricity and natural gas costs are assumed to be in 2018 dollars.

Energy prices are assumed to change over time according to EIA forecasts (U.S. Energy Information Administration (EIA) 2015, U.S. Energy Information Administration (EIA) 2018). These forecasts are embodied in the DOE Federal Energy Management Program (FEMP) Modified Uniform Present Value Discount Factors (UPV*) for energy price estimates reported in Lavappa and Kneifel $(2018)^{28}$, which are based on a $3 \%$ real discount rate. Multiplying the annual energy costs (positive or negative) by the associated UPV* $^{*}$ value for the study period of interest estimates the present value total electricity costs $\left(C_{\text {Elect }}\right)$ and total natural gas consumption costs $\left(C_{\text {Gas }}\right)$. The discount factors vary by census region, end use, and fuel type. The same methodology is implemented to develop $\mathrm{UPV}^{*}$ factors assuming an $8 \%$ real discount rate.

\subsubsection{Maintenance, Repair, and Replacement (MRR) Costs}

Building MRR costs are discounted to equivalent present values using the methodology for calculating Single Present Value (SPV) factors for future non-fuel costs (Lavappa and Kneifel 2018). These factors are calculated using the FEMP 2018 real discount rate for federal energy conservation projects $(3 \%)$ and a value that represents the long-run real return from the stock market ( $8 \%$ ). Table 5-8 reports the SPV factors for the $3 \%$ and $8 \%$ discount rates included in the BIRDS low-energy residential incremental improvements database. The MRR costs for each year $\left(C_{M R R, i}\right)$ are multiplied by the SPV for that year and assumed discount rate and then summed and indexed to determine the total present value of MRR costs $\left(C_{M R R}\right)$.

\section{Table 5-8 2018 SPV Discount Factors for Future Non-Fuel Costs, 8 \% and $3 \%$}

\section{Real Discount Rate}

\begin{tabular}{ccr} 
Yrs & \multicolumn{2}{c}{ SPV Factor } \\
& $8 \%$ & $3 \%$ \\
1 & 0.926 & 0.971 \\
\hline 2 & 0.857 & 0.943 \\
\hline 3 & 0.794 & 0.915 \\
\hline 4 & 0.735 & 0.888 \\
\hline 5 & 0.681 & 0.863 \\
\hline 6 & 0.630 & 0.837 \\
\hline 7 & 0.583 & 0.813 \\
\hline 8 & 0.540 & 0.789 \\
\hline 9 & 0.500 & 0.766 \\
\hline 10 & 0.463 & 0.744
\end{tabular}

\begin{tabular}{ccr} 
Yrs & \multicolumn{2}{c}{ SPV Factor } \\
& $8 \%$ & $3 \%$ \\
11 & 0.429 & 0.722 \\
\hline 12 & 0.397 & 0.701 \\
\hline 13 & 0.368 & 0.681 \\
\hline 14 & 0.340 & 0.661 \\
\hline 15 & 0.315 & 0.642 \\
\hline 16 & 0.292 & 0.623 \\
\hline 17 & 0.270 & 0.605 \\
\hline 18 & 0.250 & 0.587 \\
\hline 19 & 0.232 & 0.570 \\
\hline 20 & 0.215 & 0.554
\end{tabular}

\begin{tabular}{ccr} 
Yrs & \multicolumn{2}{c}{ SPV Factor } \\
& $8 \%$ & $3 \%$ \\
21 & 0.199 & 0.538 \\
\hline 22 & 0.184 & 0.522 \\
\hline 23 & 0.170 & 0.507 \\
\hline 24 & 0.158 & 0.492 \\
\hline 25 & 0.146 & 0.478 \\
\hline 26 & 0.135 & 0.464 \\
\hline 27 & 0.125 & 0.450 \\
\hline 28 & 0.116 & 0.437 \\
\hline 29 & 0.107 & 0.424 \\
\hline 30 & 0.099 & 0.412 \\
\hline
\end{tabular}

\begin{tabular}{ccr} 
Yrs & \multicolumn{2}{c}{ SPV Factor } \\
& $8 \%$ & $3 \%$ \\
31 & 0.092 & 0.400 \\
\hline 32 & 0.085 & 0.388 \\
\hline 33 & 0.079 & 0.377 \\
\hline 34 & 0.073 & 0.366 \\
\hline 35 & 0.068 & 0.355 \\
\hline 36 & 0.063 & 0.345 \\
\hline 37 & 0.058 & 0.335 \\
\hline 38 & 0.054 & 0.325 \\
\hline 39 & 0.050 & 0.316 \\
\hline 40 & 0.046 & 0.307 \\
\hline
\end{tabular}

Residential building component, and building, lifetimes are based on three data sources: National Association of Home Builders (NAHB) Research Center (2007) for building components excluding lighting, product label lifetime ratings for light bulbs, and U.S.

\footnotetext{
${ }^{28}$ Since the U.S. Energy Information Administration forecasts end at year 30, the escalation rates for years 31 through 40 are assumed to be the same as for year 30 .
} 
Census Bureau (2011) for building lifetime. A residential building's service lifetime is assumed constant across climate zones at 65 years because, when well maintained, a building can remain in use for up to or beyond 65 years. This assumption is supported by the data in Table C-010AH of the 2011 American Housing Survey (AHS), which shows that about half of all owner-occupied housing units are 40 years of age or older and $6 \%$ are 96 years of age or older (U.S. Census Bureau 2011). Additionally, the National Association of Home Builders (NAHB) Research Center (2007) estimates the lifetime of a number of house components (e.g. foundations, chimneys) to be greater than 65 years, which implies that the house structure lasts over 65 years. Insulation and air barriers are assumed to have a lifespan greater than 40 years and have no maintenance or repair requirements. Windows have an assumed lifespan of 25 years with costs that vary depending on the required window specifications. Windows are assumed to have no maintenance costs or repair costs. The heating and cooling unit (heat pump with supplemental electric element; air conditioning unit; gas furnace) is assumed to have a lifespan of 16 years while the HRV unit is assumed to last 20 years. The electric resistance and heat pump hot water heater with additional solar thermal system are assumed to have lifespans of 12 years and 20 years, respectively. The solar photovoltaic panels are assumed to have a lifetime of 25 years while the inverters last 10 years. Incandescent and fluorescent light bulbs are assumed to have lifespans of 2 years and 10 years, respectively, based on product label lifetimes.

MRR cost data are collected from two primary sources: U.S. Census Bureau (2011) and Faithful+Gould (2011). The total maintenance and repair costs per square foot of CFA represent the baseline (non-energy related) MR costs per unit of floor area, which occur for a building type regardless of the energy efficiency measures incorporated into the design. These data are collected from The 2011 AHS National Table C-12-OO and Table C-15-OO (U.S. Census Bureau 2011), which reports median floor area $\left(177 \mathrm{~m}^{2}\right.$ or 1900 $\mathrm{ft}^{2}$ ) and average maintenance and repair costs for "Total Owner-Occupied Units" Housing Units ( $\$ 33 /$ month) and "New Construction the Past 4 Years" Housing Units (\$8/month), respectively. These two data points are adjusted to 2018 dollars and used to interpolate and extrapolate for all years considered (1 through 30) as shown in Figure 5-3. Costs are assumed to remain constant after 10 years. Additional MRR costs are calculated 
for all the building systems and windows.

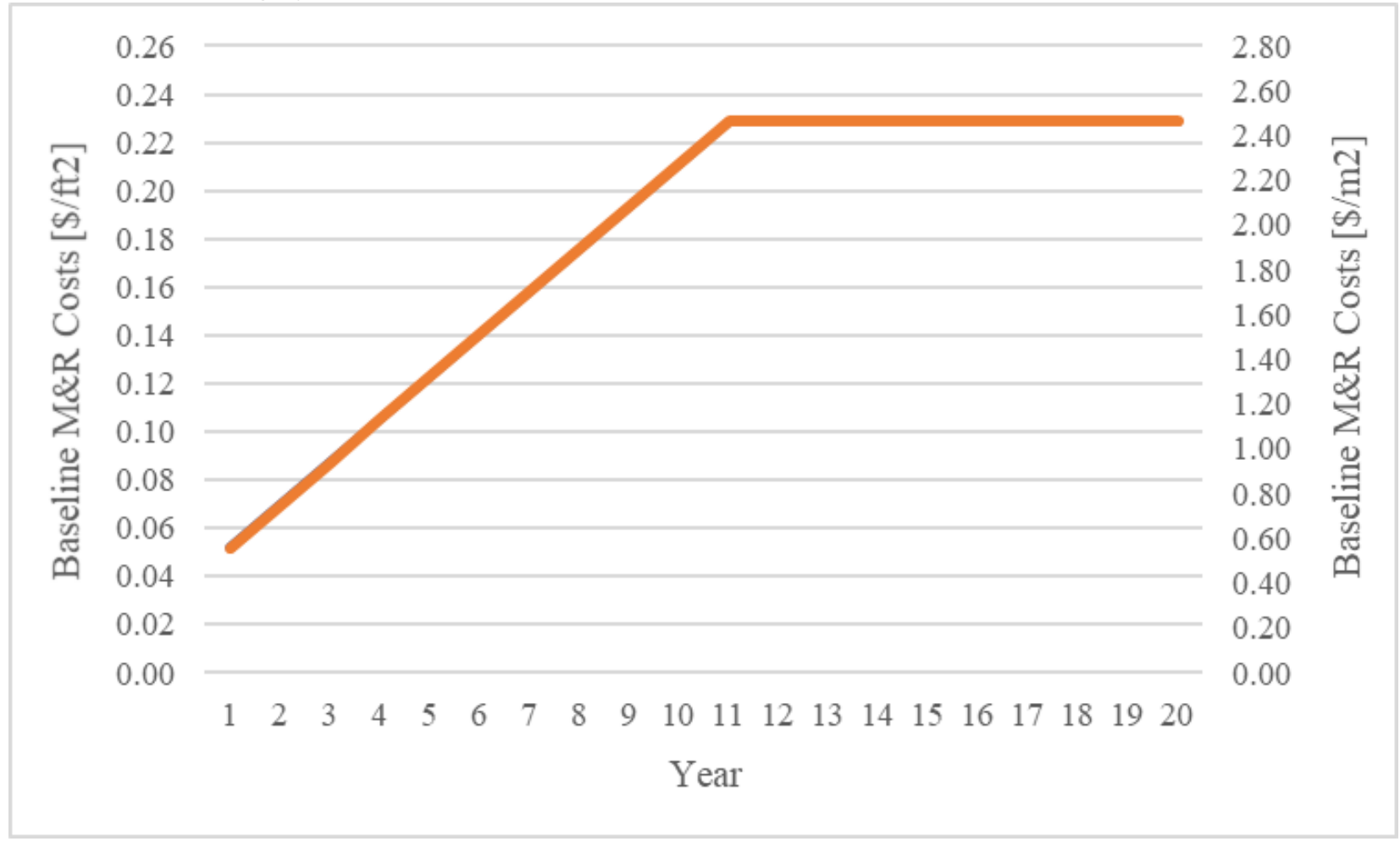

Figure 5-2 Baseline Maintenance and Repair Costs by Year

Annual maintenance and repair costs related to each building system component are shown in Table 5-9. All other components are assumed to be accounted for in the baseline maintenance and repair costs.

\section{Table 5-9 Building Component Average Maintenance and Repair Costs}

\begin{tabular}{|l|c|}
\hline System Component & Annual Cost \\
\hline Heat Pump & 200 \\
\hline HRV & 60 \\
\hline Water Heater & 100 \\
\hline Solar Thermal & 47 \\
\hline Solar photovoltaic (per kW) & 32 \\
\hline
\end{tabular}

Faithful + Gould (2012) and (Kneifel 2016) are the sources of replacement costs for the individual components for which costs change across alternative building designs, which in this analysis are the windows and the building systems (lighting, HVAC, DHW, solar thermal, and solar photovoltaic. The replacement cost of windows is assumed to be equal to the initial installation costs of the same window. The cost of replacing LED light bulbs is greater than the cost of replacing incandescent light bulbs. However, LEDs last at least 5 times longer than incandescent bulbs based on estimated operational hour lifetime (assumed to be 10 years and 2 years, respectively), which may lead to the replacements 
costs of light bulbs to be lower for the more efficient LEDs. The HVAC system assumes the same initial installation costs for the heating and cooling equipment (i.e. heat pump unit). The HVAC system capacity size varies based on the thermal performance of the building design, which results in varying replacement costs (based on first cost estimates) because smaller capacity systems are relatively cheaper. The high-efficiency system based on the NZERTF specifications includes the HRV unit that must be replaced (\$3592), which costs less than the initial system because the ductwork does not need to be replaced. The replacement cost of the solar photovoltaic inverters is assumed to be $\$ 180 / \mathrm{kW}$.

\subsection{Residual Value}

A building's residual value is its value remaining at the end of the study period. In life-cycle costing it is treated as a negative cost item. In BIRDS, it is estimated in two major parts based on the approach defined in Fuller and Petersen (1996): the building excluding components that get replaced, and the building components that get replaced (HVAC, DHW, solar thermal, solar photovoltaic system windows, and lighting). The building's residual value is calculated as the building's location-indexed first cost (excluding HVAC, DHW, solar thermal, solar photovoltaic system windows, and lighting costs) multiplied by one minus the ratio of the study period to the service life of the building, discounted from the end of the study period using the single present value factor (SPV) for the last year of the study period (T).

$$
R V=\text { First Cost } \cdot\left(1-\frac{\text { Study Period }}{\text { Service Life }}\right) \cdot S P V_{T}
$$

For example, if a building has first costs (excluding HVAC, DHW, solar thermal, solar photovoltaic, windows, and lighting) of $\$ 500000$, a 65 -year service life, a $3 \%$ discount rate, and the study period length is 10 years, the discounted residual value of the building at the end of the study period (excluding HVAC, DHW, solar thermal, solar photovoltaic system windows, and lighting) is:

$$
\$ 500000 \cdot\left(1-\frac{10}{65}\right) \cdot 0.744=\$ 314769
$$

Because they may be replaced during the study period, residual values for the excluded HVAC, DHW, solar thermal, solar photovoltaic, windows, and lighting are computed separately. The remaining "life" of a building component is determined by taking its service life minus the number of years since its last installation (as of the end of the study period), whether it occurred during building construction or replacement. The ratio of remaining life to service life is multiplied by the location-indexed installed cost of the system and discounted from the end of the study period.

For example, assume an HVAC system's installed costs are $\$ 12000$ with a service life of 15 years, and a 20 -year study period. After one replacement, the system is 5 years old at 
the end of the study period, leaving 10 years remaining in its service life. The discounted residual value in year 20 is:

$$
\$ 12000 \cdot \frac{10}{15} \cdot 0.744=\$ 5952
$$

The residual value for the DHW, solar thermal, solar photovoltaic system windows, and lighting is computed in a similar manner.

The total residual value of the building and its HVAC, DHW, solar thermal, solar photovoltaic system windows, and lighting, multiplied by the SPV factor for the number of years in the study period and assumed discount rate, estimates the present value of the residual value $\left(C_{\text {Residual }}\right)$.

\subsection{Life-Cycle Cost Analysis}

The total life-cycle cost of a prototype building $\left(C_{L C C}\right)$ is the sum of the present values of first cost and future costs minus the residual value as shown in the following equation:

$$
C_{\text {LCC }}=C_{\text {First }}+C_{\text {Future }}-C_{\text {Residual }}
$$

LCC analysis of buildings typically compares the LCC for a "base case" building design to the costs for alternative, more energy efficient building design(s) to determine if future operational savings justify higher initial investments. For BIRDS, total life-cycle costs are calculated as described above for all building design options for all study periods. The user of the tool has the option to select any of the building designs as the "base case," and compare it to any of the alternative designs. For an investor comparing mutually exclusive design alternatives, the same study period must be used for all alternatives. For those interested in the sensitivity of LCC results to the assumed study period length, BIRDS permits the study period length for a given building design to vary.

Two metrics are used to analyze changes in life-cycle costs: net LCC savings (ASTM 2012) and net LCC savings as a percentage of base case LCC. Net Savings (NS) is the difference between the base case LCC $\left(C_{B a s e}\right)$ and alternative design LCC $\left(C_{A l t}\right)$ as shown in the following equation:

$$
N S=C_{\text {Base }}-C_{A l t}
$$

Net LCC savings as a percentage of base case LCC $(P N S)$ is the net LCC savings divided by the base case LCC. This metric, shown in the equation below, allows for comparisons across building types that vary significantly in terms of floor area.

$$
P N S=\frac{N S}{C_{\text {Base }}} \cdot 100
$$




\section{Indoor Environmental Quality Performance}

A sustainable, high performing building should meet the health and comfort needs of its occupants at lower overall costs and environmental impacts. To improve consideration of building occupants, BIRDS v3.1 included the addition of sustainability metrics to account for the impacts of building performance on the building occupants. The two metrics are occupant thermal comfort and IAQ. Both metrics are estimated within the $E+$ simulations for each of the 960000 building designs as described in the following sections.

\subsection{Occupant Thermal Comfort}

One of the primary purposes of residential buildings is to provide shelter from outdoor weather conditions. One measure by which a building can be shown to fulfill this purpose is by demonstrating that indoor conditions are amenable to providing a comfortable thermal environment. ASHRAE Standard 55-2010 Thermal Environmental Conditions for Human Occupancy "outlines conditions in which a specified fraction of the occupants will find the environment thermally acceptable" (ASHRAE 2010). Based on ASHRAE Standard 55, BIRDS v3.1 utilizes the number of hours of the year for which conditions would not be acceptable for providing thermal comfort of occupants as one of its indoor environmental metrics.

E+ implements multiple thermal comfort models. BIRDS implements the ASHRAE 55 Simple Model which is based on the Graphic Comfort Zone Method for Typical Indoor Environments of ASHRAE Standard 55-2004. Conditions are considered "uncomfortable" if they are outside the summer or winter comfort zones shown in Figure 6-1, which differ in the assumed value for clothing insulation (clo value). $E+$ also requires the occupant Activity Level to be input which were defined as previously described in Section 3.6. E+ then reports the "Thermal Comfort ASHRAE 55 Simple Model Summer or Winter Clothes Not Comfortable Time" which indicates the number of hours the occupied zones $\left(1^{\text {st }}\right.$ floor and $2^{\text {nd }}$ floor $)$ are outside the comfort range. See E+ Input-Output Reference for additional information (DOE (2015)). 

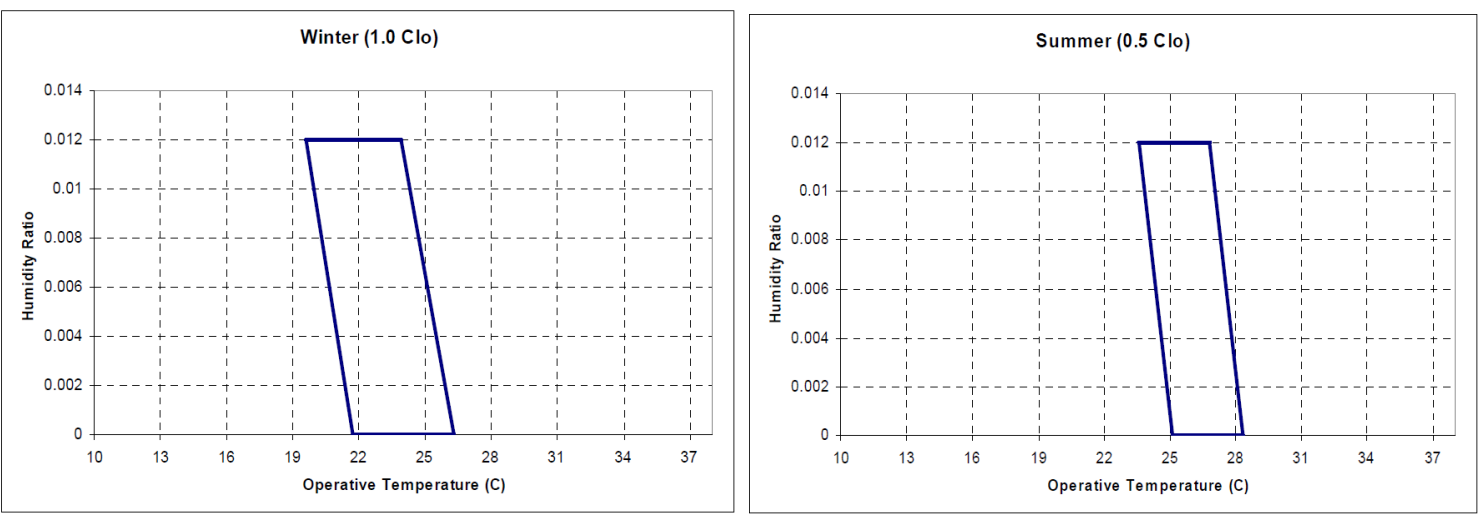

\section{Figure 6-1 ASHRAE Standard 55-2004 Thermal Comfort Range - Winter (left) and Summer (right) ${ }^{29}$}

\subsection{Indoor Air Quality}

High performance building design often focuses on improved energy efficiency measures, but an integrated approach to building design is required so as not to sacrifice acceptable indoor air quality in the process of improving energy efficiency. For example, improving energy efficiency by reducing envelope air infiltration may lead to elevated pollutant levels of indoor sources. Depending on the pollutants, this can lead to negative health outcomes ranging from minor, short-term effects (e.g., headaches and nausea) to more serious long-term effects (e.g., heart disease and cancer). Additionally, increasing envelope insulation in combination with reduced infiltration can lead to greater temperature and humidity differences between the indoor and outdoor environments, creating conditions that could potentially lead to condensation and mold growth (NIST 2012). These negative impacts can be ameliorated by providing a mechanical ventilation system as required by many ventilation standards, e.g., ASHRAE Standard 62.2.

ASHRAE Standard 62.2-2016 Ventilation for Acceptable Indoor Air Quality in Residential Buildings defines acceptable IAQ as air toward which a substantial majority of occupants express no dissatisfaction with respect to odor and sensory irritation and in which there are not likely to be contaminants at concentrations that are known to pose a health risk. As an initial demonstration of accounting for IAQ, this version of BIRDS is addressing ventilation to address the odor aspect of Standard 62.2 by simulating carbon dioxide $\left(\mathrm{CO}_{2}\right)$ emissions of building occupants (Persily 2015). It is important to note that elevated levels of $\mathrm{CO}_{2}$ are not necessarily indicative of elevated levels of other contaminants.

For these demonstration purposes, BIRDS utilizes two levels of $\mathrm{CO}_{2}$ concentration as its IAQ metrics: $1454 \mathrm{mg} / \mathrm{m}^{3}$ (750 parts per million (ppm)) and $1744 \mathrm{mg} / \mathrm{m}^{3}$ (900 ppm).

\footnotetext{
${ }^{29}$ Figure 40 and Figure 41 from E+ v8.3 Input-Output Reference (DOE 2015).
} 
These concentrations are $678 \mathrm{mg} / \mathrm{m}^{3}(350 \mathrm{ppm})$ and $969 \mathrm{mg} / \mathrm{m}^{3}(500 \mathrm{ppm})$ greater than assumed, constant outdoor air concentration of $775 \mathrm{mg} / \mathrm{m}^{3}(400 \mathrm{ppm})$ and were selected based on those mentioned in the informative appendices of two European Committee for Standardization (CEN) documents: EN 13779:2004 (BSI 2004) and EN 15251(BSI 2007). The $750 \mathrm{ppm}$ value is mentioned in conjunction with EN13779 Category 1 (high indoor air quality) and EN15251 Category II ("normal level of expectation and should be used for new buildings and renovations") while $900 \mathrm{ppm}$ is linked to EN13779 Category 2 (medium indoor air quality) and EN15251 Category III ("an acceptable, moderate level of expectation and may be used for existing buildings").

For the purposes of the $\mathrm{E}+$ simulations, the $\mathrm{CO}_{2}$ generation inside the house were all assumed to be attributed to the occupants, and the rate was assumed to be constant at 3.82 x $10^{-8} \mathrm{~m}^{3} / \mathrm{s}-\mathrm{W}$ per person $(0.0084 \mathrm{cfm} / \mathrm{met}$ per person). Future consideration should be placed on incorporating other air pollutants to better address indoor air quality with respect to contaminants of concern. 


\section{Software Development and Design}

BIRDS is a data-driven web application that enables access to a NIST-developed lowenergy residential incremental improvements database with approximately 150 million records. The database is based on 960000 energy simulations as described in previous sections of this report. Comparisons of life-cycle costs, operating energy consumption, or environmental impacts for different building designs can be evaluated using the data visualization features in the application. Technologies were selected for this project based on their utility in developing this comprehensive system. A summary of each technology is described below.

\subsection{Database}

\subsubsection{Database Management - Sql Server}

Microsoft Sql Server relational database management system is used to store the low-energy residential incremental improvements database. The data set used by the application is large, containing over 150 million records. Creating efficient indexes is important for reducing fetch times for records so the application will display data quickly.

\subsubsection{Database Development - Python}

Python is a widely used, general purpose programming language. For the BIRDS project, Python programs have been created for generating the final data set which contains over 75 million records. Python scripts have been developed to generate LCC data, operating energy data, and environmental impact data from location specific building simulation data.

\subsection{Application}

\subsubsection{Software Programming Language - C\#}

$\mathrm{C \#}$ is an object-oriented programming language developed by Microsoft. It is based on the $\mathrm{C}++$ programming language, has many similarities with Java, and was developed to work with the .Net framework. C\# is used primarily for developing the server-side code of BIRDS v3.0, including modules to process results data for visualization and data retrieval.

\subsubsection{Software Framework - .NET}

The .Net Framework is a Microsoft developed framework, which contains the common language runtime, in addition to several common class libraries. The common language runtime can be thought of as the foundation of the framework that manages processes at execution time. BIRDS targets the .Net Framework version 4.5. 


\subsubsection{Web Development Technologies - HTML, CSS, JavaScript, JQuery, jqChart}

Several web technologies were used in the creation of the user interface. Hypertext Markup Language (HTML) is the primary language used for displaying web content. Cascading Style Sheet (CSS) is the definition file used by web pages for formatting. JavaScript is a light-weight scripting language used to programmatically manipulate the input, output or display of a web page. JQuery is a JavaScript library that facilitates Document Object Model (DOM) manipulation and simplifies partial web page data refreshing through asynchronous JavaScript and XML (AJAX) requests. jqChart is a html5 charting library used to render charts based on the data for specific comparisons in BIRDS v3.0.

\subsubsection{Application Design - Visual Studio}

The BIRDS application is developed using Visual Studio's MVC 5 project template with the "database first method." Model, view, and controller functions are all placed in different code files to keep each entity separate. The general flow of the application can be seen in Figure 6-1. A user makes a request through the browser. The controller gets the request and passes the request parameters to the model, which retrieves necessary data from the database. The model passes back the data, which is merged with the view and then passed back to the browser by the controller.
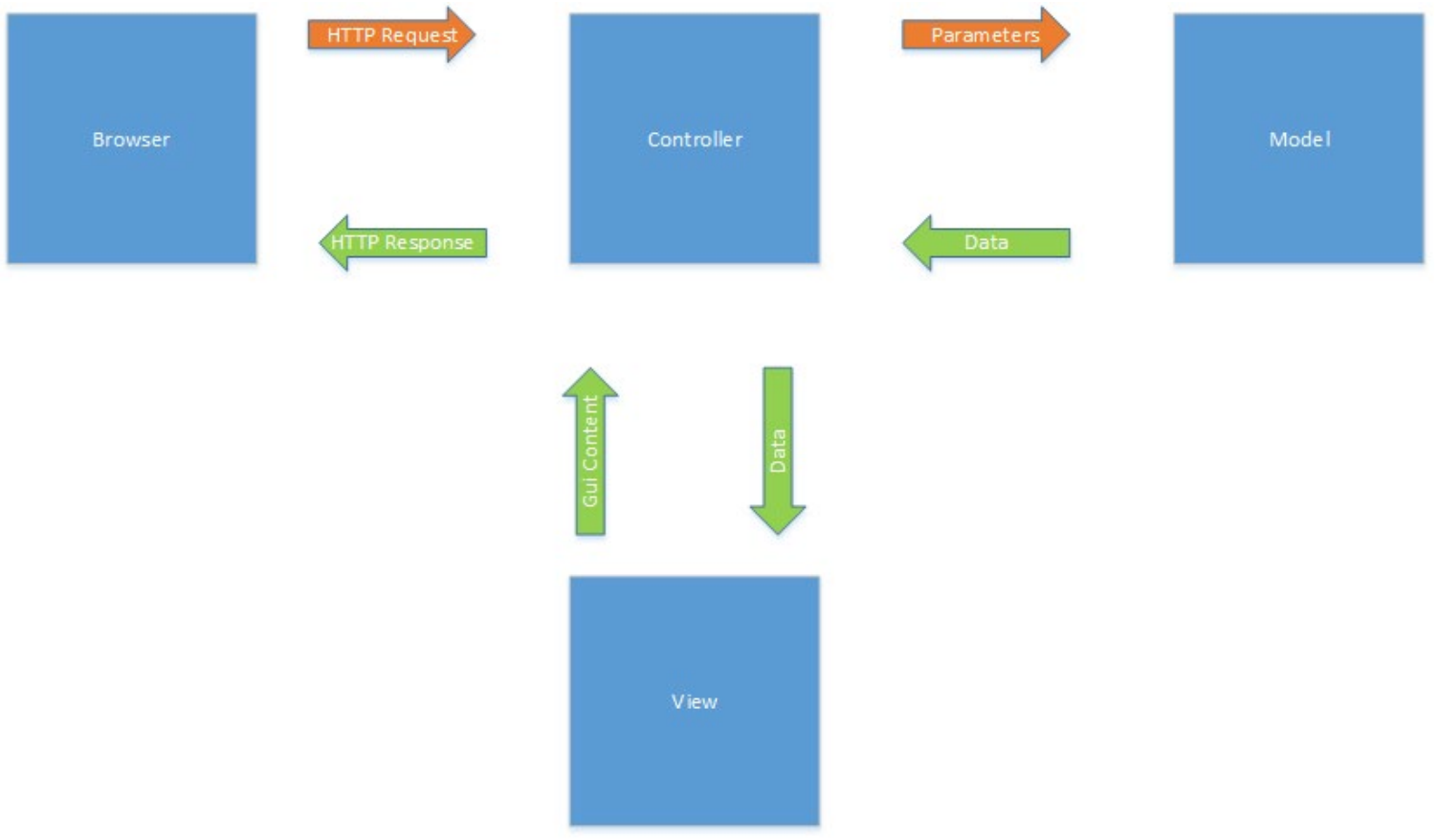

Figure 7-1 Application Information Flow

In developing the BIRDS low-energy application, the database first method is used because the BIRDS low-energy residential incremental improvements database had been developed prior to development of the user interface module. The model containing 
fourteen tables was created based on the database. Controller methods were then developed to retrieve data based on specific parameters from the model, which was then combined with the view and passed back to the browser to be displayed to the user. Comparison results are displayed by the chart module, which contains functions for ordering, formatting, and displaying data for different chart types. The capability to download the data in a .csv file is included so that data can be analyzed by the user according to their preferences. 


\section{Limitations and Future Research}

The databases in the original two versions of BIRDS (v1.0 and v2.0) allowed for analysis of a limited number of combinations of energy efficiency measures based on building energy standard and code editions across multiple (hypothetical and simplified) building prototypes located in 228 U.S. cities. Although some assumptions were allowed to vary (e.g. study period length), a number of key assumptions were held constant across the analysis (e.g. discount rate). The analysis that can be completed with such a database design could be considered an "inch-deep, mile-wide" approach.

The approach used to develop the BIRDS (v3.0) low-energy residential incremental improvements database focuses on a single location (Gaithersburg, MD) and building prototype (NIST's NZERTF), but included many more building design options (variation from four or five building designs per building prototype-location combination to 240000 building designs in one location) and additional variation across assumptions that had previously been held constant in BIRDS (e.g. discount rate, construction quality, financing). In addition, the simulation model for which the database is developed has been validated using in-situ energy performance from the demonstration phase of the NZERTF. This approach allows for a "deep-dive" into the sustainability performance of the building to determine the optimal design based on the assumptions, preferences, and goals of the BIRDS user. BIRDS v3.1 expanded on the low-energy residential incremental improvements database by incorporating additional sustainability metrics (occupant thermal comfort and indoor air quality) and additional exterior wall finishes while increasing the graphing capabilities of the BIRDS interface. BIRDS v4.0 and BIRDS v4.1 continued to expand building component options and update underlying data.

However, to get these additional features, the low-energy residential incremental improvements database is currently limited in scope. Including additional locations, building prototypes, uncertainty analysis, metrics, and flexibility into the tool would greatly strengthen the depth of its coverage.

Uncertainty analysis is needed for at least four elements of the analysis. First, consider the assumed discount rates, construction quality, and financing options. Although two options are included for each of these assumptions, additional alternatives should be included to better match potential user preferences. Second, the analysis in this study assumes the occupancy and load profiles of the "family of four" simulated in the NZERTF (Omar and Bushby 2012), which ignores the impacts from variations in occupancy and behavior patterns, in terms of plug and process load use, thermostat setpoints, and number of occupants. Future research should consider the impact that improved equipment efficiency and changes in occupant activity have on the overall energy savings realized by energy efficiency improvements to buildings. Third, the BIRDS environmental impact scores do not incorporate uncertainty analysis as required by international standards (International Organization for Standardization (ISO) 2006a, 
International Organization for Standardization (ISO) 2006b). While incorporating uncertainty analysis is problematic due to a lack of underlying uncertainty data, this omission should be brought into the interpretation of the BIRDS results in the future.

Additional locations and building prototypes should be incorporated into the BIRDS lowenergy residential incremental improvements database. Initially, the 960000 building designs should be simulated in other locations in the Building America (BA) MixedHumid Climate Zone for which the NZERTF architectural design is common because it is possible that the optimal design may be different across the climate zone. Local energy tariffs should be included to capture the variation in energy costs across the climate zone. Alternative architectural designs, such as a single-story ranch/rambler style home, should be simulated and incorporated into the database to allow users to better match their desired home prototype. Alternative foundations should also be included because even within the Mixed-Humid Climate Zone, foundation type can vary. For example, locations in the central U.S. tend to have more slab and crawlspace foundations instead of the basement foundations that are typical in Maryland. The three elements here are merely examples of areas where additional uncertainty analysis is needed. Other sources to be considered in the future are financing rates, solar photovoltaic output, electricity price, degradation rates, and unscheduled MRR.

Analysis based on the energy performance is susceptible to the limitations and variations among current whole building energy simulation tools as well as variations among different users in creating building representation with the tools. As the development and application of simulation software improves in accuracy and uncertainty, the sustainability analysis related to the modeling should improve as well.

Properly interpreting the BIRDS environmental performance results requires placing them in perspective. The environmental impact scores assess the life-cycle impacts of operating energy use based on inventories of localized energy simulation results and regional electricity grids. All other elements of the scores - including a building's use of materials and its water consumption over the study period - are based on U.S. average LCI data for prototypical buildings. The baseline data for these buildings represent status quo building technologies as of 2002, the year of the latest available input-output data from the U.S. Bureau of Economic Analysis at the time of the database development. To account for evolution in status quo technologies over time, future versions of BIRDS should incorporate newer releases of these data as they become available.

The BIRDS LCAs use selected inventory flows converted to selected local, regional, and global environmental impacts to assess environmental performance. Those inventory flows which currently do not have scientifically proven or quantifiable impacts on the environment are excluded, such as mineral extraction and wood harvesting, which are qualitatively thought to lead to loss of habitat and an accompanying loss of biodiversity. Any new or improved data and/or modeling approaches should be brought into the interpretation of the BIRDS results. 
The Environmental Problems approach that BIRDS uses for impact assessment does not offer the same degree of relevance for all environmental impacts. For global and regional effects (e.g., climate change and acidification) the method may result in an accurate description of the potential impact. For impacts dependent upon local conditions (e.g., smog, ecological toxicity, and human health impacts) it may result in an oversimplification of the actual impacts because the indices are not tailored to localities.

During the interpretation step of the BIRDS LCAs, environmental impact results are optionally combined into a single environmental performance score using relative importance weights. These weights necessarily incorporate values and subjectivity. BIRDS users should routinely test the effects on the environmental impact scores of changes in the set of importance weights by completing their analysis with more than one weighting approach.

Life-cycle impact assessment is a rapidly evolving science. Assessment methods unheard of a decade ago have since been developed and are now being used routinely in LCAs. While BIRDS incorporates state-of-the-art impact assessment methods, the science will continue to evolve and methods in use today - particularly those for land and water use are likely to change and improve over time. Future versions of BIRDS should incorporate these improved methods as they become available.

The current economic analysis does not include all potential factors that could impact costs. Federal, state, and local incentives (i.e. federal and state tax credits, state and utility rebate programs) are available in many locations for energy efficient, green, and renewable products, systems, and buildings. More recent studies have shown that some homeowners have been able to capture "green premiums" at resale, but it is unclear whether those premiums match the residual values calculated using LCCA methodology. These, as well as many other cost-related factors, should be incorporating into future LCC analysis within BIRDS.

Energy, environmental, and economic performance are but three attributes of building performance. The BIRDS model assumes that its building prototypes all meet minimum technical performance requirements. However, there may be significant differences in technical performance not evaluated in BIRDS, such as acoustic, fire, or more complex indoor environmental quality performance evaluation (e.g., alternative air quality, occupant comfort, and health measures), which may affect energy, environmental, and economic outcomes.

The BIRDS sustainability results do not apply to buildings constructed in other countries where industry practices, fuel mixes, environmental regulations, transportation distances, and labor and material markets may differ. Furthermore, all buildings of a given type are not created equal. Building designs, sizes, useful lives, materials compositions, and costs will all vary for an individual building. The BIRDS results for a building prototype do not necessarily represent the performance of an individual building of that type. Future versions of the tool should permit flexibility in building design and use of materials. 


\section{References}

(NREL), N. R. E. L. (2016). "National Residential Efficiency Measures Database v3.1.0."

https://remdb.nrel.gov/.

(VHK), V. H. e. K. (2007). B. Prepatory Study on Eco-Design of Water Heaters. Task 5 Report (Final).

Adomatis, S. (2015). What is Green Worth?, Adomatis Appraisal Services.

AHRI (2008). ANSI/AHRI 210/240-2008: 2008 Standard for Performance Rating of Unitary AirConditioning \& Air-Source Heat Pump Equipment.

AHRTI (2011). Life-cycle Climate Performance Model for Residential Heat Pump Systems, AHRTI Report No. 09003-01.

Aroul, R. and J. A. Hansz (2012). "The Value of" Green:" Evidence from the First Mandatory Residential Green Building Program." Journal of Real Estate Research 34(1): 27-49.

ASHRAE (2012). American Society of Heating, Refrigerating, and Air-Conditioning Engineers 90.22007.

ASTM (2010). E779-10 Standard Test Method for Determining Air Leakage Rate by Fan Pressurization.

ASTM (2010). Standard Practice for Measuring Life-Cycle Costs of Buildings and Building Systems, ASTM Designation E917-05. West Conshohocken, PA.

ASTM (2011). Standard Practice for Applying the Analytic Hiearchy Process Multiattribute Decision Analysis of Investments Related to Buildings and Building Systems, ASTM Designation E1765-11. West Conshohocken, PA.

ASTM (2012). Standard Guide for Selecting Economic Methods for Evaluating Investments in Buildings and Building Systems, ASTM Designation E1185-12. West Conshohocken, PA.

ASTM (2012). Standard Practice for Measuring Net Benefits and Net Savings for Investments in Buildings and Building Systems, ASTM Designation E1074-09. West Conshohocken, PA.

Athena Sustainable Materials Institute (2003). Exploratory Life-cycle Analysis of Residential Operating Energy Systems. 
Atherton, J. (2007). "Declaration by the Metals Indusctry on Recycling Principles." The International Journal of Life-cycle Assessment 12(1): 59-60.

Atlas Roofing Corporation (2012). Energy Shield/Energy Shield Plus/Cavity Wall Material Safety Data Sheet.

Bare, J. (2011). "TRACI 2.0: the tool for the reduction and assessment of chemical and other environmental impacts 2.0." Clean Technologies and Environmental Policy 13(5): 687-696.

Bare, J., et al. (2006). "Development of the method and US normalization database for life cycle impact assessment and sustainability metrics." Environmental science \& technology 40(16): 5108-5115.

Bayer MaterialScience (2008). Energy and Environmental Benefits of Insulating Commercial Buildings with Polyiso.

Bayer MaterialScience (2011). Life-Cycle Assessment of Polyiso Insulation - Final Report, Bayer MaterialSchienve.

Biswas, W. and M. Rosano (2011). "A life cycle greenhouse gas assessment of remanufactured refrigeration and air conditioning compressors." International Journal of Sustainable Manufacturing 2(2-3): 222-236.

Brundtland Commission (1987). Our Common Future: Report of the World Commission on Environment and Development. UN Documents Gatheringa Body of Global Agreements.

BSC (2009). 65\% Net-Zero Energy Residential Test Facility Construction Documents Set, National Institute of Standards and Technology.

BSI (2004). Ventilation for non-residential buildings. Performance requirements for ventilation and room-conditioning systems. BS EN 13779:2004.

BSI (2007). Indoor environmental input parameters for design and assessment of energy performance of buildings addressing indoor air quality, thermal environment, lighting and acoustics. BS EN 15251:2007.

Cohen, S. (2006). "Green Buildings." The Washington Post. from http://www.washingtonpost.com/wpdyn/content/article/2006/08/03/AR2006080301410.html. 
DAP (2005). Alex Plus Acrylic Latex Caulk Plus Silicone Material Safety Data Sheet.

DAP (2011). Technical Bulletin for ALEX PLUS Acrylic Latex Caulk Plus Silicone.

Dastrup, S., et al. (2012). "Understanding the solar home price premium: electricity generation and "green" social status." European Economic Review 56(5): 961-973.

De Kleine, R. (2009). Life-cycle Optimization of Residential Air Conditioner Replacement, Report No. CSS09-12, University of Michigan, Ann Arbor.

Earthsure (2013). Window Product Category Rule [Draft for Review]. Earthsure PCR No. 30171600.

Ecobilan (2001). Eco-profile of high-volume commodity phthalate esters (DEHP/DINP/DIDP).

Ecoinvent (2007). "Life-Cycle Inventory Database." from http://www.ecoinvent.org/database/.

Energy Efficiency and Renewable Energy (EERE) (2012). Life-Cycle Assessment of Energy and Environmental Impacts of LED Lighting Products Part 1: Review of the Life-Cycle Energy Consumption of Incandescent, Compact Fluorescent, and LED Lamps, U.S. Department of Energy.

Faithful+Gould (2011). Residential Energy Efficiency Measures: Location Factors, National Renewable Energy Laboratory.

Faithful+Gould (2012). Residential Energy Efficiency Measures: Prototype Estimate and Cost Data Revision 6.0, National Renewable Energy Laboratory.

Fraunhofer (2012). Executive Summary: Life Cycle Assessment (LCA) screening of the Maltha recycling process for Si-PV modules. http://www.pvcycle.org/.

Fthenakis, H. C. K., R. Frischknecht, M. Raugei, P. Sinha, M. Stucki (2011). Life Cycle Inventories and Life Cycle Assessment of Photovoltaic Systems, International Energy Agency (IEA).

Fuller, S. and S. Petersen (1996). Life-Cycle Costing Manual for the Federal Energy Management Program, 1995 Edition. NIST handbook. 135.

Gloria, T. P., et al. (2007). "Life-Cycle Impact Assessment Weights to Support Environmentally Preferable Purchasing in the United States." Environmental science \& technology 41(21): 75517557. 
Goedkoop, M., et al. (2008). "A Life-Cycle Impact Assessment Method which Comprises Harmonised Category Indicators at the Midpoint and the Endpoint Level. Report I:

Characterisation. ." from www.Icia-recipe.net.

Griffin, A., et al. (2009). "Certified home performance: assessing the market impacts of third party certification on residential properties." Portland, OR: Earth Advantage Institute.

Guinée, J. B. (2002). "Handbook on Life-Cycle Assessment Operational Guide to the ISO Standards." The International Journal of Life Cycle Assessment 7(5): 311-313.

Heliodyne (No Date). Helio-Pak Heat Transfer Appliance, Technical Specifications.

Hendrickson, C., et al. (2006). Environmental Life-Cycle Assessment of Goods and Services: An Input-Output Approach, Resources for the Future Press.

Hendron, R. and C. Engebrecht (2010). Building America House Simulation Protocols. Energy Efficiency and Renewable Energy, National Renewable Energy Laboratory.

Hoen, B. (2011). "An analysis of the effects of residential photovoltaic energy systems on home sales prices in California." Lawrence Berkeley National Laboratory.

HPAK, H. (No Date). "Installation Guide: HPAK Systems v.2.1.1."

ICA (2012). Life-cycle Assessment of Primary Copper Cathode, International Copper Association (ICA).

Intergovernmental Panel on Climate Change (IPCC) (2005). IPCC/TEAP Special Report: Safeguarding the Ozone Layer and the Global Climate System.

International Code Council (ICC) (2006). 2006 International Energy Conservation Code. Washington, DC, International Code Council.

International Code Council (ICC) (2009). 2009 International Energy Conservation Code. Washington, DC, International Code Council.

International Code Council (ICC) (2012). 2012 International Energy Conservation Code. Washington, DC, International Code Council. 
International Code Council (ICC) (2015). 2015 International Energy Conservation Code. Washington, DC, International Code Council.

International Copper Association (ICA) (2012). Life-cycle Assessment of Primary Copper Cathode.

International Organization for Standardization (ISO) (2006a). Environmental Management -- LifeCycle Assessment -- Principles and Framework, International Standard 14040.

International Organization for Standardization (ISO) (2006b). Environmental Management -Life-Cycle Assessment -- Principles and Framework, International Standard 14044.

Jungbluth, N. (2007). Sonnenkollektor-Anlagen. In Dones, R. (Ed.) et al. Sachbilanzen von Energiesystemen: Grundlagen fur den okologischen Vergleich von Energiesystemen und den Einbezug von Energiesystemen in Okobilanzen fur die Schweiz. ecoinvent report No. 6-XI, Swiss Centre for Life Cycle Inventories.

Jungbluth, N. a. T., M. (2007). Photovoltaics. R. E. e. a. S. v. E. G. f. d. o. V. v. E. u. d. E. v. E. i. O. f. d. S. e. r. In Dones, Swiss Centre for Life Cycle Inventories.

Kahn, M. E. and N. Kok (2014). "The capitalization of green labels in the California housing market." Regional Science and Urban Economics 47: 25-34.

Kneifel, J. (2010). "Life-Cycle Carbon and Cost Analysis of Energy Efficiency Measures in New Commercial Buildings." Energy and Buildings 42(3): 333-340.

Kneifel, J. (2011a). "Beyond the Code: Energy, Carbon, and Cost Savings using Conventional Technologies." Energy and Buildings 43(4): 951-959.

Kneifel, J. (2011b). "Prototype Commercial Buildings for Energy and Sustainability Assessment: Design Specification, Life-Cycle Costing and Carbon Assessment." NIST Technical Note 1716.

Kneifel, J. (2012). "Annual Whole Building Energy Simulation of the NIST Net Zero Energy Residential Test Facility Design." NIST Technical Note 1767.

Kneifel, J. (2012). "Prototype Residential Building Designs for Energy and Sustainability Assessment." NIST Technical Note 1765.

Kneifel, J. and P. Lavappa (2015). "Building Industry Reporting and Design for Sustainability (BIRDS) New Residential Database Technical Manual." NIST Technical Note 1878. 
Kneifel, J. and E. O'Rear (2015). "Comparing the Energy and Economic Performance of the NIST NZERTF Design across the Mixed-Humid Climate Zone." NIST Special Publication 1603.

Kneifel, J., et al. (2015). "Simulated versus Measured Energy Performance of the NIST Net Zero Residential Test Facility Design." NIST Special Publication 1182.

Kneifel, J. O. R., E. (2016). Net-Zero Energy Residential Building Component Cost Estimates and Comparisons. Special Publication 1207, National Institute of Standards and Technology.

Kok, N. and M. Kahn (2012). The Value of Green Labels in the California Housing Market: An Economic Analysis of the Impact of Green Labeling on the Sales Price of a Home. Berkely, CA, University of California, Berkely.

Lavappa, P. and J. Kneifel (2018). Energy Price Indices and Discount Factors for Life-Cycle Cost Analysis - 2018, Annual Supplement to NIST Handbook 135. National Institute of Standards and Technology.

Levin, L. (1996). Best Sustainable Indoor Air Quality Practices in Commercial Buildings. Third International Green Building Conference and Expostion - 1996, Gaithersburg, MD, NIST.

Lippiatt, B., et al. (2013). "Building Industry Reporting and Design for Sustainability (BIRDS) Technical Manual and User Guide." NIST Technical Note 1814.

Lstiburek, J. (2010). "Building Science Insights - BSI-030: Advanced Framing." from http://www.buildingscience.com/documents/insights/bsi-030-advancedframing/\#F04.

McCulloch, A. (2009). "Life Cycle Inventory Analysis of the Production of a High-performance Foam Blowing Agent HFC-245fa (1, 1, 1, 3, 3-pentafluoropropane)." Journal of Cellular Plastics.

Meakin, S. (1992). The Rio Earth Summit: Summary of the United Nations Conference on Environment and Development, Library of Parliament, Research Branch.

Nashua Tape Products (2013). 322 Multi-Purpose Foil Tape specification sheet prepared by Berry Plastics Corporation.

National Association of Home Builders (NAHB) Research Center (2007). Study of Life Expectancy of Home Components, National Association of Home Builders.

NETL (2015). "NETL Lifecycle Inventory Data - Unit Process: “\&D3\&".". from www.netl.doe.gov/LCA (http://www.netl.doe.gov/LCA). 
NIST (2010). Building for Environmental and Economic Sustainability (BEES) Online Software, Applied Economics Office, Engineering Laboratory

NREL (2012). "U.S. Life-Cycle Inventory Database (LCI)." from http://www.nrel.gov/Ici/.

Omar, F. and S. Bushby (2013). "Simulating Occupancy in the NIST Net-Zero Energy Residential Test Facility." NIST Technical Note 1817.

OSRAM Opto Semiconductors GmbH. (2009). Life-cycle Assessment of Illuminants - A Comparison of Light Bulbs, Compact Fluorescent Lamps and LED Lamps (Executive Summary).

Parsons, D. (2006). "The environmental impact of compact fluorescent lamps and incandescent lamps for Australian conditions." The Environmental Engineer 7(2): 8-14.

PE International (2010). Eco-Profile of Aromatic Polyester Polyols (APP).

PE International (2011). GaBi Database.

PE International (2012). Life-Cycle Assessment of Spray Polyurethane Foam Insulation Products, Spray Polyurethane Foam Alliance (SPFA).

Persily, A. (2015). Indoor Carbon Dioxide Concentrations in Ventilation and Indoor Air

Quality Standards. 36th Air Infiltration and Ventilation Centre Conference, Madrid, Spain.

Pfleger, W., et al. (2011). "Market impacts of Energy Star qualification for new homes." North Carolina Energy Efficiency Alliance.

Ramroth, L. (2008). Comparison of Life-Cycle Analyses of Compact Fluorescent and Incandescent Lamps Based on Rated Life of Compact Fluorescent Lam, Rocky Mountain Institute (RMI).

Ramroth, L. (2008). "Comparison of life-cycle analyses of compact fluorescent and incandescent lamps based on rated life of compact fluorescent lamp." Rocky Mountain Institute: 11-12.

Rosenbaum, R. K., et al. (2011). "USEtox human exposure and toxicity factors for comparative assessment of toxic emissions in life cycle analysis: sensitivity to key chemical properties." The International Journal of Life Cycle Assessment 16(8): 710-727. 
ROXUL (2013). "ComfortBatt Technical Product Information Sheet." from

http://www.roxul.com/files/RX-NA EN/pdf/Technical\%20Data\%20Sheets-

\%20updated/COMFORTBATT-USAwithSS.pdf.

RS Means (2015). from https://www.rsmeans.com.

Salazar, J. (2007). Life-cycle Assessment Case Study of North American Residential Windows, University of British Columbia.

SEIA (2015). "Photovoltaic recycling." 2015.

Skone, T. J. (2019). Grid Mix Explorer Version 4. United States.

SPFA (2012). "Life-Cycle Assessment of Spray Polyurethane Foam Insulation for Residential and Commercial Building Applications." from http://www.sprayfoam.org/files/docs/SPFA\%20LCA\%20Long\%20Summary\%20New.pdf.

Stucki, M. a. N. J. (2012). Update of the Life Cycle Inventories of Solar Collectors, ESU-services Ltd.

Suh, S. (2005). "Developing a sectoral environmental database for input-output analysis: the comprehensive environmental data archive of the US." Economic Systems Research 17(4): 449469.

Suh, S. (2010). Comprehensive Environmental Data Archive (CEDA). The Sustainability Practictioner's Guide to Input-Output Analysis. J. Murray and R. Wood, Common Ground Publishing.

Suh, S. and G. Huppes (2005). "Methods for life cycle inventory of a product." Journal of Cleaner Production 13(7): 687-697.

Suh, S., et al. (2004). "System boundary selection in life-cycle inventories using hybrid approaches." Environmental Science \& Technology 38(3): 657-664.

Suh, S. and B. C. Lippiatt (2012). "Framework for hybrid life cycle inventory databases: a case study on the Building for Environmental and Economic Sustainability (BEES) database." The International Journal of Life Cycle Assessment 17(5): 604-612.

Sunpower (2013). SunPower E-Series Solar Panels. Document \# 504860 Rev B /LTR EN, www.sunpowercorp.com. 
Sunpower (2013). SunPower Limited Warranty for SPRm PV Inverters. Document \#001-16799 Rev *B. http://us.sunpower.com/sites/sunpower/files/media-library/warranties/wrsunpower-limited-warranty-sprm-pv-inverters.pdf.

Sunpower (2013). SunPower Module 40-Year Useful Life. white paper.

U.K. Department for Environment, Food and Rural Affairs (Defra), (2008). Life-cycle Assessments of Natural Fibre of Natural Fibre Insulation Materials, Final Report.

U.K. Department for Environment, Food and Rural Affairs (Defra), (2009). Life-cycle Assessment of Ultra-Efficient Lamps.

U.S. Census Bureau (2011). "American Housing Survey (AHS) for the United States, Series H-150, Complete Set of Tables and Standard Errors." from http://www.census.gov/programssurveys/ahs/.

U.S. Congress (2007). H.R. 6: Energy Independence and Security Act (EISA) of 2007. P.L. 110-140.

U.S. Department of Energy (DOE) (2015). EnergyPlus Simulation SoftwareVersion 8.3.0, Building Technologies Program (BTP).

U.S. Energy Information Administration (EIA) (2015). Annual Energy Outlook 2015 with projections to 2040. Washington, DC, U.S. Department of Energy (DOE),.

U.S. Energy Information Administration (EIA) (2018). 2018 Annual Energy Outlook, with Projections to 2050. Washington, DC, U.S. Energy Information Administration.

U.S. EPA Science Advisory Board (1990). Reducing Risk: Setting Priorities and Strategies for Environmental Protection, SAB-EC-90-021. Washington, DC.

U.S. EPA Science Advisory Board (2000). Toward Integrated Environmental Decision-Making, EPA-SAB-EC-00-011. Washington, DC.

UL Environment (2011). Product Category Rule (PCR) for Building Envelope Thermal Insulation, Product Category Rule Number UL 110116.

UL Environment (2013). Spray Polyurethane Foam Insulation and Roofing Systems, Declaration \#13CA29310.101.1. 
United Nations Environment Programme (UNEP) (2005). Report of the Technology and Economic Assessment Panel (TEAP).

Vigener, N. and M. A. Brown (2012). "Building Envelope Design guide - Windows." from http://www.wbdg.org/design/env fenestration winphp.

Weather Analytics (2014). Actual Meteorological Year (AMY) Formatted Weather Data for July 1, 2013 through June 30,2014.

World Steel Association (2011). Methodology report - Life-cycle Inventory Study for Steel Products.

Yang, L., et al. (2008). "Comparison of environmental impacts of two residential heating systems." Building and Environment 43(6): 1072-1081. 